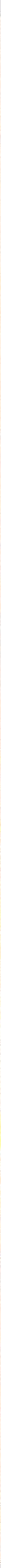


Diseño de portada: Emilius

Imagen: Última Paleta de José

Benlliure Gil. Casa Museo Benlliure.

Ayuntamiento de Valencia

Fotografía: Paco Alcántara 


\section{MATERIALES DE LA PINTURA AL ÓLEO DEL SIGLO XIX A TRAVÉS DE LAS FUENTES ESCRITAS ESPAÑOLAS}

AMPARO PERIS NAVARRO

DIRECTOR DE TESIS: SALVADOR MUÑOZ VIÑAS

28 de Marzo del 2011
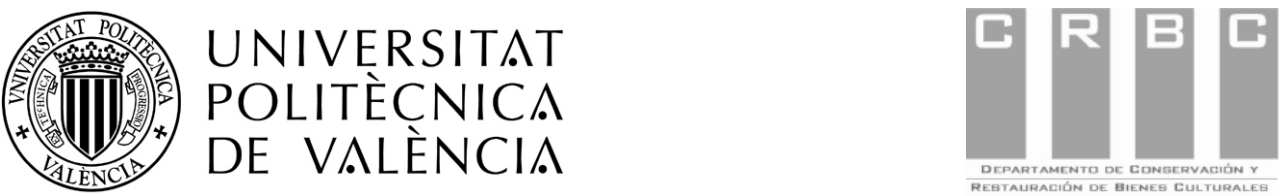



\section{SINOPSIS}

La tesis Materiales de la Pintura al Óleo del Siglo XIX a través de las Fuentes Escritas Españolas se sitúa dentro del campo de conocimiento de historia de las técnicas pictóricas, y en concreto en los estudios basados en fuentes escritas. Este tipo de estudio cuenta con una amplia tradición en el ámbito anglosajón (Eastlake, Merrifield, Harley, Carlyle, etc.), pero hasta ahora son muy escasas las investigaciones comparables que se han realizado en España, y en especial en un período tan complejo y rico como es el siglo XIX.

Esta investigación ha conducido a la identificación, localización, descripción y análisis detallado de las fuentes escritas españolas del Diecinueve sobre tecnología de la pintura. Las fuentes decimonónicas que presenta esta tesis se clasifican en cuatro categorías: (1) tratados dirigidos a pintores, (2) artículos o textos cortos escritos por pintores, (3) compendios y (4) catálogos comerciales. También se han valorado las marcas, privilegios y patentes de invención relacionadas con el campo que nos ocupa. De la misma manera, las fuentes secundarias - escritos de química, tratados de pintura decorativa o de restauración - han aportado datos relevantes sobre aspectos tecnológicos de la pintura del siglo XIX. Además, los datos de las fuentes decimonónicas españolas han sido cotejados con la información de relevantes fuentes europeas del mismo periodo y de épocas anteriores.

A través de estas fuentes se ha estudiado la evolución de los materiales de la pintura al óleo de un momento especialmente interesante porque se produjo la confluencia entre tradición e innovación técnica, conceptual y estilística. La información que desprenden estas fuentes, algunas de ellas hasta ahora desconocidas, permite examinar los materiales y utensilios empleados en pintura durante el siglo XIX y la reacción de los pintores ante la nueva situación. Así, esta tesis aborda los aceites de uso en pintura y sus procesos de elaboración, los vehículos pictóricos y los secantes y secativos. También analiza - a través de las fuentes - los pigmentos y colorantes aparecidos en el siglo XIX, los soportes pictóricos y las 
preparaciones de los mismos. A lo largo de este estudio se puede apreciar la confrontación entre los materiales tradicionales y los modernos o los nuevos procedimientos de elaboración de algunas substancias pictóricas. Pero además, queda patente que, en ocasiones, especialmente antes del establecimiento definitivo de los comerciantes de colores, los pintores adaptaban para uso pictórico materiales oriundos de la zona dónde residían. En definitiva, este estudio evidencia la elevada complejidad de los ingredientes de la pintura del siglo XIX. 


\section{SINOPSI}

La tesi Materials de la Pintura a l'Oli del segle XIX a través de les Fonts Escrites Espanyoles es situa dins del camp de coneixement d'història de les tècniques pictòriques, i en concret en els estudis basats en fonts escrites. Aquest tipus d'estudi compta amb una àmplia tradició en l'àmbit anglosaxó (Eastlake, Merrifield, Harley, Carlyle, etc.), Però fins ara són molt escasses les investigacions comparables que s'han realitzat a Espanya, i en especial en un període tan complex i ric com és el segle XIX.

Aquesta investigació ha conduït a la identificació, localització, descripció i anàlisi detallada de les fonts escrites espanyoles del Dinou sobre tecnologia de la pintura. Les fonts vuitcentistes que presenta aquesta tesi es classifiquen en quatre categories: (1) tractats dirigits a pintors, (2) articles o textos curts escrits per pintors (3) compendis i (4) catàlegs comercials. També s'han valorat les marques, privilegis i patents d'invenció relacionades amb el camp que ens ocupa. De la mateixa manera, les fonts secundàries - escrits de química, tractats de pintura decorativa $o$ de restauració - han aportat dades rellevants sobre aspectes tecnològics de la pintura del segle XIX. A més, les dades de les fonts decimonòniques espanyoles han estat confrontats amb la informació de rellevants fonts europees del mateix període i d'èpoques anteriors.

A través d'aquestes fonts s'ha estudiat l'evolució dels materials de la pintura a l'oli d'un moment especialment interessant perquè es va produir la confluència entre tradició i innovació tècnica, conceptual i estilística. La informació que desprenen aquestes fonts, algunes d'elles fins ara desconegudes, permet examinar els materials i utensilis emprats en pintura durant el segle XIX i la reacció dels pintors davant la nova situació. Així, aquesta tesi aborda els olis d'ús en pintura i els seus processos d'elaboració, els vehicles pictòrics i els secants i secatius. També analitza - a través de les fonts - els pigments i colorants apareguts al segle XIX, els suports pictòrics i les preparacions dels mateixos. Al llarg d'aquest estudi es pot apreciar la 
confrontació entre els materials tradicionals i els moderns o els nous procediments d'elaboració d'algunes substàncies pictòriques. Però a més, queda patent que, de vegades, especialment abans de l'establiment definitiu dels comerciants de colors, els pintors adaptaven per a ús pictòric materials originaris de la zona on residien. En definitiva, aquest estudi evidencia l'elevada complexitat dels ingredients de la pintura del segle XIX. 


\section{SYNOPSIS}

\section{Nineteenth Century Oil Painting Materials Through}

Spanish Writing Sources is a research work on the history of painting techniques and material, based on written sources. This kind of studies has a wide tradition in Anglo-Saxon world (Eastlake, Merrifield, Harley, Carlyle, etc.), but until now there have been very few similar works in Spain, and none dealing with the complex, rich XIXth century period.

This research has led to the identification, location, description and detailed analysis of many XIXth Spanish written sources on painting technology. Nineteenth Century sources presented in this thesis can be classified in four categories: (1) treatises written for painters, (2) articles or short texts written by painters, (3) compendia and (4) commercial catalogues. Also, trademark, privileges and patents related with our interest field have been considered. In the same way, the secondary sources - chemistry treatises, decoration instructions or texts on restoration - have contributed with relevant data on technological aspects of XIXth century painting. Besides, Spanish nineteenth-century sources have been compared with data from relevant European sources of the same period and earlier times. Through these sources the evolution of oil painting materials has been studied; this is a specially interesting moment, because there is right at the junction between technique, conceptual and stylistical tradition and innovation. The information collected from these sources (some of which were previously unknown) allows for the examination of the materials and tools employed in painting during this period, and reveals the painters' reaction faced with the new situation. Therefore, this thesis describes the oils used in painting and its making, as well as other painting mediums, dryers and siccatives. The new pigments and dyers, the painting supports and their preparations are also analyzed. Along this study, the confrontation between traditional and modern materials or the new procedures to elaborate some pictorial substances can be appreciated. This research work shows that, 
before colour merchants were set up definitively, painters often adapted native materials of the place were they lived for pictorial use. In summary, this study shows the amazing complexity of nineteenthcentury painting materials, and the evolution in the artists' approach to their craft. 


\section{ÍNDICE}

11 Introducción

I. LAS FUENTES ESCRITAS

19 1. El Estudio de las Fuentes

23 1.1. El Contenido de las Fuentes

28 1.2. Fuentes Suplementarias

\section{TRADICIÓN E INNOVACIÓN}

35 2. Evolución de los Materiales de la Pintura al Óleo en el Siglo XIX

54 2.1. Las Críticas de los Artistas

61 2.2. Los Instrumentos del Pintor

\section{MATERIALES DE LA PINTURA AL ÓLEO DECIMONÓNICA}

79 3. Aglutinantes

80 3.1. Aceites Secantes

81 3.1.1. Aceite de Linaza

85 3.1.2. Aceite de Nueces

86 3.1.3. Aceite de Adormidera

88 3.1.4. Aceite de Piñones

90 3.2. Elaboración de los Aceites

92 3.2.1. Extracción del Aceite

99 3.2.2. Clarificación

107 3.2.3. Preparación de los Aceites Grasos

118 3.3. Vehículos Pictóricos

129 3.3.1. Mediums Comerciales

133 4. Secantes y Secativos

135 4.1. Pastas Secantes

138 4.2. Secativos 
141 4.3. Materias Secantes

159 5. Materias Colorantes

161 5.1. Pigmentos Modernos

164 5.1.1. Blancos

176 5.1.2. Amarillos y Naranjas

187 5.1.3. Rojos

189 5.1.4. Azules

197 5.1.5. Violetas

199 5.1.6. Verdes

208 5.1.7. Colores de Marte

211 5.2. Colorantes Sintéticos

221 6. Soportes

222 6.1. Lienzos y Bastidores

233 6.2. Tablas

237 6.3. Papeles y Cartones

2407 7. Preparaciones e Imprimaciones

243 7.1. Preparaciones Comerciales

247 7.2. Preparaciones Tradicionales

258 7.3. El Color de las Imprimaciones

265 Conclusiones

269 BIBLIOGRAFÍA

\section{APÉNDICES}

285 Apéndice A: Descripción de las Fuentes

309 Apéndice B: Método para Preparar la Alizarina Artificial.

Privilegio 2296. (1861) Archivo Histórico de la OEPM 


\section{Introducción}

La presente tesis, Materiales de la Pintura al Óleo del Siglo XIX a través de las Fuentes Escritas Españolas se sitúa dentro del campo de conocimiento de historia de las técnicas pictóricas. Este ámbito de investigación alcanza resultados más elevados y completos cuando se forman equipos multidisciplinares integrados por historiadores, restauradores y químicos. En la actualidad ya no se cuestiona la importancia de las fuentes escritas para el estudio de los materiales pictóricos, su papel en este campo está completamente asumido e integrado. La valía de esta clase de documentos fue bien expuesta por Rutherford J. Gettens en el prólogo a Artists' Pigments c. $1600-1835$ de R. D. Harley (1982):

In addition to skill in analysis, the technical researcher needs to know the historical background of painting techniques and to be acquainted with the technology of materials going back many centuries. This in part has been supplied by translators of Theophrastus, Pliny, Vitruvius, Theophilus, and a long list of medieval manuscripts, which include such names as Sir Charles Eastlake, Mrs Mary P. Merrifield, E. Berger, Daniel V. Thompson, J. A. van de Graaf, V. and R. Borradaile and others. These people have produced notable reference books invaluable to modern investigators in all aspects of painting. (Harley, 1982: Prólogo)

Las aproximaciones bibliográficas a la tecnología de la pintura se han llevado a cabo de diferentes formas:

(1) mediante compilaciones o ediciones comentadas de tratados y otras fuentes escritas

(2) elaborando repertorios bibliográficos

(3) sirviéndose de las fuentes escritas para analizar los materiales o las técnicas artísticas

(4) a través de indagaciones capaces de compenetrar los datos relativos al estudio de las fuentes escritas con los resultados derivados de los análisis científicos 
La literatura del siglo XIX sobre tecnología de la pintura está recibiendo una atención creciente ${ }^{1}$ sin embargo, aún no se ha reconocido el interés de las fuentes españolas de este periodo. Por ese motivo, nos hemos enfrentado a una extensa laguna documental sobre el tema que nos ocupa. Hasta el momento, las indagaciones en el campo tecnológico de la pintura se han centrado en periodos anteriores al siglo XIX. Es posible que esto se deba a la falta de distancia histórica. En el caso español, podría añadirse también la escasa consideración que ha recibido la pintura de este periodo.

${ }^{1}$ Véase por ejemplo esta modesta e incompleta lista de publicaciones.

ALEXANDER, S. M.: Towards a History of Art Materials - a Survey of Published Technical and Archeological Literature in the Arts; supplements to Art and Archeology Technical Abstracts. Part III: 1751-Late 19th Century, (1970 1971) pp. 155-174. Londres, International Institute for Conservation of Historic and Artistic Works.

HARLEY, R. D. (1982): Artists' Pigments c. 160o-1835. A Study in English Documentary Sources. London: Butterworths, 1970.

BOMFORD, D., KIRBY, J., LEIGHTON, J., and ROY, A.: Art in the Making. Impressionism. Londres-New Haven, The National Gallery-Yale University Press, 1990.

SILVIA BORDINI: Materia e Immagine. Fonti sulle Tecniche della Pittura. Roma: Leonardo De Luca Editori, 1991.

CARLYLE, LESLIE: The Artist's Assitant: Oil Painting Instruction Manuals and Handbooks in Britain 180o-19oo: with Reference to Selected Eighteen-Century Sources. London: Archetype, 2002.

Historical Painting Techniques, materials, and Studio Practice. University of Leiden, The Netherlands. 26 - 29 June 1995.

Looking Through Paintings, the Study of Painting Techniques and materials in Support of Art Historical Research, editado por Erma Hermens; Londres, 1998.

Paint and Purpose, a Study of Technique in British Art editado por Stephen Hockney, Rica Jones and Joyce Townsend. Londres: Tate Gallery, 1999.

Seeing Through Paintings: Physical Examination in Art Historical Studies por Andrea Kirsh y Rustin Levenson. New haven: Yale University Press, 2000.

Art of the Past. Sources and Reconstructions. Proceedings of the First Symposium of the Art Technological Source Research Study Group. Archetype Publications, 2005.

Art Technology. Sources and methods. Proceedings of the Second Symposium of the Art Technological Source Research Study Group. Archetype Publications, 2008. 
Es fácil encontrar diferentes ediciones de tratados de pintura españoles de los siglos XVI, XVII y XVIII. Guevara [h. 1560], Carducho [1633], Pacheco [1649] y Palomino [1715 - 1724], por ejemplo, se han editado en varias ocasiones desde que vieran la luz por primera vez (Calvo Serraller, 1991; Bordini, 1995). Sin embargo, los tratados y manuales decimonónicos de pintura no han merecido esta atención. A fecha de hoy, el único tratado español del siglo XIX que goza de una reimpresión facsímil es el Curso Completo de Dibujo y Pintura de J. Soler y A. Ferrer (1837); si bien no se trata de una edición comentada. El resto de obras que forman parte de esta tesis sólo fueron publicadas durante el siglo XIX.

Por otra parte, la única investigación, hasta el momento, que compendia fuentes decimonónicas españolas es Bibliografía de la Pintura Española de García Melero (1978). Esta vastísima obra recoge fundamentalmente la bibliografía general sobre arte publicada en el siglo XX hasta el año de su publicación. Sin embargo, uno de sus mayores atractivos es que contiene un capítulo dedicado a los antecedentes bibliográficos donde aparecen textos desde el siglo XVI al XIX. Entre los escritos decimonónicos de arte que muestra este elenco aparecen algunos de los tratados de pintores que estudiamos en esta tesis.

No cabe duda que en el transcurso de esta investigación nos hemos enfrentado a un campo de marcado interés pero aún inexplorado. Creemos que el resultado es satisfactorio y las aportaciones que presentamos resultarán de utilidad a todos aquellos que se acerquen al estudio de los materiales pictóricos decimonónicos, especialmente dentro del ámbito de la pintura española.

Esta tesis Materiales de la Pintura al Óleo del Siglo XIX a través de las Fuentes Escritas Españolas se divide en tres bloques o apartados. En la primera parte - Las Fuentes Escritas - se clasifican y presentan los escritos que han servido cómo base de este estudio. El 
apartado evidencia que a través de las fuentes de toda la centuria se puede apreciar la evolución de los materiales pictóricos devenida en el siglo XIX. Esta primera parte concluye con una revisión de las fuentes suplementarias, algunas de las cuales resultan decisivas para comprender ciertos aspectos materiales de la época.

El segundo apartado - Tradición e Innovación - relata la evolución de los materiales pictóricos del siglo XIX. Esta historia se ha reconstruido a partir de datos de varias investigaciones y se ha enriquecido con la información extraída de las fuentes españolas. Las marcas de fábrica y las patentes de invención - albergados en el Archivo Histórico de la Oficina Española de Patentes y Marcas (OEPM) - han resultado documentos de gran interés para confeccionar esta crónica. Las reacciones de los pintores ante los nuevos materiales o los instrumentos propios de la pintura especialmente los desarrollados durante el siglo XIX - son los otros temas que componen este apartado.

La tercera parte de la tesis - Materiales de la Pintura al Óleo Decimonónica - es la de mayor extensión. En ella se analizan los contenidos sobre tecnología de la pintura al óleo a través de las fuentes decimonónicas españolas. Aglutinantes, Secantes, Materias Colorantes, Soportes y Preparaciones son los temas que forman parte de este vasto apartado. Algunos de los contenidos contienen referencias, datos o citas pertenecientes a tratados o textos anteriores al siglo XIX. Con esto se ha querido poner de relieve que algunos materiales apenas modificaron sus procesos de elaboración a lo largo de los siglos. Del mismo modo, se ha establecido el parangón con las fuentes decimonónicas europeas más reputadas con el fin de establecer similitudes y diferencias entre los contenidos. Una vez más, los privilegios y patentes de invención han demostrado ser documentos de un gran atractivo para demostrar algunas novedades e innovaciones materiales propias del siglo XIX.

La presente investigación nació con la pretensión de entender y aprender los aspectos tecnológicos de la pintura decimonónica española. Supone un reto considerable enfrentarse a este objetivo porque la evolución de la química y la industrialización de los productos artísticos produjeron materiales completamente 
diferentes a los tradicionales. Sin duda es un tema complejo y poco explorado hasta el momento pero apasionante y de gran atractivo. Esta tesis presenta datos, referencias e información que pueden resultar de gran utilidad a los expertos que desde diferentes áreas del conocimiento se aproximan a la pintura decimonónica española. 

I.

LAS FUENTES ESCRITAS SOBRE TECNOLOGÍA DE LA PINTURA 



\section{El Estudio de las Fuentes}

La información que transmiten las fuentes escritas sobre pintura resulta relevante para el estudio de la historia tecnológica de esta disciplina artística. Es cierto que los análisis científicos determinan con bastante exactitud los materiales propios de una pintura al óleo. También, las radiografías, los infrarrojos y otras técnicas ayudan a interpretar los procesos pictóricos de algunos óleos. Pero las fuentes escritas explican procesos y prácticas pictóricas que pueden auxiliar al investigador en la interpretación de los métodos pictóricos.

Sin duda, uno de los mayores atractivos de las fuentes decimonónicas radica en que permite apreciar el sorprendente e importante cambio que, durante el siglo XIX, se produjo en la tecnología de la pintura al óleo. El estudio de las fuentes escritas decimonónicas facilita la comprensión del devenir histórico de los materiales pictóricos y las repercusiones técnicas y estéticas en este arte. El cambio de las vejigas a los tubos plegables, el nacimiento de nuevos, brillantes e intensos pigmentos, el surgir de los colorantes sintéticos o novedosos tejidos de diferentes e incluso enormes tamaños son algunos de los factores que favorecieron cambios decisivos en la pintura. Todo esto fue posible gracias al desarrollo de la industria química y a la implantación de los fabricantes y comerciantes de colores que permitieron a los pintores desvincularse de la preparación de sus materiales y utensilios. De esta forma los artistas disponían de todo su tiempo para la creación aunque la nueva situación material tuvo, en muchas ocasiones, consecuencias negativas y los pintores manifestaron feroces críticas contra los comerciantes.

Las fuentes decimonónicas españolas que presentamos en esta investigación pueden clasificarse en cuatro categorías: (1) tratados dirigidos a pintores, (2) artículos o textos cortos (3) compendios y (4) catálogos comerciales. Los autores de los textos comprendidos en las tres primeras categorías practicaron la pintura 
alcanzando mayor o menor reconocimiento en este arte. Los documentos que analizamos fueron escritos en español o traducidos a esta lengua durante el siglo XIX o los albores del XX.

Las traducciones incluidas en este estudio, concretamente dos, comprenden manuales de pintura de origen francés y se clasifican dentro de la categoría (1) tratados dirigidos a pintores. De estos dos documentos a que nos referimos, El Pintor: Manual de Pintura al Alcance de Todo el Mundo de Camille Bellanger ${ }^{1}$ (París, 1899) no precisa más justificación que la de ser una traducción realizada en el siglo XIX. El libro original Le Peintre: Traité Usuel de Peinture à l'Usage de Tout le Monde, le Dessin, Figure Humaine, Perspective, Théorie des Couleurs, Manière de Peindre, Nature Morte, Fleurs, Glacis, Paysages, Marine, Animaux, etc... fue publicado en París un año antes que la edición en español. En cambio, la incorporación del escrito de Jehan George Vibert, La Ciencia de la Pintura (París, 1908) puede ocasionar dudas por lo tardío de su traducción y publicación en España. No obstante, nos parece suficiente alegato en su favor que transcribe, casi íntegramente, un texto de $1891^{2}$. Las lecciones que este pintor francés impartía en la Escuela de Bellas Artes de París nos llegaron, por lo tanto, con unos años de retraso. Pero, como veremos, son de gran valor para estudiar y entender los materiales de la pintura al óleo del siglo XIX.

Para familiarizar al lector con los escritos que va a encontrar continuamente citados en el presente texto incluimos el repertorio cronológico de las fuentes primarias utilizadas en esta investigación. El lector interesado puede consultar una descripción y otros pormenores de las mismas en el Apéndice A.

\footnotetext{
${ }^{1}$ Camille Félix Bellanger (1853 - 1923) fue alumno de Alexander Cabanel (1823 1889) y de William Bouguereau (1825 - 1905).

2 VIBERT, JEHAN-GEORGES: La Sciencie de la Peinture. París, 1891. La única diferencia entre ambas ediciones radica en que la impresión francesa presenta dos notas inexistentes en la tirada española: “Au Lecteur”, al principio del libro, y "Garantie Commerciale" al final.
} 
1. SOLER, J., y FERRER, A.: Curso Completo Teórico y Práctico de Diseño y Pintura en sus Tres Principales Ramos de Olio, Temple y Fresco. Barcelona: Imp. De José Torner, 1837. (1)

2. BORBÓN, SEBASTIÁN MARÍA GABRIEL DE, Infante de España: De los Aceites y Barnices de que se Hace Uso en la Pintura: Memoria Dirigida á la Real Academia de S. Fernando en Madrid. Madrid: [s.n.], 1860 (Por Aguado Impresores). (2)

3. O’NEILLE y ROSIGNOL, JUAN: Tratado de Paisaje. Palma de Mallorca: Imprenta de Pedro José Gelabert, 1862. (1)

4. AlgARRA, AgUSTÍN: Manual del Pintor Teórico Práctico o sea Principios Fundamentales sobre la Pintura al Óleo y a la Acuarela. París: Librería de Rosa y Bouret, 1864. París: Librería de A. Bouret é Hijo, 1875. (1)

5. DE LA ROCA Y DELGADO, MARIANO: Compilación de Todas las Prácticas de la Pintura, desde los Antiguos hasta Nuestros Días. Madrid: León P. Villaverde. 1880. (3)

6. POLERÓ, VICENTE: Tratado de la Pintura en General. Madrid: 1886. (1)

7. L. PÉANT É HIJOS: Catálogo General. Colores Extrafinos. Barnices, Aceites, Secantes. Material para la Pintura al Óleo, la Acuarela, la Gouache, el Pastel, el Dibujo, la Fotominiatura. Madrid, 1895. (4)

8. SALA, EMILIO: "La Desecación de la Pintura” en La Ilustración Española y Americana. Año XL. Num. 42 y 43. Madrid, 1896. (2) 
9. LÓPEZ TOMAS, JOSÉ: Educacion Artistica: Teoria y Practica del Dibujo, Pintura, Grabado y Escultura y Resumen Historico de Estas Artes en Europa. Alicante : V. Soler, 1898. (1)

10. BELLANGER, CAMILLE: El Pintor: Manual de Pintura al Alcance de Todo el Mundo. París. 1899. (1)

11. VIBERT, JEHAN-GEORGES: La Ciencia de la Pintura. Versión castellana por Miguel de Toro y Gómez, París; [Ligné: Eugenio Aubin], 1908. (1)

A estas fuentes que podríamos calificar de 'literarias' hemos incluido otro tipo de información también primaria que pertenece al ámbito de las fuentes 'documentales'. Si entre las fuentes primarias de tipo 'literario' hemos clasificado tratados y manuales de pintura, artículos especializados, catálogos comerciales y compendios, entre las fuentes de tipo 'documental' se incluyen los privilegios, patentes de invención y marcas de fábrica relacionados con los materiales de la pintura al óleo. El interés de estos documentos quedó demostrado por Harley (1971) en su interesante y esclarecedor artículo sobre el desarrollo de los envases de pintura. También el estudio de Channing Downs (1976) sobre el pigmento blanco de zinc demuestra la utilidad de estos documentos. Igualmente, San Andrés y García (2008), convencidas del interés de estos documentos, pusieron de relieve que en la actualidad existen diversas bases de datos de patentes con acceso a través de internet; aspecto que facilita enormemente la búsqueda a los investigadores. 


\subsection{El contenido de las fuentes}

El objetivo de esta investigación se ha centrado en el estudio de los materiales de la pintura al óleo pero las fuentes abordan, por lo general, otros muchos aspectos. Los tratados dirigidos a pintores (1) están orientados a enseñar al aprendiz de pintor los rudimentos y los conocimientos básicos de su arte. Estos escritos, por lo general, tratan varios temas útiles a la formación del pintor como dibujo, anatomía, perspectiva, paisaje, diferentes técnicas pictóricas, etc. Los textos cortos de los artistas (2) abordan aspectos técnicos y problemas con los materiales de la pintura. El compendio (3) localizado reúne fundamentalmente textos de los siglos XVII y XVIII sobre pintura que el compilador ha enriquecido con escritos propios de su época, mientras que el catálogo comercial (4) reúne los productos artísticos que la industria ofertaba a los artistas en el momento de su edición. (Ver Apéndice)

Como ya hemos expresado, el estudio de las fuentes escritas decimonónicas permite establecer con claridad la evolución más importante que sufrió la tecnología de la pintura al óleo. Esta transformación favoreció el salto de los materiales tradicionales a los industriales y los consiguientes cambios en los procesos pictóricos y en el propio oficio del pintor. Además los nuevos colores permitieron a los pintores el desarrollo de nuevas estéticas vanguardistas.

Los cambios materiales son muy evidentes en las fuentes. En la primera mitad del siglo XIX, los tratadistas Soler y Ferrer (1837) aportaban nociones precisas para que el propio pintor preparara sus colores de manera tradicional. Sin embargo, a mediados de la centuria los comerciantes de colores estaban plenamente establecidos y los pintores dejaron de elaborar sus materias. Por ejemplo, los tratados y manuales de mediados del siglo Diecinueve - O’Neille (1862) y Algarra (1864 y 1875) - omiten las indicaciones para la elaboración de los ingredientes de la pintura. Otro aspecto importante que también evoluciona en la tratadística es la exposición de los procedimientos pictóricos. Soler y Ferrer (1837) 
describen cómo elaborar copias, carnes, trapos, etc. En cambio, los autores del tercer cuarto del siglo omiten esta clase de información y acostumbran a dirigir al lector a las explicaciones directas de un buen maestro.

En los textos de los últimos veinte años del siglo se transmiten, sin embargo, algunos conocimientos particulares orientados a recuperar prácticas tecnológicas y procedimientos pictóricos pretéritos. Muestras de esto son la Compilación de Mariano de la Roca y Delgado (1880) y los tratados de Vicente Poleró (1886) y José López Tomás (1898). Mariano De la Roca, en lo referente a la pintura al óleo, extracta los contenidos relativos a esta técnica pictórica del Museo Pictórico o Escala Óptica [17151724] de Antonio Palomino. Por su parte, Poleró (1886) y López Tomás (1898) también incluyeron conocimientos prácticos para que los pintores elaboraran algunos de sus ingredientes. Las instrucciones que estos autores plantean derivan de El Arte de la Pintura [1649] de Pacheco y del tratado de Palomino mencionado antes. Bien pueda ser que el interés que Pacheco suscitó a mediados del siglo XIX se deba a que fuera maestro y suegro del admirado Diego Velázquez y tanto Poleró cómo López Tomás demostraron una gran fascinación por el pintor sevillano. López Tomás explicaba el porqué de la recuperación de El Arte de la Pintura de Pacheco refiriéndose a aspectos prácticos y no teóricos ${ }^{3}$.

Los procedimientos que más se practican en la pintura son los llamados á fresco, á temple, á óleo, acuarela y pastel. Pocas obras se ejecutan hoy por los dos primeros, y en malas condiciones de vida se producen, por regla general, aquellas otras que tienen por base el aceite; su práctica es conocida por todos los que nos dedicamos á la pintura, pero tanto por la autoridad del nombre, cuanto por recordar la manera de proceder en los buenos tiempos del gran arte español, preferimos copiar las instrucciones que el

\footnotetext{
${ }^{3}$ Sobre aspectos teóricos del Arte de la Pintura de Pacheco y otros textos barrocos, CALVO SERRALlER, F.: La Teoría de la Pintura en el Siglo de Oro. Madrid: Cátedra, 1991.
} 
pintor Francisco Pacheco, suegro de Velazquez, nos proporciona en su obra Arte de la Pintura. (López Tomás, 1898: 41)

Este interés romántico por Velázquez tuvo en años precedentes un carácter revolucionario. Según Díez (1992: 85), en 1864 Rosales transformó el panorama artístico de su época con el cuadro Doña Isabel la Católica Dictando su Testamento, que presentó en la Exposición Nacional. En esta obra, el pintor recuperó el realismo atmosférico de Velázquez influyendo notablemente en los pintores de su generación. Ese mismo año, Casado del Alisal plantea un redescubrimiento del pintor barroco en la composición de su lienzo La Rendición de Bailén. Barón (2007: 36) también confirma que la pintura romántica española 4 trata de rescatar efectos de color, matices atmosféricos, pinceladas características y ejecución propias de la pintura del siglo XVII.

El interés y la admiración por la pintura barroca motivó, durante la segunda mitad del siglo XIX, la edición de los tratados de V. Carducho5, J. Martínez ${ }^{6}$, F. Pacheco ${ }^{7}$ y otros. Calvo Serraller (1991: 21 - 22) expone a su juicio los motivos que propulsaron

\footnotetext{
4 El Romanticismo se introduce en España tras la muerte de Fernando VII acaecida en 1833.

5 El crítico de arte y escritor Gregorio Cruzada Villaamil demostró gran interés por la pintura del siglo XVII. En 1865 editó los Diálogos de la Pintura de Vicente Carducho que solamente se habían publicado en 1633. (Calvo Serraller: 1991: 21). ${ }^{6}$ A mediados de siglo, en 1853, Mariano Nogués y Segall publicó los Discursos Practicables del Nobilísimo Arte de la Pintura de Jusepe Martínez. Una nueva edición apareció en 1866 a cargo de Valentín Carderera quien acompañó el texto de un notable aparato erudito del cual carecía la primera edición de Nogués. (Calvo Serraler, 1991: 22)

7 En 1866, el crítico de arte y escritor Gregorio Cruzada Villaamil dirigió la edición del Arte de la Pintura, su Antigüedad y Grandeza de Francisco Pacheco. Según Calvo Serraller (1991: 22), el erudito Sánchez Cantón afirma en su edición del tratado de Pacheco (1956) que la edición de Cruzada Villaamil no era fiel al original del pintor barroco. Los saltos de palabras, líneas y hasta párrafos cometiendo otro tipo de descuidos son habituales en el volumen I de la edición de Villaamil. Unos años más tarde, en 1871 se publicó el Arte de la Pintura, su Antigüedad y Grandezas: Extractado y Enriquecido con un Tratado Nuevo para Saber Limpiar y Restaurar las Pinturas sobre Lienzo, Madera, Cobre y Piedra por Mariano de la Roca y Delgado. (Calvo Serraller, 1991: 21 - 22)
} 
estas ediciones.

...las reediciones emprendidas en el siglo XIX, al amparo del historicismos romántico, de Carducho, Pacheco o J. Martínez, tenían, desde luego, mucho que ver con el descubrimiento y valoración de aquellos estilos artísticos del pasado, tradicionalmente menospreciados y desde entonces considerados bajo el prisma de una sensibilidad afín, así como con la exaltación romántica de un arte nacional que veía en esos mismos estilos artísticos - el arte medieval y el Barroco de manera especial - los momentos privilegiados de caracterización que este arte nacional requería. (Calvo Serraller, 1991: 21-22)

Como hemos visto, la pintura barroca española alcanzó una alta consideración entre los pintores decimonónicos y algunos de nuestros tratadistas así lo reconocen. No obstante, creemos que cuando las fuentes de finales del siglo - De la Roca y Delgado, Poleró y López Tomás - extractan explicaciones de los textos barrocos demuestran la necesidad de controlar sus propios materiales ya que se encontraban ante sustancias industriales que les ocasionaban problemas técnicos.

Pero no todos los autores demuestran interés por los escritos del Siglo de Oro. En concreto, el pintor Emilio Sala (1896: XLIII, 294) se muestra abiertamente disconforme con las enseñanzas de Palomino porque “...como su libro no está escrito en el apogeo de la pintura clásica española, sino en un período de decadencia, no merece bastante confianza." Emilio Sala apreciaba más las lecciones del pintor medieval Cennino Cennini pero lamentaba que este omitiera algunas explicaciones sobre los materiales debido a que se podían encontrar en el comercio. De esta forma - asegura el pintor decimonónico - se perdían conocimientos técnicos antiguos. También Vibert, el pintor francés, expone recetas y elaboración de materiales pero lo hace desde un punto de vista diferente. Vibert, que estaba muy involucrado con la industria de los materiales artísticos, trata de concienciar al lector 
de la importancia de obtener materiales estables y de saber emplearlos. Este artista francés demuestra en todo momento una gran admiración por los grandes maestros de la pintura.

A pesar de la postura de Vibert, los pintores de finales del siglo XIX parecen tener cierta necesidad por elaborar sus propios ingredientes ${ }^{8}$. La escasa calidad de algunos productos que suministraba el comercio pudo ser, en parte, la causa de que, al declinar el siglo, los tratadistas volvieran a exponer procesos de elaboración de los materiales pictóricos. La deficiencia de los materiales preparados industrialmente causaron, en muchas ocasiones, el desagrado de los pintores. Las quejas y críticas contra los fabricantes y comerciantes de colores se incrementaron con el tiempo denotando una fuerte insatisfacción con los materiales pictóricos comerciales. Críticas tímidas aparecen en Borbón (1860) y se recrudecen a finales de siglo; el artículo de Emilio Sala (1896) o el escrito de Vibert $(1891,1908)$ son especialmente crueles. El catálogo de L. Péant e Hijos (1895: I, 30) verifica la deficiencia de algunos materiales comerciales y ofertaba una Caja de Análisis para que los pintores comprobaran la pureza de sus colores.

Por todo esto, no es de extrañar que algunos tratadistas incluyeran recetas y explicaciones tecnológicas de tratados barrocos como Pacheco y Palomino. Es lógico pensar que los pintores del siglo XIX quisieran conocer los materiales y las prácticas pictóricas de los grandes maestros barrocos que trataban de emular; incluso es razonable pensar que quisieran experimentar para lograr materiales y recursos pictóricos similares. Sin embargo, en la segunda mitad del siglo XIX, la implantación de los fabricantes y comerciantes de colores era irrevocable. Además, el descubrimiento de nuevos pigmentos y colorantes modificó sustancialmente la paleta de los

\footnotetext{
${ }^{8}$ Esto no sucede sólo entre los pintores españoles. Bomford et al. (1990:

37) refieren que, a partir de la década de 1880, Renoir demostró una especial preocupación porque los pintores ya no preparaban sus colores. Aunque el pintor francés reconocía el valioso tiempo que ahorraban los artistas delegando la elaboración de sus sustancias a otros profesionales. Según Bomford et al., hacia 1878 Renoir usaba colores que el mismo molía a mano.
} 
pintores. Y, cómo veremos más adelante, los nuevos materiales no permitían los mismos recursos pictóricos que los materiales tradicionales.

\subsection{Fuentes suplementarias}

Otras fuentes aportan datos de interés relativos a la tecnología de la pintura; son los escritos de química, pintura decorativa y restauración que se publicaron a lo largo del siglo XIX. Nos hemos apoyado en algunos de estos textos y a ellos haremos mención a lo largo de la investigación.

Durante el siglo XIX, el desarrollo de la química favoreció la invención y la producción de muchos colores nuevos de uso artístico. Esta ciencia progresó especialmente en Francia y Alemania. Según Portela (1999: 51), durante el siglo XVIII España se incorporó a la química moderna, sin embargo, los trágicos acontecimientos devenidos en el país los primeros años del siglo XIX impidieron el cultivo de esta ciencia con niveles comparables a los europeos. El mismo Portela (1998: 49 - 50) explica que la actividad científica española quedó aletargada durante el reinado de Fernando VII, dando lugar a un periodo a menudo denominado "período de catástrofe". Tras la muerte del monarca absolutista, acaecida en 1833, las circunstancias cambiaron ligeramente aunque no permitían el cultivo óptimo de la ciencia. Pero se editaron más libros de química y mayor número de traducciones que durante el reinado de Fernando VII. Fue después de la revolución de 1868 que, aprovechando una relativa atmósfera cambiada, la química comenzó a dar frutos en España.

Durante el siglo XIX se publicaron en España diferentes clases de textos de química cuyos contenidos estaban relacionados con las artes; los más habituales eran diccionarios, cursos y compendios aplicados a las artes. Éstos escritos eran competentes 
también en medicina, farmacia y otros asuntos de interés similar. Entre las primeras publicaciones del siglo XIX sobre química aplicada al arte podemos señalar el Curso de Química General Aplicada a las Artes de Jose María de San Cristobal y José Garriga y Buach. Estaba previsto que esta obra contara con cuatro volúmenes de los que únicamente se imprimieron dos en París. Pero para beneficio de las artes se tradujo la importante obra del químico francés Chaptal, La Chimie Appliquée aux Arts (1806). Los cuatro volúmenes de esta obra fueron traducidos por el químico Francisco Carbonell y Bravo y vieron la luz en Barcelona entre 1816 y 1821.

Un libro muy significativo fue el de Eugene Desmarest, Química. Compendio de esta Ciencia y de sus Aplicaciones a las Artes, traducido del francés al castellano por D. Jose Luis Casaseca y publicado en Madrid en 1828. La primera edición francesa, Chimie. Traité Abrégé de cette Science, et de ses Applications aux Arts data de 1826. La traducción al castellano de esta obra tuvo un objetivo interesante: servir de libro de texto a los alumnos del Real Conservatorio de Arte 9 . Casaseca, profesor de química en la institución mencionada, arregló la obra a los conocimientos de ciencia en el momento de la traducción. Según el traductor el escrito contiene párrafos enteros del Diccionario de Química del doctor Ure $^{10}$, aunque sin hacer una compilación servil. El texto de Desmarest trata todo tipo de materias empleadas en las diferentes artes y describe las sustancias, su procedencia, elaboración, particularidades y en algunos casos los usos o recetas.

En 1838 - 39 aparecieron en Madrid los Nuevos Elementos de Química Aplicada a la Medicina y las Artes: Redactado con

\footnotetext{
${ }_{9}^{9}$ Según noticias extraídas de José López Tomás (1898: 204), esta institución se fundó en 1824.

${ }^{10}$ Dictionary of Chemistry publicado por primera vez en 1821. Se ha querido reivindicar la figura del doctor Ure como una influencia o inspiración de Mary Shelley para concebir su magnífica obra Frankesntein. Esto se debe a que tras realizar experimentos con el cuerpo de un delincuente ajusticiado en la horca, el doctor Andrew Ure anunció que era capaz de estimular ciertos nervios en los muertos por lo que en algunos casos se podría restaurar la vida. Esto ocurrió en 1818, el mismo año que Mary Shelley compuso Frankenstein o el Moderno Prometeo.
} 
Arreglo a las Últimas Ediciones de los Tratados de Orfila, Thernard, Dumas etc. Unos años más tarde, en 1842, se editó el Curso de Química Elemental e Industrial, traducción al español de una obra de Anselme Payen. Dice Portela (1998: 53) que Apollinaire Bouchardat era un químico de mediana importancia con éxito en nuestro país por las cuantiosas reediciones de su formulario magistral de recetas. De este químico francés se tradujeron los Elementos de Química Aplicada a las Artes, a la Industria y a la Medicina editados en Barcelona en 1843 - 44 y Elementos de Química, con sus Principales Aplicaciones a la Medicina, a las Artes y a la Industria, publicado en Madrid en 1845. Llegando al final del siglo, hacia 1888, se publicó en Barcelona El Nuevo Diccionario de Química Aplicada a las Ciencias, a las Artes, a la Agricultura, a la Industria y a la Farmacia de Emilio Bouant. Podemos señalar que estos textos de química relacionados con las artes son los más significativos que se publicaron durante el siglo XIX en España.

Los tratados de restauración decimonónicos también pueden aportar datos de interés que complementen nuestras fuentes primarias, por eso hemos tenido en cuenta algunos textos de esta disciplina. En el siglo XIX la restauración comenzó a aplicar criterios más modernos. La confrontación entre la práctica más tradicional y una praxis más depurada se aprecia en el Arte de la Restauración (1853) de Vicente Poleró y Toledo. Este fue el primer tratado de restauración que se publicó en España. El Tratado de Pintura en General (1886) de este artista incorpora aspectos que no había abordado en su anterior libro como la forración de lienzos y la restauración de grabados y dibujos. En 1871 - como se ha mencionado anteriormente - de la Roca y Delgado editó el escrito de Pacheco añadiendo un Tratado Nuevo para Saber Limpiar y Restaurar las Pinturas sobre Lienzo, Madera, Cobre y Piedra. Este tratado de restauración se reeditó en el Compendio que este mismo artista publicó en 1880.

Por último nos queda tratar los atractivos e interesantes manuales de pintura decorativa. La pintura artística y la decorativa 
compartían materiales aunque la primera requería pigmentos más finos y materiales más exquisitos. Algunos de estos escritos explican formas de elaboración de materiales como el Manual Teórico y Práctico del Pintor, Decorador y Charolista de Riffault que se publicó en 1832 y 1850. Pero fundamentalmente estos textos están dirigidos a los decoradores y pintores de salas pues durante el siglo XIX el desarrollo de la burguesía incrementó la construcción y decoración de palacetes y casas señoriales. En 1857 se publicó en Barcelona El Artista Práctico. Manual que Trata de Pintura, Dorado, Plateado y Estucos de Isidro Sánchez Caro. Sobre los diferentes tipos de barnices y sus usos en 1883 apareció Fabricación de toda Clase de Barnices: Manera de Aplicarlos: Conocimiento Práctico de las Resinas, de sus Disolventes y otras Sustancias Empleadas en Dicha Fabricación de Aurelio Ruiz Miyares. Mientras que a finales del siglo, en 1899, se editó el Nuevo Tratado de Pintura Industrial, Adorno y Decorado de Paul Fleury.

En definitiva, el conjunto de fuentes - primarias y suplementarias - que presentamos en esta investigación permite estudiar de manera exhaustiva los materiales de la pintura al óleo del siglo XIX. A través de estas fuentes se comprende la evolución de los materiales de la pintura al óleo y la aceptación entre los pintores. Los datos que aporta esta investigación - como ya hemos apuntado - suponen una gran ayuda para todos aquellos que se acercan a la pintura española decimonónica desde diferentes ámbitos del conocimiento. 

II.

\section{TRADICIÓN E INNOVACIÓN}





\section{Evolución de los Materiales de la Pintura al Óleo en el Siglo XIX}

Durante la mayor parte de la historia, los pintores fueron los encargados de preparar los materiales y utensilios propios de su arte. En la formación de un pintor, el conocimiento profundo de los materiales constituía un valor fundamental. Sin embargo, en el siglo XVIII la creación de las Academias de Arte $^{1}$ y la supresión del férreo control gremial ${ }^{2}$ propiciaron que los pintores perdieran los saberes técnicos propios de su arte. De manera simultánea fueron apareciendo y creciendo en especialización los fabricantes y comerciantes de materiales artísticos. Recordemos que ya Palomino en su Museo Pictórico o Escala Óptica [1715 - 1724] señala que:

Además, que el moler las colores, y aparejar los lienzos, no es pintar [...] ni lo hace el pintor; porque éstos son oficios ministeriales, destinados privativamente a personas, que lo tienen por profesión aparte; como lo vemos en esta Corte, y en los lugares grandes, donde hay imprimadores, y moledores de colores; y donde no los hay, lo hacen los discípulos ó criados. (Palomino, [1715 - 1724] 1988: I, 224)

Callen (1983: 20) explica que a mediados del siglo XVIII comenzaron a surgir los comerciantes de colores como una clase comercial independiente. Al principio, la mayoría de ellos se centró en la fabricación de una especialidad concreta: pigmentos, barnices, acuarelas, óleos o pasteles. Por lo general, tenían que adquirir las materias primas de diferentes proveedores. Pero todos ofertaban también otros artículos esenciales para el artista: pinceles, papeles,

\footnotetext{
${ }^{1}$ Sobre las fechas de fundación de las Academias de Arte españolas y otros datos relativos a las mismas, CALVO SERRALLER, FRANCISCO: "Las Academias Artísticas en España", Epílogo de Academias de Arte: Pasado y Presente de PEVSNER, NIKOLAUS. Madrid: Cátedra, 1982. p. 209 - 239.

2 En España para que los gremios no impidieran la actividad a los artistas y permitieran el libre ejercicio de las artes se promulgaron varias Órdenes Reales en 1782, 1783 y 1785 (García Melero, 1978, 70).
} 
paletas y caballetes fabricados por otros especialistas. Es decir, eran fabricantes especializados que vendían sus propios materiales y también los productos que otros fabricaban. Es posible que el cuadro Artists' Colourman's Workshop pintado hacia 1807 por Joseph Mallord William Turner describa este tipo de comerciantes. Este óleo sobre tabla - perteneciente a The Tate Gallery de Londres representa a un hombre moliendo un pigmento rojo sobre una losa de piedra. Detrás se puede ver un caballo, burro o asno moviendo una muela que deshace pigmentos de forma más basta. Alrededor tiene botellas y vasijas que, presumiblemente, contienen pintura o aglutinantes.

A finales del siglo XVIII y especialmente durante el XIX, los comerciantes de colores se desarrollaron vinculados a la industria química y a la explotación de descubrimientos de nuevos compuestos químicos. La mecanización y la industrialización llevaron a innovadores modos de producir los materiales artísticos. Pero hasta mediados del siglo XIX era habitual que los artistas se prepararan sus propios colores. Los pintores adquirían en el comercio los pigmentos y los aglutinantes y después, en su estudio amasaban ambos ingredientes para formar la pintura deseada. Dado que hasta mediados de siglo los envases para pintura no eran excesivamente eficaces, los comerciantes no podían almacenar durante mucho tiempo pintura al óleo preparada. No obstante, podían preparar la pintura por encargo si algún pintor lo solicitaba.

El Curso de Soler y Ferrer (1837) es un atrayente tratadito en el que encontramos numerosas indicaciones para que el propio pintor elabore sus colores. Este Curso Completo aporta valiosa información sobre la elaboración y el almacenamiento de los materiales tradicionales. Estos testimonios desaparecen de los tratados posteriores porque, hacia mediados de siglo, los comerciantes de colores asumirán - casi por completo - la elaboración de los ingredientes artísticos.

Uno de los mayores atractivos del Curso de Soler y Ferrer es que explica cómo moler los pigmentos y amasarlos con el aceite. Este es uno de los aspectos que los manuales dejarán de tratar cuando los 
fabricantes de colores se responsabilizan de estos trabajos. Describe la losa y la moleta de mármol duro para moler los colores de forma manual. Pero realmente interesante - por lo novedoso y originalresulta el diseño de un mortero para moler colores en grandes cantidades (Ver Fig. 1):

Mas para una obra muy en grande en que se consume mucha cantidad de color, usando del mortero y aparato de la lámina 38. figura 26. puede ahorrarse mucho trabajo en el moler, colocando en el mortero de porfido ó piedra dura el color machacado antes medianamente con un martillo si es en terresnos ó piedra, dando vueltas á la moleta 2, que tambien es de porfido en forma de pera para que siga la concavidad del mortero, por medio del manubrio de hierro, puesta la mano en el punto 3. afianzando en la muesca 4. del brazo 5. que saldrá de la pared para recibirlo, cargando el dicho manubrio si es el color muy duro, con el peso de una bola de hierro, plomo, ó piedra proporcionada, en la parte superior del mismo 6.

En este aparato pueden molerse los colores ó bien en seco reduciéndolos á polvo finísimo llamado impalpable, ó también en agua la precisa para que el color que irá apartando á los lados la moleta vaya reuniéndose otra vez, cayendo por el pendiente del mortero, y las regatas ó estrias abiertas á este fin en la moleta; con lo que á muy poco trabajo quedará perfectamente molido el color. (Soler y Ferrer, 1837: II, 42 - 43)

El molido manual de colores permanecerá durante casi toda la centuria pero en Inglaterra y Francia, desde principios de siglo, se produjeron diversos intentos de construir una máquina de moler pigmentos. No obstante estas tentativas tuvieron un éxito relativo. El molido es una operación muy delicada pues la calidad de la pintura acabada y el brillo del color dependen en gran medida del cuidado de este procedimiento. El tamaño y la forma de los granos de pigmento afectan a las propiedades ópticas del color y a su comportamiento durante el amasado con el aceite. La mayoría de los pigmentos minerales tradicionales necesitaban un concienzudo molido para 


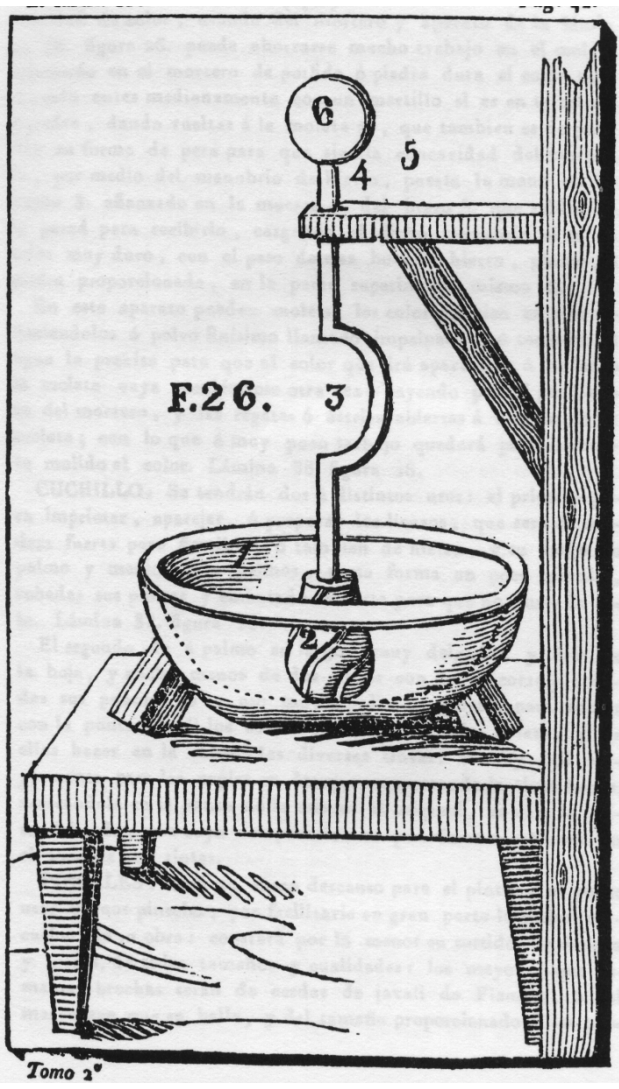

Fig. 1. Soler y Ferrer: Curso Completo Teórico y Práctico (1837). Mortero para moler grandes cantidades de color.

conseguir unas partículas finas adecuadas para su uso artístico. Por el contrario, muchos de los pigmentos modernos ${ }^{3} \mathrm{se}$ elaboran por precipitación y tienen partículas finas de origen, por eso precisan un molido menos intenso. Únicamente un buen conocedor de los materiales podía establecer estas diferencias en los molidos para lograr una mayor calidad en los materiales.

En sus inicios el molido mecánico producía colores demasiado bastos para su uso artístico aunque resultaban adecuados para elaborar pintura decorativa. Cuando se resolvió el problema del molido grueso surgió el inconveniente contrario: el molido excesivo. De esta forma se eliminaban las sutiles variaciones de cada pigmento para su molienda con el aceite y se impedían que se manifestaran sus características individuales. Todo esto afectaba al resultado final que se podía obtener con los colores.

El molido tiene lugar en dos etapas: primero el pigmento se reduce a polvo fino desde cualquiera de las formas en que lo suministran los productores: panes, conos, etc. Después se muele de nuevo con el aceite para producir la pintura final. Las máquinas moledoras tenían utilidad en ambas etapas de la preparación de la pintura. Uno de los primeros aparatos de molido eficientes fue el

3 Entendemos por pigmentos modernos todos aquellos que la industria química comenzó a elaborar desde los albores del siglo XIX. 
de Lemoine en la década de 1820. Este aparato estaba constituido por una piedra de moler que rotaba sobre otra más grande realizando movimientos que imitaban el molido a mano. Este artilugio podía moverse mediante vapor y permitía a un hombre realizar el trabajo de varios.

Otro tipo de máquina que amasaba el pigmento con el aceite estaba constituida por rodillos horizontales cuya separación podía variarse. Los primeros modelos de esta herramienta utilizaban cilindros de hierro $4 \mathrm{o}$ acero que causaban la decoloración de ciertos pigmentos como el blanco de plomo. Además, algunas partículas duras de pigmento - como ciertos granos de los ocres - dañaban los rodillos. Además, a veces, era necesario pasar varias veces el color por los cilindros y sólo se obtenían resultados mediocres. En la década de 1830, comentan Bomford et al. (1990: 39), el uso de rodillos de piedra dura y las modificaciones en el método de espaciar los rodillos mejoraron las máquinas. De esta forma se lograron molidos regulares, metódicos y rápidos. El primer comerciante que ofreció couleurs fines molidos a máquina - según Anthea Callen (1983: 23) - fue Blot de la Rue de St. Honoré de París en 1836.

Desde principios de siglo fueron varios los intentos de diseñar máquinas adecuadas para moler pigmentos: Chaptal (1807) menciona los rodillos para reducir el minio, Rawlison presentó en 1804 una maquina moledora de colores al óleo, Lemoine diseñó una máquina que imitaba los movimientos del molido a mano; y con toda seguridad otras personas se involucraron en la mejora e invención de estos y otros sistemas. Sin embargo, Winsor \& Newton (1902) se atribuyen el mérito de la invención e introducción en el mercado de las máquinas de moler:

\footnotetext{
${ }_{4}^{4}$ Chaptal (1816: III, 257-258) describe una máquina con tres pares de rodillos que se empleaba en la elaboración del minio. Los pares de cilindros estaban colocados unos sobre otros. El par superior y el intermedio estaban formados por un rodillo de hierro y uno de madera dura; mientras que en el par inferior ambos cilindros eran de madera dura. La distancia de los cilindros era mayor en los rodillos superiores y menor en los inferiores. Todo el mecanismo estaba cubierto para reducir la exposición del operario al material tóxico. (Ver 4.3.)
} 
Grinding colours by machinery was first introduced by WINSOR \& NEWTON in 1840, special apparatus being invented by them for the purpose. Since that period many further improvements have been made in original Mills; and it is believed that at present there exists no machinery which, for power and precision, combined with great cleanliness in working, can at all compare with that invented, perfected, and now used by them in the production of their Artists' Oil Colours. (Winsor \& Newton, 1902: 83)

Para Soler y Ferrer (1837: II, 60), los colores al óleo debían formar "...una pasta tan compacta, fina, y en tal espezor, que se mantenga por sí sola en la hoja del cuchillo puesto este orizontalmente...”. En cambio, los pigmentos molidos mecánicamente perdían sus propiedades individuales y las pinturas al óleo producidas mecánicamente necesitaban aditivos que les confiriesen una consistencia uniforme y cremosa. La mayoría de estos aditivos eran perjudiciales para la pintura. Callen (1983: 24) comenta que en el siglo XIX los aditivos más empleados eran el sebo de vaca y de carnero, especialmente perjudiciales porque nunca secaban. Ésta investigadora también menciona la cera, que utilizada en proporciones elevadas era igualmente perniciosa.

Otro asunto interesante que se desprende del Curso de Soler y Ferrer se refiere a la conservación de los colores al óleo preparados. Recordemos que los tubos metálicos aún no habían aparecido y conservar los colores exigía del pintor conocimientos profundos del comportamiento de sus materiales. Estos autores comentan distintas formas de conservar los colores al óleo pero, de todas ellas, la más extendida, cómoda y efectiva eran las vejigas. Aunque cómo veremos, las vejigas no eran bastante competentes.

...mas para quien no gaste el color de continuo y quiera conservarlos con limpieza, teniéndolos siempre prontos y reunidos, es lo mas propio para conservarlos en casa, en los albayaldes y ocres en especial, tenerlos en sus escudillas distintas, ó repartidos, siendo poca su cantidad, al borde de un plato plano, y en esta disposición tenerlos sumergidos en agua, y los demás ó en papeles untados en 
aceite, ó en los zurroncillos, muñequitas, y vejigas.... (Soler y Ferrer, 1837: II, 61)

Cuando el artista quería pintar al aire libre, o bien tenía que trasladarse para realizar un retrato, era común utilizar vejigas que almacenaran los colores al óleo. Según Callen (1983: 24) y Bomford et al. (1990: 39) lo habitual era utilizar vejigas de cerdo y así queda atestiguado por Bouvier (1827: 102): "Je suppose votre tas de couleur tout broyé et prêt à être mis en vessie: vous aurez chez vous de la vessie de porc, qu'il en faut pas choisir trop dure ni trop épaisse;...”. En cambio, los tratadistas españoles prefieren vejigas o zurroncillos de tripas de vaca (Palomino, [1715-1724] 1988: II, 138) o “...vejigas de pavo, cordero, ó carnero...” (Soler y Ferrer, 1837: II, 61). Estas eran pequeñas pieles en las que se introducía una pequeña cantidad de pintura - del tamaño de una nuez - y luego se ataba sin dejar aire. Para extraer el color se practicaba un pequeño orificio en la piel con una tachuela de hierro. La pintura salía al apretar por el extremo contrario y la misma tachuela servía de tapón. Las tachuelas de hueso o marfil que no reaccionaban químicamente con los pigmentos también se emplearon como tapón de estos envases.

Pero sistemas para tapar la obertura de las vejigas de color hubo varios. Así, Bouvier (1827: 107) explica que la mayoría de pintores se valían de un clavo (clou) pero presentaba el inconveniente de que podía reaccionar con algunos pigmentos. Por eso, este autor prefería practicar una incisión en cruz en la parte inferior de la vejiga. Este sistema se cerraba al juntar los trozos de piel y apoyar la vejiga sobre los cortes. Los tratadistas J. Soler y A. Ferrer exponen un sistema diferente:

...es el mejor medio conocido meterlos luego de molidos en vejigas de pavo, cordero, ó carnero secadas al aire libre después de muy limpias y rebajadas, echando en ellas el color por el agujero que á este fin se les habrá abierto, recortándolo en su parte superior, y llenas ya de color sus dos terceras partes, se humedecerá toda ella por lo esterior, se tomará un palito redondo, el que colocado perpendicular al centro del agujero, sin que llegue al color, se 
tomará todo el borde superior de la vejiga, y unido muy juntamente al palo se atará á el con una seda á muchos dobles: cuando ya seca la vejiga se quitará y pondrá en dicho agujero este palito haciendo en ella el servicio de tapón. (Soler y Ferrer, 1837: II, 61)

Esta forma de cerrar las vejigas era muy similar a la que Rawlinson 5 - fabricante de colores - presentó a la Society for the Encouragement of Arts en 1804.

'Instead of drawing the neck of the bladder close, in the act of tying it, insert a slender cylindrical stick, and bind the bladder close around it. This, when dry, will form a tube or pipe, through which, when the stick is withdrawn, the colour may be squeezed as wanted, and the neck again closed by replacing the stick. This is not only a nearer and much more cleanly mode than the usual one of perforating the bladder...but the bladder, being uninjured may be used repeatedly for fresh quantities of colour.' (Harley, 1971: 1-3)

En 1841, una fecha bastante tardía, Waring and Dimes comerciantes de colores - desarrollaron el 'Anti-tube bladders of oil colours'. Este era un sistema de cierre con tapa ajustada para las vejigas tradicionales que no distaba mucho de la mejora de Rawlinson. Waring and Dimes argumentaban que estos cierres impedían que la pintura rezumara o saliera por el orificio de salida.

Las vejigas tenían varios inconvenientes fundamentales que fueron descritos por Harley (1971: 1) y Bomford et al. (1990: 39). Estos últimos investigadores afirman que las vejigas (1) no permitían guardar grandes cantidades de pintura y (2) que ésta endurecía gradualmente porque el óleo se oxidaba debido a la falta de impermeabilidad de la piel. Tanto Harley (1971: 1) como Bomford et

\footnotetext{
${ }^{5}$ Rawlison presentó esta mejora de las vejigas a la Society of the Encouragement of Arts en 1804 como un apéndice de su informe sobre una máquina moledora de colores al óleo por la que fue galardonado (Harley, 1971: 1).
} 
al. (1990: 39) coinciden al expresar que (3) cuando la vejiga se perforaba todos los colores comenzaban a oxidarse y (4) en ocasiones, el envase reventaba cuando se apretaba para extraer el color. Pero Harley (1971: 1) explicaba también otros problemas de las vejigas: (5) aunque la mayoría de colores se mantenían en buen estado antes de perforar la piel, el azul de Prusia y las lacas rojas se deterioraban; (6) la pintura rezumaba por el orificio practicado y ensuciaba otras vejigas y las manos del pintor.

Sin duda, era necesario un envase adecuado para almacenar durante largo tiempo la pintura al óleo que además fuera fácil de manejar y limpio. Harley (1971: 2) especula con que unos de los motivos que incrementó la necesidad de un envase alternativo fue el aumento de aficionados a la pintura. En cualquier caso, artistas y comerciantes de colores se preocuparon por lograr contenedores adecuados para la pintura al óleo. Estos recipientes debían ser herméticos para que los óleos no se oxidaran y endurecieran y debían estar adaptados para extraer parte del color y conservar el resto. Aunque los textos decimonónicos españoles sobre pintura no lo mencionen, el primer envase que compitió con las vejigas fue la jeringuilla. En 1822 - dice Harley (1971: 2) -, James Harris presentó a la Society of Arts unas jeringuillas de latón cuyo interior estaba estañado $^{6}$. Las jeringuillas tenían la ventaja sobre las vejigas de conservar bien los colores y tener un uso más limpio. Además, resultaban más cómodas al pintor durante los viajes y evitaban los olores a las personas que posaban para un retrato. Según la información que suministra Harley (1971: 2), los colores al óleo envasados en jeringuillas de latón o estaño no llegaron a implantarse debido a que su coste era superior al de los colores en vejigas.

Unos años más tarde, en 1840, William Winsor ${ }^{7}$ patentó las jeringuillas de cristal enfatizando que la mayor novedad de su

\footnotetext{
${ }^{6}$ Pocas jeringuillas han llegado a nuestros días pero una caja con colores al óleo envasados en jeringuillas - similares a las que describió Harris - se encuentran en una caja de colores al óleo en The Royal Academy of Arts de Londres. Esta caja es un presente de cumpleaños que la Reina Victoria del Reino Unido recibió de su madre h. 1837. (Harley, 1971: 3, plate III)

7 De Winsor \& Newton
} 
invento residía en que el cristal permitía al pintor identificar el color inmediatamente; además, resultaban más baratas que las jeringuillas metálicas. Sin embargo, como dice Bordini (1999: 17) estos envases tenían el gran inconveniente de romperse con facilidad. Bomford et al. (1990: 39) aseguran que las jeringuillas de cristal estuvieron disponibles en Francia aproximadamente desde 1840 y su uso se prolongó durante la década de 1850.

En 1841, John G. Rand - retratista americano afincado en Londres - inventó los tubos metálicos enrollables ${ }^{8}$ que supusieron una auténtica revolución en el almacenamiento de los colores al óleo. El metal escogido fue el estaño que es muy maleable y permite el enrollado de los tubos sin reaccionar con los pigmentos. Estos envases alcanzaron una amplia repercusión como embalaje de diversas sustancias, incluso en nuestros días los tubos plegables tienen múltiples usos; pero originariamente se desarrollaron para pintura artística.

John G. Rand otorgó a Thomas Brown el privilegio de ser el único suministrador de sus tubos plegables. Así que Brown vendía los tubos llenos o vacíos y las máquinas para rellenarlos. Estos tubos llevaban el nombre del suministrador - en la tapa y en los hombros del tubo - y muchos comerciantes se negaron a vender sus colores con la marca de otro comerciante. No todos, pues - como explica Harley (1971: 8) - Roberson \& Co. aceptó utilizar los tubos con la marca Brown y pronto anunció la venta de colores en tubos. Sin embargo, Winsor decidió elaborar sus propios tubos metálicos con un sistema diferente al de J. G. Rand9. Harley (1971: 9) cuestiona la

\footnotetext{
${ }^{8}$ Harley (1971: 6) apunta que la patente de los tubos de Rand fue inscrita en marzo de 1841 con el número 8863 para las Mejoras en la Conservación de Pinturas y Otros Fluidos (Improvements in Preserving Paints and other Fluids) en la oficina de patentes de Londres. En septiembre del mismo año la patente se inscribió en Estados Unidos.

${ }^{9}$ Los tubos de J. G. Rand se fabricaban mediante procesos de extrusión del metal ('impact extrusion'). En 1842, Rand patentó mejoras en la elaboración de sus tubos plegables y en 1843 vuelve a patentar mejoras en la fabricación de los tubos mediante presión hidráulica. Los tubos de Winsor se elaboraban mediante rollos o capas delgadas de metal cubiertos en el interior con una membrana para aislar el color del metal. También presentaba diferencias en la tapa del tubo. (Harley, 1971: 7-8).
} 
honradez de Winsor \& Newton en relación a la patente de los tubos metálicos para pintura: “...there seems to be little doubt that Winsor and Newton were infringing the patent even though their tubes were made by a different process." Thomas Brown y Winsor \& Newton mantuvieron durante ocho meses una conflictiva campaña publicitaria en la que cada comerciante recomendaba sus propios tubos. El conflicto se arregló con un anuncio en la prensa que advertía que ambos fabricantes empleaban los tubos inventados por John G. Rand.

Harley (1971: 11) y Bomford et al. (1990: 40) coinciden en afirmar que algunos autores citan los tubos de plomo como contenedores de pintura. En nuestra tratadística del siglo XIX encontramos una referencia al empleo de tubos de plomo para colores a la acuarela. En concreto, Poleró en el capítulo dedicado a la pintura a la aguada dice:

Los colores que hoy alcanzan mayor aceptación son de dos clases: ó los que se venden en cajas á propósito, llenando los huecos que las subdividen, ó aquellos otros que están guardados en tubos de plomo. Estos últimos tienen la contingencia de endurecerse;... (Poleró, 1886: 125)

Pero Harley y Bomford et al. difieren en las conclusiones sobre el uso de los tubos plúmbeos. Harley (1971: 11) asegura que tanto Rand como otros fabricantes eran conscientes que el plomo estropeaba algunos pigmentos y por eso fabricaron sus tubos con estaño. La misma investigadora señala que las referencias que indican que los primeros tubos fueron de plomo probablemente se deban a que tuvieron otros usos diferentes al de albergar pintura artística. En cambio, Bomford et al. (1990: 40) consideran que dado que se sabía que el plomo reaccionaba con algunos pigmentos, los tubos de plomo debieron de tener un uso escaso como envase de pintura artística. Sin embargo, la mención de Poleró a esta clase de tubos sugiere su empleo para pintura artística en fecha tardía, aunque puede tratarse de un error del autor. En cualquier caso y por el motivo esgrimido antes, estos tubos no debieron emplearse mucho tiempo en pintura artística. 
De esta manera, como atestigua Harley (1971: 4), los colores al óleo en tubos estuvieron disponibles en Inglaterra hacia 1841. Mientras que según Bomford et al. (1990: 40) los óleos en tubos aparecieron en Francia hacia 1850. La tratadística española decimonónica aporta una interesante alusión a los tubos de pintura en 1862.

Entre las modernas invenciones es digna de aprovecharse la de los tubos metálicos para tener el color; cómodo, fácil y limpio es este nuevo y feliz invento, en ellos cierta clase de colores pueden durar en buen estado muchos años. (O’Neille, 1862: 30)

Los colores envasados en tubos convivieron muchos años con los colores en vejigas que resultaban más baratos. En este momento de la historia, los fabricantes y comerciantes de colores estaban plenamente establecidos. Pero los pintores - como el paisajista que acabamos de citar - no pierden del todo la vinculación a sus elaboraciones. Por eso, O’Neille (1862: 30) sugiere tener los utensilios necesarios para preparar algún color si hiciera falta aunque se pudieran comprar preparados. Los materiales preparados industrialmente convivieron durante algún tiempo con los materiales preparados por los pintores.

A finales de siglo, el artista francés Camille Bellanger (1899: 223-224) comenta lo absurdo que sería aconsejar a los pintores que elaboraran sus propios colores. Sin embargo, este autor piensa que sería provechoso que los comerciantes suministraran productos de mayor calidad aunque tuvieran que subir los precios. Pero este pintor francés también demuestra la importancia y la repercusión de los tubos metálicos para envasar la pintura.

Hay, no obstante, que hacer justicia á los señores comerciantes de colores y darles las gracias por la habilidad que desplegan en el envase de sus mercancias. Antes nos ofrecían los colores encerrados en vasijas sucias y feas, y hoy en bonitos tubos de metal, elegantes y coquetones y, sobre todo, muy cómodos. Cuando se quiere extraer de ellos un poco de color, se quita el 
tapón, se oprime entre los dedos el extremo inferior del tubo y se recoge sobre la paleta la cantidad de pintura que puede necesitarse por el momento. (Bellanger, 1899: 224)

Los tubos metálicos fueron cruciales para que los óleos preparados se conservaran en buen estado mucho tiempo, incluso años, antes de que llegaran a los artistas. Además, los nuevos sistemas de transporte como los ferrocarriles y los barcos de vapor permitieron que las mercancías llegaran a más sitios y más rápidamenente. Pero pronto los pintores encontraron deficiencias notables en los materiales industriales. Emilio Sala aporta en su artículo para La Ilustración Española y Americana críticas muy concretas y claras sobre los óleos envasados en tubos.

Para que los colores se conserven indefinidamente en los tubos hasta que el comerciante los venda y el pintor los use, se ha inventado una serie de combinaciones á cual más perjudicial para la pintura; y á fin de que todos los colores ofrezcan igual consistencia ó temple para su manipulación se han discurrido otras tantas combinaciones, todas malísimas [...] (Sala, 1896: XLII, 276)

Una búsqueda exhaustiva en el Archivo Histórico de la Oficina Española de Patentes y Marcas nos ha permitido localizar varias patentes de finales del siglo XIX que atestiguan diferentes intentos para establecer mejoras en la elaboración de pinturas. Entre los registros encontrados destacamos "Un procedimiento de pintura de tubos"10 (1882), "Mejoras en las maquinas distribuidoras de pintura"11 (1884), "Mejoras en el compuesto oleoso para conservar las tintas"12 (1887), "Mejoras en el procedimiento para la fabricación

\footnotetext{
${ }^{10}$ Archivo Histórico de la Oficina Española de Patentes y Marcas. No de Patente 2566. Solicitado por Somzée, Léon el 12/07/1882

${ }^{11}$ Archivo Histórico de la OEPM. No de Patente 3913. Solicitado por Whipple, John Pierce el 22/01/1884.

${ }^{12}$ Archivo Histórico de la OEPM. No de Patente 7119. Solicitado por Stanchfield, George Mellen el 18/o6/1887.
} 
de colores y pinturas"13 (1889), "Mejoras introducidas en la composición de las pinturas"14 (1890), "Mejoras referentes a la fabricación de colores o pinturas"15 (1893), "Procedimiento de fabricación de colores de anilina o minerales preparados el óleo con aceites finos secantes"16 (1895), y "Mejoras en el procedimiento de preparar la pintura para el óleo, la acuarela, etc.”17 (1899).

Algunos pintores describen de manera esclarecedora los problemas que encontraban en sus óleos envasados en tubos. Emilio Sala, por ejemplo, señala inconvenientes muy concretos con los que se encontraban los pintores:

El blanco, por ejemplo, si no se muele en condiciones á propósito, hace como hilos al dividirse en partes la masa, ya sea con pincel ya con espátula; en el ultramar, el bermellón, luego de metidos en los tubos, el aceite se separa poco á poco del color, que se va solidificando aparte; lo mismo sucede con el cobalto; en una palabra, puede afirmarse que cada colorante exíge cuidados distintos que se dominan con la práctica; y en cuanto à los otros inconvenientes, son fáciles de subsanar evitando el tener mucha cantidad de aquellos que varian al envejecer en el tubo. [...]

Los colores del comercio no se secan por dentro: el ollejo, la película que los cubre á modo de colodión, es delgada, en tanto que en los colores molidos con aceite de linaza es más gruesa y la pasta acaba por petrificarse. (Sala,1896: XLII, 276)

\footnotetext{
${ }^{13}$ Archivo Histórico de la OEPM. No de Patente 10219. Solicitado por Martin, John Cowdery el 13/11/1889.

${ }^{14}$ Archivo Histórico de la OEPM. No de Patente 10484. Solicitado por Bibikov, Nicolas A. el 08/02/1890.

${ }^{15}$ Archivo Histórico de la OEPM. No de Patente 14571. Solicitado por Blackman, William Nelson el 09/05/1893.

${ }^{16}$ Archivo Histórico de la OEPM. No de Patente 17093. Solicitado por Lotario Zoeller, Enrique el 04/03/1895.

${ }^{17}$ Archivo Histórico de la OEPM. No de Patente 23843. Solicitado por Schirm, Carl Cowen/Lessing, Otto el 18/02/1899.
} 
Como veremos adelante con más detalle, los artistas se mostraron preocupados por los problemas derivados de los materiales comerciales. Las quejas son habituales en los escritos de los pintores decimonónicos y, en gran medida, la precariedad de los materiales pudo propiciar que, hacia finales del siglo, muchos pintores abogaran por amasar sus propios colores siguiendo recetas tradicionales.

El desarrollo industrial del mercado del color corrió paralelo a los avances de la industria química. El descubrimiento de nuevos compuestos colorantes propició la creación de fabricantes especializados en color. Como consecuencia, según explican Bomford et al. (1990: 34), a mediados del siglo XIX la industria del color estaba compuesta por (1) fabricantes especializados que vendían al por mayor sus productos a comerciantes de colores o a otras industrias. También formaban parte de esta estructura comercial (2) otros productores especializados que vendían sus productos a gran escala pero que también tenían tiendas al por menor; éstos eran fabricantes y comerciantes de colores. Para finalizar el entramado industrial, los encargados de tratar directamente con los artistas eran (3) comerciantes de colores, que vendían al público una gran variedad de productos pero que no manufacturaban las materias primas. Estos comerciantes amasaban los colores y los envasaban para su venta.

En el Archivo Histórico de la Oficina Española de Patentes y Marcas (OEPM) se encuentran registradas varias marcas de fábricas que podemos ubicar en el grupo (1) de la clasificación de Bomford et al. Por ejemplo, en 1882, a nombre de Jaime Roldós Mora se inscribió en Mataró (Barcelona) la marca La Blanca Paloma ${ }^{18}$ de una fábrica de albayalde. Más tarde, en 1892 se anotó otra factoría de albayalde en Barcelona cuyo propietario era Noé y Compañía ${ }^{19}$. En la misma ciudad, un año más tarde se inscribió la marca de Grandes

\footnotetext{
${ }^{18}$ Archivo Histórico de la OEPM. No de Registro 1218

${ }^{19}$ Archivo Histórico de la OEPM. No de Registro 3424
} 

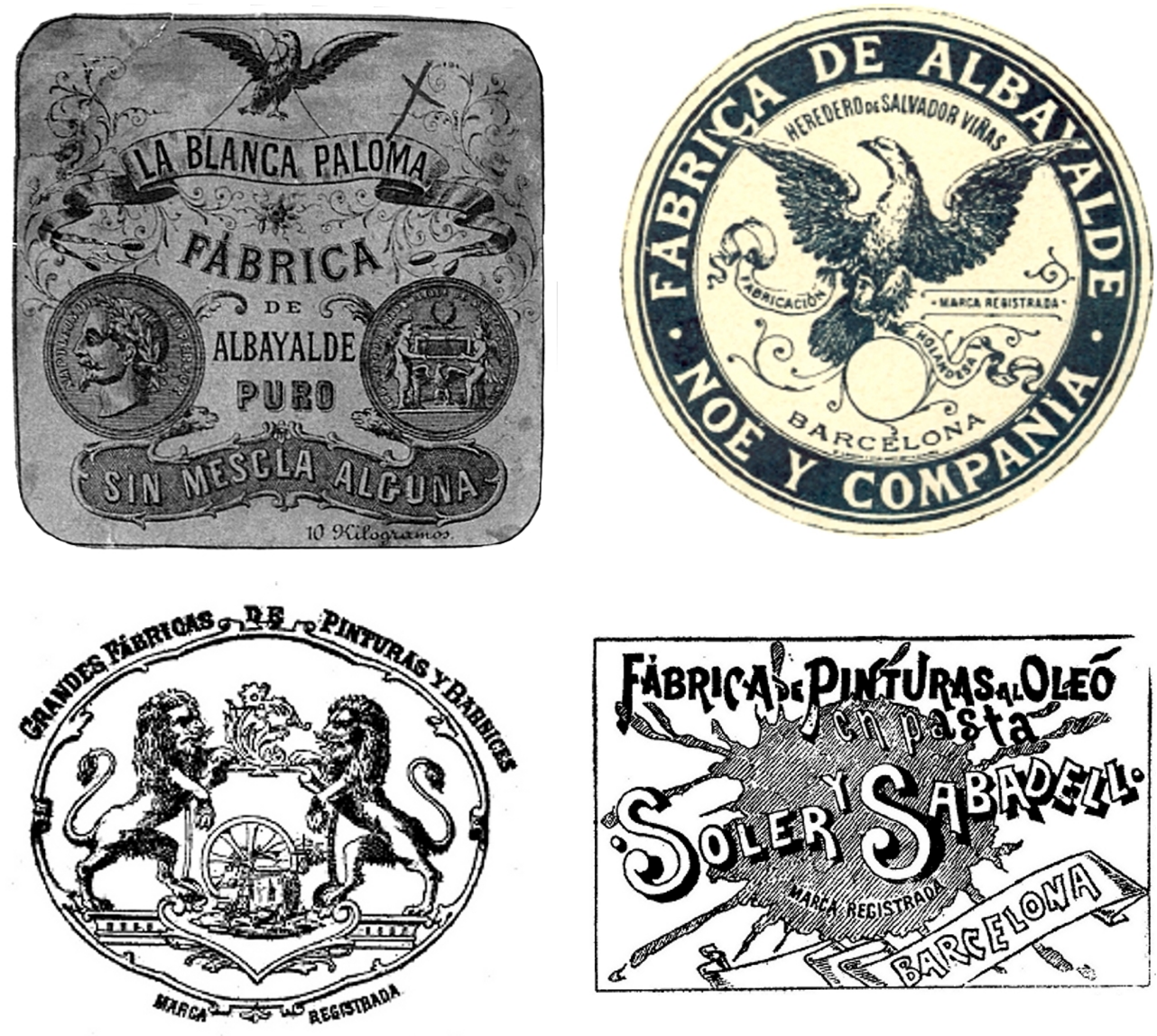

Figs. 2-5. Marcas de fábrica. Archivo Histórico de la OEPM

Marca $\mathrm{n}^{\circ} 1218$

Marca $\mathrm{n}^{\mathrm{o}} 4045$

Marca $n^{0} 3424$

Marca $\mathrm{n}^{0} 4326$ Bis 1

Fábricas de Pinturas y Barnices ${ }^{20}$ propiedad de P. Ventura y Compañía. En 1894, también en Barcelona, a nombre de Soler y Sabadell se inscribió una Fábrica de Pinturas al Óleo en Pasta ${ }^{21}$. Otras marcas de fábrica relacionadas con el sector de las Bellas Artes son la Resinera Segoviana ${ }^{22}$ inscrita en Segovia por Falcón Ruiz y Llorente en 1895; o la Compañía Ibérica de Resinas ${ }^{23}$ registrada en Madrid en 1900.

${ }^{20}$ Archivo Histórico de la OEPM. No de Registro 4045

${ }^{21}$ Archivo Histórico de la OEPM. No de Registro 4326 Bis 1

${ }^{22}$ Archivo Histórico de la OEPM. No de Registro 5150

23 Archivo Histórico de la OEPM. No de Registro 7391 
En el segundo grupo de la clasificación de Bomford et al. - es decir, entre los fabricantes y comerciantes de colores podemos incluir la empresa L. Péant é Hijos radicada en Madrid. Esta compañía fabricaba materiales para las Bellas Artes - aceites, barnices, esencias, secativo o pinceles - y los vendía al por menor junto con los artículos de otros fabricantes del ramo. En su catálogo se ofertaban productos franceses (Lefranc \& Cie), ingleses (Reeves \& Sons) y belgas (Félix Mommen). Es probable que L. Péant e Hijos vendiera sus productos al por mayor a otros pequeños comerciantes.

Uno de los hallazgos más significativos de esta tesis doctoral es un catálogo comercial de dicha empresa. Este catálogo es un documento realmente interesante porque nos muestra los materiales que los artistas tenían a su disposición cuando se editó. Pero además, se trata de un documento de gran interés puesto que no han salido a la luz otros catálogos de colores de empresas españolas decimonónicas. Hasta el momento, es es el único en su género que se ha localizado aunque no debemos descartar que se encuentren documentos similares en el futuro. El catálogo consta de dos volúmenes cuyas portadas están fechadas en 1895; mientras que la página inicial del volumen primero data de noviembre de 1893 . Las cubiertas de ambos tomos - de 1895 - tienen inscritas tres direcciones en Madrid:

39, calle de Atocha, 39,

13 y 14, plaza del Angel, 13 y 14,

13, carrera de San Jerónimo, 13,

MADRID

1895

(L. Péant é Hijos, 1895, portada)

En dos de las señas dadas estarían abiertos los comercios, mientras que en la plaza del Ángel se encontrarían los grandes talleres como indican las contraportadas de los volúmenes del catálogo. Sin embargo, la página inicial del volumen primero, fechada en 1893, consigna únicamente dos direcciones; esto puede indicar la prosperidad del negocio. 

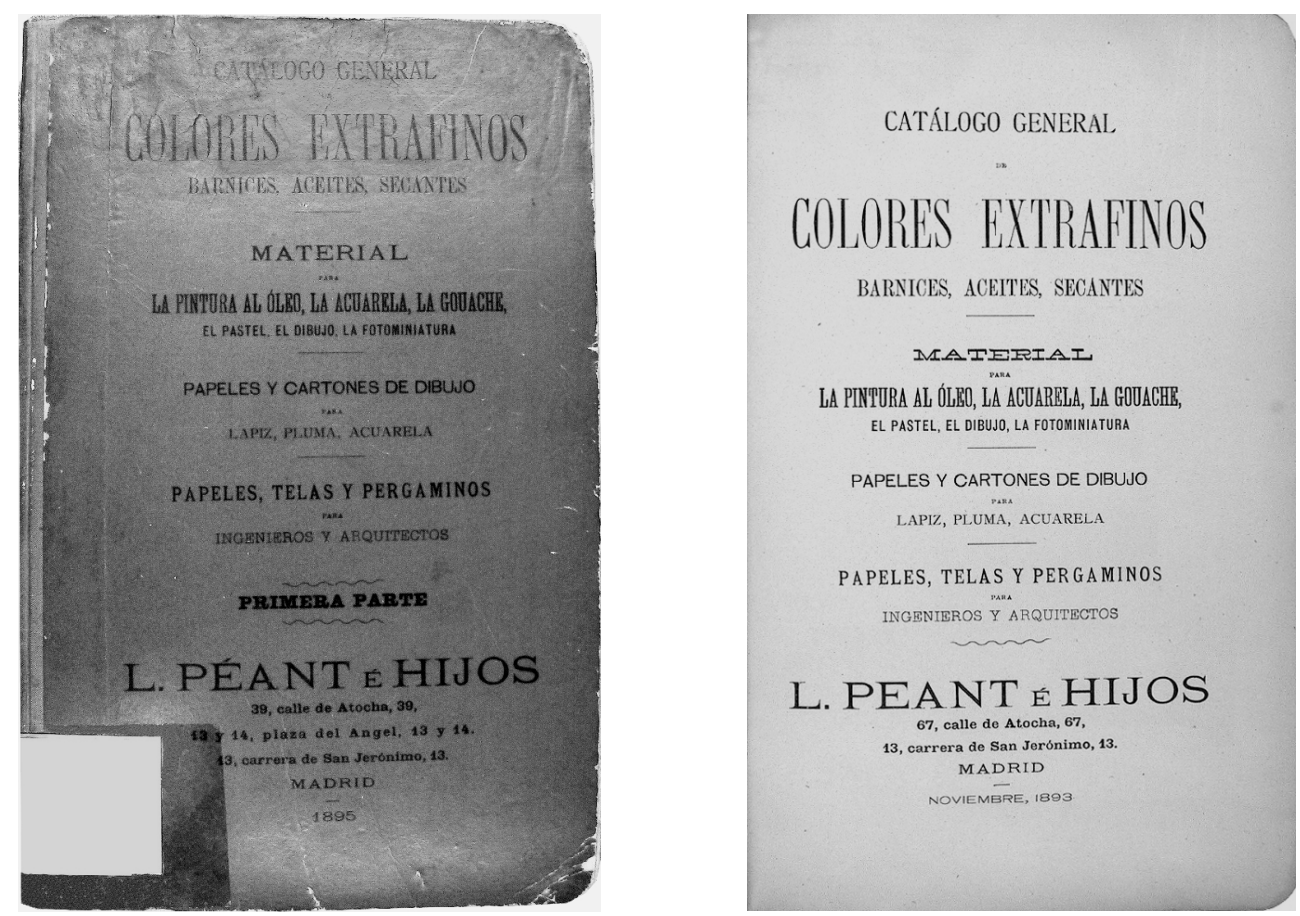

Figs. 6-7. L. Péant é Hijos: Catálogo General de Colores Extrafinos, Barnices, Aceites, Secantes. (1893 -1895). Portada y página inicial.

\author{
67, calle de Atocha, 67, \\ 13, carrera de San Jerónimo, 13 \\ MADRID \\ NOVIEMBRE, 1893 .
}

Un comercio de similares características consta entre las marcas de fábrica del Archivo Histórico de la Oficina Española de Patentes y Marcas (OEPM). Fechada en 1883, figura la Fábrica de Colores y Barnices y Droguería ${ }^{24}$ propiedad de José Martí Juliá en Figueres (Gerona).

Los materiales preparados industrialmente ahorraban mucho tiempo a los pintores en la elaboración de sus materias.

${ }^{24}$ Archivo Histórico de la OEPM. No de Referencia 1284. 


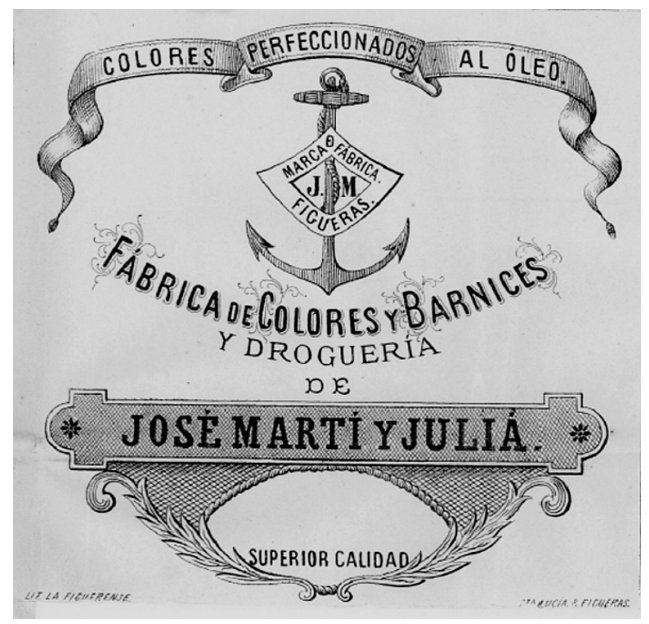

Fig. 8. Marca de fábrica. $\mathrm{n}^{0} 1284$

Archivo Histórico de la Oficina Española de Patentes y Marcas.

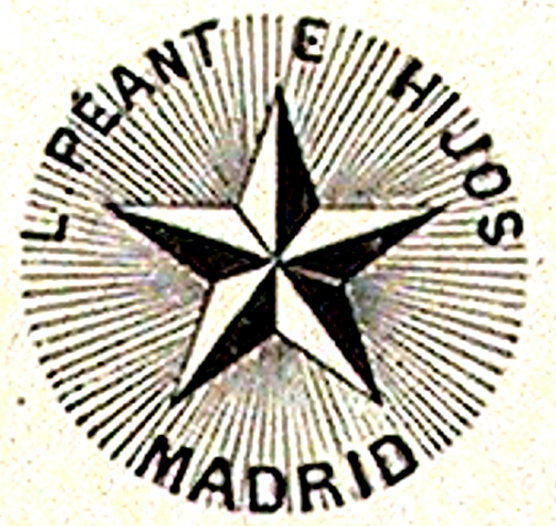

Fig. 9. Marca de Fábrica L. Péant é Hijos. Catálogo General de Colores Extrafinos, Barnices, Aceites, Secantes (1893-1895). Vol. 2.

Pero los artistas se encontraron con unos óleos con propiedades diferentes a los tradicionales. Anthea Callen (1983: 22) explica que con las nuevas pinturas producidas industrialmente y la falta de conocimientos técnicos de los pintores, era imposible reproducir efectos pictóricos de los antiguos maestros. Los óleos comerciales favorecían la pintura empastada e impedía las transparencias oscuras. Si a los materiales con nuevas características añadimos los colores modernos que produjo la industria química y la actitud antiacadémica, renovadora e investigadora de los pintores, resulta lógico el nacimiento de las primeras vanguardias de finales de siglo. Esta reflexión la expresa así Anthea Callen:

...el desarrollo de la técnica impresionista para pintar las sombras no se debió a una inspiración puramente estética, sino que la producción mecánica de colores tuvo mucho que ver en ello. Tres factores de especial importancia fueron el molido mecánico, los aceites aglutinantes y los aditivos empleados para mantener homogénea la pintura en tubos, de reciente aparición. (Callen, 1983: 22) 
En muchas ocasiones, los vendedores únicamente pensaban en su beneficio económico y sacaban al mercado productos adulterados o con deficiencias notables en su elaboración. Esta circunstancia llegó a ser tan desesperante para los pintores que desde comienzos del Ochocientos se escribieron infinidad de críticas contra los fabricantes de colores.

\subsection{Las Críticas de los Artistas}

Como ya hemos expresado, los cambios e innovaciones en los ingredientes y utensilios pictóricos se produjeron paulatinamente durante todo el siglo XIX y fueron algunos de los factores que permitieron el nacimiento de la modernidad en este arte. Los pintores, sin embargo, manifestaron un descontento generalizado con los materiales producidos industrialmente. Los textos de los artistas se llenaron de críticas - de las que ya hemos visto algunos ejemplos - que atestiguan su decepción. Algunas fuentes además, indican formas para detectar el fraude de los materiales.

En cierto modo, las consecuencias derivadas de la aparición de los nuevos materiales fueron anunciadas por Mérimée en 1830. Este pintor manifestó gran inquietud por haber dejado la elaboración de los materiales artísticos en manos de comerciantes:

Pendant long-temps, les peintres préparèrent ou firent préparer sous leurs yeux les couleurs, les huiles et les vernis qu'ils employaiet. Les élèves étaient chargés de ce soin: c'est par là que commençait leur apprentissage; de sorte qu'avant de manier le pinceau, ils étaient déjà instruits de ce qu'il convient de faire pour rendre la peinture durable. Dans la suite, ces détails devinrent exclusivement l'occupation de marchands, qui songèrent bien plus à leur profit qu'à la conservation des tableaux. Les peintres, n'apprêtant plus eux-mêmes leurs couleurs, ne furent plus en état de distinguer les bonnes d'avec les mauvaises, et les employèrent 
sans choix, telles qu’ils les avaient achetées. (Mérimée, 1830: XVIII-XIX)

El Curso Completo de Soler y Ferrer está muy vinculado a las prácticas pictóricas tradicionales y únicamente advierte de las adulteraciones de algunos de los materiales propios del pintor. Las reflexiones y quejas sobre los materiales comerciales - que con tanta claridad expone el artista y estudioso francés - no fueron recogidas en los tratados españoles hasta varios años después. La primera mención la hallamos en Borbón quien se queja de la escasa estabilidad de los materiales propios de su época.

...pero no debemos pasar en silencio que las adulteraciones de varios que el comercio nos presenta, estén ó no preparados de los diversos modos que la pintura los emplea, y singularmente los molidos al óleo, son causas asimismo, y muy poderosas, de las alteraciones que lamentamos; y lo creemos tanto mas necesario, conociendo cuán olvidada se tiene en nuestros días tan importante materia, haciéndose mas caso de la aparente belleza, que de la estabilidad de estos productos. (Borbón, 1860: 23 -24, n. f)

Sin embargo, O’Neille considera adecuado dejar las preparaciones materiales en manos de otros porque el pintor queda liberado de trabajos tediosos. Posiblemente, la visión de este artista es la más positiva que se muestra en todos los textos estudiados. Este autor no alude a problemas de adulteración o inestabilidad de los ingredientes pictóricos y deja ver la convivencia entre los colores comerciales y los preparados por el propio pintor.

Antiguamente cada pintor debía preparar y moler los colores, y al efecto tenia los enseres especiales, y uno ó dos hombres esclusivamente casi dedicados á este trabajo, y á la preparación de lienzos; pero como esta parte material es tan pesada, regularmente no faltan en el dia donde existen pintores, algunos, que separadamente se dedican á estos trabajos: así pues no me detendré en esplicar esta parte, y calculo que mas preferible será hacerlos 
preparar y arreglar que entretenerse en ello: sin embargo conviene tener á mano todo lo necesario, para el caso de que falte un color que perentoriamente se necesite y así el mismo pintor puede molerlo y arreglarlo. (O’Neille, 1862: 29 - 30)

Tampoco Algarra (1875) critica ferozmente las materias preparadas industrialmente. Este autor, simplemente alude las posibles adulteraciones de los aceites que llevan a cabo los comerciantes de mala fe. Además, reconoce que la calidad de los colores - pureza, finura y modo de preparación - depende de las fábricas que los elaboran. Tenemos que esperar a finales de siglo para volver a encontrar en los tratados españoles ideas muy similares a la expresada por Mérimée. Así, en 1886, Poleró escribió:

Es sabido que los pintores antiguos molían en su taller los colores que necesitaban, y, por consiguiente, conocían muy bien sus resultados; hoy, por el contrario, tienen que descansar en la buena ó mala fe del expendedor, aceptando los que le da, sin saber las alteraciones que puedan tener, ya por la mala calidad de aquellos, ó por la de los aceites empleados para molerlos. (Poleró, 1886: 82)

Como hemos visto antes, el pintor Emilio Sala (1896) también manifestó su descontento con los materiales industriales. Este artista da muestras de conocer los tratados de Palomino [1715-1724] y Cennini [finales del s. XIV]. Incluso critica la actitud de este último porque omite en su tratado las explicaciones de algunas recetas y a esta elipsis, comenta Sala, se debe la pérdida de las recetas de los grandes maestros. Este pintor explica los fundamentos de las quejas de los pintores por sus materiales:

De una parte el excesivo descuido con que las Escuelas de Bellas Artes, que debieran dar ejemplo, han mirado siempre cuanto se refiere al conocimiento, estudio y manipulación de ingredientes preparados para la práctica manual de la pintura, y de otra parte los 
abusos de la falsificación en todo aquello que el comercio moderno nos vende, hacen que de día en día aumenten las quejas de los artistas, y que para buscar remedio se trate de averiguar dónde radica el mal de las deficiencias de nuestra cocina de pintura, que así llamamos á estos estudios en la jerga de la profesión. (Sala, 1896: XLII, 275)

José López Tomás expresaba también en 1898 su desilusión con los materiales comerciales. Por este motivo su tratado describe cómo preparar lienzos, decolorar el aceite de linaza, elaborar secantes, arreglar barnices y cómo amasar y conservar los colores. En algunos casos se puede apreciar la dependencia de El Arte de la Pintura de Pacheco [1649]. Como hemos visto en el apartado 1.1., López Tomás reconoce que copia algunas instrucciones del pintor barroco porque era suegro de Velázquez y estaban escritas durante los mejores tiempos del Arte español.

Los pintores de todos los pueblos, desde los primeros tiempos de la pintura al óleo, hasta entrado nuestro siglo, se preparaban con esmero los lienzos, colores y barnices, preocupándose casi tanto de esta parte que parece secundaria, como de la ejecución de sus cuadros; pero los pintores contemporáneos han creido más cómodo confiar esos trabajos manuales al comercio y bien cara están pagando su apatía, pues muchas obras notables de estos últimos años, ennegrecidos unos colores, torcidos otros, perdidas casi por completo, apenas son hoy un recuerdo de lo que fueron recien salidas del estudio del autor.

Poderosa debe parecer á todos la razón expuesta para que los pintores piensen en poner remedio al grave mal que destruye sus obras, y aun á ella se puede añadir otra de bastante importancia, y es que los colores buenos molidos por uno mismo resultan más económicos que los más malos y baratos que el comercio proporciona. Como lo dicho vale para los lienzos, barnices y secantes... (López Tomás, 1898: 46 - 47) 
Bellanger (1899: 223) critica no sólo la escasa calidad de los colores comerciales sino que además comenta, con cierto tono jocoso, la profusión de colores que puede encontrar el pintor en los tubos: "el color de la carne, por ejemplo, encerrado en un tubo." Este autor demuestra tener una opinión fatalista sobre los resultados que los pintores pueden obtener con los óleos preparados comercialmente.

Y el artista acepta todos aquellos productos que no sabe cómo fueron hechos ni los elementos precisos que los componen, y que le venden sin comprobación. Sin recriminar por ello á la industria contemporánea, no puedo menos de decir que en este concepto, como en otros muchos, luchamos en condiciones muy inferiores á las de los maestros clásicos. Generalmente nuestras pinturas están condenadas á una existencia efímera. (Bellanger, 1899: 223)

Para Vibert, la generación de 1830 - es decir, la de Mérimée - ya no conocía las prácticas tradicionales de la pintura. Este pintor francés, supervisaba la elaboración de algunos productos de la marca Lefranc \& $\mathrm{C}^{\mathrm{ie}} \mathrm{y}$ además impartía clases de materiales pictóricos en la Escuela de Bellas Artes de París. En definitiva, era un entendido en materiales pictóricos y era consciente de lo importante que era que los pintores conocieran y comprendieran bien el comportamiento de sus materiales. Según él, si los artistas conservaran estos conocimientos sabrían distinguir cuándo los comerciantes preparan bien sus productos:

Desgraciadamente, la mayor parte de los que muelen los colores para los artistas no se preocupan sino del lado comercial de su industria. Su único fin es obtener colores que se conserven frescos en los tubos el mayor tiempo posible y bajo todos los climas; pero este objetivo, bueno para los grandes almacenes, no lo es para el artista. (Vibert, 1908: 104-105)

Vibert expresó sus implacables opiniones en su tratado: 
Hoy día los pintores no tienen ya esos celos pueriles y hasta desdeñan las cuestiones materiales del arte; abandonan el cuidado de preparar sus lienzos y sus colores á manos mercenarias.

Estos industriales, hábiles, pero ignorantes, inventan ungüentos, pomadas, secativos, etc., y, con nombres retumbantes no fabrican sino combinaciones desastrosas. Lo suministran todo, la caja, el caballete, los pinceles, los asuntos de cuadros y hasta sus consejos, y la benevolencia de los jurados de pintura. (Vibert, 1908: 10)

Las desesperadas críticas de los pintores hicieron reaccionar a los fabricantes y comerciantes de colores. Así, L. Péant e Hijos (1895: I, 17) - fabricantes y comerciante de colores en Madrid - ofertaba en su catálogo una Caja de Análisis para Pintores que contenía disolventes, reactivos, filtros, probetas de cristal, embudos, filtros, cuchara de hierro, y algunos instrumentos más. También Vibert (1908: 254) dedica un apartado a los ensayos de los colores, aclarando que no se pueden analizar por completo los colores sin ser químico; pero con sustancias bastante cotidianas se pueden descubrir las falsificaciones de los pigmentos.

Ambas fuentes coinciden en casi todos los reactivos necesarios para los ensayos de los pigmentos: vinagre fuerte (ácido acético), sal de cocina (cloruro de sodio), agua de cobre (ácido oxálico), agua fuerte (ácido nítrico) y cristales de sosa (carbonato de sosa); aunque el catálogo de L. Péant é Hijos también incluye la bencina y el alcohol. Cuando se quiere comprobar la pureza de un color al óleo primero hay que eliminar el aceite que lo aglutina; Vibert describe cómo realizar esta operación por medio de la bencina. El pigmento debe quedarse seco, desengrasado y reducido a polvo, y entonces pueden comenzarse los ensayos. El artista francés explica cómo realizar las pruebas a varios pigmentos: blancos de plomo y zinc, amarillos de estronciana y cadmio, bermellón y lacas garanza, azules ultramar y cobalto, verdes esmeralda y cobalto y negros.

A causa de las críticas de los pintores, los comerciantes debieron defender sus productos. La compañía L. Péant é Hijos aseguraba de sus materiales: 


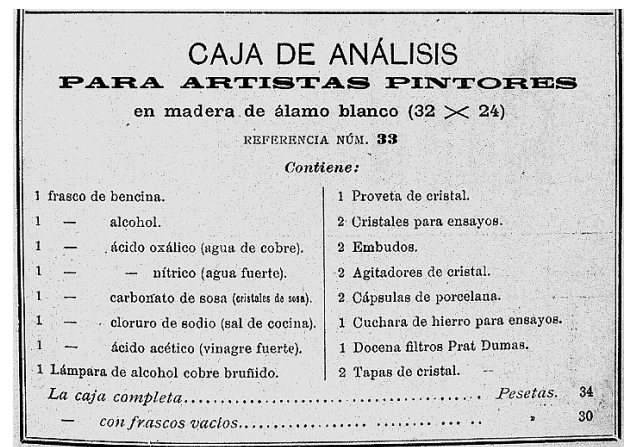

Fig. 10. L. Péant é Hijos: Catálogo General de Colores Extrafinos, Barnices, Aceites, Secantes. (189 -1895).
El esmero y

cuidado que ponemos en la elaboración de estos productos son para el artista la mejor garantía. Las primeras materias, escogidas en los mejores centros de producción, nos permiten ofrecerlos, en clases inmejorables, á precios sumamente económicos. (L. Péant é Hijos, 1895: II, 52)

La edición francesa de La Ciencia de la Pintura de Vibert en su nota al final del libro expone unas interesantes reflexiones desde el punto de vista del fabricante de colores.

Tous les produits nouveaux dont il est parlé dans ce livre se trovent à la maison Lefran et $\mathrm{C}^{\mathrm{ie}}, 64$ et 66 rue du Turenne, à Paris.

Non seulement ces produits son fabriqués d'après nos indications et nos formules, mais nous n'em avons autorisé la fabrication qu'à la condition qu'elle serait toujours soumise à notre surveillance.

On comprend qu'un auteur ait l'amour-propre de vouloir que ses inventions donnent les résultats qu'il announce et qu'il en peut pas être responsable de tout ce que l'on fabriquera ou que l'on a même déjà fabriqué avec ses procédés plus on moins mal compris. Voilà donc pourquoi cet auteur déclare qu'il en garantit, parmi les produits que le commerce peut présemter comme faits d'après ses procédés, que ceux qui portent la marque de la maison Lefranc et $\mathrm{C}^{\mathrm{ie}}$. (Vibert, 1891: GARANTIE COMMERCIALE)

En cierto modo Vibert era un visionario y empleaba su mente en buscar soluciones que combatieran la fabricación de materiales pictóricos defectuosos. Una de sus ideas más revolucionarias consistía en que los comerciantes incluyeran en las etiquetas de los 
colores, junto al nombre del color, la composición química del mismo. Así, si el comerciante o fabricante suministraba un material diferente al que aparece inscrito en la etiqueta podría ser llevado ante los tribunales como falsificador ordinario. Este fue un proyecto complejo a la vez que interesante que el pintor presentó a la Sociedad de Artistas Franceses. Cuando se publicó la primera edición de La Ciencia de la Pintura en 1891, el artista estaba esperando la respuesta de la Sociedad y la resolución no aparece en la edición en español de 1908.

\subsection{Los Instrumentos del Pintor}

Los pintores siempre han utilizado caballetes, paletas, pinceles, brochas, tientos, etc. Una mirada superficial del tema podría llevarnos a la conclusión de que los pintores del siglo XIX tenían a su disposición los mismos utensilios que los pintores de centurias precedentes. Aunque este es un tema poco explorado y estudiado, vamos a descubrir que esta afirmación no es del todo cierta. Algunos efectos pictóricos que consiguieron - y consiguen actualmente - los pintores se deben a herramientas que evolucionaron a lo largo del siglo XIX. Los equipos portátiles que desarrollaron los fabricantes también jugaron un papel decisivo en el arte y favorecieron la pintura al aire libre. En definitiva, algunos de estos utensilios y equipos colaboraron al desarrollo del paisajismo y de las primeras vanguardias.

De manera más o menos extensa, la mayoría de las fuentes españolas decimonónicas se adentran en la descripción de los utensilios propios del pintor. Soler y Ferrer (1837), O'Neille (1862), Algarra (1875), De la Roca y Delgado (1880), Poleró (1886), L. Péant é Hijos (1895) y Bellanger (1899) comentan todos o algunos de los utensilios de la profesión del pintor. En estas fuentes se hacen evidentes algunas de las modificaciones e innovaciones que hemos adelantado. Algunos instrumentos como la moleta y la piedra de 
moler los colores cayeron en desuso debido a la industrialización y a la organización de los fabricantes y comerciantes de colores. Sin embargo, estos instrumentos aparecen descritos en Soler y Ferrer (1837: II, 42 - 43). Esto llama la atención pues ni siquiera Palomino [1715 - 1724] describe la losa y la piedra de moler en un intento, suponemos, de desvincular la pintura de las operaciones mecánicas de elaborar los materiales. No obstante, la descripción de la moleta y la losa para moler los colores así cómo el procedimiento adecuado de utilizar estos instrumentos, aun aparecen en Diderot et D'Alambert [1751 - 1772], De Piles [1766] y Bouvier (1827).

El caballete era un utensilio tan común entre los pintores que aparece pocas veces descrito en las fuentes. No obstante, encontramos referencias interesantes como la que proporcionan Soler y Ferrer.

CABALLETE: Es un armazon de tres listones, á manera de trebedes, unidos en su estremo superior con una llave, sobre la que girando los dos de delante hácia los lados, y al posterior hácia atrás, se abre é inclina cuanto se quiera para colocar en él el cuadro, bajandolo y subiendolo á nuestro arbitrio, haciendo lo propio en las clavijas ó estaquillas que recibirán los agujeros abiertos en los listones, colocando así el cuadro á la altura que se quiera: su alto es regularmente el de tres varas, y aunque los hay mas grandes y de distintas formas, es este no obstante el mas portátil y cómodo, porque recogido ó cerrado, queda asi reducido á muy pequeño volúmen: podrá hacerse de la madera y grueso que se quiera,dándole solo una regular consistencia: siendo el cuadro que en él sequiera colocar muy grande, será preciso ponerle orizontal un listonde quita y pon colocado en la muesca ó regata que á este fin se habrá abierto en su llave,... (Soler y Ferrer, 1837: II, 40)

El caballete que describen Soler y Ferrer es francamente rudimentario y, como vamos a ver, este utensilio alcanzó un alto grado de sofisticación. O'Neille (1862: 27) se limita a recomendar el caballete de resorte, “...á la moderna...”, porque es más cómodo. 


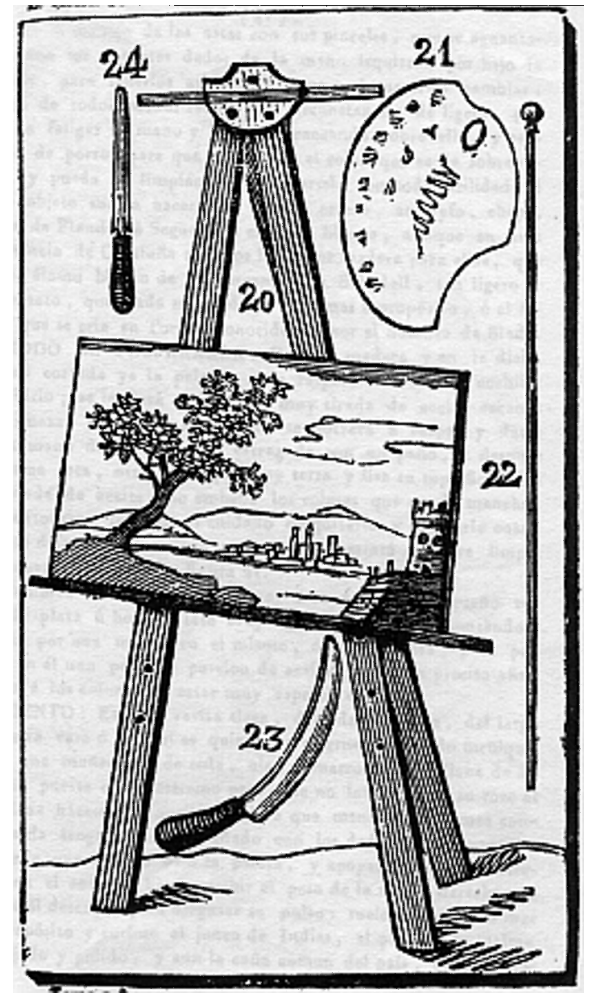

Fig. 11. Soler y Ferrer: Curso Completo Teórico y Práctico (1837). Instrumentos del pintor.

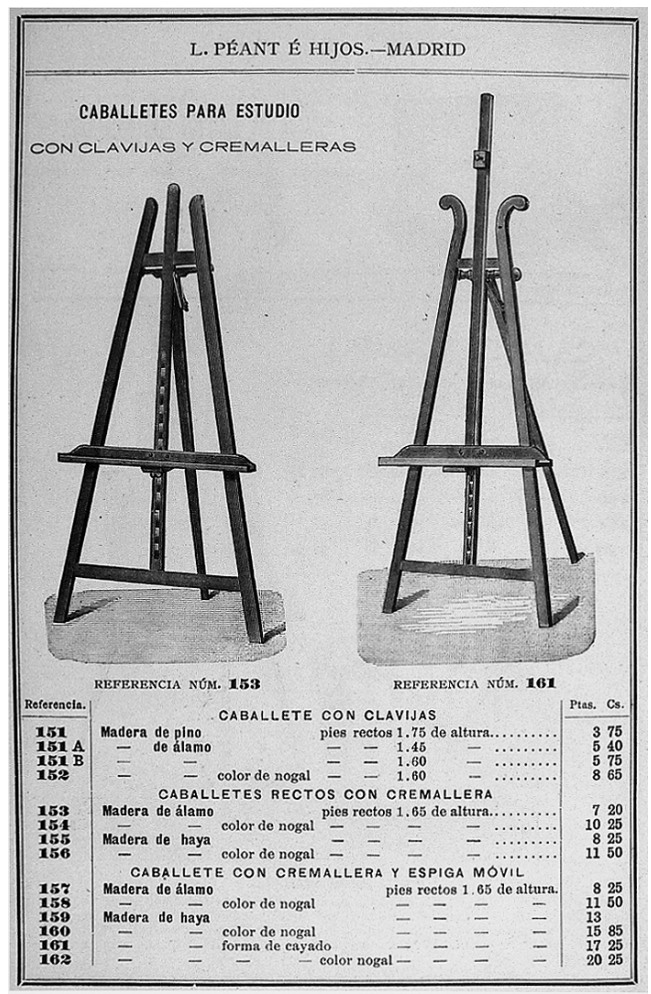

Fig. 12. L. Péant é Hijos: Catálogo General de Colores Extrafinos, Barnices, Aceites, Secantes. (1893 - 895). Caballetes.

El resto de tratados y manuales ofrece un llamativo silencio sobre este instrumento, sin duda, por ser muy conocido. Bellanger (1899: 231) expone los usos que podían tener los diferentes caballetes. Para los esbozos o cuadros medianos recomienda el caballete ordinario o con estructura de trípode; para pintar al aire libre el más apropiado es el caballete articulado portátil y para los cuadros de grandes dimensiones, el caballete recto con manivela. L. Péant é Hijos (1895: I, 36 - 40) muestran una amplia variedad de caballetes para estudio. Desde los más sencillos con clavijas hasta los sofisticados caballetes con patines de ruedas, manivela con rosca de hierro, doble frente y pupitre. 

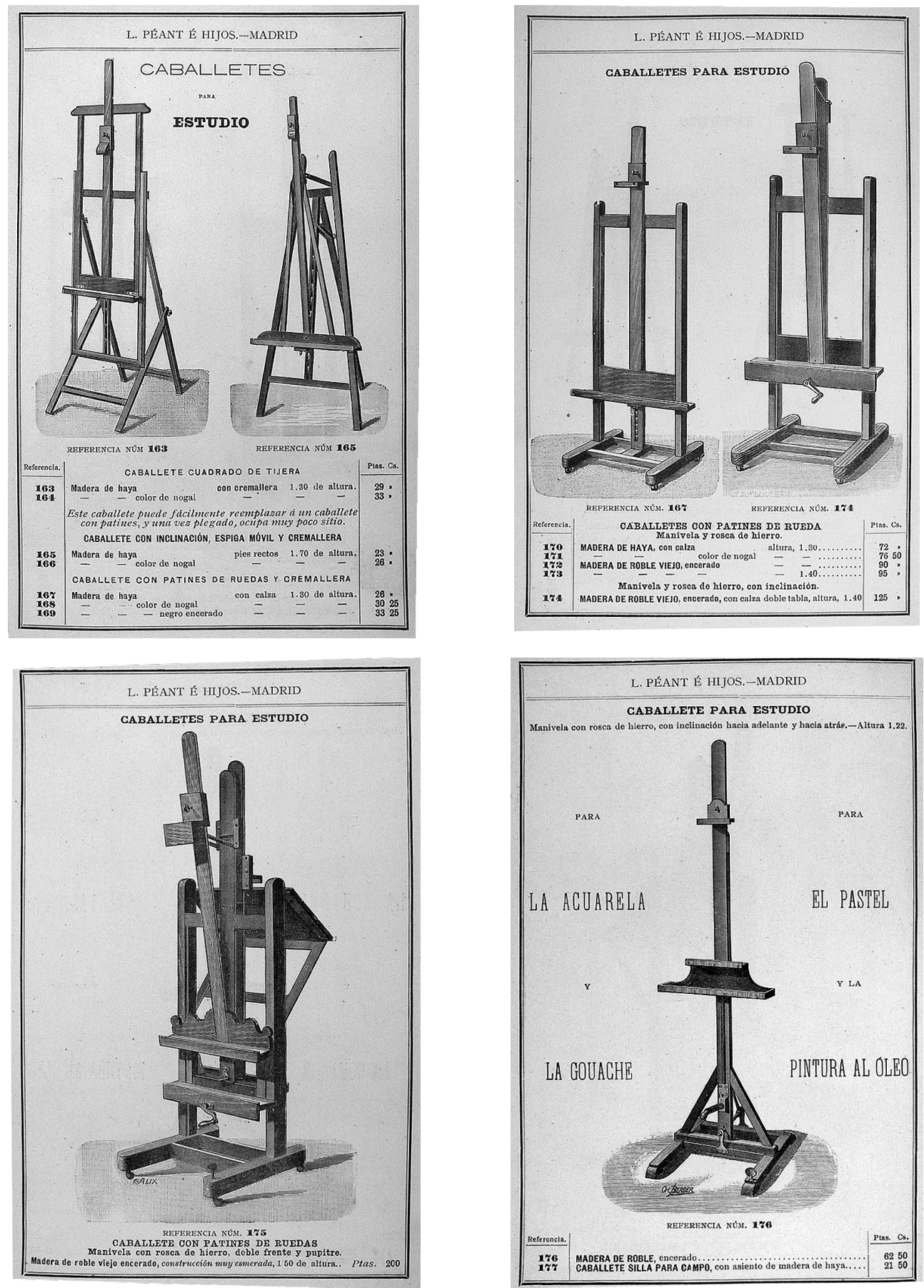

Figs. 13-16. L. Péant é Hijos: Catálogo General de Colores Extrafinos, Barnices, Aceites, Secantes. (1893 - 895). Caballetes. 
Las maderas que reseñan estos comerciantes para elaborar los caballetes son pino, álamo, haya y roble. Esta última clase de madera parece ser la preferida para los caballetes de manivela.

La paleta era otro de los instrumentos imprescindibles del pintor. Este utensilio se desarrolló mucho a lo largo del tiempo. Según Ayres (1985: 115) la paleta de los pintores aumentó de tamaño con el desarrollo de la pintura al óleo. La forma de 'paleta' (raqueta, pala) se mantuvo hasta que en el siglo XVIII se impuso la forma ovoide; durante esta centuria, aunque con menos importancia, apareció la paleta rectangular. Diderot et D'Alembert [1751 - 1772] (1980) ilustraron estos tres tipos de paleta en las láminas relacionadas con los instrumentos de la pintura al óleo. Ayres (1985: 118) explica que durante el siglo XVIII las paletas mantuvieron tamaños relativamente pequeños y a lo largo del siglo XIX volvió a aumentar el tamaño de estos enseres.

Las fuentes permiten apreciar cómo fue ganando terreno la paleta rectangular. Soler y Ferrer (1837) evidencia de nuevo en este tema la vinculación con Palomino. Este pintor tardo barroco no menciona la paleta rectangular que tampoco aparece en el tratado decimonónico de Soler y Ferrer.

PALETA. Es esta una tabla, ú oja de madera del grueso igual al canto de un duro; su largo palmo y medio, y el ancho de un palmo, de forma redonda, ó aovada la mejor; pero de todos modos robadas sus esquinas, y en una de ellas la que venga hácia el pecho, tendrá un agujero en que entrará el dedo pulgar de la mano izquierda hasta mas abajo del segundo nudo del mismo: en esta parte conviene esté la madera un tanto mas gruesa, adelgazando insensiblemente hácia abajo, y haciendo frente del agujero una pequeña sangradura, por la que pasará el manojo de las astas con sus pinceles, que se aguantarán con los restantes dedos de la mano izquierda por bajo la paleta, para tenerlos asi mas á mano, al quererlos cambiar: Debe de todos modos reunir las circunstancias de ligera, para no fatigar la mano y brazo descansando sobre ella, y cerrada de poros para que no chupe 
el color que se sobrepone, y pueda asi limpiandola, quitarse con toda facilidad: á este objeto suelen hacerse de peral, cerezo, asofayfo ${ }^{25}$, chopo, pino de Flandes ó Segura, ó castaño blanco, aunque en esta Provincia de Cataluña tenemos la mejor madera para ellas que es el álamo blanco de las cercanias de Sabadell, tan ligero y compacto, que nada de puede ya dar mas á propósito, ó el árbol que se cria en Tortosa conocido alli por el nombre Blada. (Soler y Ferrer, 1837: II, 40-41).

La aligerada transcripción de Palomino que elaboró De la Roca y Delgado (1880: 250) demuestra que los pintores hacían uso de paletas más grandes. Estas paletas de mayor tamaño - “...de media vara de largo, y una tercia de ancho,...” - se confeccionaban de nogal, cedro o caoba; si se querían muy ligeras se utilizaba madera de pino de Segura ${ }^{26}$ o chopo. Las paletas de gran tamaño no se sujetaban sobre la mano sino que se colocaban sobre una mesa. Eran útiles para poner colores en grandes cantidades y mezclar las tintas con las brochas cuando se tenían que bosquejar cuadros grandes.

Algunos tratadistas como O'Neille (1862), Algarra (1875) o Bellanger (1899) sugieren paletas ovaladas o rectangulares. O'Neille (1862: 27) otorga el uso de las paletas rectangulares a algunos pintores modernos. Algarra (1875: 186) cree más conveniente la paleta de forma rectangular mientras que Bellanger (1899: 224) indica que cada artista debe elegir la forma de la paleta en función de sus gustos o preferencias. Poleró (1886: 81) y Bellanger (1899: 224) aconsejan las paletas de madera de nogal, en cambio O'Neille (1862: 27) prefiere las de olivo viejo porque las de nogal son muy oscuras. Las paletas tienen que tratarse para que la madera cruda no embeba los colores al óleo. Soler y Ferrer (1837: II, 41) y De la Roca y Delgado (1880: 251) son los tratadistas que explican con detalle este tratamiento que consiste en raspar la madera para dejarla lisa e

\footnotetext{
25 Palomino [1715-1724] (1988: II, 118) dice de esta madera: “...azufaifo (que en el reino de Valencia llaman chincholer, o jinjoner) por ser de madera más sólida, y tersa, y que adquiere un lustre, y una tez de admirable pulimento;..." ${ }^{26}$ Palomino [1715-1724] (1988: II, 118): “... pino de Segura, o de Flandes, de que se hacen las tapas de las vihuelas, y otros instrumentos músicos;...”
} 
impregnarla con aceite secante de linaza. Tras esto, se procede de nuevo a raspar la superficie que se vuelve a impregnar de aceite hasta que quede completamente tersa y saturada. Algarra (1875: 186) y Bellanger (1899) solo mencionan que la paleta debe impregnarse con aceite. Bouvier (1827: 512) explica que el aceite que se emplea para tratar la paleta no debe estar cocido porque este seca antes en la superficie pero en el interior permanece tierno durante un tiempo. Por eso los aceites de lino o nueces crudos son preferibles al aceite graso; y entre éstos el primero es más recomendable.

Para facilitar el trabajo, algunos autores sugieren el empleo de unos pequeños recipientes de hojalata que se colocan en la paleta. Soler y Ferrer (1837: II, 41) proponen un pequeño vaso de plata u hojalata que se engancha a la paleta; este vaso es un contenedor de aceite para añadir a los colores si estuvieran demasiado espesos o duros. O'Neille (1862: 28) sugiere el uso de dos botecitos de hojalata: uno para contener aceite y otro para aceite secante o barniz. Estos vasos y botecitos recibieron en el comercio la designación de aceiteras. Recipientes similares aparecen en Diderot et D'Alembert [1751 - 1772] lo que demuestra que los utensilios de los pintores se sofisticaron pronto. La descripción de estos sencillos contenedores reza: "Gode-miché double pour contenir l'huile grasse \& l'huile d'oeillet." y "Gode-miché simple."

L. Péant é Hijos (1895: I, 48) ofertaban paletas ovaladas y rectangulares de nogal raspado o barnizado y de caoba barnizada. Este comercio tenía a disposición de sus clientes paletas de tamaños muy diferentes desde $23^{\prime} 5$ × $13^{\prime} 5 \mathrm{~cm}$. hasta 50 x $35 \mathrm{~cm}$. También suministraba paletas dobladas de nogal en tres tamaños desde $34^{\prime} 5 \times 12 ' 5 \mathrm{~cm}$. hasta $43 \times 17 \mathrm{~cm}$. que resultaban útiles para salir a pintar al campo. L. Péant é Hijos también vendían "Paletas Díaz" de 50 ó $60 \mathrm{~cm}$. también de nogal raspado o barnizado. Las aceiteras de hojalata eran utensilios igualmente suministrados por este comerciante de Madrid. En el catálogo de L. Péant é Hijos (1895: I, 46) encontramos "Aceiteras Involcables para Paletas" sencillas y dobles con o sin tapa. 
Ayres (1985: 123) señala que en el siglo XIX, la variedad de pinceles que tenía un pintor a su disposición era mayor que en tiempos anteriores. Los pinceles tradicionales eran redondos porque se fabricaban con cañones de pluma. Pero el empleo de virolas metálicas permitió elaborar pinceles planos. La virola de plata se empleó ocasionalmente durante el siglo XVII pero la virola metálica tuvo una amplia difusión en el siglo XIX para fabricar pinceles planos y redondos. Según Harley (1972: 125), la adopción de la virola de metal fue posiblemente el mayor avance en materia de instrumental artístico durante el siglo XIX. La virola metálica otorgó a los pinceles la forma y apariencia que conservan en la actualidad. Al principio, los pinceles planos se emplearon para mezclar los colores en la paleta. Pero pronto la pincelada que producen estos pinceles comenzó a ser apreciada. Dice Ayres (1985: 122) que entre los enseres de Constable (1776 - 1837), se conserva un pincel plano con virola metálica. El mismo Ayres (1985: 126) asegura que Cézanne (1839 - 1906) es probablemente el ejemplo más obvio de un pintor que ha aprovechado el potencial de este nuevo tipo de pincel. También han sido localizados pinceles planos con virola metálica entre los instrumentos del pintor Mariano Fortuny (Admella et al., 2008: 100).

Elaborar los pinceles era una tarea muy delicada y de mucha precisión por eso no es de extrañar que esta labor la realizaran profesionales especializados. La única fuente española decimonónica que explica la manera de elaborar los pinceles es De la Roca y Delgado (1880) que transcribe a Palomino [1715 - 1724]. Incluso Soler y Ferrer (1837: 44) reconocen que aunque el pintor puede preparar sus pinceles “...serán siempre mejores los de fábrica...”. Soler y Ferrer no mencionan los pinceles planos. Para estos autores, los pinceles se dividían en grandes o brochas, medianos y pequeños. Las brochas eran de pelo de jabalí u otro suave que se ataba al mango. Los pinceles medianos y pequeños eran de pelo de meloncillo o marta “...vienen ya metidos en sus cañoncitos de pluma en todos tamaños:...”. Luego estaban los pinceles para unir las tintas que eran tupidos de pelo pero suaves y de diferentes tamaños. Harley (1972: 123 - 124) asegura que aunque los pinceles de marta 

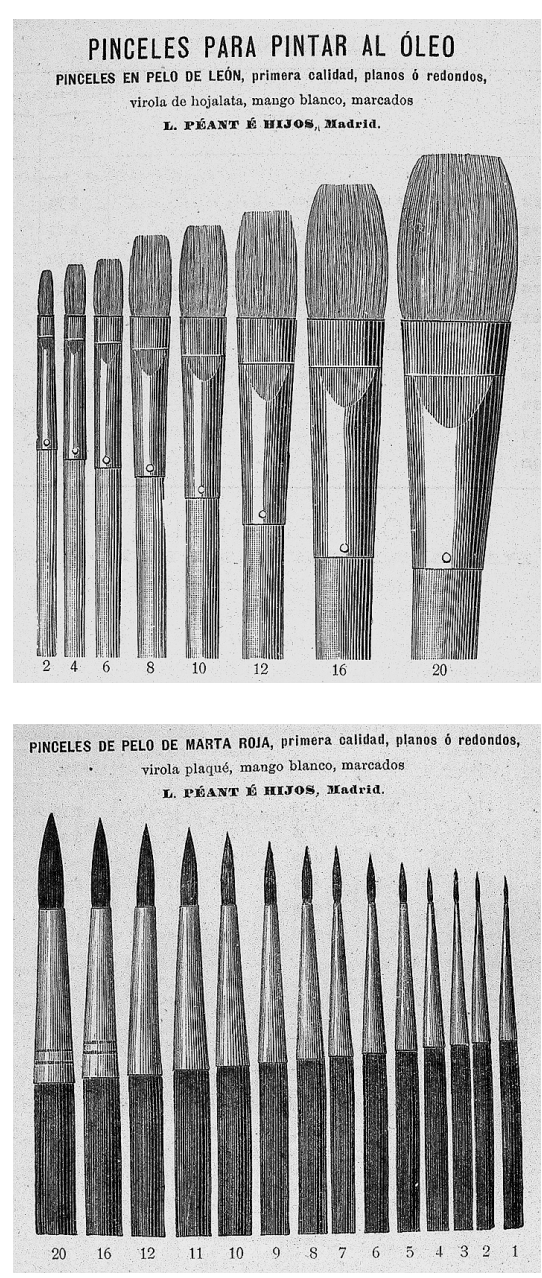

Fig. 17-18. L. Péant é Hijos: Catálogo General de Colores Extrafinos, Barnices, Aceites, Secantes (1893 - 1895). Pinceles. fueron los más apreciados durante los siglos XIX y XX debido a que forma magníficas puntas y tiene una estupenda elasticidad. Por eso, Harley califica de 'rasgo misterioso' la omisión de los pinceles de marta en los primeros escritos ingleses a pesar de que estuvieron disponibles desde el siglo XVIII y aparecen mencionados en Art of Painting in Miniature de John Payne ( $2^{\mathrm{a}}$ de. 1798).

O'Neille (1862), Poleró (1886) y Bellanger (1899) mencionan tanto los pinceles planos como los redondos de diferentes tamaños y pelos. O'Neille describe la utilidad de los diferentes pinceles:

...para bosquejar por ejemplo los mas duros y ordinarios, para pintar con detencion otros mas finos y adecuados; para retocar ó terminar, los de pelo de Marta ó de Ardilla que son finísimos; esta es una de las partes prácticas que el alumno debe ir conociendo por esperiencia. Los pinceles unidores con [sic] unas brochas grandes de pelo blando, $y$ sirven para unir el color, seguidamente de haberse puesto, $\mathrm{y}$ suavemente se pasa y repasa á fin de borrar ó unir las pinceladas demasiado marcadas; (O'Neille, 1862: 28)

El pelo de león, el de marta o el de meloncillo son los que refieren los tratados y manuales aunque Bellanger también menciona los pinceles de pelo de tejón. Una vez más, Harley (1972: 123) informa 
que los pinceles de pelo de tejón no aparecen mencionados con frecuencia en la tratadística inglesa hasta finales del siglo XVIII. La investigadora explica que las especies europeas de tejón tienen el pelo gris y para confeccionar los pinceles se usa el pelo de la espalda del animal y no de la cola. Los pinceles de meloncillo, asegura Algarra (1875: 162 - 163), únicamente se emplean en España. Según este autor, los pinceles de meloncillo son de mala calidad y tienen una vida corta porque los pelos tienden a separarse.

L. Péant é Hijos (1895: I, 18 - 23) ofrecen una gran variedad de pinceles planos y redondos con virola de hojalata aunque también encontramos con virola de plaqué ${ }^{27}$. Estos empresarios vendían pinceles de pelo de león, de marta roja y de meloncillo. Las brochas para modelar eran de pelo de ardilla; según Harley (1972: 123), este tipo de pelo carecía de elasticidad por lo que las brochas y pinceles elaboradas con el ofrecen menos control en trabajos delicados. Los difuminadores en forma de abanico que ofertaban L. Péant é Hijos eran de pelo de león, marta roja o tejón y las brochas para barnizar de pelo de león.

El cuchillo de paleta es otro de los instrumentos del pintor que sufrió una evolución decisiva en el siglo XIX. Los pintores disponían de dos cuchillos. Uno de ellos, llamado también imprimadera, servía para preparar los lienzos; era de madera o hierro y tenía forma de media luna sin filo ni punta. Esta clase de cuchillo aparece referenciado en Soler y Ferrer (1837) y De la Roca y Delgado (1880). Por otra parte, el cuchillo de paleta servía para preparar las tintas de color en la paleta. Soler y Ferrer (1837) lo describen con detalle:

...de á palmo su largo; muy delgado, y flecsible la hoja, y ancha menos de dos dedos con doble corte y robadas sus puntas: es su uso muy espedito y general para tomar con la punta de él los colores, recogerlos en la paleta, y de ellos hacer en la misma las diversas tintas; es muy útil mayormente para las copias en las que

${ }_{27}$ Chapa muy delgada, de oro o de plata, sobrepuesta y fuertemente adherida a la superficie de otro metal de menos valor. 
comparando la tinta hecha, acercandola en la punta de la misma al original, se vé sí la imita del todo,... (Soler y Ferrer, 1837: II, 43)

Poleró (1886: 81) y Bellanger (1899: 217) mencionan el cuchillo de paleta entre los utensilios del pintor pero no aportan más datos. Sin embargo, O'Neille (1862: 29) se refiere a este instrumento con la denominación de espátula. Este pintor informa de algunas precauciones a tener en cuenta porque el material de la espátula puede alterar algunos colores.

Espátula es una especie de cuchillo que sirve para tomar color, mezclarlos y formar las tintas, ó bien para limpiar las paleta recogiendo lo que sobre ó estorbe: las mas usuales son de dos clases, de acero y de cuerno; la de acero puede emplearse para todos los colores que pertenezcan al género de ocres, oscuros, negros, azules, verdes, rojos, y blanco: la de cuerno sirve para los colores finos, lacas, y especialmente el amarillo, este color manejado con la espátula de acero, con suma facilidad toma un tono verdoso sucio. (O'Neille, 1862: 29)

Hasta el momento, ninguna de nuestras fuentes decimonónicas revela ningún cambio en los cuchillos de paleta. Sin embargo, según Ayres (1985: 122) la espátula de acero con forma de llana parece ser una innovación decimonónica. Este investigador ha sacado a la luz una espátula de acero con forma de llana que perteneció a Constable (1776-1837). Callen (1983: 24) afirma que algunos fabricantes de colores justificaban la inclusión en grandes cantidades de cera en los óleos para lograr una masa adecuada para pintar con espátula. Esta investigadora señala que Courbet (1819-1877) popularizó el uso de la espátula para pintar en cuadros como El Refugio de los Ciervos ${ }^{28}$ de 1866. Según Callen (1983), a Manet (1832-1883) le gustaba emplear la espátula para extender amplias zonas de fondo. En las décadas de 1860 y 1870 , este instrumento fue profusamente empleado.

${ }^{28}$ Le Remise de Chevreuils au Ruisseau de Plaisir - Fontaine. Óleo sobre lienzo: 174 x 209 cm. Musée d'Orsay, París. 

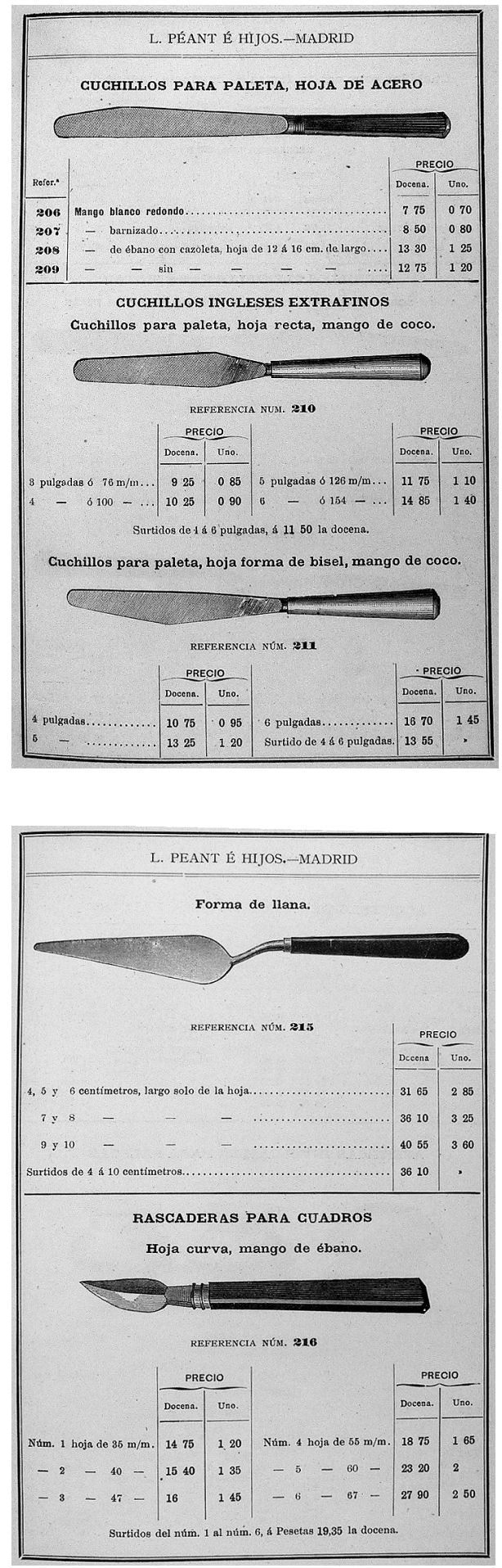

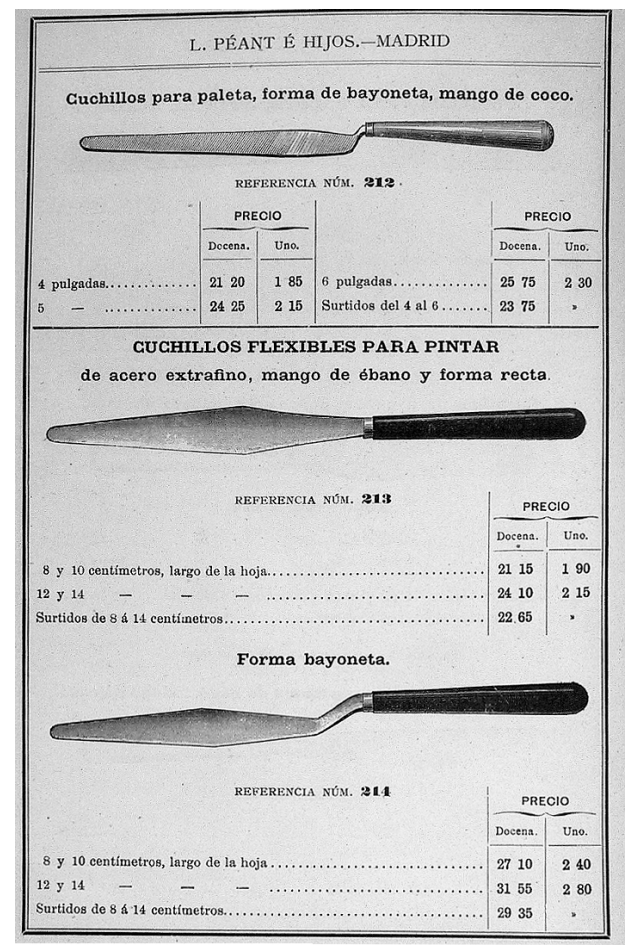

Figs. 19-21. L. Péant é Hijos: Catálogo General de Colores Extrafinos, Barnices, Aceites, Secantes (1893 1895). Espátulas y cuchillos de paleta.

Ha sido identificado especialmente en pinturas de Cézanne (1839 - 1906) y Pissarro (1830 - 1903). Sin embargo, explica Callen, la espátula deja el aceite en la superficie de la pintura incrementando el inconveniente del amarilleo.

L. Péant é Hijos (1895) muestran esta innovación o desarrollo del instrumento y además establece una clara diferencia entre cuchillos para paleta y cuchillos para pintar. El 
catálogo de estos comerciantes muestra varias formas de cuchillo: de hoja recta, con forma de bisel o de bayoneta. Los cuchillos flexibles para pintar podían tener forma recta, de bayoneta o con forma de llana. Ambas clases de cuchillos eran de acero con mango de madera y la hoja podía tener varias longitudes. Por lo que los pintores tenían un gran surtido de cuchillos donde elegir.

Para guardar los instrumentos, los pintores disponían de cajas. De esta manera los colores, la paleta, los pinceles y demás enseres estaban protegidos del polvo o de posibles contratiempos. Estas cajas también sufrieron modificaciones e incluso llegaron a ser imprescindibles en los equipos portátiles para salir a pintar al campo. Una vez más, Soler y Ferrer nos ofrecen una detallada descripción.

...será la mas reducida y portatil la de tres palmos de largo, dos de ancho, y uno de alto, abriéndose la tapadera hácia arriba como la de un estuche; su alto estará dividido en dos partes, superior, é inferior: la superior, que quedará del todo á la vista abierta su tapadera, estará dividida á lo largo, y la parte primera se dejará íntegra para contener los pinceles, lapiceros, regla, cuchillo, y demas de su medida: y la segunda tendrá tres divisiones á lo largo tambien, en las que cruzarán las particiones comunmente en al número de doce, formando asi su total treinta y seis casillas; pero de modo que puedan separarse estos divisores para dejarlas mas grandes, según nos convenga progresivamente: estas casillas contendrán, las doce primeras los botes de cristal ú hoja de lata con su color en cada uno en polvo muy sutilmente molido, por si asi quieren empelearse con solo incorporarlos al aceite: en las doce siguientes casillas encajarán las vejigas de los distintos colores molidos al aceite; y en las doce restantes los botes del secante, aceites, lápices, y demas frioleras. En la parte inferior de las dos en que se divide el alto de la caja, puede haber uno ó dos cajoncitos, en los que se guarden las paletas con sus tintas, cuando se dejen de un dia para otro;...(Soler y Ferrer, 1837: II, 42)

Esta es una caja bastante grande y más parece un mueble de estudio 
que una caja portátil. Otros autores que mencionan las cajas para contener los colores son Poleró (1886) y Bellanger (1899), sin aportar descripción de este útil, aunque por las palabras de Bellanger se infiere que hace referencia a cajas realmente portátiles y cómodas. Entre las cajas para pintura al óleo del catálogo de L. Péant é Hijos (1895) se aprecia que éstas - diseñadas ya para colores en tubos disponían de un solo piso por lo que eran más reducidas que la de Soler y Ferrer. Estas cajas eran de madera aunque también se suministraban de latón barnizado.

El desarrollo de los equipos portátiles favoreció la pintura al aire libre. Los comerciantes como L. Péant é Hijos ofertaban una gran variedad de estos equipos. Algunas de estas cajas incorporaban paletas dobladas o sistemas para funcionar como caballete. Pero los equipos portátiles podían incluir otros útiles. Por ejemplo, pies de cobre para mantener las cajas rectas a pesar de las desigualdades del terreno, sombrillas, sillas plegables o caballetes de campo. Si bien estos instrumentos se adquirían por separado, también se podía comprar una caja de campo que incluía todos los enseres.

\section{Estas cajas contienen:}

Una guarnición completa de hojalata, frascos, aceiteras de paleta con rosca de cobre, una paleta de nogal, dos tablas de madera, un caballete, una silla de tijera con armadura de cobre y acero, tres pies móviles con alargaderas de cobre y una correa sujeta por dos clavos de cobre que permite llevarlas colgadas á un lado ó en la espalda, como un saco de campo. (L. Péant é Hijos, 1895: 35)

Hemos visto los utensilios e instrumentos básicos del pintor: el caballete, la paleta, los pinceles, las espátulas y los equipos de campo. Algunos de ellos como los pinceles planos, las espátulas o los equipos de campo favorecieron la experimentación de los artistas e hicieron posible - en parte - algunas de las primeras vanguardias. Pero el pintor podía contar con otros enseres que le facilitaban el trabajo como tiento, limpiapinceles, rascaderas, muebles de estudio, escalerilla portátil para los grandes formatos, mesa para el modelo, maniquís, muñecos articulados, etc. 

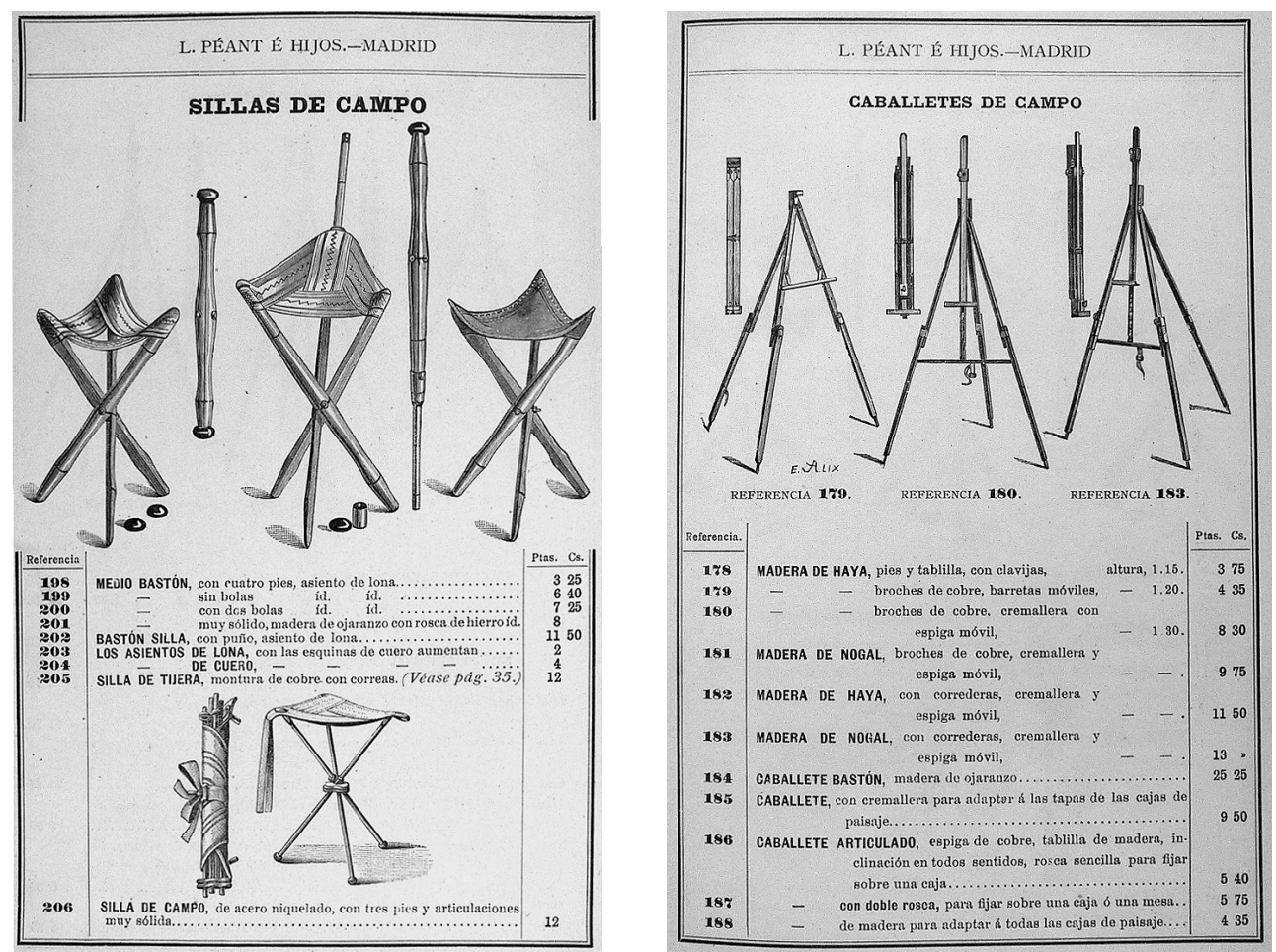

Figs. 22-23. L. Péant é Hijos: Catálogo General de Colores Extrafinos, Barnices, Aceites, Secantes (1893 - 1895). Equipos portiles.

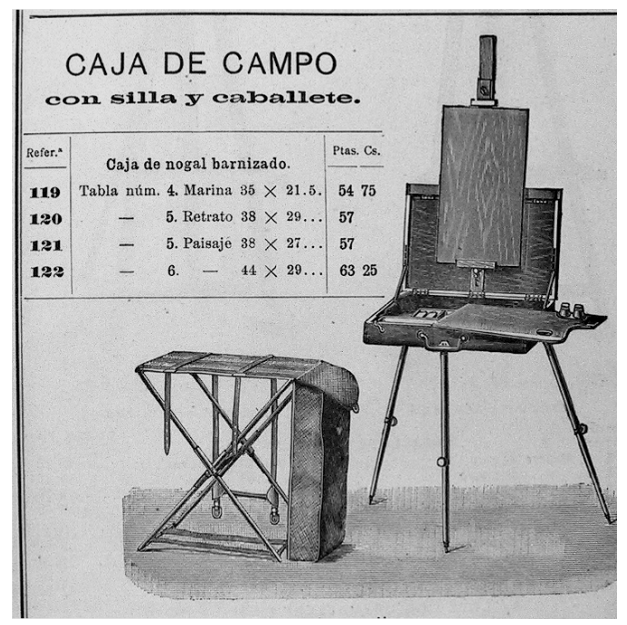

Fig. 24. L. Péant é Hijos: Catálogo General de Colores Extrafinos, Barnices, Aceites, Secantes (18931895). Caja de campo.
Y no podemos olvidar que la fotografía - nacida en el siglo XIX - se convirtió para algunos artistas en una útil herramienta de trabajo como explica Poleró:

Es un hecho innegable que hoy se han realizado verdaderos adelantos en la Pintura, merced por una parte la la nueva marcha adoptada en la dirección de la enseñanza, y por otra á los medios con que se cuenta y que antes no 
eran conocidos. Los recursos suministrados por la fotografía, que tan de realce ha puesto la manera de ver y estudiar el natural, considerándolo como se debe, están bien patentes. (Poleŕo, 1886: 102)

Como ha puesto de relieve Porretta (1999: 125), los estudios sobre la relación fotografía - pintura, realizados desde los años 60 (del siglo XX), han demostrado que casi todos los pintores se sirvieron del novedoso invento de la fotografía. Los pintores utilizaron la fotografía como ayuda en su trabajo especialmente en retratos y paisajes. La fotografía se convirtió para los pintores en una herramienta de trabajo y en una ayuda similar a la que proporcionaban los bocetos. 
III.

\section{MATERIALES DE LA PINTURA AL ÓLEO DECIMONÓNICA}





\section{Aglutinantes}

Los aceites secantes empleados más comúnmente como aglutinante de la pintura al óleo han sido los de linaza, nueces y adormidera. Cómo veremos - las fuentes indican el empleo de otros aceites que pudieron ser utilizados de forma localizada como el aceite de piñones que aparece varias veces aludido. También encontramos curiosas alusiones al aceite de claveles e incluso una patente inscrita en Cuba cita el aceite de algodón.

Los aceites para poder ser utilizados en pintura deben someterse a determinados procesos - clarificación y cocción - que les confieren las propiedades adecuadas para su uso pictórico. Muchos de estos procesos de elaboración de los aceites permanecieron inmutables durante centurias. Sin embargo, en el siglo XIX se produjeron algunas innovaciones que no aparecen reflejadas en las fuentes primarias españolas. Los aceites sometidos a procesos de clarificación y cocción podían modificarse para alterar sus propiedades. Se podían formar pomadas o vehículos pictóricos añadiendo barnices - $\mathrm{u}$ otras sustancias - al aceite. De esta manera los pintores obtenían un medium oleoso que facilitaba algunos recursos pictóricos. Pero muchos de estos vehículos resultaron perjudiciales para la pintura a diferencia de los vehículos de épocas anteriores que gozaron de buena reputación. Además - como hemos comentado en el apartado precedente - cuando los comerciantes comenzaron a envasar los colores en tubos hicieron uso de aditivos $\mathrm{y}$ adulterantes que resultaron perniciosos para la pintura; de modo que los aglutinantes y mediums pictóricos del siglo XIX se elaboraban de manera ligeramente diferente a épocas anteriores. El comportamiento de estas substancias decimonónicas llevó a los tratadistas españoles de los últimos veinte años de la centuria a reivindicar las elaboraciones propias del barroco español. 


\subsection{Aceites Secantes}

Los aceites utilizados como aglutinante pictórico se denominan aceites secantes aunque también reciben el nombre de aceites fijos. Estos aceites tienen la capacidad de oxidar y polimerizar - es decir, secar - en periodos de tiempo bastante cortos. Esto permite superponer estratos pictóricos sin que se prolongue excesivamente el tiempo de elaboración de una obra. Por el contrario, los aceites semisecantes forman capas viscosas y pegajosas; mientras que los aceites no secantes nunca llegan a formar estratos pegajosos o viscosos. Durante el secado de un aceite fijo, la temperatura y la humedad ambiente son muy importantes. En entornos húmedos y fríos el aceite tarda más tiempo en secar, mientras que el calor acelera el secado. Cuando seca, el aceite forma una capa elástica y sólida llamada linoxina. No obstante, el aceite recibe la influencia de los pigmentos $\mathrm{u}$ aditivos que se le añadan, modificando en mayor o menor medida sus propiedades. Así se producen capas mates, brillantes, porosas o esmaltadas.

Los aceites más empleados en pintura a lo largo de la historia han sido los de linaza, nueces y adormidera. Los tratados españoles y los traducidos al español durante el siglo XIX recomiendan con preferencia el aceite de linaza. Aunque debemos señalar que estas fuentes sugieren también otros aceites. Así, Algarra (1875) y Poleró (1886) sugieren el aceite de claveles para uso pictórico aunque este aceite gozaba de una menor capacidad secante. Además, cómo veremos más adelante, Soler y Ferrer (1837), Borbón (1860), De la Roca (1880) y Poleró (1886) proponen el aceite de piñones para mezclar con algunos pigmentos. El uso de este aceite en pintura aparece citado por primera vez en el tratado de Palomino: Museo Pictórico o Escala Óptica [1715 - 1724]. El empleo en pintura del aceite de piñones es la adaptación a la pintura de una substancia abundante en la península Ibérica y por lo tanto, su uso está geográficamente limitado. Después explicaremos que la adecuación a la pintura de substancias abundantes en determinadas zonas geográficas fue una práctica común a lo largo de la historia. Este argumento añade dificultad al estudio de los materiales pictóricos 
por que amplía el abanico de los mismos con substancias, en muchas ocasiones, inesperadas.

Los textos españoles que aparecen durante los últimos veinte años del siglo XIX omiten el aceite de adormideras considerando fundamentalmente los aceites de linaza, nueces y piñones. Esto puede explicarse porque los escritos de este periodo - De la Roca (1880), Poleró (1886) y López (1898) - recuperan prácticas pictóricas del barroco español. Los aceites en uso durante el XVII eran de linaza y de nueces; mientras que a principios del siglo XVIII, Palomino incluyó el aceite de piñones. Sin embargo, para Vibert (1908), los aceites más empleados en su tiempo eran los de linaza y adormideras. El aceite de nueces fue descartado por algunos tratadistas porque se enranciaba rápidamente.

Por lo general, estos aceites se someten a diferentes tratamientos que les confieren las propiedades adecuadas para su uso pictórico. Para librar a los aceites de su color amarillento se practicaba la clarificación. Para acelerar el secado fue común a lo largo de la historia cocerlos solos o con materias secantes; éste último procedimiento es el que aparece referenciado en las fuentes que estudiamos. También estos aglutinantes se solían mezclar con otras sustancias - como resinas, cargas inertes, ceras, etc. - con el fin de otorgarle las propiedades adecuadas para su uso.

\subsubsection{Aceite de linaza}

El aceite secante más empleado a lo largo de la historia de la pintura al óleo ha sido el de linaza. Este aceite forma películas estables y tiene la virtud de secar con mayor prontitud que los aceites de nueces y adormidera. Su principal inconveniente radica en el color amarillento que adquiere cuando envejece. Por este motivo y por su cualidad grasa, Soler y Ferrer (1837) lo aconsejaban únicamente para los colores oscuros y para las preparaciones de los soportes. Por el contrario, Borbón (1860) extrajo y clarificó los aceites de linaza, 
nueces, piñones y adormidera. Después de seis años concluyó que el primero y el tercero “...se mantenían claros, é inalterables mientras que el segundo y el cuarto se habían amarilleado extraordinariamente..." (Borbón, 1860: 9). La apreciación de este autor es contraria a todo lo expuesto en tratados hasta el momento pues, por lo general, los pintores expresaban el menor oscurecimiento del aceite de nueces frente al de linaza ${ }^{1}$. Borbón estima que el aceite de linaza fue el más empleado desde los albores de la pintura al óleo y es el que menos alteración sufre con el tiempo. Para Algarra (1875), el aceite de linaza es el más recomendable y asegura que algunos artistas únicamente utilizan el aceite de linaza clarificado. Este tratadista, preocupado por las adulteraciones que pueden presentar los aceites sugiere el empleo del mencionado aceite por las siguientes razones:

...la dureza que presta á los colores, y las pocas impurezas que admite en su adulteracion; estas dos cualidades bastarían, si no hablase muy alto en su favor por sus buenos resultados el uso de antiguas prácticas. (Algarra, 1875: 179)

Las fuentes españolas a lo largo de todo el XIX otorgan un especial aprecio al aceite de linaza para uso pictórico. También Poleró expone,

\footnotetext{
${ }^{1}$ Vasari [1550] (1997: 81) decía "...vanno poi macinando i colori con olio di noce o di seme di lino (benché il noce è meglio, perché ingialla meno)..." Pacheco [1649] corrobora el empleo del aceite de nueces para colores claros y apreciados azules, sin duda para que no se vieran afectados por el matiz dorado del aceite:
}

Dicen los más que, después de ser el azul de lindo color, delgado y bien afinado y limpio, se temple en el tablón con aceite de nueces fresco; y, recién sacado, pondráse aparte cantidad de blanco molido con aceite de nueces... Pacheco, [1649] 2001: 485)

Aunque este pintor asegura que “...no ven mis azules ni mis blancos el aceite de nueces, tan reverenciado por todos, porque nunca lo uso, o muy pocas veces;..." (Pacheco, [1649] 2001: 487). Palomino [1715-1724] (1988: II, 139) sugiere el mismo empleo del aceite de nueces “...se muelen generalmente todos los colores, porque es más robusto, graso y secante que el de nueces del cual solo se usa para azules y blancos a el tiempo de acabar...” 
aunque de manera confusa, las preferencias en materia de aceites secantes y parece recomendar el aceite de linaza clarificado.

Entre los aceites que se usaron figuraba el de linaza y también el de nueces, á los que sucedieron en nuestros días el de piñones y el de claveles. Entre todos éstos, el primero, por ser más transparente y menos propenso á torcerse, una vez bien clarificado, es el más recomendable. (Poleró, 1886: 83)

Por su parte, Emilio Sala (1896: XLII, 276) expresa que hay variedad en los aceites secantes útiles en pintura y que “...cada uno seca de diverso modo, y que, de todos ellos, el que reúne mejores condiciones es el de linaza;...”. Por su parte, López Tomás (1898) sólo trata el aceite de linaza aunque comenta que el de nueces sin secante es útil para los blancos.

Bellanger, a finales de siglo, ha asumido que la confección de los materiales es competencia de los fabricantes y comerciantes especializados. Este artista reconoce las deficiencias que los pintores encuentran en los ingredientes de elaboración comercial. Para este pintor francés, los colores se adquieren ya preparados aunque una caja de colores debe estar provista de aceite de lino. $\mathrm{Y}$ añade que "Los líquidos empleados para extender las combinaciones y facilitar el manejo de las pastas son el aceite de lino y la esencia de trementina." (Bellanger, 1899: 226). Pero sin duda, es Vibert ${ }^{2}$ (1908) quien nos ofrece mayor información sobre las sustancias pictóricas industriales. Este artista asegura que los aceites de linaza y el de adormideras son los que en su época se empleaban con preferencia.

El aceite de linaza es el más secante de los dos, adquiere mayor dureza y queda más transparente cuando se seca; pero

\footnotetext{
${ }^{2}$ Vibert debía conocer perfectamente los procesos industriales de elaboración de materiales artísticos puesto que algunos productos de Lefran \& $\mathrm{C}^{\mathrm{ie}}$ se fabricaban según sus indicaciones.
} 


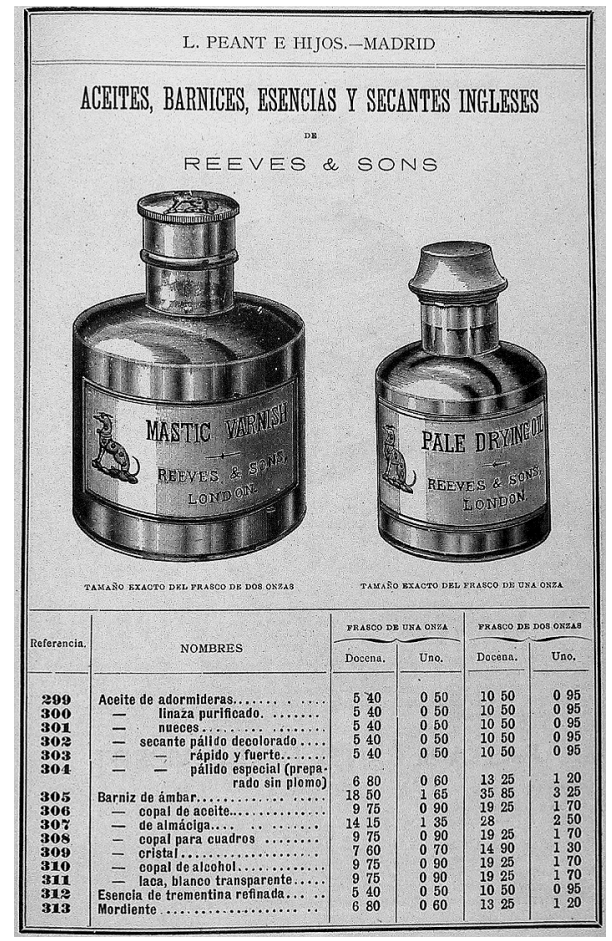

Fig. 25. L. Péant é Hijos: Catálogo General de Colores Extrafinos, Barnices, Aceites, Secantes (1893 1895). Aceites, Barnices, Esencias y Secantes Ingleses de Reeves \& Sons. también es más viscoso que el aceite de adormideras y tiene mayor tendencia á acidificarse. (Vibert, 1908: 103).

Vibert explica que los aceites adquieren acidez durante los procesos de clarificación (Ver 3.2.2.) y en los tratamientos para tornarlos más secantes. La acidez del aceite - asegura el pintor galo es una de las causas responsables de que agrieten los cuadros. Vibert comenta que algunos colores oscuros se amasaban con aceite de linaza "...por hacer este los colores menos viscosos.” (Vibert, 1908: 105); en cambio, el resto de colores se amasaba con aceite de adormidera.

El Catálogo de Colores de L.

Péant é Hijos (1895) ofertaba diferentes aceites para la pintura al óleo. En frasco pequeño o grande, el pintor podía adquirir aceite de linaza y aceite de linaza decolorado fabricado por L. Péant é Hijos. Estos comerciantes también tenían a disposición de sus clientes aceite de linaza y linaza decolorado de la marca Lefranc \& $\mathrm{C}^{\mathrm{ie}}$ y Aceite de linaza purificado de la empresa Reeves \& Sons. A pesar de que algunas series de colores de Lefranc \& Cie que muestra este catálogo presentan la composición de los pigmentos, la aclaración sobre el aglutinante se ignora por completo. 


\subsubsection{Aceite de nueces}

El aceite de nueces tenía la ventaja frente al de linaza de amarillear menos al envejecer. Por este motivo, los pintores preferían este aceite para amasar los blancos y azules. De esta forma evitaban que los primeros se tornaran amarillos y los segundos verdes. Sin embargo, este aceite tenía la desventaja de secar con mayor lentitud que el aceite de lino y además tenía una marcada tendencia a volverse rancio si no se usaba.

Soler y Ferrer (1837) comentan que el aceite de nueces para uso general abundaba en el comercio y demuestran preocupación por la adulteración de esta sustancia.

La menor mezcla que tenga de aceite comun, ó cualquier otro estraño, lo que solo confusamente puede distinguirse por el gusto, lo inutiliza, y con él toda la obra en que se haya empleado, aunque bueno de cualidad, será muchas veces rancio ó muy colorado. (Soler y Ferrer, 1837: II, 58)

Dada esta cualidad de 'rancio' que pronto adquiría esta sustancia oleosa, los autores del Curso Completo recomiendan que cada uno extraiga su aceite (Ver 3.2.1.).

Cuando en el siglo XIX se extendió la comercialización de pinturas preparadas, las desventajas del aceite de nueces se convirtieron en un problema relevante. Se debe tener en cuenta que las pinturas pueden producirse años antes de llegar a manos del pintor y el aceite de nueces se enranciaba prontamente. Esto llevó a una restricción importante en el uso del aceite de nueces y aumentó la cantidad y variedad de aditivos. Algunos pintores y fabricantes de colores desaconsejaron el uso de este aceite por su facilidad de tornarse rancio. Por ejemplo, O’Neille (1862: 30) - sin dar explicaciones - expresa: "Creo inútil recomendar que sea el aceite de nueces el que se emplee." Por su parte, Poleró (1886) considera perjudicial el empleo de este aceite porque se enrancia y para usarlo sin riesgo propone mezclarlo con barniz de almáciga. Vibert (1908) no menciona este aceite en ningún momento. 
Sin embargo, por el catálogo de L. Péant é Hijos (1895) sabemos que Lefranc \& Cie, Reeves \& Sons y los propios vendedores L. Péan é Hijos elaboraban aceite de nueces para uso pictórico. El aceite de nueces fabricado por Lefranc \& $\mathrm{C}^{\mathrm{ie}} \mathrm{y}$ por L. Péant é Hijos era más caro que los aceites de linaza o adormideras y alcanzaba el precio de estos decolorados. El aceite de nueces ha sido identificado por Bomford et al. (1990: 73-75) en algunas pinturas impresionistas de Camille Pissarro, Claude Monet y Paul Cézanne. Todo parece apuntar a que durante el siglo XIX el empleo del aceite de nueces descendió notablemente, en cambio se popularizó el aceite de adormideras o amapola.

\subsubsection{Aceite de adormidera}

$\mathrm{El}$ aceite de adormideras ${ }^{3}$ era más claro y tenía menor tendencia a amarillear durante su envejecimiento que los aceites de linaza o nueces. La principal desventaja del aceite de adormidera frente a los otros residía en su menor velocidad de secado. Sin embargo, este inconveniente podía tornarse en beneficio durante los periodos de intenso calor estival porque las altas temperaturas aceleran el secado de los aceites. Gracias al aceite de adormidera, los aficionados mantenían frescos los colores por más tiempo y podían corregir los errores con mayor facilidad, como indican Soler y Ferrer (1837):

...más también es en cambio muy endeble, y casi insecable; por lo que apenas suele usarse más que entre aficionados, y más en verano, pues por ser poco secante, conserva tierno el color por más tiempo, con lo que admite más correcciones lo pintado. (Soler y Ferrer, 1837: II, 59)

\footnotetext{
3 El aceite de adormideras se empleaba en Holanda a mediados del siglo XVII, fue muy apreciado por los pintores barrocos de otras partes de Europa y posteriormente por los Impresionistas.
} 
En los escritos españoles posteriores, el aceite de adormidera aparece mencionado en Borbón (1860) y Algarra (1864 y 1875). Borbón no considera esta sustancia apta para elaborar sus vehículos oleosos, mientras que Algarra se limita a exponer que el aceite de amapola es adecuado para la pintura al óleo. La omisión directa de este aceite en De la Roca y Delgado (1880), Poleró (1886), Sala (1896) y López Tomás (1898) podría deberse a su común anhelo por recuperar las prácticas pictóricas de periodos pretéritos. Pero también podría deberse a que el descontento generalizado de los pintores con los materiales comerciales, les impulsara a buscar maneras de conseguir sustancias estables para sus pinturas. Todos estos autores - a excepción de Sala - abordan la tecnología de la pintura al óleo a partir de los tratados de Pacheco y Palomino que describen los aceites de su tiempo: linaza, nueces y piñones. Por su parte, el artículo de Emilio Sala es una feroz crítica a los óleos comerciales.

En cambio, Vibert otorga al aceite de adormideras una gran importancia: “...hoy día sólo se emplea el de adormideras, excepto para algunos colores sombríos para los que se preconiza el aceite de linaza..." (Vibert, 1908: 105). La importancia que adquirió el aceite de adormidera queda patente en el catálogo de colores de L. Péant é Hijos. Estos comerciantes ofertaban diferentes cajas de paisaje guarnecidas; el único aceite que aparece en el contenido de algunas de estas cajas es el de adormidera (L. Péant é Hijos. 1895: I, 32 - 33). También este catálogo ofrecía aceite de adormideras y aceite de adormideras decolorado fabricados por Lefranc \& Cie y por el mismo anunciante (L. Péant é Hijos. 1895: I, 56 y 53). Sin embargo, en el catálogo mencionado sólo se presentaba aceite de adormideras - sin decolorar - de la empresa Reeves \& Sons (L. Péant é Hijos. 1895: I, 57). Es muy probable que los industriales apreciaran la menor capacidad secante del aceite de adormidera porque permitía almacenar los colores en tubos durante más tiempo. Del mismo modo, podría ser que los pintores prefirieran este aceite para pintar al aire libre. 


\subsubsection{Aceite de piñones}

Algunos tratados españoles como Soler y Ferrer (1837), Borbón (1860), De la Roca (1880) o Poleró (1886) reflejan el uso pictórico del aceite de piñones. Esta sustancia aparece por primera vez mencionada para usar con azules y blancos en el tratado tardo barroco de Palomino (1988: II, 139) quien dice "Otro aceite hay, en vez del de nueces, para azules, y blancos, que es el de piñones..." Emilio Sala (1896) se muestra escéptico antes esta afirmación.

Palomino habla de usar otro aceite para el blanco; pero como su libro no está escrito en el apogeo de la pintura clásica española, sino en un período de decadencia, no merece bastante confianza. (Sala, 1896: XLIII, 294)

En cambio, encontramos otros artistas que corroboran el empleo de esta sustancia oleosa entre los pintores españoles. Soler y Ferrer (1837: II, 59) comentan sobre el aceite de piñones. "Este apenas se vende, $[\ldots]$ y se usa en especial para blancos que no los trastoca por su poco color. Apenas podrá venir caso de usarlo teniendo el de nueces...”. Si bien esta afirmación verifica el uso del aceite de piñones, parece que se trate de un uso esporádico o puntual. En cambio, la Memoria de Borbón (1860) constata un uso más amplio del aceite de piñones para pintura al óleo:

Usábamos por lo general del de linaza para todo, y del de piñones tan solo para los casos en que queríamos se mantuviese fresco el color por mucho tiempo, pues hemos descubierto que dicho aceite tiene esta propiedad notable, utilísima durante los calores, y cuando no puede concluirse una parte en el dia cosa que puede impacientar al artista, y hacerle ó precipitar la mano, sin que esta sea guiada por la reflexion que se requiere, ó que cansada aquella, y no menos la mente, por un trabajo excesivo, produzca pobrísimos resultados. (Borbón: 1860, 9) 
Este autor explica que el aceite de piñones preparado con una disolución de goma elástica era de gran utilidad en las tintas que incluyen elevadas cantidades de albayalde, cobalto y otros colores de notable poder secante (Ver 3.3). Ya hemos visto la curiosa exposición de Poleró afirmando que los aceites de piñones y claveles sustituyeron a los aceites de linaza y nueces aunque el autor no incluya posteriores instrucciones o descripciones de los aceites sustitutos.

El uso del aceite de piñones en la pintura española sólo está confirmada por las fuentes escritas. No obstante, nos hallamos ante la adaptación a la pintura de un material abundante en la Península Ibérica. Podría resultar interesante incluir la identificación de este aceite cuando se realicen análisis para establecer el tipo de aceite empleado en una pintura española del siglo XVIII y de la primera mitad del XIX.

No debería causar extrañeza que en algunas zonas geográficas se desarrollaran algunos materiales propios, especialmente antes de la industrialización y del desarrollo de los grandes medios de transporte. Recordemos que, por ejemplo, las gomas que se han empleado en pintura a lo largo de la historia han sido muy variadas y generalmente los artistas usaban la que tenían más a mano. Eastlake (1847) comenta que el empleo de las resinas en la pintura al óleo dependía mucho de la zona. Así por ejemplo, este investigador supone que el mastic o almáciga era empleado en zonas mediterráneas mientras que las resinas fósiles cómo el ámbar o el copal eran más propias de los flamencos. O que los pintores flamencos del siglo XV tenían preferencia por la caparrosa blanca como secante de sus aceites. Mientras que, según Merrifield (1849), esta sustancia tuvo escaso reflejo en las fuentes italianas de la época. Y se podrían buscar muchos más ejemplos.

Es verdad que la interpretación de las fuentes es compleja y, a veces, se pueden identificar erróneamente las sustancias. Pero lo cierto es que existen evidencias de usos locales de ciertos materiales. Y si los tratadistas españoles señalan el empleo del aceite de piñones, encontramos un documento aún más sorprendente en el Archivo 
Histórico de la OEPM. Una patente registrada en el Gobierno Civil de La Habana ${ }^{4}$ el año 1894 que sugiere el aceite de algodón como aceite pictórico (Ver 3.3).

\subsection{Elaboración de los Aceites}

A principios del siglo XVIII, Palomino [1715-1724] (1988: II, 139), comentaba que el aceite de linaza “...en grande abundancia se saca en Segovia, y otros lugares de Castilla la vieja, aunque no se han descuidado en esto en Andalucia, especialmente en Sevilla y Granada.” El pintor tardo barroco continúa explicando la clarificación del aceite de linaza y la extracción de los aceites de nueces y piñones; después enseña la manera de cocer los aceites. Probablemente los pintores de esta época hallaban en el mercado el aceite de linaza que sometían con posterioridad a procesos de clarificación y cocido. Sin embargo, parece que los aceites de nueces y piñones preferían extraerlos ellos mismos, tal vez porque los encontraban rancios en el comercio o porque no estuvieran ampliamente disponibles.

Una situación similar se refleja en el Curso Completo de Soler y Ferrer (1837). Pero después la extracción desaparece de los escritos, con toda probabilidad, porque los artistas adquirían el aceite en los comercios. En 1860, Borbón sólo explica la clarificación de los aceites sin explicar la extracción. Este autor tampoco comenta la confección de los aceites grasos aunque sugiere interesantes composiciones para confeccionar pomadas o mediums pictóricos ${ }^{5}$. O'Neille (1862) y Algarra (1875) omiten por completo las explicaciones sobre los procesos de elaboración de los aceites.

\footnotetext{
${ }^{4}$ Archivo Histórico de la OEPM. No de Registro 16355.

5 Pomada es el término con el que Borbón designa a los vehículos pictóricos de carácter untuoso como el megilp. Por lo general, estos mediums pictóricos estaban compuestos fundamentalmente de aceite secante y resina.
} 
Esto representa un indicio claro de la asunción de los materiales comerciales.

Sin embargo, todos los procesos para elaborar los aceites reaparecen a finales de siglo en la Compilación de De la Roca y Delgado (1880) quien extracta las explicaciones de Palomino sobre la pintura al óleo. Poleró (1886) aborda la clarificación y las preparaciones de los aceites secantes claramente influenciado por Palomino. Mientras que López Tomás (1898) expone el método de clarificación de Pacheco y una fórmula para elaborar aceite graso también dependiente del mismo pintor barroco. Cómo ya hemos aclarado con anterioridad, la necesidad de retomar los materiales tradicionales podía obedecer a la precariedad de los materiales comerciales y a la admiración por la pintura barroca. En cambio, Bellanger (1899) y Vibert (1908) vuelven a obviar todos los procedimientos de elaboración de los aceites aunque Vibert comenta diversos problemas derivados de algunos de los tratamientos surgidos durante el siglo XIX.

Es interesante destacar que este retorno a las elaboraciones del pasado - concretamente del barroco español - que demuestran las fuentes decimonónicas de los últimos veinte años del siglo no sucede en los tratados ingleses. Carlyle (2002: 31) cuenta que los tratados ingleses publicados durante la primera mitad del siglo XIX aportan información detallada sobre la clarificación y otros tratamientos de los aceites. Sin embargo, en la segunda mitad de la centuria, los autores obviaron estos pormenores porque se asumió que los pintores adquirían sus colores ya preparados en el comercio. Church $^{6}$ resulta ser una excepción - apunta Carlyle - pues, aunque no proporciona recetas, describe algunos métodos comerciales de preparación de materiales.

${ }^{6}$ CHURCH, SIR ARTHUR H.: The Chemistry of Paints and Painting. London, 1890. 2nd: 1892; 3rd: 1901; 4th: 1915. 


\subsubsection{Extracción del aceite}

Las operaciones básicas - tradicionales - para extraer el aceite consisten en: limpieza de la semilla, reducción del tamaño de la misma, tratamiento con calor y prensado. Este sistema de extracción ha permanecido prácticamente invariable durante siglos aunque con el tiempo se haya modernizado la maquinaria empleada en los procesos. Las fuentes españolas decimonónicas tratan, aunque brevemente y con escasa atención, este proceso y el único sistema que aparece mencionado es el prensado en caliente. Los aceites prensados en frío se destinaban a alimentación o medicina y apenas encontramos una curiosa referencia al empleo de estos aceites empleados como aglutinante pictórico. Las fuentes españolas del siglo XIX omiten completamente el sistema de extracción del aceite mediante disolventes; un procedimiento que fue inventado en las primeras décadas del siglo XIX. Según Carlyle (2002: 31), las fuentes inglesas del siglo XIX demuestran también un limitado interés por los procesos de extracción de los aceites.

Soler y Ferrer sugieren que cada artista extraiga su aceite, sobre todo si va a pintar una obra de grandes dimensiones porque así se evitan las adulteraciones del comercio. Según estos autores, con el sistema de extracción del aceite que proponen, los artistas podían lograr un aceite más fresco, fluido y decolorado que el del comercio. El Curso Completo de Soler y Ferrer (1837) explica un proceso de extracción del aceite que muestra una clara dependencia del sistema que expone Palomino en su tratado. Recordamos una vez más que las lecciones de Palomino fueron publicadas en 1880 en la Compilación de De la Roca y Delgado.

Aunque las explicaciones de Soler y Ferrer muestran una clara dependencia de Palomino se aprecian varias diferencias entre ambas enseñanzas. El Curso Completo explica como eliminar la piel que recubre la carne de la nuez (o piñón puesto que el autor comenta que el mismo sistema se emplea en ambos casos), en cambio Palomino resulta más parco en este detalle. Otra desigualdad entre los tratados de Palomino y de Soler y Ferrer reside en un filtrado 
final del aceite que menciona el Curso decimonónico pero no aparece en el tratado tardo barroco.

...tómense para ello una porción de nueces cuando ya secas, esto es al mes ó dos meses después de cogidas, quebrantadas y abiertos sus grifos, pónganse en agua tibia por el tiempo que baste á levantar su piel ó tunica amarilla que los cubre, quiteseles á todos con limpieza, dejando puro el blanco de su carne como se hace en las almendras; pónganse a continuación al sol hasta que estén sin humedad alguna; en ésta disposición se machacarán en almirez, y calentando al fuego módicamente en un perolillo la pasta, rociandola con agua ó vino blanco, se mete en sus serillos de lienzo crudo fuerte, ó esparto fino, se coloca en la prensa, la mejor de hierro que á este fin tienen los Boticarios, y en ella se esprime el aceite recogiéndolo con toda limpieza, y filtrándolo luego dos ó tres veces por papel de estraza fino y carbón animal, ó sea negro de marfil, se obtendrá el aceite fresco, hermoso, sin color. (Soler y Ferrer, 1837: II, p. 58)

Otro de los detalles interesantes que podemos comparar en ambos textos es la forma de referirse a la 'prensa'. Soler y Ferrer recomiendan una prensa de hierro que utilizaban los Boticarios. Mientras que Palomino se refiere a la prensa con tanta familiaridad como si se tratara de un utensilio habitual en los talleres de los pintores.

Otro aceite hay, en vez del de nueces, para azules, y blancos, que es el de piñones, dejándolos enranciar algún tiempo después de quebrantados; y descascarados, y luego se machacan en almirez, y calentándolos a el fuego en un perolillo, rociándolos con agua, o vino blanco, se exprimen en la prensa en sus serillos de esparto fino, o de lienzo crudo fuerte; y de esta misma forma se saca el aceite de nueces, teniendo abajo su tablerillo con fondo, donde reciba y despida el aceite por su espita ó cañoncillo, cayendo en alguna vasija apropósito. (Palomino, 1988: II, 139) 
Como hemos visto, las nueces o los piñones tienen que limpiarse y despojarse de su piel antes de proceder al prensado. También las semillas de lino - cómo comenta Van den Berg (2002: 10) - tenían que someterse a unos tratamientos previos al prensado para librarlas de ciertas sustancias que pudieran acompañarlas. El proceso de extracción del aceite de lino que expone este investigador es similar al de nueces y piñones descrito por Palomino y Soler y Ferrer. Riffault (1850: 122) lo explicó de una manera sencilla: "Se extrae tostando la semilla del lino para destruir el mucílago que la recubre, moliéndola despues, calentándola con un poco de agua, y exprimiéndola."

Los procedimientos descritos por Palomino, Soler y Ferrer o Riffault proceden de una práctica en la elaboración de los aceites que ha permanecido sin alteraciones durante centurias. Para demostrar esto vamos a establecer un parangón entre las explicaciones de estos tratadistas de los siglos XVIII y XIX y los de épocas anteriores. Por ejemplo, Teófilo [s. XI - XII] - la primera fuente escrita que conocemos dónde se expone la pintura al óleo - explica un proceso de extracción del aceite muy similar al que acabamos de ver.

Take some flax seed and dry it in a pan over the fire without water. Then put it in a mortar and pound it with a pestle until it becomes a very fine powder. Put it back in the pan, pour in a little water, and heat it strongly. Afterwards wrap it in a new cloth and put it in the press where oil is usually pressed from olives, nuts, and poppy seeds, and press out this oil in the same way.' (Teófilo, [s. XI - XII] 1979: I, 27)

$\mathrm{Y}$ un proceso semejante puede apreciarse en el Manuscrito Bolognese del siglo XV.

205. A fare olio de semj de lino.__ Piglia uno quarto de semj de lino necta et pura et amachala uno poco poi la pone in uno vaso al foco et cum uno cochiaro la vienj mistando poi va piu volte in lo fondo del dito vaso cum lo ditto cochiaro et falli spatio che se li possa infondare la granatella et volse imborsarla cum uno poco 
daqua acio diventi morbida poi la mecte in panno de lana forte et polla ali frescoli et uscira fuora lolio.7 (Merrifield: 1849: II, 489)

Pero volviendo a los textos decimonónicos, los escritos de química corroboran que los aceites prensados en caliente se empleaban para uso artístico y describen maquinaria industrial para realizar la extracción. Desmarest (1828: II, 168) aclaraba que los aceites para pintura se prensaban en caliente alcanzando los $100^{\circ}$ centígrados; el calor facilitaba la extracción produciendo aceites más fluidos. Este químico aseguraba que los procesos de extracción en frío se empleaban para los aceites alimenticios porque el calor producía alteraciones y afectaba al sabor. Los Elementos de Química de A. Bouchardat, traducido al español en 1845, describen la extracción en frío y en caliente del aceite.

La mayor parte de las semillas sueltan aceite á la temperatura ordinaria, siendo el obtenido por este medio el mejor y mas puro; pero si se ha de estraer totalmente es necesario que la espresion se verifique á una temperatura un poco elevada, lo que se consigue calentando con precaucion las semillas hasta la mayor temperatura que puedan aguantar sin descomponerse, esprimiéndolas despues entre dos láminas metálicas previamente calentadas. Procediendo de este modo el aceite adquiere mas fluidez... (Bouchardat, 1845: 467).

Bouchardat (1845: 467) comenta que los aceites extraídos mediante este procedimiento pueden estar alterados. El exceso de calor puede quemar las semillas y estas pueden producir alguna sustancia que no

\footnotetext{
7 Si caben dudas acerca de la interpretación de este fragmento, la traducción que Merrifield hizo de este fragmento es la siguiente:

205. To make linseed oil.__ Take one quart of clean and pure linseed, damp it a little and then put it into a vase over the fire and stir it on with a spoon, and then push the spoon several times ti the bottom so as to moisten all the seeds. You must add a little water in order to soften them; then put the seeds into a strong woollen cloth, place it in the press, and the oil will flow out. (Merrifield, 1849: 488)
} 
segregan durante la expresión en frío. En cualquier caso, advierte el químico que los aceites extraídos en caliente se enrancian con más facilidad que los expresados en frío.

Hacia finales de siglo aparece un texto que resulta mucho más esclarecedor en sus explicaciones del sistema de extracción del aceite. El Nuevo Diccionario de Química de E. Bouant (h. 1888: 10) expone un sistema industrial de extracción de los aceites que cumple los mismos principios expuestos por los tratadistas. El químico aclara que los aceites sufrían varios procesos de extracción que podrían originar diferentes calidades de aceites. Las semillas se machacaban y se convertían en pasta en molinos de piedra con muelas verticales. La pasta se introducía en sacos de tela, lana, crin o esparto y apilados uno sobre otro o bien intercalando planchas metálicas. Entonces se practicaba la presión. Así se obtenían los aceites prensados en frío. El lino, la adormidera y la nuez se extraían en frío produciendo un aceite de mayor calidad que se empleaba con fines culinarios o médicos. Después de esta extracción se cambiaban las planchas frías por otras que se calentaban mediante un sistema interior de vapor. También podía aplicarse el calor moliendo de nuevo la torta con agua hirviendo, utilizando el fuego directo o calderas de doble fondo para después volver a comprimir la masa en la prensa. Los aceites para pintura eran los que procedían de la extracción en caliente.

Las fuentes secundarias comentan que los aceites prensados en frío se empleaban con fines culinarios o medicinales; sin embargo encontramos una curiosa excepción en el Manual Teorico y Practico del Pintor, Dorador y Charolista de Riffault (1850). Este manual expone el proceso de extracción en frío de Leonardo da Vinci. Eastlake (1847) señala que el ejemplo más notable de cuidado en la extracción del aceite es precisamente el de Leonardo da Vinci ${ }^{8}$. Un di vetro, zinc e possi levarne la buccia: remettile quindi in acqua pura, e cangiala ogni volta che la vedi intorbidarsi, per sei e anche otto volte. Dopo qualche tempo le noci, movendole, si disfanno e stempransi formando quasi una lattatta. Mettile in piatti all'aria aperta; evedrai lólio galleggiare alla superficie. Per cavarlo purísimo e netto prendi stoppini de bambagia cheda un capo stiano nell'olio, e 
método similar se practicó en las escuelas del Norte durante el siglo XVII. Es, sin duda, singular e inaudito que un manual para pintores de sala y fabricantes de colores exponga una de las formas de extracción del aceite más exquisita y cuidadosa que haya existido.

El célebre pintor Leonardo de Vince (sic) ha dejado en un manuscrito que posee el instituto, un método de extraer el aceite de nueces, y hacerle mas á propósito para la pintura.

Este método consiste en escoger las mejores nueces, quitarlas la corteza y echarlas despues en agua clara hasta que se separe la pelicula que las cubre. Entonces se vuelven á poner en agua clara, la cual se muda luego que está turbia, repitiendo esto seis ú ocho veces. $\mathrm{Al}$ cabo de algun tiempo removiendo las nueces se deslíen por sí solas en el agua formando un líquido lechoso, y exponiendo esta disolucion al aire libre viene el aceite á la superficie. Este aceite se saca muy limpio por medio de torcidas de algodón, poniendo una punta dentro del aceite y otra dentro de una redoma: de este modo irá pasando el aceite muy claro á la redoma. (Riffault, 1850: 123-124)

Los aceites extraídos en frío eran de mejor calidad y no se decoloraban. Por eso Eastlake argumenta que en los periodos más refinados de la pintura - renacimiento y barroco - los artistas se preocuparon por conseguirlos. Los datos que aporta Eastlake son concluyentes:

Birelli (Secreti, Firenze, 1601, p. 541) begins a recept: "R. Olio di lino (sine igne) una parte," \&c. De Mayerne, speaking of nut oil,

dall'altro pendano fuori del piatto, ed entrino in una caraffa, due ditta sotto la superficie dell'olio ch'è nel piato. A poco a poco l'olio filtrandosi per lo stoppino carda limpidisimo nella caraffa, e la feccia restará nel piato. Tutti gli olj in se etessi son limpidi, ma gli altera la maniera d'estrarli.

(Amoretti, Carlo: Memorie Storiche Intorno alla Vita et alle Opere di Leonardo da Vinci. 1804. Venturi, J. B.: Essai sur les Ouvrages Physico-Mathématiques de Léonard de Vinci, 1797. (Eastlake, 1847: 323, n.) 
says: "Si elle est tirée sans feu elle será beaucoup meilleur." (MS. p. 151. Verso) In the Venetian MS. we read: "R. dello seme de chanapa e fane quantitad e secca al solombra," \&c. (Eastlake, 1847: I, $321 \mathrm{n}$ )

Que un manual de pintura decorativa se adentre en explicaciones sobre los procesos más sublimes de la elaboración de los materiales artísticos causa cierta extrañeza. Pero también despierta nuestro asombro la omisión en las fuentes españolas del proceso de extracción desarrollado durante el siglo XIX. Durante esta centuria, cómo demuestra Church (1915: 47), se practicó también la extracción del aceite mediante la acción de disolventes.

...the general methods of extracting them first demand a few words of explanation. There are two different processes in use. In one of these, which has been practised widely from very early times, the oil is obtained by pressure; in the other process, invented some seventy years ago, the oil is extracted by means of an appropriate solvent. We may dismiss this latter process almost summarily, for the product which it yields, though much greater in quantity, is decidedly inferior to that obtained by pressure.... (Church, 1915: 47)

Carlyle (2002: 31) informa que este dato ya aparece en la primera edición de The Chemistry of Paints and Painting de Church que data de 1890. Puesto que Church - en 1915 - asegura que el sistema fue inventado setenta años antes, la fecha del descubrimiento referido data de la década de 1845 .

Durante la primera mitad del siglo, la situación material era similar a la de la centuria precedente como ya hemos sugerido. Es decir, el aceite de linaza se producía, casi con total seguridad, en caliente y los pintores podían adquirirlo en el comercio. Los procesos de clarificación y cocción podía realizarlos el propio pintor según sus preferencias, hábitos o sustancias que tuviera disponibles. En cambio, los aceites de nueces y piñones debían ser más escasos en el mercado porque se enranciaban velozmente. Por eso, es probable que en alguna ocasión los pintores extrajeran dichos aceites y los 
sometieran a los procesos pertinentes.

El vacío de datos relativos a la elaboración de los aceites en los tratados desde mediados de siglo hasta 1880 evidencia que los propios artífices no estaban preocupados por estas labores.

Posiblemente esto se debiera a que los fabricantes y comerciantes de colores las habían asumido. Aunque en 1880 la Compilación de De la Roca explica de nuevo la manera de extraer los aceites de nueces y piñones no creemos que los pintores retomaran esta práctica. Sin embargo, es factible que algunos pintores durante estos últimos años de siglo se animaran a realizar algunas operaciones de purificación y cocción de los aceites.

\subsubsection{Clarificación}

La purificación o clarificación de los aceites secantes es necesaria para eliminar la materia mucilaginosa que podría ocasionar coloración en el aceite y problemas de secado en la película pictórica. Según Van den Berg (2002: 14 - 15), todas las materias que tengan una influencia negativa en los procesos adicionales a los que se somete el aceite deben ser eliminadas, especialmente si el aceite va a cocerse. Nuestros tratadistas decimonónicos parecen tener esto muy claro. Agustín Algarra (1875: 177) explica que "Entre las circunstancias que se requieren en los aceites que se emplean en el óleo, son las mas indispensables pureza y clarificación.”

Los métodos de clarificación de los aceites no sufrieron grandes variaciones a lo largo de la historia pero en el siglo XIX se produjo alguna innovación de interés. Los sistemas de clarificación más habituales a lo largo de los siglos fueron: el reposo o exposición al sol, el lavado con agua, la mezcla con sustancias o el filtrado. Existen también noticias interesantes de un procedimiento mediante enfriamiento del aceite con nieve que, lógicamente, sólo podía llevarse a cabo en los países fríos. Este procedimiento lo explica Tingry en The Painter and Varnisher's Guide (1816: 38 - 39). Consistía en mezclar el aceite con nieve y exponerlo al frío hasta que 
la llegada de las temperaturas cálidas deshiciera la nieve y separara los líquidos. Años más tarde - en 1847 - Eastlake (1847: I, 340 n.) comentaba que el enfriamiento con nieve era un procedimiento ocasionalmente utilizado en sus días. No cabe duda que la industrialización y los medios de transporte modificaron e incluso hicieron desaparecer muchas prácticas.

Una de las novedades desarrolladas durante el siglo XIX fue el uso del ácido sulfúrico para purificar los aceites. Como veremos más adelante, este sistema ya se empleaba a principios de siglo aunque no aparece reflejado en los escritos de nuestros pintores decimonónicos que muestran una clara dependencia de los procesos de clarificación de épocas pretéritas. Tenemos que esperar a finales de siglo para encontrar el sistema de purificación mediante ácido sulfúrico explicado en un texto de química francés traducido al español. En definitiva, los tratados decimonónicos españoles muestran diferentes procesos de clarificación de los aceites mediante (1) exposición al sol, (2) albayalde, (3) filtrado o (4) lavados con alcohol. Todos estos métodos tienen un fuerte arraigo en los sistemas tradicionales de clarificación de los aceites en los que la exposición al sol es fundamental.

La exposición al sol es posiblemente uno de los métodos de clarificación más sencillos; consiste en dejar el aceite reposar durante algún tiempo al sol o al sereno. Como veremos, la exposición al sol complementaba otros procesos de purificación. Soler y Ferrer explican este sistema en el que el aceite se introduce en botellas que se dejan a la intemperie durante varios meses.

El mejor y menos engorroso de todos los métodos, es tomar muy en tiempo y por mayor el aceite, ponerlo en botellas en cantidad de dos ó tres libras cada una, y bien tapadas sin mas preparación, ponerlas al descubierto en parage donde le dé libremente el sol y sereno por tres ó cuatro meses en invierno, y dos ó tres en verano. (Soler y Ferrer, 1837: II, 59)

Ninguna otra fuente española decimonónica vuelve a tratar este sistema de purificación de forma independiente. Y hacia finales de 
siglo el químico Bouant (h. 1888: 10) asegura que el reposo da “...por resultado una clarificación suficiente, pero no llega á dar un aceite bastante puro: es necesaria, para esto, una purificación química con ácido".

La clarificación mediante albayalde consiste en mezclar blanco de plomo en polvo con el aceite y agitar hasta que adquiere aspecto lechoso. Después se deja a la intemperie durante unos días, removiendo la mezcla de vez en cuando. El albayalde se añadía al aceite porque atraía las partes crasas y las arrastraban al fondo; al decantar el aceite estas materias quedaban en el poso junto con el componente añadido. Este sistema de clarificación fue referido por Soler y Ferrer (1837), por De la Roca y Delgado (1880) y por Vicente Poleró (1886: 83). La clarificación del aceite con albayalde fue explicado de esta forma por De la Roca y Delgado quien, recordemos, transcribe a Palomino.

...se puede clarificar el de linaza, echándole en una redoma y en ella una porción de albayalde en polvo, y rebotarlo muy bien, de suerte, que todo parezca blanco, y dejándolo al sol y al sereno, hacer la misma diligencia de agitarlo cada veinte y cuatro horas, $\mathrm{y}$ haciendo esto hasta tres veces, luego usar de él, porque si se repite más se engrasará. (De la Roca y Delgado, 1880: 276)

La influencia de Palomino se deja notar en los escritos de Soler y Ferrer y Poleró. El método que exponen estos autores es idéntico al sistema de clarificación del pintor tardobarroco con ligeras modificaciones en el tiempo que debe durar el tratamiento; Palomino indica tres días, Soler y Ferrer aconsejan tres o cuatro días mientras que Poleró sugiere dos jornadas. Otra diferencia de los tratadistas decimonónicos con respecto al pintor tardo barroco estriba en que los primeros finalizan el tratamiento mediante un filtrado del aceite que no menciona Palomino. Nótense las similitudes entre Palomino y Soler y Ferrer quienes además refieren que con este procedimiento se obtienen resultados más prontamente que con el anterior: 
Mas para cuando se quiere mas pronto el resultado, se echará en su botella una porción de albayalde en polvo batiéndolo en ella fuertemente hasta que quede una leche; se dejará asi al sol y sereno por tres ó cuatro dias, rebatiéndolo como la vez primera cada veinte y cuatro horas, y al cuarto dia, quitar el aceite por decantación, cuidando no se le mezcle el aceite del pósito, y luego filtrarlo por papel de estraza y negro marfil. (Soler y Ferrer: 1837: II, 59)

Las indicaciones de Poleró son similares a las que acabamos de ver.

La clarificación del aceite de linaza se consigue fácilmente agregándole una porción de albayalde en polvo á la botella en donde está depositado, removiéndole con un palo de cuando en cuando durante un par de días, que se tendrá expuesta al sol.Quedando por este medio, y después de bien filtrado con papel de estraza, tan transparente como se desea. (Poleró, 1886: 83)

También Riffault (1850: 125) describe un procedimiento de purificación para que el aceite de linaza se torne tan claro como el de adormidera. El autor sugiere una exposición prolongada al sol y el uso de blanco de cerusa (o albayalde) y talco: “...esta mezcla atrae al fondo las partes crasas y aclara el aceite."

Hemos visto cómo algunos tratadistas sugieren finalizar la operación de clarificación del aceite mediante filtrados; pero también encontramos una referencia en la que repetidos filtrados sirven para realizar esta operación. Borbón (1860: 11) propone filtrar el aceite a través de papel de estraza hasta diez veces “...mezclándole en cada una de ellas una pequeña parte de carbón...”. Para que la operación sea efectiva debe después exponerse el aceite al sol durante ocho o diez días.

Borbón propone también otro método que consiste en lavar el aceite con alcohol puro; ambos líquidos deben agitarse y después dejarlos reposar al sol. Luego se decanta el alcohol.

...y para quitarle enteramente, puede hacerse con una muñequita de algodón, puesta en una varita ó asta de pincel. De este modo 
se abrevia la operación, pues deja gran parte de las materias colorante y glutinosa disueltas en el alcohol, que quedará de color amarillo muy fuerte,... (Borbón, 1860: 12)

La operación debe repetirse dos o tres veces sustituyendo en cada ocasión el alcohol. Podríamos parangonar este procedimiento al de Pacheco que fue transcrito por José López en su Educación Artística:

\section{DECOLORACION DEL ACEITE DE LINAZA.}

Tómese una redoma de vidrio, y á una libra de aceite de linaza limpio y claro, se le echan tres onzas de aguardiente fino, que llaman de cabeza, y dos onzas de alhucema ó espliego en grano, y póngase al sol fuerte quince días, meneándolo dos veces cada dia, y de esta manera queda claro y purificado, y colándolo en otro vidrio se pueden aprovechar de él en los blancos y azules. (Pacheco99.) (López Tomás, 1898: 49-50)

Merrifield (1849: I, ccxxxiv) asegura que probó a clarificar el aceite de linaza mediante el procedimiento de Pacheco y tuvo éxito. La investigadora explica que el alcohol adquiere el color que pierde el aceite mientras que el mucílago se deposita en el fondo de la vasija con los granos del espliego. Según Merrifield, el color amarillo que adquiere el espíritu del vino podría explicarse porque cierta cantidad del aceite es soluble en el. Tal vez este argumento explica porque se colorea el alcohol en el sistema que propone Borbón.

El sistema de clarificación mediante ácido sulfúrico se desarrolló en los albores del siglo XIX. Carlyle (2002: 34) asegura que este procedimiento aparece ocasionalmente en las fuentes inglesas decimonónicas. En cambio, las referencias a este modo de purificación son inexistentes en la tratadística española. No obstante, podemos encontrarlo explicado a finales de siglo en el Nuevo Diccionario de Química de Bouant.

9 Ver FRANCISCO PACHECO: El Arte de la Pintura. Madrid: Cátedra, 2001. p. $487-488$. 
El procedimiento químico actualmente en uso data de 1801 y es debido á Thenard. Muchos otros métodos han sido propuestos desde aquella época y hasta han llegado á ponerse en práctica; ninguno, sin embargo, se ha generalizado. (Bouant, $\mathrm{h}$. 1888: 10)

El procedimiento es sencillo; consiste en mezclar aceite con un 2 ó 3\% de ácido sulfúrico concentrado “...para producir la carbonización del mucílago.” El conjunto debe agitarse varios minutos, luego se deja reposar y se continúa con la agitación. El líquido se torna verdoso y finalmente oscurece por la carbonización de las materias mucilaginosas. Estas sustancias se depositan después de unas horas y el aceite queda limpio. La operación concluye batiendo el aceite con agua hirviendo o bien haciendo pasar una corriente de vapor. Tras el reposo conveniente, la mezcla se separa en tres estratos ${ }^{10}$; el superior corresponde al aceite purificado que debe filtrarse a través de una masa de algodón en rama o de lana cardada. La preparación de los colores al óleo es uno de los usos que Bouant atribuye a los aceites así tratados.

Van den Berg (2002: 15) sugiere que el método de clarificación más importante se lleva a cabo añadiendo al aceite un ácido suave como el vinagre ${ }^{11} \mathrm{o}$ el ácido sulfúrico. Este investigador

${ }^{10}$ El estrato inferior está formado por agua y ácido sulfúrico muy diluido; según el autor del diccionario, este líquido se emplea en la obtención de la caparrosa. El estrato intermedio es un aceite muy impuro que resulta útil para la elaboración de jabón o bien podría someterse de nuevo al tratamiento de purificación.

${ }^{11} \mathrm{El}$ sistema de purificación propuesto por Leonardo da Vinci [s. XVI] para la eliminación del olor de los aceites se basa en hervir dicha sustancia con vinagre.

“COMO DESPOJAR AL OLEO DE SU COLOR

Toma diez bocales de óleo fuerte, échalos en una tinaja y señala en ésta con una marca la altura que alcancen; añade entonces un bocal de vinagre y haz hervir la mezcla hasta que el óleo se rebaje, sin exceder la marca. Tendrás así la certeza de que el óleo ha tornado a su volumen primitivo y de que el vinagre se ha evaporado, llevándose consigo todo mal olor. En mi opinión, deberías hacer esto mismo con el aceite de nuez y con cualesquiera aceites que tengan mal olor". (Da Vinci [s. XVI] 1980: 431) 
compara este procedimiento con los sistemas actuales de refinación con ácido. Según Van den Berg (2002: 15), el uso de ácidos suaves destruye los fosfatos (phosphatides) además de la materia colorante. Su principal inconveniente radica en que se forman ácidos libres que, por otra parte, pueden eliminarse mediante lavados con agua.

Vibert manifiesta que los aceites sometidos a ciertas operaciones de clarificación acusaban problemas de acidificación con consecuencias devastadoras. También Sala emite un juicio negativo sobre los tratamientos de purificación de los aceites.

El mejor aceite secante es el de linaza, según ya hemos declarado. Cierto que el comercio lo falsifica, y que para purificarlo ó aclararlo pronto emplea medios perjudiciales: cierto que á otros aceites se les añaden ingredientes nocivos para darles condiciones secativas; pero, en primer lugar, esto todo el mundo lo sabe,... (Sala, 1896: XLIII, 294)

Los inconvenientes que se producían en los colores amasados con aceites acidificados debieron resultar muy molestos para los pintores. Además las pinturas elaboradas con estos aceites podían sufrir mayores alteraciones o problemas de conservación como comenta Vibert.

El aceite de linaza...tiene mayor tendencia á acidificarse. En este último caso se producen en los tubos combinaciones químicas con ciertos colores, sobre todo con los que tienen la alúmina por base, como las lacas, las cuales se convierten en una especie de caucho. Cuando los colores han sufrido esta transformación, deben tirarse, pues aunque podrían emplearse desleídos con aceite ó con esencia, nunca se secan por completo. El empleo de colores molidos con aceites acidificados es, por lo demás, una de las causas más frecuentes de que se agrieten los cuadros. (Vibert, 1908: 103-104).

Por eso, Vibert (1908: 104) aconsejaba "Se debe tener cuidado, antes de moler los colores, de asegurarse, por medio de un papel tornasol, de que el aceite no es ácido...”. Esta advertencia estaba dirigida tanto 
a fabricantes de colores como a pintores que se preparaban sus propios colores.

Pero una vez más Riffault nos sorprende. El Manual del Pintor, Dorador y Charolista de Riffault (1850, Portada) está dirigido a quienes ejercen estas profesiones y "...á los fabricantes de colores, y á los que quieran pintar por sí mismos sus habitaciones." Este escrito asombra porque a veces expone métodos delicados de la elaboración de materiales de la pintura artística. En lo relativo a la clarificación de los aceites, Riffault comenta un sistema en el que el aceite se mezcla con arena y agua ${ }^{12}$ y se expone al sol $^{13}$.

En Holanda ponen en una olla bien bañada un tercio de arena fina y otro tercio de agua con el aceite de linaza que se quiere blanquear. Cubierta la vasija con una tapa de hierro se expone al sol removiéndola por lo menos una vez al día, y luego que el aceite está bastante blanco se deja reposar por dos dias, después de lo cual se saca de la olla. (Riffault, 1850: 125)

Riffault está en lo cierto. Según Eastlake (1847: I, 337-338) el empleo de la arena procedía de los tiempos de Rubens. Eastlake comenta que Theodore Thurquet De Mayerne recogió la forma de clarificar los aceites de Daniel Mytens the Elder ${ }^{14}$ en la que el aceite se mezclaba con arena.

\footnotetext{
${ }^{12}$ Muchas son las fuentes que citan el agua - sola o mezclada con otras materias - como una sustancia adecuada para proceder a la clarificación de los aceites. Gracias a Eastlake (1847: I, 327 - 328, 329, 335 - 336, 338 - 339) sabemos que el Padre Jesuato, Felipe Nunes [1617] y De Mayerne [1620] mencionan el uso de esta sustancia para purificar los aceites. También Merrifield (1849: II, 621) deja constancia que el MS. Marciana [s. XVI] sugería purificar el aceite cociéndolo con agua. Van den Berg (2002: 15) explica que el método más sencillo consiste en el lavado con agua que precipita el material proteínico y los ácidos grasos libres. El agua también se utilizaba en los métodos empleados para conferir a los aceites mayor capacidad secante aunque nuestras fuentes decimonónicas tampoco reflejen este uso.

13 El mismo sistema fue referido por Chaptal (1816: II, 206).

14 Daniel Mytens the Elder (1590 - 1647-8) fue pintor de Charles I de Inglaterra antes de la llegada de Van Dyck.
} 
Colourless and thin linseed oil.__ Mix the oil with water and white sand in a glass bottle; shake it three or four times a day till the contents appear like milk, and leave it constantly exposed to the sun in the month of March. In a month the oil will be as clear as water; and every time [after the vessel is shaken], the warmth of the sun, separating the oil from the water, purifies it, and at last bleaches it perfectly. (Eastlake, 2001, I, 337 - 338)

De Mayerne (Eastlake, 1847: I, 338 - 339) también comunica el método de purificar el aceite de Van Sommer en el que la arena funcionaba como un filtro. Eastlake (1847: I, 337) concluye que siendo De Mayerne una fuente tan fiable, éste procedimiento tenía que ser clasificado como uno de los métodos familiares entre los pintores flamencos y alemanes.

\subsubsection{Preparación de los Aceites Grasos}

Una vez purificado y blanqueado, el aceite está preparado para usarse en pintura. Sin embargo, hay una serie de tratamientos adicionales para mejorar su comportamiento. En particular, los aceites se someten a procesos para aumentar su viscosidad y reducir los tiempos de secado. Los procedimientos más referenciados a lo largo de la historia de la pintura al óleo son: (1) exposición al sol, (2) cocción y (3) cocción con pigmentos secantes. Los dos primeros métodos producían aceites viscosos y eran adecuados para aglutinar colores con elevado poder secante como los pigmentos de plomo. Los aceites cocidos con agentes secantes eran adecuados para aglutinar los pigmentos con escasas propiedades secantes como las lacas. Estos tratamientos se conocen desde antiguo y apenas se modificaron con el tiempo. Por ejemplo, la exposición del aceite al sol consta en documentos de épocas tan distantes como los tratados de Cennini [1390] y Pacheco [1649] o un catálogo de Winsor \& Newton de 1902.

Los aceites que sufrían estos procesos de elaboración aparecen referidos a lo largo de la historia como aceites secantes, 
grasos, cocidos o barnices y emplearemos estas denominaciones indistintamente a lo largo del texto. Por otra parte, los aceites cocidos únicamente con litargirio aparecen frecuentemente bajo la denominación de aceites litargiriados y así llamaremos a estos aceites.

Las fuentes españolas del siglo XIX que comentan la cocción de los aceites son Soler y Ferrer (1837), De la Roca y Delgado (1880), Poleró (1886) y López Tomás. El tratado más temprano, Soler y Ferrer apareció en un momento en el que los fabricantes y comerciantes de colores especializados aún no estaban plenamente establecidos. Mientras que los escritos de los últimos veinte años de la centuria exponen estos procedimientos por una clara reacción frente a los materiales precarios de la industria ya establecida. Los textos de Borbón (1860), O'Neille (1862) y Algarra (1875) no comentan estos procesos de elaboración, tal vez porque vieron la luz durante los primeros balbuceos de la industria de los materiales artísticos.

Soler y Ferrer (1837), De la Roca y Delgado (1880), Poleró (1886) y López Tomás (1898) hacen referencia a la cocción del aceite con materias secantes, en cambio omiten los métodos de exposición al sol o la cocción del aceite sin aditivos. Tampoco plantean sistemas de cocción del aceite en los que se incluye agua ${ }^{15}$. La mayoría de aceites grasos que encontramos en los escritos españoles del siglo XIX incluyen el litargirio entre sus ingredientes pero, por lo general, aparece en conjunción con otros agentes secantes. Las sustancias secantes más referidas son compuesto de plomo como el minio o el albayalde aunque podemos encontrar alusiones al vidrio molido y a la caparrosa (Ver 4.3).

Únicamente López Tomás propone un aceite cocido cuyo

\footnotetext{
15 Tingry (1816: 36-37) y Paillot de Montabert (1829 - 1851: IX, 94) describen procesos en los que el agua es un ingrediente importante para conferir mayor carácter secante a los aceites. No obstante, el uso del agua en la elaboración de aceites secantes tuvo detractores como explica Tingry, porque si no se eliminaba por completo confería color al aceite y una consistencia cremosa. Sin embargo, asegura este autor, si la operación se realiza correctamente el aceite resultante es extremadamente secante y muy claro.
} 
único agente secante es el litargirio; pero en este caso resulta muy difícil identificar a que se refiere el autor con el término litargirio. Aunque todo apunta a que el autor ha incurrido en un error al referirse al litargirio cómo protóxido de hierro puesto que, en realidad, el litargirio es un óxido de plomo.

SECANTES. Aceite de linaza cocido con un poco de almártaga $^{16}$ (litargirio, protóxido de hierro) en polvo, la cual se mezcla estando cocido el aceite y apartado del fuego. Se ve que está cocido cuando echando un poco de pan ${ }^{17}$ salga tostado. (López Tomás, 1898: 50)

Encontramos que entre las fuentes secundarias, Desmarest (1828) y Riffault (1850) también describen la elaboración de aceites litargiriados. Desmarest (1828: II, 168) explica que se aumenta la capacidad secante de los aceites “...haciéndolos hervir con litargirio (óxido de plomo); se usan entonces mucho en pintura, y se llaman aceites litargiriados." Riffault (1850) expone que antes de emplear el aceite de linaza es necesario aumentar su capacidad secante.

...lo cual se consigue, segun Mr. Thenard, haciendo hervir este aceite y removiéndolo bien con siete ú ocho partes de su peso de litargirio; se espuma bien, y luego que adquiere un color rojizo se aparta del fuego y se clarifica por reposo. (Riffault, 1850: 239)

Riffault comenta que el aceite de adormideras tratado de este modo se emplea para humedecer y amasar el blanco de plomo. Esto se debe a que el aceite de adormideras es más transparente que el de lino. Sin

\footnotetext{
${ }^{16}$ Almártaga de dorar es uno de los nombres que Palomino da al litargirio.

${ }^{17} \mathrm{El}$ pan es un indicativo del estado de la cocción del aceite que aparece en Pacheco.
}

...tomando la cantidad conveniente de aceite de linaza claro en una olla, y unos dientes de ajos mondados, y una miga de pan con un poco de azarcón en polvo, se le puede dar un hervor al fuego hasta que el pan y los ajos se tuesten y colarlo después de frío, y usarlo luego dél. (Pacheco, [1649] 2001, 495-496) 
embargo, Mérimée (1830: 59) que demostró gran aprecio por los aceites grasos elaborados con litargirio aseguraba que jamás serían blancos ("mais elle n'est jamais blanche).

El litargirio fue un material empleado para elaborar los aceites grasos desde los albores de la pintura al óleo y muchos autores han dejado constancia de estas elaboraciones. El MS. Paduano [s. XVI - XVII] (Merrifiled, 1849: II, 693) incorpora una fórmula para elaborar aceite cocido con litargirio adecuado para dorar y pintar sobre vidrio. Lebrun en el Manuscrito de Bruselas [1635] (Merrifield, 1849: II, 816) aconseja los aceites cocidos con litargirio para los colores que tienen pobres capacidades secantes. También Eastlake (1847: I, 351) aporta una receta de Soreau ${ }^{18}$ en la que el litargirio es el único secante del aceite. Podemos encontrar recetas similares en los escritos del Padre Lana ${ }^{19}$ [1670] (Merrifiled, 1849: II, 746, n.), Volpato [h. 1680] (Merrifield, 1849. II, 741) y Baldinucci (1681). Aunque el litargirio ha sido una substancia muy apreciada para elaborar los aceites cocidos, Merrifield (1849: I, ccxl) llama la atención sobre la incompatibilidad de algunos colores con el plomo. Por eso, los pintores tendrían que tener cuidado con algunos pigmentos que no podían amasar con aceites litargiriados o que contuvieran otros secantes plúmbeos.

Pero nuestras fuentes decimonónicas sugieren especialmente la mezcla de varios compuestos metálicos que ejercen la función de secantes. Los aceites clarificados son bastante secantes - comentan Soler y Ferrer (1837: II, 60) - salvo si se tiene mucha prisa; en ese caso es necesario tratar los aceites de nueces o linaza.

Se toman cuatro libras de aceite de nueces ò linaza, occido ceroso amarillo, sal de saturno, y vitriolo blanco, de cada

\footnotetext{
18 "'M. Soreau, en Allemand Sorg' (probably the scholar of David Teniers)." (Eastlake, 1847: I, 335).

${ }_{19}$ Merrifiled (1849: II, 746, n.) en una nota al texto de Volpato aporta algunas anotaciones de un texto del Padre Lana. El texto al que se refiere se titula Prodromo overo Saggio di Alcune Inventione Nuove Premesso al Opera che Prepara il P. Francesco Lana, Bresciano, della Compagina de Gesù y fue publicado por primera vez en 1670.
} 
cosa media onza, y litarge seis onzas; se pulvorizan estas drogas, y hechan en una muñequita colgada de un hilo de modo que no toque al fondo ni lados, atando al mismo hilo dos ó tres granos de ajo sueltos y mondados, y en esta disposición se ponen con su dicha cantidad de aceite en un caldero ó puchero grande vidriado, en que quede otro tanto vacío de los que ocupa el aceite, por lo que subirá la espuma en sus hervores: se pone asi dispuesto el puchero á una lumbre lenta en que hierva muy ligeramente, hasta que acabe de espumar, y los granos de ajo estén ya tostados; en esta disposición quitándose prontamente del fuego, se formará luego sobre el aceite una gran capa espesa á manera de tela, la que luego se precipitará, arrastrando con ella todo lo craso y colorado del aceite: á los dos ó tres dias ya reposado, sepárese con cuidado el aceite de este sedimento, filtrese por papel de estraza y negro marfil, ó pongase á clarificar al sol y sereno si de pronto no queremos emplearlo. (Soler y Ferrer, 1837: II, 60)

Esta receta describe de manera clara e incluso entrañable una receta de la que podemos analizar varios puntos. El primero de ellos estriba en los secantes empleados. Es cierto que no podemos identificar el 'óccido ceroso amarillo' pero el resto de materias metálicas son fácilmente reconocibles. La 'sal de saturno' es acetato de plomo y el 'vitriolo blanco', también conocido con la denominación caparrosa blanca es sulfato de zinc. Ambas sustancias son blanquecinas y no aportarían al aceite coloración. En cambio, el 'litargirio' es un óxido de plomo ligeramente amarillo que - cómo ya hemos insinuado aportaba cierta coloración a los aceites. Otro aspecto que destacamos de esta fórmula es el empleo de los ajos; este ingrediente aparece citado en otras fuentes españolas y de otras nacionalidades y lo analizaremos más adelante.

Ahora queremos explorar un detalle inexistente en el resto de escritos españoles decimonónicos: la 'muñequita' con los ingredientes secantes que pende de un hilo dentro de la olla. De la Roca y Delgado (1880), Poleró (1886) o López Tomás (1898) no aluden al empleo de esta 'muñequita'. Y entre las fuentes 
suplementarias, únicamente hallamos referencia a esta forma de proceder en Chaptal:

Los pintores que preparan por si mismos sus aceites, ó los charolistas que los fabrican por mayor, ponen óxide de plomo en una muñeca, y los suspenden en el aceite mientras se caliente este. (Chaptal, 1816: III, 263)

También otros autores - de diferentes zonas geográficas y épocas - aconsejaban el uso de un saquito para evitar que las sustancias secantes se quemaran y estropearan el aceite: Lebrun [1635] (Merrifield, 1849: II, 816), Volpato [h. 1680] (Merrifield, 1849: II, 741) o Tingry (1816) son algunos de ellos. Este último autor resulta claro y conciso en la explicación de por qué debe emplearse una bolsita con las materias secantes.

A little negligence in the management of the fire has often an influence on the colour of the oil, to which a drying quality is communicated: in this case it is not proper for delicate painting. This inconvenience may be avoided by tying up the drying matters in a small bag; (Tingry, 1816: 31-32)

El resto de fuentes españolas decimonónicas que abordan este proceso de elaboración de los aceites datan de los últimos años de la centuria. De la Roca y Delgado (1880), Poleró (1886) y López Tomás (1898) se encargaron de enseñar de nuevo estos procesos. Insistimos, una vez más, en que el descontento con los materiales comerciales pudo motivar que los pintores reconsideraran algunos procesos tradicionales de elaboración de sustancias pictóricas.

De la Roca y Delgado (1880) transcribe los procesos de elaboración de los aceites grasos de Palomino quien indica varias formas de elaboración.

...el más común es el aceite de linaza cocido con azarcon ó litargirio, que por otro nombre llaman almartaga de dorar; de lo cual se le puede echar una onza á media libra de aceite y otra de vidrio molido 
y una cabeza de ajos sin cáscara, quebrantados, y echarlo todo junto en una vasija vidriada y que le quede otro tanto de vacío, porque poniéndolo á cocer (aunque ha de ser á lumbre mansa) sube tanto la espuma, que con facilidad se saldrá; y áun así es menester tener una cuchara fria que meterle de cuando en cuando, tanto para menear los ingredientes y rebotarlo muy bien, cuanto para que se baje la espuma, y volver á sacar fuera la cuchara, con la cual sacarán los ajos para ver si están ya tostados, y en estándolo, está ya el secante en su punto, y luego se arrojan los ajos y se deja sentar y es bellísimo secante. (De la Roca y Delgado: 1880, 277)

De la Roca y Delgado (1880: 277) reproduce también otra forma de elaboración de estos aceites que consiste en cocer el aceite de linaza con "una porción de colores viejas". Asegura este autor que tanto este secante como el anterior son buenos para todos los colores excepto para azules y blancos porque los primeros se vuelven verdes y los segundos amarillos. Para blancos y azules sugiere otro aceite graso.

...se puede hacer con aceite de nueces en una ampollita de vidrio, echándole vidrio molido, á proporcion, y un poco de litargirio y albayalde molido con el mismo aceite y otro poco de azarcon, como una onza de cada cosa á media libra del aceite de nueces, rebotándolo con ello una y otra vez, poniéndolo á cocer dentro de agua en un perolito; en habiendo cocido un rato el agua está hecho el secante y no es menester que sea á lumbre mansa, pero no muy fuerte. (De la Roca y Delgado, 277 - 278)

Esta receta incluye elementos que aportan color al aceite como el azarcón (minio) o el litargirio lo que puede resultar contradictorio. Sin embargo, se hace con aceite de nueces que es más claro que el de linaza y además se cuece al baño maría: "dentro de agua en un perolito". La cocción al baño maría impide que el aceite esté en contacto directo con el fuego por lo que la cocción es más lenta y segura. Además desaparece el riesgo de que las materias secantes se alteren por un exceso de calor y aporten mayor coloración al aceite. Una receta muy similar a la anterior - que recordemos 
procede de Palomino - podemos encontrarla en Poleró (1886).

Con el aceite de nueces se confecciona otro secante de parecidas condiciones al anterior, consistente en agregar á una media libra de aquel líquido dos onzas de azarcón, otras dos de litargirio, una porción de vidrio molido y otra igual cantidad de albayalde; y todo reunido en una vasija, se pondrá al fuego, guardando las mismas prevenciones antedichas. (Poleró, 1886: 84)

En este caso el autor ha obviado el detalle de la cocción al baño maría y en las "prevenciones antedichas" se refiere a emplear fuego moderado y remover continuamente. Poleró comenta que los aceites secantes y otras sustancias semejantes son fáciles de encontrar, sin embargo explica cómo confeccionarlos de manera económica. Otra fórmula que propone el pintor-restaurador reza:

En una vasija vidriada, sea de la forma que quiera, se echará media libra de aceite de linaza é igual porción de vidrio molido, un cuarterón de litargirio y dos cabezas de ajos sin cascarilla. Todo esto se pondrá á hervir á fuego lento, removiéndolo de vez en cuando con espátula, á fin de que dichos ingredientes, posándose no se quemen.

Cuando los ajos sobrenaden en el aceite con señales de estar tostados, tendremos una prueba evidente de que la operación está terminada, pudiendo desde luego embotellarse el líquido, pasándolo antes por tamiz, á fin de descartarle de cualquiera impureza que como residuo pueda quedarle. (Poleró 1886: 84)

El ajo aparece cómo una constante en las recetas de Soler y Ferrer, De la Roca y Delgado ${ }^{20}$ y Poleró. Merrifield (1849: I, ccxxxvii - ccxxxviii) explica que el ajo produce un jugo gelatinoso que proporciona humedad al aceite de este modo se evita la carbonización durante la cocción. El ajo, en definitiva se ha

${ }^{20}$ Por lo tanto, el ajo también aparece en Palomino. 
empleado como indicativo del estado de la cocción del aceite y se pueden encontrar muchas referencias en las fuentes escritas.

El empleo del ajo en la cocción del aceite también aparece mencionado por Tingry (1816) en algunas de sus recetas para otorgar a los aceites mayor cualidad secante. Este químico además expone que se puede sustituir la cabeza de ajos por una cebolla pequeña. Merimée (1830) también indica que el ajo o la corteza de pan son ingredientes que algunos recomiendan incluir en el aceite durante la cocción. Cómo hemos visto previamente, el pan utilizado con estos fines también aparece citado en Pacheco y López Tomás. Pero incluso mirando mucho más atrás en el tiempo, se puede rastrear el empleo del ajo como ingrediente de la elaboración de los aceites grasos. El MS. Bolognese [s. XV] (Merrifield, 1849: II, 520 - 523) en su receta No. 262. "To make a good liquid varnish" contempla incluir treinta o cuarenta dientes de ajo en la elaboración de los aceites que componen el barniz.

Muchas de las indicaciones que hemos visto eran útiles para que los pintores preparan sus propios aceites grasos. Pero en los procesos industriales también se tenía que controlar la cocción del aceite. Vibert (1908) reflexiona sobre este asunto:

Los procedimientos de fabricación no han variado tampoco. Algunos industriales, que ignoran la existencia de termómetros de mercurio que señalan hasta 400 grados, no tienen otro medio de reconocer la temperatura del aceite que el de freir en él un diente de ajo ó una corteza de pan. (Vibert, 1908: 126)

Las recetas analizadas hasta el momento incluyen litargirio entre sus compuesto secantes - bien sólo o mezclado con otras materias metálicas -. Sin embargo, López Tomás propone elaboraciones en las que el litargirio no comparece y otorga más protagonismo a otro óxido de plomo: el minio o azarcón.

Otro procedimiento consiste en cocer óxido de plomo con aceite de linaza ó cualquier otro aceite secante, en el baño maría, hasta consistencia conveniente; se extiende enseguida el producto 
asi obtenido con esencia de trementina. Este secante es limpio, claro y no altera los colores; conviene sobre todo al blanco. (López Tomás, 1898: 50)

La verdad es que López Tomás resulta complejo de entender en este tema. Pero identificamos el óxido de plomo con minio porque así lo refiere en otra elaboración de un secante: “Aceite de linaza revuelto con azarcón (minio, óxido de plomo) en polvo, ó con alcaparrosa (caparrosa, deuto - sulfato de hierro) también molida en polvo.” El calor no es necesario para formar el aceite secante que también se obtiene agitando el aceite y el secante durante un largo periodo de tiempo. Aún así, nos mostramos cautelosos antes esta receta porque al no indicar la cocción de los ingredientes podría tratarse de un secante de paleta (Ver 4.1). Además, el autor crea confusión introduciendo como secante el sulfato de hierro o caparrosa verde pues esta sustancia ha tenido escasa o nula participación como secante pictórico ${ }^{21}$. El vitriolo o caparrosa utilizado generalmente en el arte de la pintura ha sido el sulfato de zinc que es blanco (Ver 4.3).

Cuando hemos abordado la extracción y la clarificación de los aceites, los datos nos han llevado a exponer algunos casos excepcionales que aportaba el Manual del Pintor, Dorador $y$ Charolista de Riffault. Nos referimos a estos datos de Riffault cómo 'casos excepcionales' porque resultan completamente diferentes a la información del resto de fuentes - primarias y secundarias - que manejamos. Una vez más, este autor proporciona una forma de elaborar los aceites grasos completamente diversa de lo que hemos visto hasta ahora.

El aceite graso es sin contradicción el mejor de los secantes. Para prepararlo se mezcla con una libra de aceite de linaza, media de litargirio, igual cantidad de cerusa calcinada, y lo mismo de tierra de sombras y de talco, en todo dos onzas; se pone á hervir la mezcla por cerca de dos horas á fuego suave é igual, removiéndola

\footnotetext{
${ }^{21} \mathrm{El}$ sulfato de hierro o caparrosa verde fue especialmente empleado en la elaboración de los colores de Marte (Ver 5.1.7.)
} 
frecuentemente para que no se ennegrezca el aceite: luego que hace espuma se va quitando esta, y cuando cesa de espumar y empieza á ponerse rojizo el aceite es señal de que está bastante cocido; entonces se deja reposar y al cabo de tiempo queda claro, siendo mucho mejor cuanto mas antiguo. (Riffault, 1850, 179)

Ésta fórmula, sin lugar a dudas, procede de Bouvier²2:

\section{Recette pour faire l'Huile grasse}

"Elle se prépare en mettant dans un pot tout neuf et vernissé une demi-once de litharge d'argent, autant de ceruse calcinée, autant de terre d'ombre, et autant de talco u de Pierre à Jésus: en tout deux onces de matières pour un libre d'huile de lin, qu'on fait boullir à feu doux et égal, de peur que l'huile noircisse. Quand elle mouse, il faut l'écumer. Lorsque l'écume commence à se raréfier et è devenir rousse, l'huile est suffisamment cuite et dégraissée. Les matières, qui se trouvent alors denatures en partie, laissent un marc ou sédiment dans lequel se trouve une portion de la matière muqueuse de l'huile, qui s'est combinée avec les ingrédients sous une forme emplastique. On laisse ensuite reposer l'huile ainsi desséchée et preparée, parce que, dans les intervalles du repos, elle devient plus claire. Plus elle est ancienne, meilleure elle est. Réservez-la pour les occasions où vous en aurez besoin.” (Bouvier, 1827: 92 - 93)

Bouvier, autor del Manuel des Jeunes Artistes et Amateurs en Peinture asegura que ha transcrito la receta de L'Art du Vernisseur de Watin [1782]. También Paillot de Montabert (1829 - 1851: IX, 94 -95) recoge una receta similar a la que expone Bouvier.

Los pintores y artistas podían adquirir en el comercio algunas variedades de aceites grasos. A finales del siglo XIX, L. Péant é Hijos

\footnotetext{
${ }^{22}$ Las explicaciones de Bouvier (1827: 92-99) sobre la elaboración y el uso de los aceites grasos son especialmente detalladas. El artista aclara incluso con que colores es adecuado mezclarlo y con cuales no; o el recipiente adecuado para poner el liquido en la paleta, según se vaya a abordar una obra de pequeño o gran formato.
} 
(1895: I, 53) fabricaban aceites grasos que ofertaban es su catálogo aunque se omiten los ingredientes y lo procedimientos de elaboración. El mismo catálogo (1895: I, 56) ofrecía 'aceite graso' y 'aceite graso blanco' fabricados por Lefranc \& $\mathrm{C}^{\mathrm{ie}}$. De Reeves \& Sons, los vendedores de Madrid muestran en su catálogo de 1895 tres tipos de aceites secantes: 'pálido decolorado', 'rápido y fuerte' y 'pálido especial (preparado sin plomo)' (L. Péant é Hijos, 1895: I, 57).

La elaboración de los aceites grasos, tanto a nivel casero cómo industrial, implicaba ciertos riesgos. Este inconveniente pudo ser uno de los factores que animara a los pintores a abandonar estas operaciones en manos de fabricantes especializados. El peligro se conocía desde fechas muy tempranas y ya Cennini, a finales del siglo XIV, señalaba el riesgo de prender fuego a la casa durante la cocción del aceite. Las advertencias de este peligro, a principios de siglo XIX llegan a plantear escenas de terror en palabras de Pierre François Tingry (1816: 127 -128): "Geneva never reflects without terror on the fires which have taken place on different occasions, and on the misfourtunes which have thence resulted to individuals." Por eso produce cierta extrañeza no encontrar ninguna mención a este tema en las fuentes españolas decimonónicas.

\section{3•3. Vehículos Pictóricos}

Los términos vehículo o médium pictóricos hacen referencia a sustancias que se mezclan con los colores al óleo para modificar sus propiedades. En ocasiones pueden aparecer referidos como barnices. Estos se pueden componer de diferentes formas pero, por lo general, involucran a barnices, aceites y secantes de plomo. Las fuentes escritas demuestran que algunos de estos vehículos oleosos, apreciados por los pintores decimonónicos, causaron problemas en las pinturas. En cambio, los mediums de épocas anteriores se han comportado - por lo general - de manera estable. Una vez más queremos ahondar en la idea, ya esgrimida, que plantea la dificultad de lograr con los materiales decimonónicos, recursos pictóricos 
propios de la pintura de periodos anteriores. Por otra parte, Townsend et al. (1998: 209) llaman la atención sobre el compromiso que adquiere el restaurador que afronta la tarea de eliminar el barniz de una superficie pictórica rica en determinados mediums.

Pocas son las fuentes españolas decimonónicas que abordan el tema de los mediums pictóricos. Borbón (1860), Poleró (1886), L. Péant (1895) y Vibert (1908) son los únicos escritos que tratan este tema y son muy escasos los datos que aportan. También entre las patentes de invención de finales de siglo hemos encontrado algún documento interesante.

Borbón y Poleró aluden al controvertido megilp aunque no se refieren a el con esta denominación. Este vehículo alcanzó gran aprecio por parte de los pintores, especialmente entre los anglosajones de los siglos XVIII y XIX. El megilp era un tixotrópico que permitía a los pintores realizar tanto empastes como veladuras. Este vehículo estaba comúnmente compuesto por la mezcla de un aceite cocido con un secante de plomo al que se añadía barniz mástic. Ambas sustancias se agitaban y formaban un gel de fácil manipulación. Carlyle (2002: 104) comenta que la mayoría de fuentes inglesas del siglo XIX explican la preparación en frío del megilp y sólo algunos de estos tratadistas aportan instrucciones para elaborar el medium en caliente. Eastlake (1847: I, 540) cuenta que Sir Joshua Reynolds (1723 - 1792) cita esta mezcla en las notas que tomó hacia 1767 sobre sus materiales y procedimientos pictóricos: "Duchess of Ancaster, prima magilp, seconda olio, terza olio". Esta podría tratarse de una de las primeras referencias a este medium pictórico. El megilp, afirman Townsend et al. (1998: 205) estuvo disponible comercialmente hacia 1835 .

Las pomadas que describe Borbón (1860: 24) estaban compuestas por lo general “...de barniz de almáciga y de aceite de nueces ó de linaza cocidos con litargirio ó sal de saturno (protóxido y acetato de plomo)...”. El autor parece aludir al megilp marrón y al blanco o pálido que mencionan las fuentes inglesas (Carlyle, 2002: 103). El primero se confeccionaba empleando cómo secante del aceite el litargirio que es de color amarillo, mientras que en el 
segundo caso se utilizaba el acetato de plomo que es blanco. No obstante, las fuentes inglesas explican que el megilp pálido se elaboraba sin cocer el aceite, de esta manera el líquido no adquiría coloración rojiza que le confería la cocción. En definitiva, con todo este procedimiento se pretendía lograr un megilp muy transparente. Hay que tener presente que existió una gran variedad de recetas y procedimientos de elaboración de estas sustancias. Este punto ha sido demostrado por Carlyle en su admirable estudio de las fuentes inglesas decimonónicas ${ }^{23}$.

Townsend et al. (1998: 209) indican que los megilps de litargirio se usaban con las pinturas oscuras como el bitumé. En cambio, los megilps de acetato de plomo tendían a emplearse con los colores claros. Esto ha podido verificarse en algunas obras de Turner. El megilp ha sido estudiado por investigadores de la Tate Gallery y del Canadian Conservation Institute. Gracias a estos estudios se pudo identificar el megilp en algunas pinturas del mencionado pintor inglés. Incluso se pudo determinar que Turner prefería el megilp blanco para pintar los celajes y los resaltes blancos ${ }^{24}$.

Una formulación diferente podemos encontrarla en Poleró. Este autor se refiere a una suerte de vehículo elaborado con aceite de

23 Una de las variaciones que tuvo mayor éxito fue ideada por Ibbetson y se llamó Gumtion. Esta composición se elaboraba con resina de almáciga - no con barniz -, y aceite sin cocer. Ambos ingredientes se amasaban conjuntamente al acetato de plomo sin emplear calor (Carlyle, 2002: 107). La receta apareció por primera vez en la edición póstuma (1828) de An Accidence, Or Gamut of Oil Painting In Oil de Julius Caesar Ibbetson (Carlyle, 2002: 308).

24 Para ver los pormenores de esta interesante investigación: TOWNSEND et al.: (1998). Otros estudios interesantes sobre mediums pictóricos: TOWNSEND, J. H.: "Whistler Oil Painting Materials and Technique" en Burlington Magazine, Vol. 136, 1994, p. 694. COVE, SARAH: "Mixing and Mingling: John Constable's Oil Paint Mediums c. 1802-37, Including the Analysis of the 'Manton' Paint Box." Painting Techniques History, Materials and Studio Practice. Contributions to the Dublin Congress. London: The International Institute for Conservation of Historic ans Artistic Works, 7-11 September 1998. p. 211-216. TOWNSEND et al.: "Cobalt Blue, Emerald Green and Rose Madder in Copal-Based Mediums as Used by the Pre-Raphaelites" en Art Of the Past. Sources and Reconstructions. Proceedings of the 1st Symposium of the Art Technological Source Research Study Group. London: Archtype, 2005. 
nueces y barniz de almáciga. Sin embargo, este artista no aclara si el aceite está cocido - o mezclado - con un secante de plomo y según Townsend et al. (1998: 205), cuando un aceite sin secante se mezcla con barniz de almáciga no llega a adquirir un estado viscoso. Los compuestos plúmbeos son imprescindibles para lograr que la composición adquiera la consistencia de gel. No obstante, Poleró compara esta mezcla con el "medium inglés" haciendo referencia posiblemente al megilp.

El aceite de nueces, contando algún tiempo de embotellado, se enrancia, y, por lo tanto, es perjudicial su empleo. La manera de usarlo con reconocidas ventajas es mezclándole una corta cantidad de barniz de almáciga, con cuya mixtión se produce una especie de gelatina muy excelente para gastar los colores, y que al propio tiempo les comunica propiedades secantes no desatendibles. Una imitación de esto es el barniz medium inglés, que hoy emplean algunos artistas con provecho. (Poleró, 1886: 83)

El único autor español que menciona las proporciones empleadas en la composición de estas materias es Poleró (1886: 91) quien expresa que por medium se entiende “...una especie de gelatina compuesta de dos partes de aceite de linaza y secante y una de barniz de almáciga”. Townsend et al. (1998: 205) indican que en las fuentes inglesas anteriores a 1850, la relación más popular entre el aceite secante y el barniz era 2:1 seguida de la proporción 1:1. Después de esta 1850, la relación 1:1 es la que más consignan las fuentes británicas.

Como ya hemos insinuado, las recetas para elaborar mediums pictóricos fueron muy variadas. Entre las más habituales encontramos aquellas que sustituyen la almáciga por copal o ámbar y que, según Carlyle (2002: 104 - 105), recibían el nombre de Copal Megilp y Amber Megilp. También, entre los documentos del Archivo Histórico de la OEPM se halla una interesante patente, fechada en 1897, por "Un producto industrial titulado 'Medium Españoleto"”25

\footnotetext{
${ }^{25}$ Arcbivo Histórico de la OEPM. No de Patente 21804. Solicitado por Plácido Francés y Pascual.
} 
que sustituye la álmaciga por copal.

Por cuanto he leido y estudiado sobre la Escuela Española y el resultado que en la práctica he observado me han llevado á componer el líquido Medium, que así se llama, excelente para repintar sobre seco; es indudablemente el que se empleo por nuestros grandes maestros. Su composición esta reducida á la unión de tres sustancias que de no estar perfectamente puras y bien clarificadas dejaria mucho que desear bajo este concepto la unión del aceite de linaza, con el aguarras y la goma copal son los componentes á que queda reducida la composición del Medium Españoleto. (Archivo Histórico de la OEPM, 1897: No 21804)

Causa extrañeza la ausencia del secante plúmbeo en esta patente pues, como ya hemos indicado, esta materia es necesaria para formar el medium gelificado. Tenemos que señalar también qué el barniz de almáciga es otro ingrediente indispensable en estas composiciones. Según Carlyle (2002: 104-105), este matiz ya fue tratado por Field en la segunda edición de su Chromatography (1841). La investigadora indica que las escasas recetas de Copal Megilp que constan en las fuentes británicas incorporan tanto barniz de almáciga como de copal.

La experimentación propia de la época otorgó protagonismo a otras sustancias para la elaboración de vehículos oleosos. Carlyle (2002: 101) señala que para elaborar los mediums, se incorporaban al aceite una gran variedad se sustancias como huevo, almidón, resina, cera ${ }^{26}$, sílice, gelatina, bórax, etc. Una de estas variantes experimentales la encontramos en Borbón que propone una curiosa preparación del aceite de linaza que podemos asimilar con un medium oleoso. El autor asegura que esta mezcla es bastante secante y produce colores brillantes.

\footnotetext{
${ }^{26}$ Mérimée (1830: 65-66, 70) aporta varias fórmulas para elaborar barnices adecuados para mezclar con los colores. En algunas de ellas la cera es un ingrediente constituyente de las mezclas.
} 
De aceite, doce onzas; de esencia de trementina rectificadísima, onza y media; de disolucion de goma elástica ${ }^{27}$ otra onza y media. Podrán añadirse también de diez á doce gotas del barniz claro de resina copal dura de la India Oriental, como lo usan varios artistas en su práctica, para darle mayor solidez. (Borbón, 1860: 13)

Sin duda, recetas para la elaboración de vehículos pictóricos hubo muchas y muy variadas. De nuevo, el Archivo Histórico de la OEPM nos muestra una interesante patente que explica cómo fabricar un aceite secante con carácter de medium. Además, esta patente de invención registrada en La Habana (Cuba) en 1894 contiene el atractivo de mostrar el empleo de una substancia cultivada en la isla: el algodón.

Tomo aceite de algodón crudo según sircula [sic] en plaza 30 gramos. de colofonia de $1^{\mathrm{a}} 10$ gramos $=$ estas dos sustancias las incorporo por medio del calor en una paila de metal y despues de estar unidas y frias le agrego especifico cuanta de aguarras 1 gramo como materia secante $\mathrm{p}^{\mathrm{a}}$ la pintura. (Archivo Histórico de la OEPM, 1894: $\left.\mathrm{N}^{\mathrm{o}} 16355\right)^{28}$

El aceite de semillas de algodón se ha empleado especialmente en alimentación pero también en la elaboración de jabones y pinturas. La fórmula que presenta esta patente contiene un dato muy interesante: la resina se funde en el aceite. Este es un procedimiento de elaboración completamente diferente a los que hemos estudiado hasta el momento. Pero que, sin embargo, guarda concomitancias

\footnotetext{
${ }_{27}$ Carlyle (2002: 122) relata que Bachhoffner (Chemistry as Applied to The Fine Arts) probó el uso de la goma elástica (o caucho) como aglutinante pictórico y descubrió que permanecía en estado viscoso durante semanas. El caucho también se empleó en las preparaciones de los lienzos para conseguir mayor elasticidad del soporte (Ver 7.1). Esta substancia, según Tingry (1816), Bouchardat (1843 - 44), o Ruiz Miyares (1883), servía para moldear objetos, para telas y calzado impermeables, para las unturas de los barcos, etc.

${ }^{28}$ La patente fue solicitada por Bernardo Gonzalez é Iglesias “...para España Islas [ilegible] y Provincias de Ultramar..."
} 
con los métodos de elaboración de barnices para pintar de épocas anteriores. Señalamos también la ausencia de secantes metálicos en esta fórmula.

Los vehículos pictóricos como el megilp resultaban muy atractivos para los pintores. Una de las grandes virtudes de estas sustancias es que proporcionaban a la pintura una consistencia adecuada para ser manipulada. Los vehículos oleosos impartían transparencia a la pintura para enriquecer los colores y las sombras con veladuras. Además, incorporados a los colores opacos se conseguían semi transparencias. Otra de las cualidades que se encuentra descrita en algunas fuentes es su capacidad secante. Poleró señala otra de las aplicaciones de los mediums oleosos.

Si por efecto de correcciones que deban hacerse, por tener que borrar alguna parte de lo labrado ó por cambios necesarios haya que retocar lo hecho, para ver con más claridad y trabajar con acierto, deben humedecerse aquellas partes que lo requieran por medio del medium,... (Poleró, 1886: 91)

Lamentablemente, los megilps oscurecían, decoloraban y craquelaban la pintura arruinando en unos años la obra en la que se había utilizado. Por esto, la popularidad del megilp decreció notablemente durante las primeras décadas del siglo XIX; sin embargo muchos pintores siguieron utilizándolo atraídos por la maravillosa consistencia que otorgaba a los colores. Borbón expuso de una manera llamativa los desastres que causaban las pomadas en la pintura y además resalta que estas fueron sustancias ampliamente utilizadas por los pintores españoles.

...la resina de almáciga disuelta en la esencia de trementina... [mezclada] tambien con el aceite y otras materias para componer las pomadas, de que ha abusado la escuela de nuestros dias, ha producido tales daños que dificilmente pueden repararse, y así vemos, á cada paso, obras apreciabilísimas de nuestros artistas, envejecidas antes de tiempo, alteradas y expuestas á perderse 
prematuramente con estupor de sus mismos autores, y con general sentimiento de los amantes del arte. (Borbón, 1860; 7-8)

Una muestra de las críticas que recibieron los megilps desde las primeras décadas del siglo XIX ha sido claramente expuesta por Carlyle (2002: 105 - 106). Esta investigadora señala también la ambigua convivencia entre las opiniones opuestas sobre estos mediums. Por una parte, aquellos que insistían en los problemas que causaban los megilps y, por otra, aquellos que defendían sus maravillosas propiedades de manejo. Las apreciables cualidades de manejo de los megilps son incuestionables a juzgar por la amplia difusión que tuvieron y que atestiguan las fuentes escritas. Pero, si los vehículos oleosos se han empleado a lo largo de toda la historia de la pintura, ¿por qué sólo se reseñan inconvenientes en los mediums decimonónicos?.

El estudio de los mediums oleo resinosos es sumamente complejo. Pero podemos demostrar que los vehículos oleosos utilizados hasta el siglo XVIII se confeccionaban de manera diferente a los del siglo XIX a pesar de estar compuestos de manera similar. Eastlake (1847) y Merrifield (1849) estudiaron ampliamente los barnices empleados en pintura desde el siglo XII hasta el XVIII. El primero de los investigadores mencionados se centró principalmente en las prácticas flamencas, mientras que la segunda estudiosa abordó la praxis italiana. Ambas investigaciones, basadas fundamentalmente en fuentes escritas, evidencian la dificultad de interpretar algunos materiales o sustancias. A pesar de este considerable inconveniente, los resultados que aportaron resultan esclarecedores. Merrifield establece una clasificación de los barnices dependiendo de su estabilidad. Algunos de ellos se empleaban para barnizar las pinturas y para mezclar con los colores al óleo. Esta reflexión evidencia la abundante cantidad de recetas de barnices que existía.

The firmest and most durable varnishes were undoubtedly those composed of amber and oil; the next were those composed of other resins, such as sandarac, mastic, and pece Greca with oil, or of 
amber or copal dissolved in a balsam; and the last class, which consisted only of resins dissolved in essential oils, was decidedly the least durable. (Merrifield, 1849: I, cclxxiv)

La cualidad de estos barnices que se incorporaban a los colores - ya amasados con un aceite secante - puede apreciarse a través de diferentes recetas. Eastlake y Merrifield coinciden en la apreciación de que los vehículos que se mezclaban con los colores al óleo eran muy espesos por eso se añadían en muy poca cantidad. Una interesante receta del MS. de Estrasburgo [s. XV], transcrito y traducido al inglés por Eastlake, nos permite comprender cómo eran por lo general estos mediums.

Here I will teach how to make a good varnish of three materials_a good and superior varnish out of each of the materials separately. In the first place take $1 \mathrm{lb}$. of sandarac or of mastic, whichever you please, and pulverise it in a clean mortar. Then take $3 \mathrm{lb}$. of linseed oil, or hempseed oil, or old nut oil, and boil this in a clean vessel, skimming it and taking care, above all, that it does not run over. After it has boiled and has been skimmed [throw in and] stir the powdered resin little by little in the boiling oil: thus the powder dissolves in the oil. When it is quite dissolved let the varnish seethe gently with a moderate heat, stirring it continually that it may not burn; and when you find that the composition has become thick, like melted honey, take a drop of the varnish on a knife, and, after suffering it to cool a little, touch it and draw your finger slowly off; if the varnish strings it is well boiled, but if not, boil it better till it strings. Then take it from the fire and suffer it to cool; strain it through a strong piece of linen, wringing it through the cloth into a clean glazed vessel, and keep it well covered for use. Thus you have an excellent and clear varnish of the best kind. (Eastlake, 1847: I, 279-280)

El MS. de Estrasburgo contiene explicaciones de diferentes vehículos pictóricos que podían mezclarse con los colores. De la misma manera, Eastlake transcribe y analiza algunos pasajes del MS. 
Sloane que tratan sobre las prácticas pictóricas de algunos pintores de la corte inglesa del siglo XVII. De Mayerne, autor del mencionado manuscrito narra el empleo de vehículos de ámbar y aceite similares a los del MS. de Estrasburgo. El autor del MS. Sloane expone un vehículo oleoso similar al que empleaban Orazio Gentileschi y otros pintores para mezclar con los colores y para 'aceitar' la superficie seca:

The amber, re-dissolved in a powerful drying oil, was at first turbid, but it could be clarified with pulverised brick (as recommended by Rosello), and, when duly prepared, it was kept in Italy by all vendors of colours. (Eastlake, 1847: I, 303)

A diferencia de la fórmula extractada del MS. de Estrasburgo, esta de De Mayerne utiliza 'drying oil' que podemos interpretar cómo un aceite graso. El mismo autor dice: "The oils fit for making varnishes are nut oil and linseed oil. These are rendered drying with litharge, or, whichc is better, with calcined white copperas," (Eastlake, 1847: I, 312).

También el pintor italiano Armenini introdujo en De los Verdaderos Preceptos de la Pintura [1587] la forma de elaborar diferentes barnices o vehículos oleosos. Armenini [1587] (1999: 175) indica que estas sustancias necesarias se mezclaban con los colores para producir veladuras pero también se empleaban para reavivar zonas de la pintura ya seca. Por ejemplo, para mezclar con azules y lacas el pintor italiano sugiere una mezcla de almáciga y aceite de nueces. Esta composición se elaboraba en caliente y para otorgarle mayor brillo se podía añadir alumbre de roca quemado. Según Armenini, una de las grandes virtudes de esta mezcla era su rápida capacidad de secado. Otra de las mixturas indicadas por el artífice italiano se confeccionaba con almáciga y sandáraca a partes iguales. Estas materias se pulverizaban y se calentaban con aceite de nueces. Después de colar esta mezcla se añadía aceite de abeto. Las principales escuelas italianas - asegura Merrifield (1849: II, cclxxvi) - utilizaban los barnices en las veladuras y en los colores oscuros pero también en las preparaciones de los soportes. 
Para demostrar que en el siglo XVIII los barnices seguían mezclándose con los colores al óleo, Merrifield (1849: I, cclxxvii) narra una curiosa anécdota acaecida al 'Lo Spagnuolo' mientras pintaba el retrato del Cardenal Lambertini. Lo sucedido ocurrió en una fecha imprecisa entre 1717 y 1732. Luigi Crespi, uno de los hijos de Lo Spagnuolo estaba un día presente mientras el Cardenal posaba para su padre. Entonces, un hermano de Luigi entro en la estancia súbitamente con la carta de otro hermano que se encontraba en Módena. El Cardenal cogió la carta y le pidió al pintor que siguiera trabajando mientras el leía la epístola. El Cardenal inventó el contenido de la carta contando una historia en la que el hijo ausente se mostraba humillado y pedía el perdón de su padre por no evitar una promesa de matrimonio a una mujer llamada Apolonia. Lo Spagnuolo se levantó de un salto tirando al suelo todos los instrumentos y materiales de trabajo que incluían aceite y barniz y profiriendo todo tipo de exclamaciones. Según Merrifield, el hecho de que el pintor tuviera el barniz junto a la paleta mientras pintaba el retrato prueba que la sustancia se mezclaba con los colores. Por supuesto, el Cardenal trató de calmar al pintor pero el día de trabajo tuvo que concluir.

Insistimos en lo complejo de este tema por la amplia variedad de recetas y por la patente dificultad de interpretar los textos. Pero, sin duda, ha quedado demostrado que los vehículos oleosos utilizados hasta el siglo XVIII se confeccionaban por lo general fundiendo una resina en un aceite que podía haber sido previamente cocido con un secante. Esto es una diferencia fundamental con los mediums decimonónicos. Como hemos visto, estos se preparaban diluyendo la resina en un disolvente para confeccionar un barniz que luego se mezclaba con un aceite graso. Pero en el siglo XIX podemos encontrar ciertas excepciones que indican también estas elaboraciones en las que la resina se funde y disuelve en el aceite. Dos casos señalados son Tingry (1804: 87) y Mérimée (1830: 70). Tal vez, la forma de elaboración predetermina el posterior comportamiento de la mezcla. De esta forma, según las fuentes, el vehículo oleoso preparado mediante fusión de la 
resina en aceite es más estable que el resultante de mezclar en frío barniz con aceite graso.

\subsubsection{Mediums Comerciales}

A pesar de que algunas fuentes explican la manera de preparar vehículos pictóricos, muchos de ellos estuvieron disponibles comercialmente antes de que el siglo XIX alcanzara su meridiano. Podemos encontrar en el catálogo de L. Péant é Hijos ejemplos de estas substancias que se comercializaban en España a finales de la centuria. L. Péant é Hijos (1895) ofertaba varios vehículos oleosos para mezclar con los colores pero presenta un silencio abismal sobre la composición y procedimientos de elaboración de los mediums que anuncia. Aunque no aporta la composición de estas sustancias es probable que algunas de ellas estuvieran compuestas por un aceite graso y barniz a modo de megilp. Entre los productos que ofrece este comerciante de materiales artísticos hallamos anuncios interesantes.

\section{MEDIUM PARA PINTAR AL ÓLEO}

$\mathrm{DE}$

REEVES \& SONS

Este medium, mezclado á los colores, aumenta su brillantez y su fijeza y los hace secar con mucha rapidez.

\section{BARNIZ CRISTAL EN TUBOS SE MEZCLA Á LOS COLORES AL ÓLEO PARA DISMINUIR SU INTENSIDAD}

(L. Péant, 1895: I, 6)

Estas pastas se suministraban en tubos de diferentes tamaños al igual que los colores al óleo. El primer catálogo en el que Reeves \& Sons anuncia megilp en tubo - informa Carlyle (2002: 105) - data de 1856. Catálogos posteriores de este comerciante advierten del megilp en botes y del megilp copal en tubo y en bote (Carlyle, 2002: 395). 


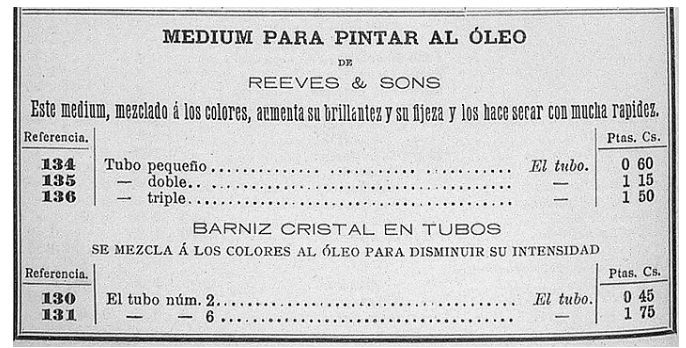

Fig. 26. L. Péant é Hijos: Catálogo General de Colores Extrafinos, Barnices, Aceites, Secantes (1893-1895). Mediums.
Otros proveedores como

Winsor \& Newton, Rowney o Roberson también anunciaban la venta de mediums desde sus primeros catálogos fechados antes de la mitad del siglo XIX.

L. Péant é Hijos (1895: I, 9) también tenían a disposición de sus clientes una "POMADA PARA RETOCAR" en tubo o

en frasco cuadrado. Pero, lamentablemente, tampoco aporta ninguna clase de dato sobre su composición o elaboración. Estos comerciantes muestran en su catálogo de 1895 otros barnices apropiados para mezclar con los colores. En este caso, son pastas elaboradas bajo las indicaciones de Vibert para Lefranc \& Cie: el barniz para pintar y el barniz para retocar. La única indicación sobre su composición que aparece en el catálogo español es que contienen petróleo. No obstante, Les Couleurs et les Vernis de J.-G. Vibert editado por Lefranc \& $\mathrm{C}^{\mathrm{ie}}$ en 1892 aporta algunas explicaciones sobre la elaboración y composición de estos barnices. Según estas enseñanzas, los barnices preparados bajo las indicaciones de Vibert se confeccionaban con resinas naturales. Pero como las resinas naturales contenían muchas impurezas, éstas debían ser eliminadas, al igual que las partes acuosas y los aceites esenciales que contienen. Las resinas empleadas en los barnices de Vibert eran además privadas de cualquier parte alterada que pudiera dar malos resultados. Lefranc \& $\mathrm{C}^{\text {ie }}$ aclaran que:

De plus, les résines que doivent entrer dans la composition des vernis destinés à être mélangés aux couleurs étant solubles dans l'huile à froid, s'y incorporent complètement et les rendent ainsi plus solides et plus éclatantes. (Lefranc \& $\mathrm{C}^{\mathrm{ie}}, 1892:$ 30)

Por su parte, Vibert (1908: 131) dice sobre la composición de los barnices que deben componerse con "resina normal". Este dato tampoco esclarece los verdaderos ingredientes y procedimientos de 
elaboración de los mencionados barnices. Pero el artista francés aclara que la resina constituyente de los barnices tenia que ser “...incolora, dura, cristalizable, absolutamente transparente, soluble en frío en el aceite y en el petróleo...”. Vibert (1908: 134-135) también señala los graves inconvenientes de las sustancias que se añaden a la pintura - barnices, pomadas y secantes - porque ennegrecen e introducen en la pintura materias frágiles y quebradizas.

El barniz para pintar y el barniz para retocar elaborados bajo las indicaciones de Vibert tenían cualidades diferentes pero los mismos usos que hemos estudiado en los megilps. Según la explicación del catálogo de L. Péant é Hijos, (1895: 55) el "BARNIZ PARA PINTAR" se mezclaba con los colores para conferirles mayor fluidez y untuosidad. Esta pasta retardaba el secado de los colores al óleo por lo que el pintor podía trabajar más tiempo la pasta pictórica tierna. Vibert (1908: 133) explica también que este barniz se ponía en el pocillo de la paleta y se mezclaba con los colores. Era de gran utilidad para las veladuras y para retocar zonas de pintura aún frescas.

Por el contrario, el "BARNIZ PARA RETOCAR" secaba en pocos minutos y era apropiado para eliminar los embebidos ${ }^{29}$ de la pintura. Este barniz también podía mezclarse con los colores otorgándoles más brillo y solidez. El anuncio de L. Péant é Hijos (1895: 55) advierte que este barniz hace más fluidos los colores “...pero una vez evaporado el petróleo, toman una consistencia más espesa, pero no viscosa." Vibert (1908: 132) comenta que esta masa es útil para veladuras rápidas pero no es apta para los empastes. Una de las grandes ventajas de este barniz de retoques estriba precisamente en su rapidez de secado. Según Lefranc \& $C^{\text {ie }}$ (1892: 32), si se añadía gran cantidad del barniz de retocar de Vibert al color para elaborar una veladura, ésta secaba casi instantáneamente y se

${ }^{29}$ Para eliminar los embebidos, Vibert (1908: 125) alude también al barniz Sohné. Pero según este artista el barniz Sohné es muy pernicioso para la pintura porque está compuesto por goma laca que es insoluble en el aceite. De esta manera los estratos pictóricos forman “...una especie de hojaldre...” muy frágil. Algarra (1875: 184) alude únicamente al empleo de barniz Soehnée como barniz final para pinturas al óleo otorgándole resultados óptimos. 
podía repintar encima de manera inmediata. Conforme a las explicaciones de Lefranc \& $\mathrm{C}^{\mathrm{ie}}$ (1892), ambos barnices, de retocar y pintar, podían mezclarse para acomodar los tiempos de secado de la pintura al gusto y necesidades de trabajo del pintor.

Le Vernis à retoucher représentant le degré de sicativité le plus rapide et le Vernis à peindre le plus lent, il est possible d'obtenir tous les degrés intermédiaires en mélangeant les deux vernis dans toutes les proportions que l'on désire pour la commodité de l'essication. (Lefranc \& C $\mathrm{C}^{\mathrm{ie}}, 1892: 33$ )

Como hemos visto a lo largo de este capítulo, los aglutinantes y vehículos pictóricos que tenían a su disposición los pintores del siglo XIX eran variados. En una misma obra el pintor podía emplear varios aceites y mediums pictóricos pero era importante que supiera emplearlos adecuadamente porque la estabilidad de la obra dependía en parte de ello. 


\section{Secantes y Secativos}

La capacidad secante de los óleos puede acelerarse con compuestos metálicos. Estos al incorporarse al aceite incrementan la polimerización favoreciendo el secado. Como hemos visto, los secantes se utilizaban en la elaboración de los aceites grasos y de los vehículos oleosos. (Aunque en este ultimo caso, las resinas también aportaban su capacidad secante a la masa.) Además, los secantes servían para constituir los llamados secantes de paleta o secantes en pasta. Estas mezclas se confeccionaban amasando aceite con una materia secante y adquirían un carácter cremoso.

Las fuentes españolas decimonónicas muestran cierta preferencia por los compuestos plúmbeos para la elaboración de los aceites grasos. El litargirio es el compuesto más citado; generalmente acompañado de otros secantes pero también como único secante en la composición de los aceites litargiriados. El minio también es un secante bastante mencionado en las fuentes para la elaboración de estos aceites. Mucho menos aludidos son el albayalde, la azúcar o sal de Saturno (acetato de plomo) o el vidrio molido; y aún menor presencia tiene la caparrosa o vitriolo blanco (sulfato de zinc).

En cambio, los textos muestran otras preferencias para elaborar los secantes de paleta. Para los colores claros se indican pastas secantes compuestas por vidrio molido o caparrosa y para los colores oscuros se sugiere el empleo de secantes elaborados con cardenillo o esmalte. De manera excepcional y dudosa aparece una referencia al minio. Las preferencias de los tratadistas españoles a la hora de elegir los secantes son diferentes a las predilecciones que muestran los textos ingleses. Carlyle (2002: 41) asegura que en las fuentes inglesas los materiales secantes mas comunes son el litargirio, el azúcar de plomo y el sulfato de zinc. Con menos asiduidad aparecen mencionados el albayalde y la tierra sombra.

Todos los compuestos secantes mencionados hasta ahora son materiales tradicionalmente empleados en la pintura. Pero en el siglo XIX se popularizó el uso del manganeso y del cobalto aunque sobre este último aún hay grandes lagunas. Se considera que algunas 
tierras y vidrios empleados tradicionalmente como secantes ejercían una función secante debido a su contenido en manganeso. Podemos encontrar alusiones al manganeso como secante de pintura desde las primeras décadas del siglo XIX. Sin embargo, asegura Carlyle (2002: 48) que este material no se adoptó hasta que se incentivó la retirada de los secantes de plomo. El empleo del manganeso aparece de manera muy escasa en las fuentes españolas.

En el último tercio del siglo XIX, se popularizó un nuevo aditivo: el secativo. Carlyle (2002: 48) asegura que Field ${ }^{1}$ utilizó en 1835 el término secativo como sinónimo de secante y después de la mitad del siglo, el 'siccatif' apareció como un producto separado en los catálogos de los comerciantes de colores. Los secativos que alcanzaron mayor renombre fueron los de Harlem y de Courtai; ambos fueron difundidos ampliamente y aparecen mencionados con asiduidad en las fuentes de finales de siglo.

Las combinaciones del aceite con compuestos metálicos pueden llegar a producir alteraciones en las pinturas. Los compuestos de plomo y zinc empleados como secantes o pigmentos reaccionan con los ácidos grasos de los aceites formando jabones metálicos. Katrien Keune (2005: 114) ha explicado los fenómenos, asociados al exceso de jabones metálicos, que se producen en la pintura. Se puede originar un incremento de la transparencia de los estratos pictóricos, protuberancias en las capas, aumento de la fragilidad de los estratos y eflorescencias.

\footnotetext{
${ }^{1}$ FIELD, GEORGE: Chromatography; or A Treatise on Colours and Pigments, and of their Powers in Painting. London, 1835.
} 


\subsection{Pastas Secantes}

Las pastas secantes - como hemos indicado - son mezclas de aceites y materias secantes con una consistencia cremosa semejante a la de un color al óleo. Palomino [1715 - 1724] (1988: II, 141) explica que estos secantes se pueden guardar "...como las colores, que dijimos, en vejigas, e irlo sacando, y poniéndolo en la paleta, cuando sea menester." Estas pastas secantes se mezclaban con los colores ya preparados en la paleta y eran útiles para los pigmentos con escasa capacidad secante. Algunas fuentes decimonónicas atestiguan el uso de estas pastas; Soler y Ferrer (1837), De la Roca (1880) o López Tomás (1898) aportan información sobre esta clase de substancias. También el catálogo de L. Péant é Hijos (1895) ofertaban pastas secantes.

Los secantes de paleta podían componerse según el color cuyo secado quería acelerar el pintor, es decir, se podían componer secantes para los colores claros, para los oscuros o para los azules. Por ejemplo, Soler y Ferrer (1837) proponen un secante claro confeccionado con materias que otorgaban poca coloración a la mezcla.

No será tampoco fuera del caso tener molidos y guardados como los demás colores algunos secantes en pasta para poner en la paleta, y son de escelente recurso para todos ellos: son los mas á propósito el de vidrio muy bien molido, caparrosa, ó vitriolo, templados y molidos en pasta espesa como los demás colores, usándolos y agregandolos á ellos en muy poca cantidad, segun se haga preciso. (Soler y Ferrer, 1837: 60)

De la Roca y Delgado (1880: 278) también expone que para todos los colores es útil la pasta elaborada con vidrio molido y aceite de linaza o nueces. Un secante similar puede elaborarse con caparrosa “...como un color al óleo y usar de él, poniéndolo en la paleta, á que podemos añadir la piedra alumbre quemada y después molida con el aceite de linaza...". Aunque el autor reconoce no haber empleado jamás esta mezcla. 
Los secantes en pasta para colores oscuros se componían con otros compuestos metálicos. Así, De la Roca (1880: 278) transcribiendo a Palomino - indica que el cardenillo (acetato de cobre $)^{2}$ molido al óleo es especialmente bueno para carmines y negros “...porque en los demás colores sería perjudicial”. Aunque advierte que es necesaria cierta precaución en el uso de los secantes porque un exceso de estos podría perjudicar al color con que se mezcla. Finalmente, este autor incluye una pasta secante útil para el ultramar y el añil que está formada por "...esmalte remolido con aceite de nueces..." (De la Roca y Delgado, 1880: 279). El esmalte es un pigmento metálico - óxido de cobalto - con sutiles propiedades secantes.

Los datos que aporta López Tomás (1898: 50) son algo confusos, este pintor recomienda el secante elaborado con linaza revuelto con azarcón para ayudar en el secado del amarillo de cadmio. Sin embargo, como ya hemos indicado (Ver 3.2.3), no podemos precisar si se trata de un aceite graso o un secante de paleta. También los comerciantes suministraban pastas secantes; así podemos verlo, a finales de siglo, ofertado por L. Péant é Hijos.

\section{PASTA SECANTE DE J. G. VIBERT}

La PASTA SECANTE se añade á los colores cuando se desea aumentar la sicatividad, sin cambiar, aun momentáneamente, su consistencia. No debe introducirse la PASTA SECANTE en los colores á medida que se pinta, con el pincel, pues así se mescla desigualmente, pero se mezclará con el cuchillo sobre la paleta, en la proporción deseada. (L. Péant é Hijos, 1895: I, 58)

\footnotetext{
${ }^{2}$ Las propiedades secantes del cardenillo se han aprovechado tradicionalmente en la pintura al óleo. Cennini [s. XIV] lo menciona como secante de mordientes. Armenini [1587] y De piles [1766] lo recomiendan para el negro, mientras que Volpato [h. 1680] sugiere el uso del cardenillo para ayudar al secado del negro y el asfalto. Palomino [1715-1724] lo aconseja para negro y carmín. El único tratadista decimonónico que lo menciona - al igual que el esmalte - es De la Roca y Delgado. Como sabemos, este autor transcribe a Palomino y la omisión en otras fuentes españolas del siglo XIX nos lleva a pensar que estas mezclas ya no se empleaban en la mencionada centuria.
} 
PASTA SECANTE DE J. G. VIBERT Referencia. 128
129 SECANTE se añade á los colores cuando se desea aumenta debe introducirse la PASTA SECANTE en los colores a medida que pinta, con el pincel, pues asi se mescla desigualmonte, pero se mercla

Fig. 27. L. Péant é Hijos: Catálogo General de Colores Extrafinos, Barnices, Aceites, Secantes (1893-1895). Pasta Secante.

estos fabricantes aseguran que:
Esta pasta secante comercial, a diferencia de las otras, era útil para todos los colores ya fueran claros, oscuros o azules. La única aproximación a los componentes de esta pasta secante de Vibert la hallamos en Lefranc \& Cie (1892: 37),

La Pâte siccative qui a les mêmes principes chimiques que le Siccatif de Courtrai en a les mêmes effets, mais ne contenant ni Essence de térébenthine ni impuretés, elle n'en a pas les inconvénients. (Lefranc \& $\mathrm{C}^{\mathrm{ie}}$, 1892: 37)

Una de las grandes incomodidades creadas por los fabricantes y comerciantes de colores estriba en que omitieron, en su mayoría, la composición de los productos que vendían. Esta preocupación en lo referente a los secantes fue tratada por Emilio Sala.

...pues el que emplee secantes, si de antemano no conoce la preparación ó base que ha de sustentar su pintura, se expone á que ésta se altere, y todavía más, á que se cuartee. (Sala, 1896: XLII, 294)

En las fuentes inglesas aparece también referenciado un secante en pasta aunque no aparece referido con esta denominación. El azúcar de plomo en tubo era suministrado entre los colores al óleo (Ver 4.3) por algunos comerciantes ingleses; lo que indica que se trataba de un secante de paleta. 


\subsection{Secativos}

Las pastas secantes y los aceites grasos, como hemos visto, están formados por mezclas de aceite y compuestos metálicos. Los primeros tienen una consistencia cremosa mientras que los segundos son - por lo general - más fluidos. En el último tercio del siglo se popularizó el secativo que, según Carlyle (2002: 48) apareció como un producto diferente de los secantes en los catálogos de los comerciantes de colores a finales del siglo XIX. Los secativos Courtrai y de Harlem - Siccatif de Courtrai, Siccatif de Harlem fueron los más populares durante ese periodo.

Nuestras fuentes decimonónicas se refieren a estas substancias como secantes. Por ejemplo, Poleró elabora la siguiente reflexión:

Todo género de secantes tiene por base el aceite de linaza, y alguna vez el de nueces, mezclándoles ciertas materias secantes, con las que después toman las denominacion de aceite graso, inglés, courteay, Arlem, etc. (Poleró, 1886: 83-84)

En L. Péant é Hijos (1895: I, 11) podemos leer "SECANTE DE COURTRAI" que se vendía en frasco o tubo. También las traducciones al español de los textos franceses aluden a estas sustancias como secantes. Bellanger (1899: 216) entre las herramientas del pintor cita "Secante de Courtrai ó de Harlem". En Vibert (1908: 116 y 128) leemos "...secante de Curtray y secante de Harlem”. En cambio, en el siglo XX el término secativos se impuso.

Todo parece apuntar a que estamos ante una rimbombante denominación comercial: siccatif, siccative, secativo. Sin embargo, si analizamos los datos de las fuentes, encontramos algunas características que podrían llevarnos a pensar que los secativos son un tipo de secante diferente al tradicional. Hasta ahora hemos visto que los artistas preferían que sus aceites grasos fueran claros especialmente si iban a utilizarse con azules y blancos. En cuanto a los secantes en pasta, aquellos que se elaboraban con pigmentos 
oscuros - como el cardenillo - se mezclaban con colores también oscuros cuyo matices no se vieran afectados por el secante. También hemos visto el secante azul elaborado con esmalte que era útil para los pigmentos azules. Digamos que estos secantes se confeccionaban tradicionalmente dependiendo del pigmento que iba a ser empleado. En cambio, los secativos eran productos destinados a todos los colores sin diferencia y eran señaladamente oscuros y muy fluidos.

El carácter líquido de los secativos era debido - según Vibert - al elevado contenido de esencia ${ }^{3}$ entre sus ingredientes. La fluidez de esta materia constituía un riesgo porque los pintores podían abusar de ella lo que podría causar problemas en la pintura. Para Vibert (1908: 128) los secativos son falsos secantes que en realidad no secan los colores al aceite. "Parece que los seca porque la esencia de espliego se evapora en seguida, pero introduce también en la pintura una materia extraña que no forma cuerpo con ella...”.

Ralph Mayer (1993: 262) dice que los secativos de Haarlem y de Courtrai se elaboran hirviendo resinatos de plomo y manganeso en aceite. Este autor advierte que con el tiempo los ingredientes de esta mezcla se vuelven negros. La inclusión de resina en la composición de los secativos constituye una diferencia sustancial con los aceites grasos y los secantes en pasta. Las fuentes aportan escasos datos sobre estas substancias, y sólo se ha podido confirmar que la resina era un componente del Secativo de Harlem. Podemos corroborar esto en La Ciencia de la Pintura de Vibert.

Cuando el copal ha perdido de esta suerte la décima parte de su peso, puede disolverse en la esencia de espliego: constituye entonces el copal á la esencia, que forma la base del secante de Harlem (que sería inútil buscar en dicha ciudad). (Vibert, 1908: 128)

También Church en la segunda edición de su obra The Chemistry of

\footnotetext{
3 Vibert, (1908: 118) aconseja que el secativo Curtray se fabrique con esencia de petróleo. Este pintor (Vibert, 1908: 111 - 114) esgrime varios argumentos en favor de la esencia de petróleo frente a la esencia de trementina.
} 
Paints and Painting 4 (1892) indica que el secativo de Harlem contaba con resina entre sus ingredientes. La misma afirmación consta en la cuarta edición de la obra:

Siccatif de Haarlem (sic) is a resinous preparation, which produces, on drying, a hard, brilliant and tough film. This acquires, in course of time, a deep yellow hue, which, however, hardly affects the colour of the paints with which the siccative has been employed, because of the small proportion used. (Church, 1915: 129)

Vibert (1908: 117) asegura que esta sustancia podría elaborarse químicamente pura para que tuviera menos color y además podría fabricarse en pasta. Así, en el catálogo de L. Péant e Hijos (1995: I, 11) encontramos que el secante de Courtrai se vendía tanto en frascos como en tubos, lo que indica que se comercializaba líquido y en pasta. Según Carlyle (2002: 48), los secativos de Harlem y Courtrai ya aparecen mencionados en documentos comerciales de Roberson en 1858. Y diferentes comerciantes ofertaban secativos en sus catálogos: Rowney desde 1860 y Reeves desde 1878; y Winsor \& Newton ofrecían "Siccatif de Harlem (Duroziez's) en su catálogo de 1883. Vibert, que confiaba poco en los comerciantes de colores, describía las manipulaciones que los tenderos hacían de los secativos:

La verdad es que la mayor parte de los tenderos no fabrican ellos mismos el secante y que la mayor parte no sabe como se hace. Se contentan con exigir que sea muy negro (esto es absurdo, pero muy exacto), de suerte que el fabricante que podría, con cuidado, fabricar un producto mejor, tiene toda la libertad para dejar todas las impurezas, y aun no son éstas suficientes para darle color á su producto, pues siempre tiene que agregarle negro de humo.

Los vendedores de colores reciben este secante en latas y se contentan con ponerlo en botellitas, lo más chiquitas posible, Los

\footnotetext{
4 CHURCH, SIR ARTHUR H.: The Chemistry of Paints and Painting. London, 1890. 2nd: 1892; 3rd: 1901; 4th: 1915 .
} 
que son más honrados (hay algunos) antes de ponerlo en botellas, esperan algún tiempo para que se aclare, pero de esta suerte queda en el fondo un poso bastante abundante, y es preciso tener mucha conciencia para consentir semejante pérdida. (Vibert, 1908: 117)

Los secativos están envueltos en una gran controversia que sólo los análisis químicos de las sustancias podrían aclarar. Los datos que expone Carlyle aportan aún más confusión sobre los secativos del siglo XIX. Esta investigadora transcribe un extracto de un catálogo de Lechertier Barbe \& Company datado en 1879 que otorga al secativo de Harlem usos muy diversos e inesperados:

"Durozier's siccatif de Harlem is a substitute for drying oils and salts of lead, which are commonly used as dryers. It is mixed with the colours on the palette in every proportion, in its pure state, or diluted in oil when it is required to retard the drying up, and in turpentine when required to accelerate it. It preserves the tints, prevents the sinking-ing or makes it disappear; it prevents also the cracking, and is used to retouch and restore pictures. It gives body to the colours, and makes them keep their place. Mixed with turpentine, it is employed for glazing, and also to varnish paintings over." (Carlyle, 2002: 49)

\subsection{Materias Secantes}

Los compuestos metálicos tienen la capacidad de acelerar la polimerización de los aceites. Como hemos visto, estas materias son necesarias para la formación de los aceites grasos, de los secantes de paleta y de los secativos. En las fuentes españolas decimonónicas, los compuestos metálicos más citados para acelerar el secado de las pinturas son los óxidos de plomo. Chaptal decía que estos óxidos se prefieren sobre los demás porque: 
...el aceite adquiere la propiedad de secarse mas pronto, y de formar un barniz; y ademas de esto se espesa hasta volverse consistente, si se carga demasiado de oxide. El aceite toma una parte del oxígeno del plomo, y disuelve una porcion del mismo óxide: por medio de este se espesa hasta formar un cuerpo semejante á los preparados farmacéuticos llamados emplastros y el oxígeno le hace consistente y algo parecido á las resinas. Por estas dos propiedades de los óxides de plomo, son preferidos estos á todos los demas. (Chaptal, 1816: III, 263)

Pero de todos los óxidos plúmbeos, el que parece tener más importancia entre nuestros tratadistas decimonónicos es el litargirio o monóxido de plomo amarillo. Esta materia aparece sola o en combinación con otras sustancias en las recetas y fórmulas que proponen Desmarest (1828), Soler y Ferrer (1837), Riffault (1850), De la Roca y Delgado (1880), Poleró (1886) y López Tomás (1898). El minio o tetróxido de plomo se encuentra entre las materias secantes mencionadas por De la Roca y Delgado (1880), Poleró (1886) y López Tomás (1898).

Otros compuestos de plomo aparecen citados aunque con menor asiduidad. Así, De la Roca y Delgado, y Poleró aluden al albayalde y al vidrio molido. Esta última materia ejercía una acción secante sobre los aceites debido a su contenido en plomo, manganeso o ambos. Menor importancia pareció tener la Sal de Saturno (acetato de plomo) que únicamente es aludido por Soler y Ferrer (1837). Entre los secantes no plúmbeos, pero de gran tradición para la elaboración de aceites grasos y barnices, encontramos la caparrosa o vitriolo blanco (sulfato de zinc) mencionada por Soler y Ferrer y en López Tomás.

Los escritos de pintores españoles del siglo XIX apenas aportan explicaciones sobre los agentes secantes, éstos textos sólo explican cómo emplear los compuestos metálicos para elaborar las recetas que refieren. Debemos dirigirnos especialmente a las fuentes secundarias para encontrar documentación de la época que aborde las materias secantes. 
La substancia plúmbea más importante en las fuentes españolas decimonónicas es el litargirio o monóxido de plomo $(\mathrm{PbO})$. Este se elabora mediante la oxidación del plomo fundido; lo que produce una materia vitrificada o cristalizada. Chaptal (1816), Riffault (1850) y Bouant (h. 1888) indican que la forma más habitual de elaborar este material era en los procesos de separación de la plata del plomo5 ${ }^{5}$. Desmarest explica de forma muy clara el principio y el proceso de copelación para separar el plomo de la plata.

La copelacion está fundada en la inalterabilidad de la plata; la mina de plomo que contiene plata, quebrantada, tostada y despojada de sus soroque, se mete en una copela grande en un horno conveniente, en el cual hay un fuego vivo. El plomo oxidado se funde y sobrenada, la plata como menos fusible queda en el fondo en estado metálico: "por una disposición particular del horno, pasa el óxido de plomo, líquido, á un depósito donde cristaliza y forma el litargirio.” (Desmarest, 1828: II, 5)

Algunos tratados de química exponen otra forma de elaborar el litargirio que consiste en precipitar un polvo blanco mezclando una sal de plomo con una disolución alcalina. Este polvo se calienta para obtener el litargirio. Varios son los químicos que hacen referencia a este sistema de fabricación del litargirio: Desmarest (1828), Bouchardat, (1845) y Bouant (h. 1888). Una vez más, el más explícito es Desmarest:

Se obtiene tambien, preparando una disolución de nitrato de plomo, y descomponiéndola con un exceso de carbonato de potasa; se precipita un polvo blanco, que si se seca y se calienta hasta cerca del rojo moreno, toma un color amarillo. Este óxido se conoce en el

\footnotetext{
5 Chaptal (1816: II, 260-261) explica la forma de preparar el horno para la copelación del plomo y cómo proceder durante el proceso. Este químico asegura que en Inglaterra la fabricación de litargirio alcanzó mayor perfección debido al uso de un combustible que da mucho calor y produce poco humo.
} 
comercio con el nombre de litargirio, "cuando está cristalizado en láminas amarillentas; y contiene siempre entonces una corta cantidad de ácido carbónico”. (Desmarest, 1828: I, 404-405)

Las fuentes describen dos tipos de litargirio según su color: de oro y de plata. El primero tiene un matiz rojizo mientras que el segundo es pálido. Riffault (1850: 177) asegura que la única diferencia entre ambos consiste en el grado de fusión. El litargirio de oro se ha fundido de forma mas imperfecta y “...se ha enfriado en masa..."; en cambio, el litargirio de plata ha sufrido un mayor grado de calor y se "...ha desparramado y corrido en forma de pajillas...”

El monóxido de plomo forma también otro compuesto: el massicot que es de un amarillo más pálido que el litargirio. Pero el massicot, a diferencia del litargirio, no está vitrificado. Se obtiene con facilidad calcinando suavemente el blanco de plomo en contacto del aire. Riffault (1850: 39) asegura que el massicot se empleó mucho en la pintura en otros tiempos. Según este autor en el comercio se distinguían tres suertes de este material: blanco, amarillo y dorado. Estos diferentes matices amarillos se obtenían como resultado de los diversos grados de calor a los que se sometía el albayalde. El massicot se conoce también bajo la denominación de cerusa calcinada (Riffault 1850: 39).

El minio - tetróxido de plomo $\left(\mathrm{Pb}_{3} \mathrm{O}_{4}\right)$ - es otro de los compuestos de plomo que aparece mencionado con abundancia en las fuentes españolas decimonónicas. Es de color rojo anaranjado por lo que algo de coloración tenía que impartir a los aceites con que se mezclaba. Tal vez, por este motivo el minio no comparece en las fuentes inglesas del siglo XIX. Este material ${ }^{6}$ podía obtenerse de diferentes formas. Los procedimientos más sencillos consistían en calentar a $480^{\circ} \mathrm{C}$ el albayalde ${ }^{7}$ o el massicot. Bouchardat (1845: 274-

\footnotetext{
${ }^{6}$ Chaptal (1816: III, 254) en Química Aplicada al Arte asegura que a pesar de que ingleses y holandeses habían hecho un secreto de la elaboración del minio, en Francia ya se elaboraba exitosamente.

7 Este procedimiento aparece reseñado en fuentes tan antiguas como Teófilo [siglos XI-XII] y Pietro di Sant'Audemar [Siglos XIII-XIV].
} 
275) o Mérimée (1830:123) - comentan estos procedimientos. Pero según Mérimée, el minio obtenido mediante la calcinación del albayalde es más claro y brillante.

Desmarest (1828: I, 405) describe la fabricación de esta materia a partir del litargirio aunque Bouant (h. 1888: II, 526) indica que el litargirio difícilmente puede llegar a convertirse en minio. Sin embargo, Gettens y Stout (1966: 152) señalan que el rojo de plomo se puede lograr mediante la calcinación del litargirio o el blanco de plomo. Harley (1982: 123) asegura que durante el siglo XVIII el rojo de plomo se obtenía en el Condado de Flintshire (Gales del Norte) calcinando el litargirio. Mientras que en el Condado de Derbyshire (Inglaterra) se elaboraba mediante la calcinación directa del metal de plomo ${ }^{8}$.

Esta forma de producir el minio o rojo de plomo mediante la incineración directa del metal plúmbeo fue tratado por Chaptal (1816), Riffault (1850) y Bouant (h. 1888) aunque las explicaciones resultan muy confusas. Chaptal (1816: III, 255) indica que la elaboración del minio se realiza con 10 panes de plomo de 150 libras 9 cada uno. De estos panes, 9 deben ser de plomo puro fundido en horno de reverbero y uno del producto de la fundición de las escorias del plomo. Los autores resultan muy confusos en la identificación del producto que se obtiene de la calcinación y fusión del plomo: no hay mucho consenso en el reconocimiento del massicot y el litargirio. Pero podemos encontrar descripciones e indicaciones de los hornos de reverbero y otra maquinaria útil en estos procesos. Por ejemplo, Bouant (h. 1888: II, 526) señala el empleo de muelas para triturar el massicot antes de la segunda calcinación.

También Chaptal expone una forma de elaboración del minio en que la materia, tras la primera calcinación, debía molerse a través de un sistema de seis rodillos. La obra de Chaptal fue publicada por primera vez en 1807; momento en que se estaba experimentando con

\footnotetext{
${ }^{8}$ West Fitzhugh (1986: 121) indica que en la Antigüedad Clásica el minio se elaboraba a partir del blanco de plomo pero en el siglo XV en Alemania comenzó a prepararse partiendo del metal plúmbeo.

9150 libras equivalen a 68,0388 kg.; entonces, Chaptal está dando indicaciones para elaborar más de $600 \mathrm{~kg}$. de minio.
} 
rodillos para la molienda de todos los colores. La investigación para conseguir eficientes aparatos para la molienda de los pigmentos aún se prolongó hasta la década de 1830 y principios de la década de 1840. (Ver II.2.)

Se colocan paralelamente en un mismo nivel dos cilindros, uno de hierro pulido, y otro de madera dura: estos cilindros pueden apartarse ó acercarse uno á otro mediante dos fuertes roscas: debajo de ellos hay otros dos construidos de la misma manera; y debajo de los segundos otros dos de madera dura. Estos tres órdenes de cilindros colocados unos sobre otros tienen encima una tolva, en la cual se pone el minio: este pasa por entre todos los cilindros, y cae en una caja puesta en la parte inferior. Un mismo mecanismo da movimiento á todos estos cilindros, ó á este triple castillejo. Todo el aparato está cubierto de mampostería, ó de tablas bien unidas. El movimiento le recibe de á fuera por un manubrio, de modo que nada se desperdicia, y que las emanaciones no perjudican á la salud de los operarios. Es facil entender que la separacion entre los dos cilindros superiores debe ser mas grande que la que hay entre los del medio, y la de estos mayor que la de los últimos. (Chaptal, 1816: III, 257 - 258)

Bouchardat (1845: 274) comenta que el óxido de plomo “...absorbe oxígeno con ayuda del calor, y lo pierde a una temperatura elevada.” Probablemente, a esta reacción se refiere Chaptal (1816: III, 258) cuando expone que si en la elaboración del minio se procede a una tercera calcinación, el material mutaría su color de rojo a anaranjado. Gettens y Stout (1966: 152) también exponen la reversibilidad del procedimiento y advierten que si la temperatura es excesiva el minio vuelve a convertirse en litargirio. Según Gettens y Stout (1966: 152), la forma de elaboración - desde el metal de plomo o desde un pigmento plúmbeo - configuraba la estructura del minio: bien cristalina, bien amorfa.

Pero las fuentes escritas aún proporcionan otra manera de producir el minio. Bouant explica un procedimiento propio de su época. 
Hoy día se aprovechan para la obtención de un buen minio, el sulfato y el cloruro de plomo, resultantes como productos secundarios de otras operaciones, á cuyo fin se les mezcla nitro de Chile y carbonato de sosa, sometiendo el todo á la temperatura del rojo sombra; se forma sulfato ó cloruro de sodio, y el ácido nítrico del nitro suministra el oxígeno necesario al plomo para convertirlo en minio, que debe sugetarse á la lixiviación á fin de separarle las citadas sales, juntamente con el nitrito de sosa que se ha formado. (Bouant, h. 1888: II, 526)

Además de los óxidos de plomo - litargirio y minio - los tratadistas indican, aunque con menor relevancia, otros compuestos de plomo. El carbonato básico de plomo o albayalde aparece mencionado como secante de los aceites grasos por De la Roca y Delgado y por Vicente Poleró. Como hemos visto, esta sustancia también fue empleada en algunos procesos de clarificación del aceite.

Desmarest (1828), Riffault (1859) y Bouant (h. 1888) abordan diferentes procedimientos de elaboración del blanco de plomo. El sistema de someter láminas de plomo a los vapores del vinagre y a los fermentos carbónicos del estiércol - también llamado método holandés - fue uno de los sistemas que datan de la antigüedad clásica ${ }^{10}$. Desmarest (1828), Riffault (1850) o Bouant (h. 1888) explican detalladamente este método del que pueden encontrarse una gran cantidad de variantes.

Para llevar a cabo el procedimiento, las láminas de plomo se enrollaban en espiral y se introducían en vasijas que contenían vinagre. Las espirales plúmbeas no tocaban el ácido acético que se

\footnotetext{
10 Según Rinaldi (1995: 23), la elaboración del blanco de plomo fue descrita por Teofrasto (372 a. C - 287 a. C). El filósofo griego indicaba que el plomo se sometía a la acción de los vapores de vinagre en unos tarros. Después de diez días el acetato de plomo que se formaba en la plancha se rascaba y molía en húmedo. La plancha se exponía a los vapores del ácido acético hasta su completa consumición. También Plinio el Viejo (23 - 79 d. C.) y Vitruvio (I d. C.) reportan la elaboración de esta sustancia. Con la particularidad de que Plinio explica dos formas de elaboración del albayalde: una en la que el plomo se somete a los vapores del vinagre y una segunda en la que el metal plúmbeo se sumerge en el mencionado ácido acético.
} 
encontraba en el fondo del recipiente. Para evitar el contacto del metal con el líquido, las espirales se sujetaban en un reborde de la vasija o de cualquier otra forma. Las vasijas se tapaban con coberturas de plomo ${ }^{11}$ y se cubrían de estiércol. Los botes y el estiércol se alternaban en estratos que podían llegar a alcanzar los 5 ó 6 metros de altura. Este montaje se disponía en cámaras donde el aire circulaba en todas direcciones; el estiércol fermentaba produciendo ácido carbónico y aumentando la temperatura de la estancia. La temperatura ligeramente elevada era necesaria para que el oxígeno, el ácido acético y el ácido carbónico actuaran sobre las láminas de plomo. En unas semanas ${ }^{12}$ las ollas se podían abrir para sacar las espirales con el albayalde.

Dada la elevada toxicidad del plomo, se desarrollaron aparatos para proteger a los trabajadores que elaboraban el blanco de plomo. Bouant (h. 1888: II, 530) describe un aparato ${ }^{13}$ en el que un operario despliega las láminas de plomo y las coloca sobre una tela sin fin que lleva las planchas a unos cilindros acanalados. Estos cilindros comprimen las láminas de plomo y las partes carbonatadas y frágiles se desprenden ${ }^{14}$; después pasan por un tamiz y llegan a un depósito con agua. En cambio, las láminas resisten la acción de los cilindros y salen por el otro extremo del torno desde donde llegan a una caja.

Las escamas separadas de este modo no están completamente exentas de plomo metálico, por esto deben someterse a otras operaciones. También Bouant (h. 1888: II, 530-

\footnotetext{
${ }^{11}$ Algunos investigadores argumentan que al cerrar los recipientes herméticamente sólo se formaba acetato de plomo que debía ser ulteriormente tratado para convertirlo en carbonato de plomo.

12 Mérimée (1830: 225) y Riffault $(1850,8)$ indican que las espirales pueden desenrollarse pasadas seis semanas.

13 Harley $(1982,169)$ describe una máquina similar que puso en marcha Walker, Ward \& Co. de Islington (Londres) durante la década de 1790.

${ }^{14} \mathrm{La}$ acción de separar las escamas de carbonato de plomo que cubrían las espirales recibía el nombre de descortezar (Bouant, h. 1888: II, 530). Tradicionalmente se llevaba a cabo golpeando las láminas desenrolladas con una maza de madera. De esta forma, las escamas de albayalde se soltaban de la parte del plomo metálico no atacado por los gases.
} 


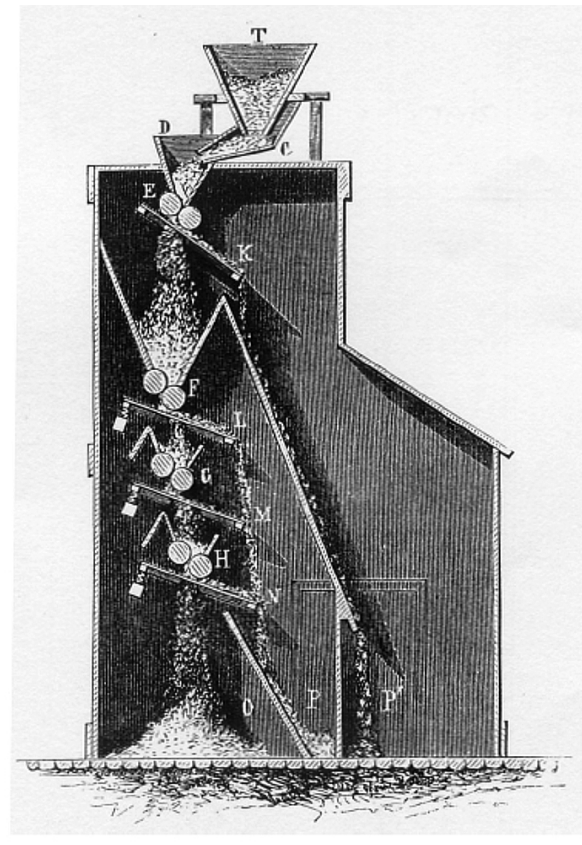

Fig. 28. Emilio Bouant: Nuevo

Diccionario de Química Aplicada a las Ciencias, a las Artes, a la Agricultura, a la Industria y a la Farmacia. (h. 1888). Aparato para separar el metal plúmbeo del albayalde.

531) detalla un instrumento especial para separar el albayalde del plomo no atacado. Este aparato está formado por cuatro pares de rodillos, planos inclinados y tamices. Para prevenir cualquier contacto de los trabajadores con el polvo del albayalde, estos aparatos estaban completamente cubiertos de madera y se cerraban herméticamente. No obstante, el blanco de plomo tras pasar por la trituradora aún necesitaba molerse con agua para formar una papilla que permitía que la materia tomara la forma de los moldes en los que se metía tras el molido. Para efectuar esta molienda Bouant (h. 1888: II, 531) sugería la acción de 8 ó 9 muelas horizontales. Todos estos aparatos diseñados para proteger a los trabajadores del plomo obedecen a las devastadoras enfermedades que sufría este colectivo. El blanco de plomo tenía múltiples y amplios usos y era el pigmento blanco de la pintura al óleo. Pero los problemas de salud de los obreros del plomo motivaron investigaciones para encontrar un substituto (Ver 5.1.1.).

Otra elaboración del albayalde basada en la exposición del plomo a los vapores del vinagre es el llamado procedimiento alemán. La diferencia de este sistema con el holandés radica en que no se emplea estiércol; el ácido carbónico y el calor necesarios para la reacción proceden de otras fuentes. El procedimiento alemán aparece reflejado en Riffault (1850) y en Bouant (h. 1888). El texto de este último químico resulta muy interesante porque fue traducido 
y anotado por varias personas competentes en química ${ }^{15}$ que conocían bastante la industria española (o al menos la catalana). Por lo que esta obra nos proporciona algunos datos muy atractivos. Por ejemplo, comenta sobre el método alemán: "Este sistema se ha introducido ya en España practicándose en una importante fábrica de Mataró” (Bouant, h. 1888: II, 531). Curiosamente, el Archivo Histórico de la Oficina Española de Patentes y Marcas alberga un expediente datado en 1882 de una fábrica de albayalde sita en Mataró. Según el diseño que se registró, La Blanca Paloma ${ }^{16}$ producía albayalde puro.

Bouant explica muy brevemente el procedimiento alemán.

Las láminas de plomo se colocan en unas traviesas de madera, dispuestas por centenares en cámaras calentadas por vapor acuoso; el aire, el ácido carbónico y el ácido acético penetran por unas aberturas que se hallan repartidas por el suelo en todas direcciones, las cuales comunican con aparatos á propósito dispuestos en el sótano. (Bouant, h. 1888: II, 531)

El proceso alemán también sufría variantes. Mérimée (1830: 227 - 228) explica como elaborar el proceso en cajas con el fondo impermeable. El plomo debía colocarse sobre unas traviesas de madera para que no alcanzaran el vinagre. Mientras que el ácido carbónico se conseguía con heces de uva o tártaro crudo que, según el artista, producían carbonato de potasa. Este autor también sugiere

\footnotetext{
15 D. Ramón de Manjarrés y Bofarull, Ingeniero Industrial; Director y Catedrático de Química Industrial y Análisis en la Escuela de Ingenieros Industriales de Barcelona. D. Federico Trémols y Borrell, Doctor en Farmacia y Catedrático de Química Inorgánica en la Facultad de Farmacia de la Universidad Literaria de Barcelona. D. Juan Antonio Vidal de Solano, Doctor en Ciencias; Ingeniero Industrial, y Ayudante de Química General en la Facultad de Ciencias de la propia Universidad. D. Casimiro Brugués y Escuder, Doctor en Farmacia y Ayudante de la Facultad de Farmacia de la misma Universidad. D. Ramón de Manjarrés y Pérez-Junguto. Ingeniero Industrial Químico y Mecánico; Licenciado en Ciencias; Ayudante de Química en la Escuela de Ingenieros Industriales. ${ }^{16}$ Archivo Histórico de la OEPM. Marca registrada a nombrare de D. Jaime Roldos. Expediente $\mathrm{N}^{\mathrm{O}} 1218$.
} 
que el ácido carbónico se podía lograr introduciendo en el vinagre piezas de mármol calcáreo (Mérimée, 1830: 226). Para que la reacción tuviera lugar, la caja cerrada se colocaba sobre un conducto de calor que no debía superar los $30^{\circ}$ centígrados con el fin de evitar una evaporación excesivamente rápida del vinagre. Riffault (1850: 9-10) expone una variante de este procedimiento que fue ideada por "Mr. Montgolfier". En este sistema, un tubo comunicaba un horno encendido con un tonel de vinagre. A su vez, otro tubo conectaba el tonel con una caja llena de hojas de plomo colado sin laminar.

Las fuentes coinciden en que el blanco elaborado mediante el procedimiento alemán es más blanco que el elaborado con el sistema holandés. Esto es debido a que los vapores de la fermentación del estiércol ennegrecen el blanco. Bouant (h. 1888: II, 531) apunta que el procedimiento alemán permite obtener mejores resultados en menos tiempo que el sistema holandés.

A principios del siglo XIX (Rinaldi, 1995: 26) se desarrollaron diferentes procesos por precipitación debido fundamentalmente a dos factores: a) la necesidad de producir un blanco de calidad a bajo coste, y b) la aparición cada vez mayor en todo el mundo de fábricas de albayalde. Este procedimiento consistía en atravesar con gas de bióxido de carbono una solución de sal básica de plomo; el resultado era un precipitado blanco: carbonato básico de plomo. Thènard desarrolló este procedimiento que se empleaba en la afamada fábrica de Clichy (Francia).

El método de Clichy está explicado en los textos de Desmarest (1828: 89 - 90), Riffault (1850: 10 - 12) y Bouant (h. 1888: 529). Este último químico comenta que el procedimiento de Clichy "...se practica en algunos establecimientos de la ciudad de Barcelona." La preparación del método de Clichy consistía en pasar una corriente de ácido carbónico a través de una disolución de acetato básico de plomo. El carbonato de plomo precipitaba al fondo de la vasija; después, este compuesto se lavaba y secaba y podía entonces introducirse en el mercado. 


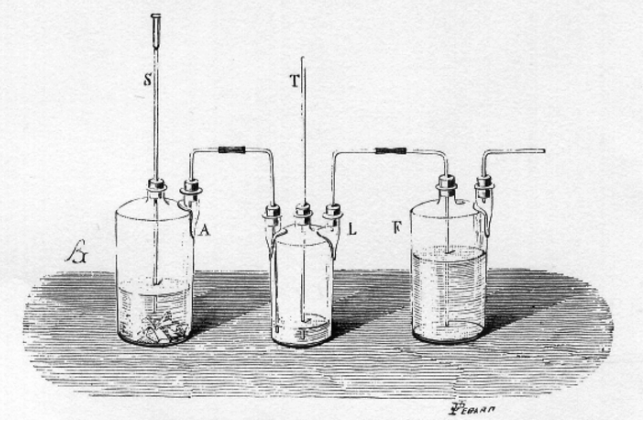

Fig. 29. Emilio Bouant: Nuevo Diccionario de Química Aplicada a las Ciencias, a las Artes, a la Agricultura, a la Industria y a la Farmacia. (h. 1888). Preparación de la cerusa por precipitación.
La disolución

dispuesta en grandes cubas de madera forradas de plomo, se sujeta á la corriente de ácido carbónico conducida por 800 ó más tubos de desprendimiento. El ácido carbónico procede de un horno destinado á la calcinación de la piedra calcárea, que es de cocción continua y que se alimenta de $\operatorname{cok}^{17}$. El gas que resulta, mezcla de nitrógeno (del aire) y de ácido carbónico resultante del carbonato de cal, y de la combustión del carbón, se lava en un gran receptáculo lleno de agua, luego pasa á un gran tubo distribuidor desde donde se reparte á los tubos de desprendimiento. En el horno se recoge como residuo la cal cáustica que puede utilizarse. Al cabo de doce horas la operación queda terminada, el precipitado de albayalde que se ha formado se debe recoger, lavar, ponerlo en los moldes y luego á secar, mientras que el acetato neutro se convierte otra vez en sal básica mediante litargirio. (Bouant, h. 1888: II, 529)

Vibert (1908: 142) comenta que el blanco que se fabrica mediante el procedimiento de Clichy es menos cubriente. Este artista manifiesta que cada fabricante tiene su secreto de elaboración de este pigmento y que por lo general tratan de elaborarlo lo más barato posible.

Finalmente, Bouant (h, 1888: II, 531) expone otra método de elaborar el blanco de plomo. El químico le otorga el nombre

\footnotetext{
${ }^{17} \mathrm{El}$ traductor se refiere al coke: carbón.
} 
de procedimiento inglés y comenta que es una modificación de la técnica empleada en Clichy. En este proceso, el litargirio se humedece con un soluto de acetato neutro de plomo y se coloca en artesas de pizarra donde recibirá una corriente de ácido carbónico. La materia debe revolverse para aumentar los puntos de contacto con el gas. Este procede de la combustión del cok (carbón) y es impulsado por máquinas soplantes - desde el horno hasta las artesas - a través de tubos sumergidos en agua, que se renueva constantemente. De esta forma el gas siempre llega frío a su destino.

Otro compuesto plúmbeo que aparece citado como secante es el acetato de plomo también conocido como sal o azúcar de Saturno. Soler y Ferrer son los únicos tratadistas españoles decimonónicos que mencionan esta sustancia en una fórmula para elaborar un aceite graso que contiene otras materias secantes (Ver 3.2.3.). Según Desmarest (1828: II, 87), el acetato de plomo se preparaba por exposición de las hojas de plomo al aire y al vinagre. Pero después comenzó a elaborarse tratando el litargirio con vinagre. Bouant (h. 1888) añade el massicot como materia a partir de la cual se puede fabricar la sal de Saturno.

Desmarest añade que durante la reacción entre el ácido y el litargirio se produce, además de la disolución de éste último, un aumento considerable de la temperatura. De esta forma, la cristalización podría ser confusa; por eso, el químico, para bajar la temperatura, propone añadir aguas de lavado (Desmarest, 1828: II, 88). “...entonces se deja posar algún tiempo, y despues se vierte en unos lebrillos, en los que cristaliza pasadas 36 horas, se ponen los lebrillos de canto, y las aguas madres se escurren...”.

Algunas fuentes inglesas decimonónicas - según Carlyle (2002: 44) - apuntan que el acetato de plomo tiene tendencia a ennegrecer si no se calcinaba antes de su uso. También la tendencia a recristalizar fue señalada por Eastlake (1847: I, 350) quien aseguraba que la recristalización del acetato de plomo era peligrosa porque tornaba los colores más transparentes y sin brillo. Este notable 
estudioso aseguraba que un abuso innecesario del azúcar de plomo ${ }^{18}$ podía producir eflorescencias.

A pesar de que en las fuentes españolas esta sustancia no tiene relevancia, las fuentes inglesas demuestran que tuvo una gran importancia como secante en pasta. Por ejemplo, en el catálogo de Winsor \& Newton el azúcar de plomo aparece entre los colores al óleo y continúo ofertándose en los catálogos de esta compañía a lo largo de la centuria (Carlyle: 2002, 44). Este dato se puede corroborar en el catálogo de W\&N (1902: 86) de 1902 que perteneció a J. Sorolla.

Entre los secantes no plúmbeos que mencionan las fuentes españolas decimonónicas nos encontramos con la caparrosa $^{19}$ también conocida con la denominación vitriolo blanco (sulfato de zinc). Soler y Ferrer (1837: 60) sugieren el uso de esta sustancia para la elaboración del aceite graso y de secantes en pasta. De la Roca y Delgado (1888: 278) y López Tomás (1898: 50) mencionan la caparrosa para preparar secantes en pasta.

Riffault (1850: 178) indica que en el comercio existían tres vitriolos diferentes: blanco (sulfato de zinc ${ }^{20}$ ), azul o de Chipre

\footnotetext{
${ }^{18}$ Eastlake (1847: I, 349-350n) señala que el acetato de plomo debe secarse cuando va a mezclarse con los colores porque sino se toma esta precaución podría alterar la pintura. Eastlake transcribe una interesante reflexión de J. Wilson Neil que apareció en Transactions, \&c. vol. XLIX, part. 2, p. 55.

All sugar of lead contains about $14 \cdot 2$ per cent of the water of crystallization, so that to use it in that state is very injurious to the varnish, as its water prevents that complete union of the particles of gum, oil, and lead, which ought to combine and form a whole.
}

${ }^{19}$ Según Eastlake, la caparrosa era el secante común de la escuela flamenca del siglo XV, sin embargo, esta era una sustancia rara en las fórmulas de la escuela italiana. Este investigador aporta datos del MS. de Estrasburgo, de De Ketham y De Mayerne en las que aparece la caparrosa como elemento secante. (Eastlake, 1847: I, 130 - 131, 284, 298 - 299, 310 - 312). Tanto Eastlake como Merrifield apuntan que es extraño encontrar la caparrosa blanca en los textos italianos.

${ }^{20} \mathrm{El}$ sulfato de zinc $\mathrm{Zn}\left(\mathrm{SO}_{4} \cdot 7\left(\mathrm{H}_{2} \mathrm{O}\right)\right.$ se da en la naturaleza como un mineral vítreo procedente originalmente de las minas de Goslar (Alemina) por lo que recibe la denominación de Goslarita. 
(sulfato de cobre ${ }^{21}$ ) y verde (sulfato de hierro ${ }^{22}$ ). El único sulfato que se empleaba como secante en la pintura era el de zinc que se conocía bajo las denominaciones de caparrosa y vitriolo blanco. Según este autor:

Debe elegirse en pedazos gruesos, blancos, duros y muy limpios, semejantes á azúcar rosada: dichos pedazos deben secarse si están húmedos, evitando mientras se secan el respirar los vapores que producen. (Riffault: 1850: 178)

La caparrosa o vitriolo blanco se recomendaba como secante de los colores claros al óleo aunque se imponía precaución porque, según Riffault, perjudicaba la hermosura del color cuando secaba.

El vitriolo blanco podía elaborarse artificialmente de tres formas diferentes: a) mediante la reacción del ácido sulfúrico en disolución acuosa con el zinc o el óxido de zinc; b) mediante la oxidación del sulfuro de zinc; y c) a partir de los sulfatos de cobre o hierro con zinc sólido. Para Chaptal (1821: IV, 58), la elaboración más sencilla del vitriolo blanco consistía en disolver el metal en una disolución de ácido sulfúrico.

Desmarest (1828: I, 367) aporta explicaciones confusas sobre la elaboración de la caparrosa blanca. Según este químico, la caparrosa blanca se obtenía por exposición de la pirita o sulfuro de zinc a la humedad y al aire; de esta forma, el mineral se apoderaba del oxígeno y se convertía en sulfato de zinc. Sin embargo, la identificación que el autor hace de la pirita con el sulfuro de zinc es errónea pues la pirita está compuesta mayoritariamente por sulfuro de hierro. De esta forma, la exposición al aire de la pirita produciría sulfato de hierro o caparrosa verde. Este proceso de vitriolización de

\footnotetext{
${ }^{21} \mathrm{El}$ sulfato de cobre $\mathrm{Cu}\left(\mathrm{SO}_{4}\right) \cdot 5 \mathrm{H}_{2} \mathrm{O}$ es un mineral llamado calcantita (del griego calkos (cobre) y anthos (flor)). Este compuesto se puede elaborar de forma sintética mediante la reacción del ácido sulfúrico con cobre u óxido de cobre. ${ }^{22} \mathrm{El}$ sulfato de hierro $\left.\mathrm{Fe}^{2+(} \mathrm{SO}_{4}\right) \cdot 7\left(\mathrm{H}_{2} \mathrm{O}\right)$ en su forma mineral recibe el nombre de melanterita (del griego melas que significa negro). Este mineral se halla asociado frecuentemente con la pirita pues se forma mediante la oxidación del sulfuro de hierro.
} 
la pirita fue ampliamente tratada por Chaptal (1821: IV, 44 - 49). Desmarest (1828: I, 367) para eliminar las impurezas que contenía la caparrosa del comercio sugiere que se purifique “...disolviéndola en agua y echando en la disolución granalla de zinc, que precipita los metales extraños, ocupando su lugar".

El vidrio molido es otro secante que mencionan nuestras fuentes aunque aparece referenciado de manera escasa. De la Roca y Delgado (1880: 277 - 278) sugiere el uso de este material como uno de los ingredientes para elaborar el aceite de linaza cocido y como componente de secantes en pasta. Vicente Poleró propone el vidrio molido únicamente en la elaboración de los aceites grasos. Según Merrifield (1849: I, ccxl), el empleo del vidrio molido como secante para los colores tuvo origen en la antigua costumbre de añadir este ingrediente al oropimente. Los objetivos de esta mezcla eran mejorar las propiedades de amasado del pigmento amarillo y favorecer su secado cuando formaba una pintura al óleo. Podemos ver en Pacheco como el vidrio se apreciaba para secar el oropimente ${ }^{23}$.

Suelen algunos valerse del Jalde, $\mathrm{u}$ oropimente para los amarillos finos a olio; búscase el más subido de color, el cual se muele bien a l'agua y se pone a secar, o para templallo en el tablón con aceite de linaza, o para molello con él tiene necesidad de secante; algunos le echan vidrio, teniéndolo molido al agua;... (Pacheco, [1649] 2001, 484)

La propiedad secante del vidrio debe atribuirse a su contenido de óxido de plomo; no debemos olvidar que el vidrio se elaboraba con óxidos de plomo como el litargirio. Aunque también es posible qué el vidrio contuviera otros óxidos metálicos como el manganeso que propician el secado de los aceites. Este argumento fue expuesto por

\footnotetext{
${ }^{23} \mathrm{El}$ oropimente sufre una reacción adversa en conjunción con elementos plúmbeos y, generlamente, los tratados desaconsejaban mezclarlo con blanco de plomo para aclararlo. Por este motivo, Merrifield (1849: I, ccxliii) asegura que el vidrio no era una buena elección para acelerar el secado del oropimente.
} 
Merrifield (1999: I, ccxlii).

El uso del manganeso como secante de los aceites se popularizó en el siglo XIX como una alternativa a los secantes plúmbeos. Una de las referencias más tempranas sobre el uso del manganeso la proporciona Mérimée (1830: 58). El pintor incorpora el óxido de manganeso en una lista de secantes adecuados para la elaboración de los aceites grasos. Carlyle (2002: 53, n 16) aclara que durante el siglo XIX se otorgó capacidad secante a diferente compuestos de manganeso como al cloruro y al borato ${ }^{24}$. Otro compuesto secante de manganeso era la pirolusita o dióxido de manganeso. Como hemos visto, ésta era una de las opciones de Leclaire para acelerar el secado de los aceites que se amasaban con el blanco de zinc (Ver 5.1.1).

El empleo del manganeso aparece de manera excepcional en las fuentes españolas, Vibert y Sala son los únicos que mencionan esta substancia. Según el pintor francés (Vibert, 1908: 114 -115), el único medio que se conocía para que el aceite adquiriera mayores propiedades secantes consistía en agregarle óxidos de manganeso y plomo en igual proporción. Emilio Sala cuenta los efectos del manganeso en la pintura a través de una curiosa anécdota. Sala cuenta que un compañero suyo estaba pintando al aire libre un cuadro. Uno de los elementos de la obra era una tapia blanca. Estaba terminando la sesión cuando se percató que la tapia blanca comenzaba a amarillear de una manera desoladora en su tabla. Así que se afanó en pintar otras partes de la obra. Pronto la tapia se encontró tan amarilla que el pintor, desilusionado, volvió a su casa pensando que tendría que borrarlo todo. Cuando al día siguiente se disponía a raspar la tapia amarillenta encontró que el matiz amarillo había desaparecido y la tapia volvía a ser blanca. Después de muchos años, la tapia seguía manteniéndose blanca. Emilio Sala - con razón o sin ella - atribuye este efecto a los secantes de manganeso y plomo.

\footnotetext{
${ }^{24}$ Carlyle informa que ha extraído estos datos de A. C. Elm: "A Century of Progress in Driers” en Industrial and Engineering Chemistry, Vol. 26, 1934, p. 386.
} 
Y digo yo que este fenómeno se debe, sin duda alguna, á las adiciones que sufren algunos aceites para aclararlos y hacerlos secativos, pues el manganeso y óxido de plomo que en tales casos se emplean hacen que, al efectuarse la desecación, la absorción del oxígeno determine, por la intervención del óxido de manganeso, una cierta coloración que desaparece en cuanto la pintura se seca. (Sala, 1896: XLIII, 294)

Aunque el manganeso aparece excepcionalmente mencionado en las fuentes decimonónicas, fue uno de los elementos secantes para pintura que se impuso en el comercio durante la siguiente centuria. En cambio, los secantes de plomo y otros desaparecieron poco a poco a lo largo del siglo XX. 


\section{Materias Colorantes}

El abanico de colores que tenían disponibles los pintores de la primera mitad del siglo XIX era bastante restringido debido a que algunos pigmentos ofrecían limitaciones o inconvenientes. El único blanco posible para la pintura al óleo era el blanco de plomo ${ }^{1}$. Las principales propiedades de este pigmento fueron siempre muy apreciadas por los pintores. Sin embargo, su elevada toxicidad suponía un auténtico riesgo para la salud de los trabajadores de las fábricas de albayalde y para los pintores decoradores. Entre los amarillos, sólo el de Nápoles - antimoniato de plomo - era un pigmento opaco pero de escasa intensidad. Los azules tampoco estaban exentos de inconvenientes. El ultramar, el más deseable de todos los azules, procedía de una escasa piedra semipreciosa y por este motivo su precio era excesivamente elevado. Según Bomford et al. (1990: 56), la azurita, el esmalte y el índigo no eran satisfactorios y, el azul de Prusia - inventado hacia 1704 - no solucionó las necesidades de los pintores. Entre los verdes que tenían a disposición los pintores de principios del siglo XIX, las tierras verdes eran de matiz apagado; la malaquita y el verde verditer presentaban dificultades de trabajo; y el verdigrís tenía que emplearse con precaución - según la mayoría de fuentes escritas desde el siglo XVII - debido a su escasa estabilidad y a su incompatibilidad con algunos pigmentos. Afortunadamente, los rojos, aunque escasos en número, resultaron ser bastante adecuados. El bermellón era un pigmento opaco y brillante que demostró ser de gran utilidad a lo largo de todo

\footnotetext{
${ }^{1}$ A principios del siglo XIX, el químico suizo Tingry (1816: 180-181) realizó análisis para determinar la composición química de varios blancos del comercio suministrados baja la denominación Blanco de Cremnitz. Tingry encontró óxido de bismuto en varias muestras mientras que el carbonato de plomo únicamente estaba presente en dos casos. Pero advierte que el blanco de Cremnitz elaborado con plomo poseía mejores cualidades para la pintura que el blanco fabricado con bismuto. Algunos pintores del siglo XVII ya ensayaron con blancos de estaño y bismuto. Eastlake (1847: I, 536) recoge una confusa narración de De Mayerne sobre unos experimentos que Van Dyck y Mytens llevaron a cabo con estas alternativas al albayalde.
} 
el siglo XIX. La laca rubia fue el principal color rojo transparente que tenían los pintores de principios del siglo XIX en la paleta y ofrecía resultados satisfactorios. En cuanto a los ocres, tierras rojas y pardas son todos colores apagados por su propia naturaleza aunque de elevado provecho y estabilidad. A principios del siglo XIX, los pintores usaban principalmente las variedades naturales de las tierras y ocre.

El desarrollo de los colores artísticos modernos ha estado siempre ligado al progreso de la industria química y a la caracterización de nuevos elementos químicos. Gettens y Stout (1966, 141) sitúan el principio de los pigmentos sintéticos modernos en 1704 cuando Diesbach descubrió el azul de Prusia. A pesar de este temprano nacimiento, a mediados del siglo XVIII no se descubrieron nuevas materias colorantes. Hubo que esperar al último cuarto del siglo para que, de nuevo, se produjeran importantes hallazgos de los que se beneficiarían tiempos postreros.

Durante las tres primeras décadas del siglo XIX- aseguran Bomford et al. (1990: 51) -, la paleta de los pintores vivió una evolución sin parangón, especialmente en Francia, Alemania e Inglaterra. Gettens y Stout explican clara y concisamente este fenómeno de aparición profusa de colores:

In the XIX century, nearly every decade was marked by the discovery of some such compound that later become a pigment. Some of them remained useless, scientific curiosities for years before they were finally put into production. (Gettens y Stout, 1966: 142)

En definitiva, una gran variedad de pigmentos aparecieron en el siglo XIX y fueron decisivos para la evolución de la pintura. De acuerdo con Bomford et al., los pigmentos nuevos causaron un impacto sobre la técnica sin precedentes en la historia de la pintura. La explosión de color en las primeras vanguardias - Impresionismo, Postimpresionismo y de otros ismos - fueron posibles gracias a la intensidad de los nuevos pigmentos y colorantes. Pero no sólo los pigmentos contribuyeron a estos cambios en la paleta artística. A 
mediados del siglo XIX se produjo un autentico y progresivo desarrollo de los tintes y los colorantes que contribuyeron enormemente al cambio de la paleta de los pintores. De esta forma, se descubrieron variados colorantes como las anilinas y sus derivados - los llamados colores de carbón de hulla ${ }^{2}$-, muchos de los cuales resultaron tener una escasa estabilidad. Aunque desde que un color se descubría hasta que se conseguía aplicar y comercializar para la pintura al óleo podían pasar años.

\subsection{Pigmentos Modernos}

Los tratadistas españoles del siglo XIX demuestran diferente interés por los nuevos colores y pigmentos que estaba desarrollando la industria química. En todos los textos de esta investigación conviven los pigmentos tradicionales con los modernos. La excepción la presenta De la Roca y Delgado (1880) que propone una paleta tardo barroca, puesto que transcribe las enseñanzas de la pintura al óleo de un texto de principios del siglo XVIII. Realmente, los tratados españoles no demuestran los grandes avances en materia de pigmentos artísticos. Únicamente López Tomás (1898) y las traducciones de los textos de Bellanger (1899) y Vibert (1908), revelan la penetración de los nuevos pigmentos en la paleta de los pintores.

Queremos señalar dos aspectos interesantes de los pigmentos que sugieren los tratadistas. El primero de ellos lo encontramos en los pigmentos blancos. A pesar que el blanco de zinc estuvo disponible en pintura al óleo desde mediados del siglo XIX, este pigmento únicamente comparece en las traducciones de los textos franceses; es decir, en los manuales de Bellanger (1899) y Vibert (1908). El resto de tratados y manuales, recomiendan el empleo del blanco de plomo omitiendo por completo el blanco de

${ }^{2}$ Colores de alquitrán de hulla (Coal - tar colours) y sus derivados son las anilinas, los tintes azo, la eosina, la alizarina y el índigo artificiales. 
zinc. Sin embargo, el catálogo de colores de L. Péant é Hijos (1995) ofertaba este color al óleo. También algunas patentes de finales del siglo XIX, albergadas en el Archivo Histórico de la OEPM, registraron procesos de elaboración de este pigmento blanco.

El segundo aspecto reseñable recae sobre los pigmentos verdes. Llama la atención que, por lo general, las fuentes indiquen la mezcla de pigmentos para lograr diferentes matices de verde; especialmente porque desde las primeras décadas de la centuria aparecieron en el comercio nuevos pigmentos verdes. Una vez más son los escritos de López Tomás (1898), Bellanger (1899) y Vibert (1908) los que introducen algunos pigmentos verdes modernos.

Las nuevas materias colorantes que llegaban al mercado resultaban, en muchas ocasiones, deficientes bien porque estaban adulterados bien porque se fabricaban defectuosas. Algunos de estos colores podían causar deterioro prematuro en las pinturas. La adulteración de los pigmentos - asegura Carlyle (1993: 57-58) podía llevarse a cabo de tres formas diferentes: (1) mediante la adición de materiales más baratos; esto aumenta el peso y el volumen de las materias auténticas; (2) substituyendo completamente el pigmentos; es decir, se vendía el material substituto bajo el nombre del original; y finalmente (3) se podía intensificar el color del pigmentos añadiendo colores más baratos y brillantes; los tintes eran muy empleados con este objetivo. Vibert (1908) comenta la substitución de los pigmentos e incluso la intensificación del material substituto.

Desde el punto de vista técnico es igualmente difícil entenderse, si cada uno se empeña en dar á la misma cosa nombres diferentes, ó el mismo nombre á cosas distintas. Así por ejemplo, un autor en quien tenemos confianza, nos afirma que el bermellón es un color sólido; lo empleamos pues, pero, si en lugar de sulfuro de mercurio que nos aconsejó, nos venden como bermellón yoduro de mercurio ó minio teñido con eosina, no sólo nos hacen pagar á razón de 15 francos el kilogramo lo que vale 2 pesetas, sino que comprometen nuestra obra. (Vibert, 1908: 93) 
Para añadir mayor confusión, en muchas ocasiones, el nombre comercial de las pinturas no permitía vislumbrar las materias que componían sus colores. Vibert (1908), que reflexionó mucho sobre los materiales y la forma de subsanar las deficiencias de los materiales suministrados por los comerciantes, expone éste caos del que hablamos.

En efecto, si compramos un tubo de azul celeste, dicho azul puede estar fabricado con azul de Prusia ó con cualquier otra cosa, el tendero puede llamar azul celeste al color que le de la gana. El comprador mismo lo encuentra suficientemente celeste, puesto que lo compra. Si al fin y al cabo los artistas, al darse cuenta de que su azul celeste no vale nada, dejan de comprarlo, se le cambie el nombre y de transforma en azul turquesa, azul zafiro, azul de Esmirna, etc. Está lejos de haberse agotado el vocabulario de nombres de piedras preciosas, flores, pájaros y ciudades que emplean los vendedores de colores... (Vibert, 1908: 92)

Por estos motivos, no resulta extraño que Vibert (1908) incluyera en su texto los análisis que un pintor podía realizar para verificar la composición de los colores. E incluso adquiere relevancia que un comerciante de colores como L. Péant é Hijos ofertara a sus clientes una caja de análisis para pigmentos provisto de los reactivos necesarios (Ver 2.1). Vibert para intentar paliar la situación ideó un proyecto para que los comerciantes incluyeran la composición química de los colores en los tubos.

De esta suerte, si el comerciante no nos diera lo que anuncia, podría ser llevado ante los tribunales como un falsificador ordinario, pues nos engañaría en la calidad de la mercancía. Mientras que ahora ni si quiera podemos quejarnos, puesto que las denominaciones de laca capuchina, laca geranio, rosa de China, etc., que da á productos cualesquiera no le comprometen nada, lo mismo que las de amarillo de oro, verde malaquita, rojo de Venecia, etc. (Vibert, 1908: 92) 
La Ciencia de la Pintura de Vibert datada en 1908 reproduce casi íntegramente la edición francesa de 1891. Si atendemos al catálogo de L. Péant é Hijos (1895: 4 - 7), Vibert consiguió en parte sus objetivos. Pues los colores al óleo - extrafinos y superfinos ${ }^{3}$ de Lefranc \& $\mathrm{C}^{\mathrm{ie}}$. aparecen en el mencionado catálogo con la composición química acompañando al nombre del color. Sin embargo, no era una práctica habitual informar al pintor de la composición de los colores que empleaba.

\subsubsection{Blancos}

El blanco de plomo ha sido, por excelencia, el blanco de la pintura al óleo. Sus magníficas propiedades - opacidad, elevado poder secante, escaso índice de aceite, capacidad para crear jabones - lo convirtieron en un pigmento muy apreciado por los pintores. Sin embargo, el blanco de plomo no está exento de inconvenientes. Este pigmento tiende a combinarse con el oxigeno o el azufre produciendo compuestos negros o pardos que pueden derivar en importantes cambios estéticos. Pero, sin duda, el mayor problema del blanco de plomo radica en su elevada toxicidad. El Saturnismo, enfermedad provocada por el metal plúmbeo, llegó a ser preocupante especialmente entre los trabajadores que fabricaban el blanco de plomo. Rinaldi (1995: 36) aporta algunos testimonios del siglo XVII que describen los síntomas de la enfermedad (dolores abdominales, convulsiones, respiración débil, mareos, ceguera y parálisis). No es de extrañar que ya en la mencionada centuria, la inquietud por este

\footnotetext{
3 Los colores superfinos, según el catálogo L. Péant é Hijos (1895, 7) se preparaban por los procedimientos de Vibert.
}

COLORES SUPERFINOS PREPARADOS PARA EL ÓLEO

POR LOS PROCEDIMIENTOS DE

J. G. VIBERT

LEFRAN y $\mathrm{C}^{\mathrm{a}}$, únicos fabricantes.

L. PÉANT É HIJOS, únicos depositarios en Madrid. 
problema condujera a pintores y comerciantes a realizar experimentos para substituir el venenoso pigmento.

La búsqueda de un sustituto para el blanco de plomo fue una empresa de gran importancia. Cuenta Harley (1982: 177) que en 1782 Guyton de Morveau informó sobre diferentes exámenes realizados a todos los pigmentos blancos conocidos y a las materias que podían servir como pigmento blanco para acuarela y óleo. En este informe, el químico declaraba que el blanco de zinc era la mejor alternativa al venenoso blanco de plomo. Pero en ese momento, Courtois - auxiliar de laboratorio de la Academia de Dijon - ya manufacturaba el pigmento con fines comerciales. El químico se dio cuenta que el blanco de zinc amasado al óleo carecía de cualidad secante. Para remediar esta deficiencia, Courtois incluía en la mezcla de blanco de zinc y aceite un agente secante: el sulfato de zinc, es decir, caparrosa o vitriolo blanco (Ver 4.3).

Este primer intento no tuvo éxito. Las propiedades del blanco de zinc al óleo no podían competir con las del blanco de plomo; además, elaborar blanco de zinc era económicamente más costoso que elaborar blanco de plomo. Aunque, como excepción, Constant de Massoul, un comerciante de colores francés, ofrecía blanco de zinc en su establecimiento londinense de New Bond Street. De Massoul es el autor de A Treatise on the Art of Painting, and the Composition of the Colours, Containing Instructions for All the Various Processes of Painting publicado en Londres en 1797. En este libro, el comerciante dice del blanco de zinc:

Mr. De Morveau first conceived the idea of substituting Lime of Zinc, instead of Cerusa, and, by that means, has rendered a very essential service to Painting.

\section{WHITE OF ZINC}

White of Zinc has the property of not changing its colour, by any of those means that would immediately blacken any Whites extracted from Lead. It unites perfectly with all other colours; but, as it wants body, it is mixed with White extracted from silver, ... (De Massoul, 1797: 135) 
De Massoul expone una de las ventajas del blanco de zinc frente al albayalde: la aparente inmutabilidad del color ante los vapores sulfurosos4. Este aspecto convirtió al blanco de zinc en una opción muy interesante frente al blanco de plomo en los colores a la acuarela. Ya en 1828, Desmarest (1828: I, 366) informaba sobre la utilidad de este pigmento en pintura para técnicas acuosas: "El zinc no forma sino un solo óxido, que es un polvo blanco,... Este compuesto se usa con buen éxito en pintura, para hacer el color de agua,..." De hecho, en la década de 1830 el blanco de zinc se estableció como un color para acuarela. Winsor \& Newton comenzó a venderlo en 1834 bajo la denominación Blanco Chino ${ }^{5}$.

A principios del siglo XIX, el químico y farmacéutico suizo Pierre François Tingry reconocía la labor de Guyton de Morveau y explicaba la forma de elaboración del blanco de zinc.

Guyton de Morveau thought he should be able to discharge this task reserved to chemistry, by substituting sublimated oxide of zinc (flowers of zinc) for the oxides of lead and bismuth (white lead and calx of bismuth), the use of which was attended with discouraging the utmost care in the establishment of a manufactory of the sublimated oxide of zinc, in order that he might give effectual assistance to the art of painting. (Tingry, 1804: 298)

Sublimated oxide of zinc is obtained by fusing that metal in an earthen tube, which performs the office of a crucible, and which is placed obliquely in a reverberating furnace, or in any other capable of producing a heat sufficient to make it enter into fusion. The metal then soon inflames, and emits thick white fumes, which, if the zinc be pure, are converted into very white wooly flakes. These flakes, which adhere to sides of the tube, are called sublimated

\footnotetext{
${ }^{4}$ Cuando el blanco de zinc se combina con el azufre produce sulfuro de zinc. Pero este compuesto es blanco por lo que esta alteración carece de consecuencias perceptibles.

${ }^{5}$ Con este nombre aún aparece en algunas cartas de colores a la acuarela del catálogo L. Péant é Hijos (1895).
} 
oxide of zinc (flowers of zinc).

If the zinc contains iron, the oxide is of an orange yellow colour: the metal is purified by throwing into it, while in fusion, some pinches of the flowers of sulphur. (Tingry, 1804: 299 - 300)

Desmarest resulta más conciso y aporta datos muy interesantes que reflejan dos sistemas de elaboración del blanco de zinc.

OXIDO. El zinc no forma sino un solo óxido, que es un polvo blanco, fijo, insípido, é insoluble en el agua; se obtiene calentando el metal con el contacto del aire, y recogiendo el vapor ó calcinando la calamina. (Desmarest, 1828: I, 366)

El primer procedimiento que indica este químico es similar al método expresado por Tingry en el que se opera calentando el metal de zinc. Este es el método que Leclaire patentó en Francia hacia $1840^{6}$. El segundo procedimiento que sugiere Desmarest es el que se realiza calentando la calamina; ésta es una mezcla de varios minerales que contienen zinc. El sistema de elaboración del nuevo blanco a partir de la calcinación directa de un mineral de zinc - y no del metal - fue patentado en 1854 por R. Jones en Estados Unidos.

Leclaire está reconocido actualmente como descubridor del blanco de zinc. El método de fabricación de Leclaire $^{7}$ - explicado más detalladamente - consistía en reducir el mineral de zinc a metal. Entonces el metal sometido a una temperatura de $900-1000^{\circ} \mathrm{C}$ produce vapores de zinc. Una corriente de aire atravesaba los vapores transformándolos en óxido de zinc que se recogía en unos depósitos adecuados. Éste sistema de fabricación recibía el nombre de 'proceso indirecto' y, según Channing Downs (1976: 87), también se conocía como 'proceso Leclaire' o 'método francés'. Leclaire resultó más efectivo que Courtois en la forma de subsanar la deficiente capacidad secante del blanco de zinc al óleo. Leclaire

\footnotetext{
6 Leclaire patentó el mismo procedimiento en Estados Unidos hacia 1850.

${ }^{7}$ Leclaire fue galardonado con una medalla de oro que le concedió la Société d'Encouragement por sus esfuerzos. (Bomford et al., 1990: 65)
} 
solucionó el problema amasando el pigmento con óleos secantes. Bomfod et al. (1990: 65) explican que Leclaire utilizaba para éste propósito aceites tratados con litargirio o pirolusita (dióxido de manganeso). Finalmente, el blanco de zinc se introdujo en la pintura al óleo en 1849 y resultó ser una buena opción frente al blanco de plomo.

A finales de siglo, Emilio Bouant aporta alguna información sobre la producción a gran escala mediante el procedimiento indirecto del blanco de zinc.

En la industria se prepara en grande escala siempre por oxidación directa del metal. La sociedad de las minas y fundiciones de zinc de la Vieille Montagne, en sus talleres de Francia, Bélgica y Prusia, fabrica anualmente más de 8 millones de kilogramos de blanco de zinc. El procedimiento empleado es teóricamente muy sencillo. Se calienta á una elevada temperatura el metal contenido en retortas; así se reduce á vapor; los vapores arden en una corriente de aire y engendran el óxido, que se condensa en una serie de cámaras situadas al lado de las retortas (Bouant, h. 1888: II, 936).

El procedimiento patentado por Jones que partía de un mineral de zinc y no del metal se conocía bajo el nombre de 'proceso americano' o 'proceso directo'. Según Rinaldi (1995: 41), el mineral de zinc - smithsonita $\left(\mathrm{ZnCO}_{3}\right)$ o esfalerita (blenda $\left.\mathrm{ZnS}\right)$ - se calentaba sobre una tela metálica con carbón y creta. El objetivo del carbonato cálcico o creta era descomponer los silicatos de zinc y ayudar a su transformación en óxido que se producía gracias al aire caliente. Los vapores de zinc se condensaban y finalmente se recogían. Kühn (1986: 176) explica que el blanco de zinc elaborado mediante el procedimiento francés era de mayor pureza que el mismo blanco elaborado mediante el procedimiento americano o directo, aunque este último blanco tenía mayor resistencia a los agentes atmosféricos. 
La sensibilidad ante los problemas de salud que causaba el blanco de plomo creció notablemente por lo que la inocuidad del blanco de zinc comenzó a valorarse como una apreciable virtud. Una impactante exposición del tema fue publicada en el Brooklyn Daily Eagle del 14 de octubre de 1850. Este artículo explica las ventajas del óxido de zinc descubierto por Leclaire comparándolo con los desastres de salud que ocasionaba el blanco de plomo (Chaning Downs, 1976: 90): “... in the process of making white lead, thousands of human beings have been, and still are, yearly sacrificed." No debemos olvidar que esta preocupación suscitó, muchos años antes, la búsqueda de un pigmento blanco que sustituyera al extremadamente tóxico carbonato básico de plomo. El Brooklyn Daily Eagle llegó a considerar que la elaboración del blanco de zinc podría ser el descubrimiento moderno más importante.

En las fuentes primarias españolas el blanco de zinc tiene escasa repercusión. Podemos considerar que la primera mención a esta sustancia consta en el Archivo Histórico de la OEPM. A nombre de Francisco Ruizmalo Álvarez y con fecha del 3 de enero de $1891^{8}$ aparece "Un procedimiento para la obtención de blanco de zinc (óxido de zinc)"9. Otra patente del año 1896 a nombre de Gaston Harmegnies rezaba "Un procedimiento para la fabricación del blanco de zinc, por vía húmeda." ${ }^{10}$ Una patente registrada en 1901 refleja el proceso americano de elaboración del pigmento. William Beebe Middleton patentó "Un procedimiento para obtener blanco de zinc u otros cuerpos análogos directamente de los minerales y de una manera continua merced a un aparato apropiado."11

\footnotetext{
${ }^{8}$ Realmente hay una patente anterior en que se mencionan los pigmentos de zinc pero el título de la misma es menos explícito. La patente a que nos referimos ( $\mathrm{N}^{\mathrm{O}}$ 2078) está a nombre de Andrew Gordon French y es de 1881: "Un procedimiento o aparato mejorado para hacer composiciones o pigmentos blancos de los materiales o minerales que consistan o contengan plomo o zinc." Archivo Histórico de la OEPM.

${ }^{9}$ Archivo Histórico de la OEPM. No de patente 11640.

${ }^{10}$ Archivo Histórico de la OEPM. No de patente 19847.

${ }^{11}$ Archivo Histórico de la OEPM. No de patente 28940.
} 
El catálogo de L. Péant é Hijos (1895: 7) ofertaba el blanco de zinc entre los "Colores Superfinos Preparados para el Óleo por los Procedimientos de J. G. Vibert". El precio del "Oxido de zinc" era ligeramente más elevado que el precio del blanco de plata. Entre los tratados, el nuevo pigmento únicamente comparece en las traducciones de los textos franceses: Bellanger (1899) y Vibert (1908). Las descripciones que Bellanger (1899: 184) elabora de los pigmentos son muy breves y concisas. "Blanco de zinc. _ Óxido de zinc, obtenido por combustión". También Vibert (1908: 244) explica que "El blanco de cinc se obtiene oxidando los vapores de cinc por medio de una corriente de aire." Es muy probable que ambos artistas se refieran al 'proceso francés'.

Uno de los inconvenientes del blanco de zinc al óleo es su escaso poder cubriente. Emilio Bouant (h. 1888: II, 937) expone que "Es objeto aún de controversia la cuestión de si el blanco de zinc cubre mejor ó peor que el de plomo." Vibert (1908) intenta aportar soluciones a este problema del blanco de zinc.

No es inalterable (sic) como el blanco de plomo, pero no adquiere con el aceite la misma solidez; permanece más frágil, más fácil de desmoronar, y no cubre tan perfectamente. Sin embargo, puede dársele más cuerpo comprimiendo fuertemente el polvo de óxido de cinc con la prensa hidráulica antes de molerlo, ó moliendo previamente este polvo con agua, para formar panes que se secan en una estufa. (Vibert, 1908: 244)

Este artista francés recomienda emplear el blanco de zinc en las mezclas con bermellón y con cadmio porque el contenido en azufre de estos compuestos puede alterar el blanco de plomo. En cambio, el óxido de zinc - como ya se ha explicado - permanece blanco aún cuando se combina con el azufre. Vibert explica sencillos ensayos que los pintores podían realizar al blanco de zinc para determinar las diferentes adulteraciones a las que podía haber sido sometido el pigmento. 
Blanco de cinc.

(Óxido de cinc)

$\mathrm{El}$ óxido de cinc debe disolverse en vinagre. Si queda un residuo blanco muy pesado, es porque el blanco contenía carbonato de barita. Cuando esté disuelto el óxido de cinc, se agrega la disolución de sal (dos veces el volumen del cinc), el líquido debe seguir claro; si se forma precipitado, es señal de que contiene plomo. La disolución clara de oxido de cinc, diluida en quince veces su volumen de agua, si se le agrega un volumen de agua cobre, debe permanecer clara. Si hay precipitado es porque contenía carbonato de cal. (Vibert, 1908: 256)

Cuando en 1849 comenzó a comercializarse el blanco de zinc al óleo, las autoridades francesas proclamaron la primera prohibición del blanco de plomo. Este pigmento fue definitivamente prohibido para pintura decorativa en 1909. De acuerdo con Bomford et al. (1990: 65) otros países europeos siguieron el ejemplo francés en materia de legislación contra el uso del blanco de plomo. El blanco de zinc fue la única alternativa eficiente para el blanco de plomo hasta que apareció el blanco de titanio entre 1916 y 1919. Aunque los pintores eran reacios a abandonar el blanco de plomo porque sus propiedades eran superiores a las del óxido de zinc y para ellos no suponía un riesgo para la salud.

Las investigaciones para encontrar un suplente para el blanco de plomo fueron intensas a lo largo de todo el siglo XIX y aportaron, además del blanco de zinc, otras materias útiles para el uso pictórico. Algunas sustancias que se investigaron y ensayaron para ejercer como pigmento blanco no resultaron útiles como pigmento para el óleo. En cambio, demostraron un funcionamiento muy eficiente como pigmento para acuarela, como sustrato para los tintes o como carga de otros colores al óleo. Éste es el caso del sulfato de bario.

Guyton de Morveau expuso - en su informe sobre los blancos datado en 1782 - las posibilidades del sulfato de bario como pigmento que resultó útil en pintura a la acuarela pero deficiente para el óleo. Esta sustancia demostró tener propiedades óptimas 
como base para pigmentos tipo laca y como carga. Según Feller (1986: 49) la variedad natural de la barita debió introducirse en las pinturas hacia 1782-1783, poco después de que Guyton de Morveau presentara su informe. La barita podía elaborarse artificialmente; de este modo se obtenía un producto más puro. Tradicionalmente, la variedad artificial de sulfato de bario ha recibido el nombre de blanco fijo; a veces se puede encontrar con la denominación de blanco permanente pero esta acepción es confusa porque el blanco de zinc también puede encontrarse con este nombre. Feller comenta que The Cyclopedia de A. Rees - publicada entre 1810 y $1824-$ indicaba varios procedimientos para fabricar a bajo coste el sulfato de bario. La fuente citada, además mencionaba un método que publicó el Dr. Hope en las Edinburgh Transactions de 1793. Chaptal (1816: II, 45 - 48) expone los experimentos y procedimientos determinados por diferentes químicos para precipitar la barita.

La barita se incluyó como adulterante del blanco de plomo en la década de 1820. Una referencia interesante al empleo de la barita para este propósito se halla entre los privilegios del Archivo Histórico de la OEPM. Melchor Ibarrondo solicitó el 2 de marzo de 1843 un privilegio para la "Fabricacion del albayalde artificial con sulfato de barita." ${ }_{12}$ Otro privilegio solicitado por Carlos de Villedenil en 1861 atestigua el empleo de la barita como carga: "Procedimiento para aplicar a la pintura el sulfato de barita natural o artificial."13 Según Bouant, (h. 1888: I, 231), el sulfato de bario natural o "baritina" era de gran utilidad en las mezclas con albayalde; mientras que la variedad artificial se empleaba para pintar al temple, en la pintura silícea, para satinar papeles pintados, etc.

El sulfato de bario demostró tener otras capacidades interesantes. En 1847 - cuentan Rinaldi (1995: 47) - el francés Guillaume Ferdinand descubrió que al mezclar sulfato de zinc con sulfuro de bario precipitaba un pigmento blanco que se componía por la íntima conjunción del sulfuro de zinc y el sulfato de bario. Este compuesto fue bautizado en 1870 con el nombre de litopón. Según

\footnotetext{
${ }^{12}$ Archivo Histórico de la OEPM. No de privilegio 657.

${ }^{13}$ Archivo Histórico de la OEPM. No de privilegio 2249.
} 
Gettens y Stout (1966: 125), el pigmento fue aparentemente patentado y comercializado por primera vez hacia 1874, en Inglaterra por John Orr. Este pigmento resulto útil como carga de otros colores o como base para las lacas; además puede encontrarse en las preparaciones de los soportes.

Rinaldi (1995: 48) explica que Georde Henry Hurst en Painters' Colours, Oils and Varnishes: a Practical Manual (1892) describía el método de preparación de un pigmento llamado blanco Griffith o blanco inglés. Este compuesto, introducido en 1876, se obtenía a partir del zinc y tenía una composición similar a la del litopón. Griffith \& Cawley patentó en 1879 un método más novedoso de preparar esta sustancia. Según Uebele (1913: cap. IV) ${ }^{14}$, este proceso demostró ser el mejor de todos los que se introdujeron en el mercado en aquellas fechas. Es interesante encontrar entre las patentes del Archivo Histórico de la OEPM un registro a nombre de "Griffiths, Thomas" datado en diciembre de 1879 cuyo título expresa "Procedimiento para la fabricación de pigmentos blancos que contienen sulfuro de zinc"15.

Pero alternativas al albayalde hubo varias algunas de las cuales eran derivados plúmbeos. En 1837 Soler y Ferrer informaban de otra alternativa, igualmente plúmbea: el submuriato de plomo.

Con la precipitacion del sal saturno por el ácido muriatico, se consigue un blanco de este nombre, el que despues de limpio, puede molerse y emplearse en esta pintura, pues no se toma absolutamente nada. (Soler y Ferrer, 1837: II, 50)

Soler y Ferrer cautelosos ante este nuevo material advierten que “...como no obstante es descubrimiento moderno, y ninguna necesidad tenemos de valernos de él, no puede aun haberse hecho su experiencia: asi es que no se garantiza su solidez.” Puesto que no

\footnotetext{
14 Chapter IV. Lithopone White. Manufacture, Composition And Uses Of The Pigment, Which Has In Recent Years Come Into General Use. (Uebele, 1913) ${ }^{15}$ Archivo Histórico de la OEPM. No de patente 703.
} 
aconsejan su uso, la inclusión de este pigmento entre los blancos parece ser un dato puramente informativo de su existencia.

El ácido muriático es uno de los nombres que recibe el ácido clorhídrico. Por eso, el submuriato de plomo que anuncian Soler y Ferrer podría ser un cloruro de plomo. Buant (h. 1888) explica una forma de elaboración de este compuesto.

Cuando se trata el litargirio por ácido clorhídrico diluído é hirviendo, por enfriamiento se depositan unos cristales blancos de aspecto anacarado de cloruro de plomo $\mathrm{Pb} \mathrm{Cl}$. También se prepara por doble descomposición, cuando se trata una sal soluble de plomo por un cloruro. (Buant, h. 1888: II, 527)

Cuenta este químico que el cloruro de plomo puede convertirse en oxicloruro de plomo ${ }^{16}$ y formar, de esta forma, magníficos colores amarillos. Según Carlyle (2002: 516), algunas fuentes inglesas Salter (1869), Mallet (1870), o Church (1890) - describen un oxicloruro de plomo llamado blanco Pattison. Apunta Carlyle que en el manual de Scott Taylor (1885) el pigmento aparece mencionado entre los colores que no tenían uso ordinario.

Otra alternativa al carbonato básico de plomo fue el sulfato de plomo.

SULFATOS DE PLOMO (Esc. Sinóp. 40 ácido sulfúrico, 112 óxido de plomo). El ácido sulfúrico no obra sobre el plomo, á no ser que esté concentrado é hirviendo: el ácido se descompone entonces, una parte oxida el plomo y el ácido se desprende en estado de ácido sulfuroso: la otra parte de ácido que no se ha descompuesto se combina con el óxido formado.

"Esta sal es un polvo blanco insoluble en el agua y sin sabor; con el calor se vaporiza en el aire en forma de vapores blancos. En

\footnotetext{
${ }^{16}$ Un oxicloruro de plomo amarillo fue descubierto por Scheele en 1770 y patentado en la década siguiente por James Turner. Los nombres más comunes con los que se conocía este pigmento eran amarillo patente, Turner o mineral. (Ver 5.1.2.)
} 
las artes se prepara esta sal en gran cantidad al mismo tiempo que el acetato de alúmina, con el acetato de plomo y el alumbre." Suele emplearse para reemplazar el albayalde. (Desmarest, 1828: I, 408)

Explica este químico que el escaso poder cubriente del sulfato de plomo llevó a que se intentara convertir en albayalde “...a cuyo fin se hierve con una disolución de carbonato de amoníaco ó de sosa.” (Bouant, h. 1888: II, 532). Pero el químico explica que la operación referida sólo tendría provecho en las fábricas dónde se produce el sulfato de plomo en cantidad. Un privilegio de 1866: "Nuevo procedimiento para producir los sulfatos de plomo y su reduccion a albayalde por medio de acidos"17 demuestra que ésta podía ser una práctica relativamente común.

El sulfato de plomo y otros productos de este metal aparecen también entre las patentes albergadas en el Archivo Histórico de la OEPM. En el año 1887, y con apenas unos meses de diferencia, el artista Farhnam Maxwell Lyte ${ }^{18}$ inscribió sendas "Mejoras en la fabricación de sulfato básico de plomo y cloruro básico de plomo y formas básicas de otras sales de plomo insolubles o ligeramente solubles de modo que las haga aptas para emplearse como colores blancos."19 En el año 1896, Solomon Ganeli patentó “Mejoras en la producción de un sustituto para el albayalde y otras sales oxigenadas de plomo, obtenidas del sulfato de plomo y del clórido de plomo.”2o

\footnotetext{
${ }_{17}$ Archivo Histórico de la OEPM. No de privilegio 4224. Solicitado por Fell, Tomas Mara \& Fell, Ambrosio Jorge.

${ }^{18}$ Farnham Maxwell Lyte (Inglaterra, 1828-1906). Fotógrafo. Vivió mucho tiempo en Francia. En Pau se encontró con un grupo de fotógrafos y fotografió la zona. El Museo de Arte de Cleveland conserva algunas de sus fotografías de los Pirineos. Lyte fue el responsable de algunas innovaciones y mejoras técnicas, entre ellas destacan las mejoras en los métodos de trabajo con el colodión y el papel encerado. Además elaboró un procedimiento que llamó metagelatina que fue adoptado por algunos de sus contemporáneos.

${ }^{19}$ Archivo Histórico de la OEPM. No de patente 7279 y 7599 . El título de esta última patente varía únicamente en una palabra que cambia por completo el sentido de la patente: “...que las haga aptas para emplearse con colores blancos". Si hacemos caso a esta definición, los compuestos referidos no se elaborarían como pigmentos blancos sino como cargas.

${ }^{20}$ Archivo Histórico de la OEPM. No de patente 18973.
} 
Aún en 1902, el sulfato de plomo era considerado una alternativa al albayalde y James Ballantyne Hannay patentó "Un procedimiento perfeccionado para la fabricación de un pigmento blanco de sulfato de plomo por medio del aparato que se describe.”21

Según Carlyle (2002: 515) algunas fuentes inglesas también mencionan el sulfato de plomo (Ibbetson, 1803; Field, 1835; Salter, 1869) aunque este estaba considerado como un blanco de inferior calidad que el carbonato básico de plomo. El sulfato de plomo encontró aplicación al óleo en las mezclas de blancos. Según la información destacada por Carlyle, un manual de colores fechado hacia finales de siglo enumera un "Permanent Flake White" patentado por Freeman \& Co. formado por sulfato de plomo y óxido de zinc. Esta mezcla tuvo cierta repercusión y aparece en varios manuales: Seward (1889), Church (1890 y 1901), Standage (1892), Laurie (1895). Las mezclas de compuestos plúmbeos y de zinc también quedaron reflejados entre las patentes que se registraron en el territorio español a finales del siglo XIX. En 1893, A. C. J. Chartier solicitó la patente por las "Mejoras en aparatos para la fabricación de pigmentos metálicos o compuestos y en la producción de pigmentos o compuestos de plomo y zinc y combinaciones de estos por los referidos aparatos." 22

\subsubsection{Amarillos y naranjas}

Entre los primeros pigmentos amarillos modernos, los pintores contaron con un derivado del plomo. El incansable químico y farmacéutico Carl Wilhelm Scheele descubrió en la década de 1770, un pigmento de color amarillo compuesto por oxicloruro de plomo. El proceso de elaboración del pigmento fue patentado en 1781 por James Turner en Inglaterra. Este amarillo se introdujo en el comercio con las denominaciones amarillo Patente y amarillo Turner

\footnotetext{
${ }^{21}$ Archivo Histórico de la OEPM. No de patente 29189.
}

${ }^{22}$ Archivo Histórico de la OEPM. No de patente 15016. 
pero también se le concedieron otros nombres: 'amarillo Cassel', 'amarillo Montpellier', 'amarillo mineral', 'amarillo Verona', 'amarillo Veronés', 'amarillo inglés', etc. Dada la escasez de amarillos en la paleta artística decimonónica, este pigmento tuvo cierto éxito. Además su contenido de plomo ${ }^{23}$ contribuía a sus buenas cualidades de secado y a facilitar el trabajo al óleo.

Encontramos escasas referencias e este compuesto en las fuentes españolas decimonónicas. La primera de ellas se muestra en la voz "COLORES" del "Diccionario Explicativo de las Voces y Términos mas usados en la Pintura..." en el Manual del Pintor de Agustín Algarra. Este autor (1875: 222 - 223) enumera una serie de colores “...que se emplean mas generalmente en la pintura á la aguada y al óleo,...”; y entre ellos menciona el amarillo mineral. Pero se trata de un elenco con las denominaciones de los colores sin aportar la composición química ni descripción alguna. Para el químico Bouant los amarillos compuestos por oxicloruro de plomo son colores adecuados para la pintura.

[El cloruro de plomo] Es susceptible de combinarse con el protóxido de plomo, suministrando diferentes oxicloruros, que constituyen magníficas materias colorantes empleadas en pintura, como son: los amarillos de Cassel, de París, de Vérone y de Turner. (Bouant, h. 1888: II, 527)

En cambio, Vibert (1908: 247) esboza argumentos contrarios. Este pintor francés asegura que todos los amarillos que suministra el plomo son malos porque se oscurecen o descomponen otros colores metálicos con los que se mezclan. El "Amarillo mineral (oxicloruro de plomo)" es uno de los pigmentos integrantes de esta lista de colores proscritos por Vivert.

Harley (1982: 100) indica que el amarillo Patente al óleo aparece en catálogos de colores de la primera mitad del siglo XIX; pero la omisión en catálogos del mismo periodo sugiere que el

\footnotetext{
${ }^{23}$ Precisamente el contenido de plomo facilitaba la propensión del color a ennegrecer cuando estaba amasado a la acuarela.
} 
pigmento fue - en alguna medida - substituido por el amarillo de cromo. De hecho, el amarillo de cromo tiene más repercusión en nuestras fuentes decimonónicas. Aparece mencionado cómo un pigmento válido en Soler y Ferrer (1837: 51 - 52), O'Neille (1862: 39), Algarra (1875: 222), L. Péant é Hijos (1895: 4, 8, 11 y 12) y López Tomás (1898: 48).

El descubrimiento del cromo - puntualizan Gettens y Stout (1966: 142) - supuso un hallazgo importante en la historia de los pigmentos porque de el derivan numerosos pigmentos y proporciona un rango de colores mayor que cualquier otro elemento. El químico L. N. Vauquelin anunció en 1797 el descubrimiento de un nuevo metal que formaba parte del Plomo Rojo de Siberia ${ }^{24}$. Éste es el nombre que en el siglo XIX los franceses concedían a la actual crocoita. La antigua denominación francesa - Plomb Rouge de Sibérie - es muy descriptiva. El mineral se encontró por primera vez en Siberia, tenía un intenso color rojo y, según la creencia generalizada, estaba compuesto por plomo.

Vauquelin bautizó el nuevo componente del Plomo Rojo de Siberia con el nombre de cromo - color en griego - por su capacidad de impartir color. Desde entonces quedó claro que este mineral rojo era un cromato de plomo natural. A pesar de que esta piedra cuando se pulverizaba producía polvos de distintos tonos - desde el rojo anaranjado hasta el amarillo rojizo - no existe indicación de que fuera empleada como pigmento. Desde un poco antes de 1800, Vauquelin comenzó a realizar infinitud de experimentos con el cromo hasta que consiguió sintetizar el cromato de plomo puro, un intenso color amarillo.

Hacia 1803 - 1804, Vaquelin y su entonces colaborador Berthollet reconocieron la utilidad del cromato de plomo como pigmento. En 1809 Vauquelin publicó su investigación completa sobre la química de los colores de cromo: amarillos, naranjas, rojos y el verde de cromo que alcanzaron mayor o menor difusión como pigmentos artísticos. Mérimée (1830: 104) comenta sobre los

${ }^{24}$ Kühn y Curran (1986: 188) advierten que J. G. Lehmann mencionó por primera vez este mineral en una carta dirigida al naturalista G. L. L. de Buffon en 1762. 
diferentes colores que se obtienen del cromo: "En effet, le chromate de plomb est jaune, le chromate de mercure ${ }^{25}$ est rouge, et celui d'argent pourpre; enfin l'oxide de chrôme est une couleur verte,..." Pero Bomford et al. (1990: 62) aseguran que el principal atractivo del cromo como fuente de colores artísticos radica en la amplia variedad de amarillos y naranjas que produce.

De acuerdo con Kühn y Curran, el amarillo de cromo fue identificado en una obra de Sir Tomas Lawrence: Retrato de un Caballero, datado entre 1800 y $1810^{26}$. Este dato indicaría que el pigmento estuvo disponible poco después de su descubrimiento. Como sugiere Philip Ball (2003: 203), cuando Vauquelín publicó su investigación en 1809, el amarillo de cromo ya estaba en la paleta de los artistas. Si la crocoita tenía que llegar desde Siberia para que los fabricantes elaboraran los pigmentos de cromo, éstos podían resultar muy caros. Afortunadamente, en 1818 se descubrió en Francia la cromita un cromato de hierro del que se podía extraer el cromo para elaborar los pigmentos derivados de éste metal. Dicen Gettens y Stout (1966: 107) que el amarillo de cromo no se produjo comercialmente antes de esta fecha. Yacimientos de cromita comenzaron a explotarse en 1820 en Inglaterra. Pero fueron las minas americanas las que exportaron mineral de cromo a Europa para la elaboración de pigmentos porque la avidez por los pigmentos de cromo dejó casi exhausto el yacimiento francés en 1829. Mérimée (1830: 105) indica que un mineral que contenía óxido de cromo, similar al que se encontró en Francia, fue descubierto en EEUU: "On en a également trouvé aux Éstats-Unis, dans le Mariland, et c'est de Baltimore que vient en grande partie celui du commerce."

Bomford et al. (1990: 62) cuentan que el informe de Vauquelin explicaba que la precipitación del cromato de plomo se obtenía mediante una solución de cromato de potasio. La variación

25 Kühn y Curran (1986: 212) señalan que el cromato de mercurio rojo fue un pigmento poco significativo como colorante en la pintura.

26 El Doerner-Institute de Munich detectó el amarillo de cromo en 205 pinturas de los siglos XIX y XX pertenecientes a la Bayerische Staatsgemäldesammlungen (Colección de Pintura del Estado Bávaro) entre ellas la mencionada pintura de Sir Tomas Lawrence. (Kühn, H. y Curran, M., 1986: 213) 
del color dependía de la acidez o alcalinidad de la solución y de su temperatura. A partir de una solución neutra se obtenía un cromato de plomo de color amarillo - naranja; con una solución ácida precipitaba un color amarillo limón intenso; y mediante una solución alcalina se obtenía un rojo amarillento. Si la disolución presentaba un exceso de álcali se alcanzaba un intenso color rojo. Los naranjas y rojos estaban formados por cromato básico de plomo.

Todas las posibilidades del amarillo de cromo como pigmento para la pintura artística fueron detalladamente expuestas por Soler y Ferrer.

CROMO: El cromato de plomo, amarillo real, ó cromo dicho mas comunmente, es el mas precioso amarillo por su viveza y brillantez, de modo que en sus tonos mas claros es el que mas analogía tiene al del iris ó prisma: es muy flojo ó ligero, y de poco cuerpo; por lo que, y ser principalmente mudable de tal modo que insensiblemente baja hasta el tono ocre claro, se usa apenas mas que para lo indispensable. Lo hay de distintos tonos desde el amarillo dicho de canario, hasta el naranjado; y entre ellos es el mejor el mas subido, pues da mas de si y admitiendo mas albayalde, adquiere con el mas cuerpo y solidéz. Es de un uso general para la composición de los distintos verdes vivos, é intensos unidos al merlino, ó azul de Prusia, y cobalto; con los que toma un cuerpo y brillo admirable que tampoco mudará cuidando de barnizar el cuadro luego de seco, y aun con esta prevencion podrá gastarse puro en toques de oro y demas que sea preciso. No necesita de pórfirizarse, y bastará el pastarlo incorporándolo al aceite con el cuchillo sobre la paleta. (Soler y Ferre, 1837: II, 51-52)

A pesar de la reconocida alteración que sufre este color, los autores mencionados sugieren el pigmento para conseguir verdes brillantes. En el comercio se podía encontrar que el amarillo de cromo formaba parte de diversos verdes; algunos de estos se ofertaban en el catálogo de L. Péant é Hijos. Aunque como el cromato de plomo no era estable algunos autores rechazarán este pigmento y todas las mezclas en las que se incluya. (Ver 5.1.6.) 
En el catálogo de L. Péant é Hijos aparecen varias referencias a los diferentes matices del amarillo de cromo. Entre los "Colores Extrafinos en Tubos para Pintar al Óleo" de A. Lefranc encontramos con la composición "Cromato de plomo" diversos amarillos de cromo: claro, oscuro, naranja y limón. Todos considerados estables y marcados “*” (L. Péant é Hijos: 1895, I, 4). Los colores al óleo para el decorado artístico de Lefranc y $C^{\text {ie }}$ también enumeran amarillos de cromo claro, oscuro y naranja pero, en esta ocasión, los matices claro y oscuros están marcados con una estabilidad completa “**” mientras que el amarillo naranja tiene consignado “*” de color estable (L. Péant é Hijos, 1895: I, 11). La carta de colores de Félix Mommen también enumera los matices claro, oscuro y naranja del amarillo de cromo. Posiblemente, estos son los tonos que ofrece Lefranc \& Cie en su carta de "Colores Finos Preparados para la Pintura al Óleo": amarillo "cromo, 3 tonos" (L. Péant é Hijos, 1895: I, 8).

El amarillo de cromo tuvo muchos usos en su época como atestigua Riffault en su Manual Teórico Práctico del Pintor, Decorador y Charolista.

Este amarillo se emplea con ventaja en la pintura sobre lienzo y porcelana, en la fabricación de papeles pintados, en la pintura de las habitaciones, y asímismo para hacer fondos amarillos, particularmente en las cajas de los coches. (Riffault: 1850: 40)

Pero el cromato de plomo amarillo tenía los inconvenientes de los colores plúmbeos que oscurecen con los vapores sulfurosos de la atmósfera. Según Mérimée (1830: 106), el amarillo de cromo, con los años, tomaba un matiz ocre. Como ya hemos visto, la misma apreciación fue hecha por Soler y Ferrer (1837). Esta alteración fue el motivo de que Bellanger (1899) y Vibert (1908) rechazaran el pigmento. Mérimée (1830: 106) pensaba que se podía solucionar este inconveniente mezclando el cromato de plomo con sílice y alúmina y sometiendo la mezcla a cierto grado de calor.

La aparición de los amarillos y naranjas de cromo supuso una pequeña revolución en la pintura. Cuando estos colores entraron en 
el mercado, los pintores pudieron desarrollar nuevos recursos técnicos y estéticos. De esta forma se hicieron posibles las nuevas tendencias pictóricas que se desarrollaron a finales del siglo XIX. Por una parte, el amarillo de cromo poseía un elevada intensidad del color y una gran capacidad cubriente que permitió a los pintores utilizar este pigmento alla prima. Por otro lado, el naranja de cromo fue el primer pigmento de este color con un matiz verdaderamente puro y vivo. Según Philip Ball (2003: 203), los pintores gustaron de emplear este color para crear efectos dramáticos. Entre las fuentes primarias españolas el naranja de cromo no tiene repercusión. Pero Mérimée habla de el en De la Peinture a l'Huile.

Chromate orangé de plomb (sous-chromate de plomb).

Cette couleur est moins brillante que le minium et que l'orpin rouge (le réalgar); elle est plus solide que le chromate jaune.Toutefois, les huiles ont trop d'action sur les oxides de plomb, pour que cette couleur soit parfaitement solide: on ne doit donc l'employer qu'avec précaution à des draperies où l'alteration de la couleur peut n'être pas d'une grande importance. (Mérimée, 1830: 121)

Otros pigmentos amarillos de cromo aparecieron en el mercado de materiales pictóricos. Los cromatos amarillos de bario, de estroncio y de zinc tuvieron cierta repercusión como pigmentos artísticos. Estos tres cromatos tenían el inconveniente de adquirir, en mayor o menor medida, un matiz verdoso cuando se exponían a la luz. Además todos ellos han compartido algunas denominaciones como amarillo limón o ultramar. Aunque también han tenido otras designaciones; por ejemplo; el cromato de bario puede encontrarse bajo los nombres amarillo de barita, de bario o de Steinbühl; el cromato de estroncio se puede hallar referenciado como amarillo de estronciana; y el cromato de zinc como amarillo permanente, botón de oro, jaune de chrôme malterve o amarillo citrón. Estos cromatos amarillos aparecen mencionados en las fuentes decimonónicas españolas más tardías bajo diferentes designaciones. Con las denominaciones genéricas de amarillo limón y ultramar, sin explicar 
la composición, se encuentran entre los "Colores finos preparados para la pintura al óleo” de Lefranc \& $\mathrm{C}^{\mathrm{ie}}$. y entre los colores al óleo del belga Félix Mommen que se ofertaban en el catálogo de L. Péant é Hijos (1895: I, 8 y 12).

De éstos cromatos el de estroncio es el que aparece más veces mencionado en las fuentes españolas decimonónicas. L. Péant é Hijos (1895), López Tomás (1898) y Vibert (1908) reconocen la utilidad de este pigmento para uso artístico. Un "Cromato de estronciana" designado cómo amarillo de estronciana podía adquirirse en el establecimiento de L. Péant é Hijos (1895: I, 4) en Madrid a finales de siglo. El color, marcado como estable “*”, pertenecía a la gama de colores al óleo de A. Lefranc. También este catálogo ofertaba el mismo color con idéntica composición entre los colores al óleo que Lefranc elaboraba mediante los procedimientos de Vibert (L. Péant é Hijos, 1895: I, 7). Esto no es de extrañar pues el pintor francés - que sólo recomienda amarillos modernos - propone el amarillo de estroncio como uno de los mejores amarillos para pintura. Para comprobar las posibles adulteraciones del cromato de estronciana el pintor francés propone:

Se agregan al cromato de estronciana diez veces su volumen de agua fuerte. Debe disolverse enteramente. La solución se pone anaranjada si se agrega sal. Si precipita un residuo amarillo, éste sería amarillo de cromo. (Vibert, 1908: 256)

Lefranc \& $\mathrm{C}^{\text {ie }}(1892,18)$ explican que se trata de un pigmento de elevada opacidad por lo que su uso es más provechoso en los tonos luminosos. La breve mención de López Tomás (1898: 48) a este color se limita a expresar "También se pueden usar los amarillos de cromo (cromato de plomo) y de estronciana (cromato de estronciana)". El cromato de estroncio - dice Carlyle (2002: 522) - apareció en los catálogos de Winsor \& Newton por primera vez h. 1861 y, después de un intervalo, se ofertó de nuevo en el catálogo fechado h. 1896. Reeves lo ofrecía en su catálogo de 1872 y Rowney en el de 1885.

El cromato de bario también fue incluido por Vauquelin en su informe de 1809 pero tuvieron que transcurrir bastantes años hasta 
que fuera considerado su uso como pigmento artístico. Según Kühn (1986: 205), en 1807 Klaproth \& Wolff sugirieron el empleo del cromato de bario para porcelana. Sin embargo, empezó a reconocerse como pigmento para la pintura artística a mediados del siglo XIX. Harley (1982: 103) explica que el cromato de bario - de acuerdo con Bachhoffner ${ }^{27}$ - apareció en Inglaterra cuando Field ${ }^{28}$ lo propuso en 1835 como una alternativa barata al amarillo de platino.

El amarillo de bario era un pigmento de bajo poder cubriente y escaso poder de tinción; además adquiría un matiz verdoso por exposición a la luz. Vibert (1908: 247), que lo denomina "Amarillo de ultramar (cromato de bario)", lo considera como un pigmento no adecuado para la pintura. Pero este color al óleo lo suministraban L. Péant é Hijos en 1895. El cromato de barita, llamado ultramar amarillo, constaba entre los "Colores extrafinos en tubos para pintar al óleo" de A. Lefranc (L. Péant, 1895: I, 4). El belga Félix Mommen proporcionaba un color al óleo denominado “Amarillo barita” (L. Péant, 1895: I, 12).

Vauquelin también mencionó en su informe de 1809 el cromato de zinc aunque no hay noticias de su uso como pigmento hasta mediados de siglo. Milaneschi (1995: 244) considera que Leclaire y Parruel fueron los primeros en proponer el cromato de zinc como pigmento otorgándole el nombre de amarillo botón de oro ${ }^{29}$. Carlyle (2002: 523) explica que la primera mención del cromato de zinc en las fuentes inglesas la proporciona Martel ${ }^{30}$ en 1859. Según este último autor, los esfuerzos por reemplazar los compuestos de plomo dieron sus frutos gracias a la elaboración de pigmentos de zinc; en este caso, el cromato de zinc sustituiría al

\footnotetext{
${ }_{27}$ Bachhoffner, George, H.: Chemistry as Applied to the Fine Arts. London, 1837. ${ }^{28}$ Field, George: Chromatography: or a Treatise on Colours and Pigments, and of their Powers in Painting. London, 1835.

${ }_{29}$ Botón de oro es el nombre genérico que reciben algunas plantas de brillantes flores amarillas como el ranúnculo de la familia ranunculaceae o caléndula de la familia astaraceae (Herbario Virtual del Mediterráneo Occidental). Tal vez, se eligió este nombre porque hacía referencia a hermosas flores de intenso color amarillo.

$3^{\circ}$ Martel, Charles: On the Materials Used in Painting with A Few Remarks on Varnishing and Cleaning Pictures. London: George Rowney and Company, 1859.
} 
cromato de plomo. Tanto Kühn y Curran (1986: 201) como Milaneschi (1995: 244) informan que en 1847 el químico escocés James Murdock - o Murdoch - producía tres matices diferentes del cromato de zinc: marigold, limón y amarillo pálido ${ }^{11}$.

El cromato de zinc era un pigmento amarillo brillante y limpio que tenía la ventaja de ser inocuo para la salud y además los vapores sulfurosos no lo oscurecían. Y, a pesar de no tener la consistencia del cromato de plomo y de tender al verde bajo la influencia de la luz, fue uno de los pigmentos amarillos recomendados por Vibert. En la lista de los colores que el pintor puede emplear con toda seguridad, Vibert (1908: 90) incluye el "Amarillo de cinc (cromato de cinc)". Sin embargo, en materia de denominaciones de pigmentos es todo muy confuso. Si por una parte Vibert (1908: 247) recomienda el cromato de zinc, por otra desaconseja enérgicamente el "Amarillo botón de oro”. Tal vez Vibert no veía inconveniente en que los pintores usaran este pigmento, sin embargo el color no se encontraba entre los colores Lefranc que se fabricaban bajo sus indicaciones.

Carlyle (2002: 523) comenta que un amarillo citrón aparece en los catálogos de Winsor \& Newton datado h. 1861; y en el catálogo de la misma compañía fechado h. 1896 se muestra la denominación cromato de zinc. De manera similar, en el catálogo de Reeves h. 1896 se exhibe un amarillo citrón que fue reconocido en el catálogo de h. 1898 como cromato de zinc. Una identificación interesante del pigmento se obtuvo en la colección de pigmentos de Arnold Böcklin (1827-1901).

Otro de los elementos que ha dado lugar a una amplia gama de colores es el cadmio, identificado por F. Strohmeyer en 1817. Amarillos, naranjas y rojos nacen del cadmio y a pesar de su temprana identificación, los amarillos de cadmio no se comercializaron hasta la década de 1840. Bomford et al. (1990: 64) asegura que los amarillos y naranjas de cadmio debieron tener

${ }^{31}$ Kühn y Curran recogen este dato de Remington, J. S.: Pigments, Their Manufacture and Properties. London, 1944. Mientras que Milaneschi extrae la información de Hurst, G: Painters' Colours, Oils and Varnishes. Londres: Griffin \& Co., 1892. 
un precio muy elevado en la década de 1870 y debieron estar más disponibles en Alemania e Inglaterra que en Francia. Según Getten y Stout (1966: 101), en 1892 una patente alemana menciona la fabricación de un rojo - naranja de cadmio, sin embargo, la producción comercial de este color no comenzó hasta 1910.

El amarillo de cadmio comparece en las fuentes españolas de finales del siglo XIX. El catálogo de colores e L. Péante é Hijos (1895) lo ofertaba entre los colores de Lefranc y Félix Mommen. En las diferentes gamas de colores de Lefranc, el sulfuro de cadmio amarillo podía llegar a encontrarse con diferentes matices: limón, claro, mediano y obscuro (L. Péant é Hijos, 1895: I, 4, 7, 8, 11). Mientras que Félix Mommen suministraba amarillo cadmio claro, oscuro y naranja (L. Péant é Hijos, 1895: I, 12). López Tomás (1898) también señala diferentes matices de este color.

AMARILLO, cadmium (naranja, claro, limon; sulfuros de cadmio). Molido al agua como los anteriores y luego con aceite de linaza. Su mejor secante es el aceite de linaza revuelto con azarcón en polvo... (lópez Tomás, 1898: 48)

Este pigmento - amarillo de cadmio claro y oscuro - aparece entre los colores que Bellanger considera útiles para la pintura al óleo. El amarillo de cadmio - aseguran Lefranc \& C $C^{\text {ie }}$ (1892:18) - se podía usar en pasta o en veladuras bastante transparentes cuando se le añadía barniz de retoques o de pintar. Además era útil en la formación de verdes cuando se amasaba con azules. Vibert (1908: 248 - 249) considera que los amarillos de cadmio - anaranjado, claro y limón - son colores estables. Este pintor francés recomienda estos sulfuros de cadmio aunque alerta sobre las alteraciones que puede causar al blanco de plomo si el cadmio contuviera un exceso de azufre. Los ensayos que Vibert propone para que un artista comprueba la calidad del amarillo de cadmio que ha adquirido se elaboran de la siguiente manera:

Se pone el sulfuro de cadmio en un vaso con cuatro veces su volumen de ácido nítrico; debe disolverse, formando una disolución 
lechosa y sobrenadando cierta cantidad de azufre. Si la disolución es gris más ó menos obscura y se torna azul verdosa después de reposar, es señal de que contenía cromato de plomo, y si el residuo es rojo intenso, es porque tenía bermellón. (Vibert, 1908: 257)

Cómo vemos, la variedad de amarillos que apareció durante el siglo XIX amplió considerablemente las opciones de este color en la paleta de los pintores.

\subsubsection{Rojos}

Entre tanta profusión de pigmentos nuevos llama la atención la escasa innovación en materia de rojos. Los rojos modernos no consiguieron arrebatarle al bermellón su primacía. Uno de los pigmentos rojos que aparecieron en el siglo XIX fue el rojo de cromo - cromato de plomo - del que informó Vauquelin en 1809. Ya hemos hablado de la importancia de los amarillos y naranjas de cromo para la paleta de los pintores (Ver 5.1.2.). Según Bomford et al. (1990: 62) los naranjas y rojos de cromo debieron introducirse como pigmento artístico hacia la década de 1830 ó 1840. Pero el rojo de cromo no resultó ser un color permanente en la paleta de los pintores. Probablemente - dicen Gettens y Stout (1966: 106) debido a su falta de brillo y a su facilidad de alterarse con los vapores sulfurosos de la atmósfera. Harley (1982: 130) explica que en las fuentes inglesas decimonónicas son muy pocas las alusiones a este pigmento y, por lo general indican procesos de elaboración con algunas variaciones. Esta magnífica investigadora cuenta que Winsor \& Newton ofertaban en su catálogo de h. 1840 - 42 un escarlata de cromo que no volvieron a anunciar en ulteriores ediciones.

Las fuentes españolas decimonónicas no mencionan el rojo de cromo. La única y dudosa excepción la presenta el catálogo de L. Péant é Hijos (1895: I, 5). Entre los colores Extrafinos de A. Lefranc se anuncia un "Cinabrio amarillo núm. 1, 2 y 3 ” cuya composición es cromato de plomo y cianuro de hierro. Sin duda, esto se debe a que 
no fue un pigmento con grandes repercusiones en la pintura. Los únicos rojos modernos que citan nuestras fuentes de finales de siglo - L. Péant é Hijos (1895) y Vibert (1908) - son los rojos de Marte (Ver 5.1.7.).

Uno de los rojos que menciona Mérimée (1830) es un derivado del cromo: el cromato de mercurio. Pero Kühn y Curran (1986: 212) señalan la efímera e insignificante utilidad de este rojo como pigmento (Ver 5.1.2.). Estos investigadores indican que el cromato de mercurio aparece mencionado en varias fuentes alemanas del siglo XIX. La referencia más temprana es en 1807: Chemisches Wörterbuch de Klaproth y Wolff. En 1840 el diccionario enciclopédico de Hartmann alude el cromato de mercurio como un pigmento comercial. Finalmente, Gentele en 1860 remarcó la poca importancia del pigmento en pintura debido a su escasa estabilidad pues al óleo adquiría un matiz muy oscuro. Encontramos otro pigmento de mercurio utilizado para substituir al bermellón en Vibert (1908: 93). En este caso el pintor francés se refiere al yoduro de mercurio ${ }^{32}$ teñido con eosina aunque en lugar del compuesto de mercurio podía emplearse el minio teñido. Vibert advierte que esta falsificación ponía en peligro la estabilidad de la obra en que se usaba.

En general, no parece que los rojos del siglo XIX tuvieran gran importancia en la paleta de los pintores. Pero a finales del siglo XIX - concretamente en 1892 - se patenta el rojo de cadmio. Un color muy estable, intenso y brillante. Pero la comercialización de este pigmento no fue efectiva hasta 1910 (Gettens y Stout, 1966: 101). No obstante, asegura Carlyle (2002: 505) que en la tratadística inglesa decimonónica se encuentran tres referencias a este color: Salter en 1869, Scott Taylor en 1885 y Standage en 1887. El rojo de cadmio consiguió desbancar de la paleta de los pintores al apreciado bermellón.

A pesar de esta escasa variedad de pigmentos rojos

32 Mérimée (1830: 133) incluye entre los colores rojos un "Deuto - iodure de mercure". 
- cuenta Carlyle (2002: 504) -, los artistas podían encontrar en los catálogos de Winsor \& Newton y en los de Reeves and Rowney del siglo XIX una gran diversidad de este color. La oferta de rojos superaba a la de cualquier otro color. Esto era posible porque la mayoría de estos rojos eran variaciones del color elaborados con un rango pequeño de pigmentos y colorantes como la rubia, la cochinilla y los cromatos. A los que se unieron - pasada la mitad del siglo - los tintes sintéticos.

\subsubsection{Azules}

La mayoría de azules que surgieron a lo largo del siglo XIX fueron el resultado de investigaciones encaminadas a buscar un substituto para el azul ultramar. Este pigmento procedía de un precioso y escaso mineral - lapis lazuli - y por lo tanto su precio era elevado. Los primeros estudios que dieron sus frutos se basaron en el cobalto. Este fue individualizado, según Bordini (1999: 13) - en 1735 por el químico G. Brandt33. Del cobalto surgieron, a lo largo de todo el siglo XIX, colores verdes, azules, violetas y amarillos. El primer color moderno procedente del citado metal fue el azul cobalto. Mientras Chaptal ejercía el cargo de Ministro del Interior de Francia encargó la búsqueda de un nuevo azul.

Mr. Thernard, á quien encargué siendo yo ministro algunas investigaciones sobre los colores, juntamente con Mr. Merimée, inventó un preparado de cobalto que reemplaza con ventaja el de ultramar; [...]

Tres partes de alúmina precipitada del alumbre por el amoníaco, mezcladas con una parte de arseniate ó de fosfate de cobalto, reducidos uno y otro á la consistencia de una especie de jalea, secados y calcinados en un crisol por espacio de media hora,

33 En cambio, Emilio Bouant en el tomo I de su Nuevo Diccionario de Química publicado en Barcelona hacia 1888, asegura que Brandt aisló el cobalto en 1733. 
forman una composicion de un hermoso azul, igual al de ultramar, y que puede servir como este para la pintura al óleo. La experiencia ha manifestado la perfeccion de este resultado, y este azul de cobalto se ha hecho ya un ramo de comercio. (Chaptal, 1816: III, 242)

La fecha aceptada del descubrimiento del azul cobalto por Thenard es 1802 aunque, según Harley (1982: 57), la invención del color se publicó un año más tarde. El azul cobalto es un pigmento muy estable compuesto por aluminato de cobalto. Su matiz era más intenso que la azurita, el Prusia o el índigo y - como comenta Chaptal - fue rápidamente empleado como pigmento. Según Harley (1982: 57), este color comenzó a producirse en Francia en 1807.

Las fuentes españolas decimonónicas demuestran la gran difusión que tuvo el azul cobalto. Este color aparece mencionado en Soler y Ferrer (1837), O'Neille (1862), Algarra (1875), Poleró (1886), L. Péant é Hijos (1895), López Tomás (1898), Bellanger (1899) y Vibert (1908). Sin embargo, no todos estos textos demuestran el mismo aprecio por este color. Soler y Ferrer (1837) comentan las virtudes de este color de origen francés.

El cobalto es un resultado de la mezcla de alumina con una sal de cobalto calcinada: se fabrica en Francia y es su precio de cuarenta hasta sesenta reales la onza. Los mas prácticos y distinguidos artistas lo usan como á el mas seguro y hermoso azul para celages y demas tonos claros, tanto azules como morados, y verdes que de él se compongan y quieran hermosos é invariables. (Soler y Ferrer, 1837: II, 56)

O'Neille (1862: 46) explica que el azul cobalto - igual que el azul guimet $^{34}$ - se empleaba como sustituto del ultramar natural. Pero aunque los azules de cobalto y guimet tenían un uso muy difundido no consiguieron reemplazar al ultramar. El paisajista sugiere que no

34 Guimet descubrió el ultramar artificial en 1828 y azul guimet es uno de las denominaciones que recibe este pigmento. 
se emplee el ultramar natural para estudios porque es demasiado caro. Para los estudios y la mayor parte de paisajes - expone O'Neille - el azul cobalto es suficiente. Por su parte, Algarra (1875: 196) comenta algunos inconvenientes de este azul que carece del intenso brillo del ultramar natural “...y es difícil su empleo. Es necesario escogerle muy bien molido, lo que es muy raro."

Poleró (1886: 82) simplemente enumera el azul cobalto entre los colores que deben ponerse en la paleta. En 1895, el catálogo de colores de L. Péante é Hijos ofertaba este color al óleo. Entre los “Colores Extrafinos en Tubos para Pintar al Óleo" de A. Lefranc aparece el azul cobalto ("Aluminato de cobalto") marcado con ** que indican la fijeza completa del material (L. Péant é Hijos, 1895: I, 4). El mismo catálogo (1895: I, 7) en su serie de colores superfinos, preparados según los procedimientos de Vibert, ofertaba el azul cobalto ("Aluminato de cobalto"). En la gama de "Colores Finos Preparados para la pintura al Óleo” de Lefranc \& C Cie, el catálogo de L. Péant é Hijos (1895: I, 8) enumera el azul cobalto, aunque en esta ocasión, sin expresar la composición química. Los fabricantes de colores franceses también elaboraban colores al óleo para el decorado artístico, según reza el catálogo de L. Péant é Hijos, 1895).

Esta nueva serie de colores, de primera calidad y de un molido perfecto, reune todas las ventajas como precio y empleo para las grandes ejecuciones.

La pueden emplear los artistas pintores de panoramas, decorados, techos, muestras y letras. (L. Péant é Hijos, 1895: I, 10).

El azul cobalto aparece también en el elenco de colores para el decorado artístico aunque tampoco se hace referencia a la composición química de los pigmentos. Igualmente, el mencionado catálogo (1895: I, 12) ofertaba "Colores Extrafinos Preparados para el Óleo de Félix Mommen, de Bruselas.” entre cuyos colores, sin indicar la composición química, se muestra el azul cobalto "extra".

Los tratadistas López Tomás y Bellanger únicamente 
expresan la composición del pigmento. Para López Tomás (1898: 48), el azul cobalto ("combinación de aluminio y óxido de cobalto á alta temperatura") es un buen pigmento azul. Mientras que el comentario de Bellanger (1899: 186) se limita a expresar: "Azul de cobalto._Calcinación de alúmina y de sal de cobalto (metal)." Para Vibert (1908: 251) no hay más que dos azules buenos para pintura; uno de ellos es el azul cobalto ("alúmina y óxido de cobalto") y el otro es el ultramar. Este autor, siempre preocupado por los buenos materiales del pintor, explica los ensayos que los pintores podían hacer a este azul para detectar su adulteración.

Cobalto.

(Óxido de cobalto)

El cobalto, puesto en un vaso con diez veces su volumen de agua de cobre, debe conservar su color. Se hace hervir ó se deja reposar un instante, debiendo ser incoloro el líquido. Si es azul, es señal de la presencia del azul de Prusia.

El olor á huevos podridos indica la presencia del ultramar. El cobalto debe arde en la cuchara sin vapores. (Vibert, 1908: 258 259)

Los constantes esfuerzos por encontrar un pigmento azul que sustituyera al ultramar dieron de nuevo sus frutos en la década de 1820. Clément y Désormes dilucidaron en 1806, la composición del ultramar natural. Unos años más tarde, en 1814, Vaquelin informó sobre unas masas cristalinas que producían los hornos de vidrio de Saint-Gobain ${ }^{35}$. El químico demostró que la composición de estas masas cristalinas era bastante similar a la del ultramar natural;

\footnotetext{
35 Plester (1993: 55) explica que la primera observación sobre un pigmento utilizado como suplente del ultramar la aportó Goethe. Mientras el escritor viajaba por Italia en 1787 advirtió unos depósitos azules en los hornos de cerámica cerca de Palermo. Goethe señaló que estas masas azules se empleaban como sustituto del lapislázuli en trabajos decorativos. El fenómeno fue percibido, años más tarde, por Tassaert que encontró las masa azules en la fábrica de Saint Gobain y llevó las muestras a Vaquelin para que las analizara.
} 
este dato, asegura Harley (1982: 58), centró la atención en la posibilidad de fabricar un ultramar artificial. El gran interés por hallar un pigmento que sustituyera al ultramar, cuenta Harley, llevó a la "Royal Society of Arts" a ofrecer, en 1817, un premio a quien pudiera demostrar que se podía fabricar un ultramar artificial.

El nuevo pigmento debía tener igual calidad que su homólogo natural pero debía ser más barato; nadie reclamó el premio. En 1824, la Société d'Encouragement pour l'Industrie Nationale de Francia ofreció un premio más generoso y Jean Baptiste Guimet obtuvo el premio en 1828. El químico alemán Gmelin reclamó la recompensa y demostró que había publicado el método de elaboración un año antes. Guimet se defendió argumentando que elaboró el pigmento en 1826 pero que no lo había publicado por tratarse de un secreto. El químico francés notificó que el pigmento había sido utilizado por eminentes pintores como Ingres ${ }^{36}$. Actualmente, el ultramar artificial está considerado una invención francesa. Gettens y Stout (1966: 163) exponen que los alemanes Gmelin y Köttig perfeccionaron el proceso. Rápidamente, en 1830, el ultramar artificial comenzó a fabricarse en Francia y Alemania; poco después la elaboración empezó en Inglaterra37, Bélgica y Estados Unidos.

El ultramar artificial es uno de los azules modernos que aparece mencionado en nuestras fuentes con más frecuencia. Soler y Ferrer (1837), O'Neille (1862), Bellanger (1899) y Vibert (1908) citan el ultramar artificial como un color adecuado para la pintura al óleo. Soler y Ferrer, en la tercera década del siglo, consideran que cómo el ultramar tiene un precio elevado - como el azul cobalto - y cubre poco es preferible emplearlo en la última capa de pintura sobre

\footnotetext{
36 Según Mérimée - aclara Plesters (1993: 56) -, Ingres empleó en 1827 el ultramar artificial para pintar los ropajes de uno de los principales personajes de su obra La Apoteosis de Homero. Esta pintura se realizó para el techo de una de las habitaciones del Musée Charles X en el Louvre. La obra fue reemplazada por una copia en 1855 y el original se encuentra entre las colección de pintura francesa del siglo XIX del Museo del Louvre.

37 Carlyle (2002: 473) indica que Winsor \& Newton ya incluyeron en su primer catálogo (c. 1835) ambos ultramares: el natural y el artificial.
} 
el merlino o Prusia. Pero, una gran ventaja de este pigmento argumentan los tratadistas - es su elevada estabilidad. Es interesante constatar que en fecha relativamente temprana - 1837 - después de la invención del color ya encontramos referencias en las fuentes españolas. Soler y Ferrer (1837) explican que:

El ultramar artificial que se debe á los repetidos ensayos de Mr. Guimet es de una tinta azul claro muy limpio y brillante: nos viene de París en donde está á cien reales la onza y va en un nos frasquitos de cristal con el sello de la fábrica. Siendo su tono tan bajo, y su cuerpo tan poco dá poquisimo color; por lo que es en todos sentidos muy caro; asi es que no se usa mas que en los celages muy despejados para los que es de una transparencia y belleza sin igual. (Soler y Ferrer, 1837: II, 56)

Ya hemos comentado que O'Neille (1862) opinaba que aunque los azules de cobalto y Guimet eran muy empleados, no consiguieron suprimir al ultramar natural. Para este paisajista, el ultramar natural era necesario en la paleta aunque tuviera un sustituto artificial. Bellanger (1899: 186), en su descripción de las materias colorantes, incluye el "Azul mar38" como un color azul que en tiempos pretéritos se extraía del lapislázuli pero "Hoy en día se obtiene mediante el silicato de alúmina, el silicato de sosa y el sulfuro de sodio." De esta forma, parece que a finales de siglo, el ultramar artificial o francés sustituyó completamente al ultramar natural. 39

Todas las cartas de colores que presenta L. Péant é Hijos (1895) - Lefranc y Félix Mommen - incluyen el azul ultramar sin especificar la variedad: natural o artificial; por lo que se dificulta la interpretación. En las series de colores extrafinos y superfinos ${ }^{40}$ al óleo de Lefranc y $\mathrm{C}^{\mathrm{ie}}$, los colores incluyen la composición química.

\footnotetext{
38 Creemos que esta denominación pueda deberse a la traducción del texto.

39 Bomford et al. (1990: 57) explican que los artistas sintieron gran atracción por el ultramar sintético y durante la década de 1870 se convirtió en el azul preferido para la pintura al óleo en Francia.

${ }^{40}$ Recordamos que esta serie de colores se preparaban mediante los procedimientos de J. G. Vibert.
} 
En ambas series, al ultramar - extra, claro, oscuro,... corresponde la composición "Sulfuro de sodio y silicato de alúmina”. Cómo ambos azules tienen una composición química similar ${ }^{41}$ resulta complejo esclarecer a que variedad se alude si no se expresa explícitamente. Los precios de los colores constituyen una pista interesante. En todos los casos, el ultramar es más barato que el azul cobalto. Esto podría ser otro indicio de que a finales del siglo XIX, el ultramar artificial había reemplazado definitivamente a su homólogo natural.

López Tomás (1898: 48) también suscita dudas de interpretación cuando dice "...ultramar (silicato de aluminio, silicato de sosa y sulfuro de sodio),...”. Podría referirse al ultramar artificial pues dada la fecha de publicación del texto no sería extraño que la variedad artificial hubiera desbancado a la natural. Sin embargo, podría aludir a la variedad natural y tradicional del pigmento. La incertidumbre surge porque entre los azules recomendados por este autor aparece la azurita, un pigmento tradicional. Por su parte, Vibert (1908: 85) reconoce que "...el ultramar Guimard ${ }^{42}$ es la reconstitución del lapislázuli...”. Pero cuando vuelve a referirse al ultramar resulta complicado establecer si alude al artificial o al natural. En cualquier caso, si la composición de ambos es similar, las pruebas que sugiere Vibert para identificar las adulteraciones del este pigmento serían útiles tanto para la variedad natural como para la artificial.

El ultramar debe disolverse en frío en diez veces su volumen de agua de cobre, desprendiendo un olor á huevos podridos. La disolución es gris. Si fuera azul, sería señal de la presencia del azul de Prusia.

En la cuchara de hierro el ultramar arde sin despedir vapores. Si se producen vapores purpúreos es porque contiene añil. Esta última falsificación es poco frecuente. (Vibert, 1908: 258).

\footnotetext{
${ }^{41} \mathrm{La}$ diferencia entre ambos pigmentos radica en la forma de las partículas, aspecto fácilmente apreciable mediante microscopía.

$4^{2}$ Con la denominación "ultramar Guimard”, Vibert se refiere al ultramar de Guimet o ultramar artificial.
} 
El azul cobalto y el azul ultramar sintético fueron pigmentos muy importantes para los pintores decimonónicos. Pero durante el siglo XIX otro pigmento azul derivado del cobalto vio la luz: el azul cerúleo. Gettens y Stout (1966: 103) conceden al azul cerúleo estabilidad y un limitado poder de tinción. Además, es el único azul de cobalto que carece de matiz violáceo. Este color se conocía desde principios del siglo XIX pero el sistema de fabricación, que consistía en calentar a altas temperaturas el óxido de estaño con una solución de cobalto, no era efectivo. El desarrollo del pigmento fue posible porque se logró fabricar por precipitación; de esta forma su elaboración resultaba fácil comparado con la del azul cobalto.

Rowney and Co., introdujeron el pigmento por primera vez en el comercio en 1860 bajo la denominación comercial - según Gettens y Stout (1966: 103) - de "coeruleum"43. La mencionada empresa sugería el empleo de este azul para acuarela y óleo. Bomford et al. (1990: 56), indican que el pigmento estuvo ampliamente disponible en Francia en la década de 1870 y ha sido identificado en algunas pinturas impresionistas.

Nuestras fuentes primarias obvian este pigmento. Ni siquiera el catálogo de colores de L. Péant é Hijos (1895) que ofertaba colores al óleo del fabricante francés A. Lefranc mostraba este color en sus cartas de pintura al óleo. La única referencia explícita la encontramos en una fuente secundaria: Nuevo Diccionario de Químia de Emilio Bouant (h. 1888).

CERULEUM (Celina, azul celeste)._Color azul más claro que el anterior pero que no experimenta ningún cambio á la luz artificial: se usa en la pintura al óleo y en la acuarela. Contiene óxido de cobalto, óxido de estaño y sulfato de cal. (Bouant, h. 1888: 424)

Bouant otorga a este color el nombre de azul celeste. Este dato

\footnotetext{
43 Según Bomford et al. (1990: 56), el nombre que recibió el color fue "caeruleum”. Sin embargo, Gettens y Stout (1966: 103) explican que el término "caeruleum" se empleaba durante la antigüedad clásica para designar varios pigmentos azules.
} 
podría llevarnos a pensar que el "Azul celeste" de la carta de colores de Félix Mommen - que aparece en el catálogo de L. Péant é Hijos (1895: 12) - se trata de azul cerúleo. Sin embargo, no podemos llegar a esa conclusión pues, como hemos visto, los comerciantes podían llamar a sus materias cómo quisieran sin explicar su composición.

\subsubsection{Violetas}

Los pintores siempre habían tenido que recurrir a mezclas de pigmentos para elaborar matices violáceos. Pero por fin, en 1859 apareció el primer pigmento violeta oscuro: el violeta de cobalto aunque no fue ampliamente empleado por los pintores hasta la década de 1870 . Este color no tenia una gran capacidad cubriente y tampoco un gran poder de tinción pero proporcionaba a los pintores un color violeta que no tenían que elaborar mediante mezclas de otros pigmentos. Según Bomford et al. (1990: 64), el violeta de cobalto podía estar formado por fosfato o arseniato de cobalto o bien por mezclas de ambos. Sin embargo, Virno (1995: 424-425) asegura que existían dos variedades de violeta de cobalto. Uno compuesto por arseniato de cobalto, que poseía un matiz claro; y otro formado por fosfato de cobalto, que era de tono oscuro.

En las fuentes decimonónicas españolas el violeta de cobalto comparece a finales de siglo en L. Péant é Hijos (1895), López Tomás (1898), Bellanger (1899) y Vibert (1908). El catálogo de colores de L. Péant é Hijos (1895: I, 6) muestra este color entre los "Colores Extrafinos en Tubos para Pintar al Óleo“ de A. Lefranc. Esta gama de colores al óleo contiene la composición química de los pigmentos y con el nombre "Violeta de cobalto" se suministraba fosfato de cobalto. El color esta marcado con "***" que expresa la completa estabilidad del material. De nuevo un violeta de cobalto - esta vez sin indicación de la composición química - aparece entre los "Colores Finos Preparados para la Pintura al Óleo" de Lefranc \& Cie (L. Péant é Hijos, 1895: I, 9). Algunas dudas suscita la presencia de un "Óxido 
violeta de manganeso" entre los colores de Félix Mommen (L. Péant é Hijos, 1895: I, 13). Pues podría tratarse de un violeta de Marte (Ver 5.1.7.).

López Tomás (1898: 49) y Bellanger (1899: 218) incorporan el violeta de cobalto como un pigmento adecuado para la pintura al óleo. El mencionado pintor francés sugiere integrar este color entre los colores de la paleta para pintar naturalezas muertas, metales, flores y frutas; sin embargo excluye los violetas de la paleta para retratos y figuras (Bellanger, 1899: 218). Vibert (1908) desaconseja todos los violetas de anilina y los que proceden de tintes naturales. Pero este artista propone varios violetas útiles para el pintor.

Le preferimos el violado de cobalto (fosfato y silicato de cobalto) y sobre todo el violado mineral (fosfato de manganeso). Este último color, muy sólido y que cubre bien, es muy útil. Se hace en dos matices igualmente buenos.

Así pues, para los colores violados, deben emplearse de preferencia el de cobalto, el mineral y el de Marte. (Vibert 1908: 252-253).

El violeta mineral o de manganeso fue preparado por primera vez en Alemania por Leykauf en 1868. Al igual que el violeta de cobalto carece de capacidad cubriente y su poder de tinción es escaso. Por esto, Gettens y Stout (1966: 128) aseguran que no fue un pigmento excesivamente apreciado por los pintores. Pero era otro pigmento violeta que permitía a los artistas lograr este color sin recurrir a mezclas. Bomford et al. (1990: 64) incluso argumentan que Monet no hubiera podido pintar las sombras violáceas producidas por el intenso sol sin los pigmentos violetas.

López Tomás (1898: 49) también menciona el violeta mineral o de manganeso entre los colores aptos para la pintura al óleo. Además era uno de los colores al óleo que ofertaba L. Péant é Hijos (1898: I, 6) en la gama de "Colores Extrafinos en Tubos para Pintar al Óleo” de A. Lefranc. El violeta mineral núm. 1 y 2 compuesto por fosfato de manganeso estaba marcado con una estabilidad completa “**”. 
El violeta de Marte (Ver 5.1.7.) es otro de los pigmentos violáceos que parecen apreciar las fuentes españolas de finales del siglo XIX. L. Péant é Hijos (1995: I, 6, 7, 9, 13) suministraba este pigmento en las diferentes gamas de colores de Lefranc y en los colores de Félix Mommen. También Bellanger (1899) lo sugiere como un pigmento adecuado en la paleta para pintar naturalezas muertas, frutas y flores. Y para Vibert (1908), como hemos visto, el violeta de Marte es uno de los tres violetas recomendables para la pintura al óleo.

\subsubsection{Verdes}

Los verdes modernos hicieron su aparición en el comercio en una fecha temprana: el verde Scheele (arseniato de cobre) en 1812, el esmeralda (acetoarseniato de cobre) en 1814, el viridian (óxido de cromo hidratado) en 1830 y el verde cobalto (óxidos de cobalto y zinc) en 1835. Sin embargo, los pigmentos verdes modernos no comparecieron en las fuentes españolas hasta finales del siglo XIX y - como vamos a ver - estaban acompañados de una gran confusión en sus denominaciones.

El venenoso arsénico ${ }^{44}$ dio origen a dos pigmentos verdes modernos. El verde Scheele, denominación que debe a su descubridor, es un arseniato de cobre aparecido en $1775^{45}$ que, sin embargo, comenzó a suministrarse en 1812 en Inglaterra. Pero dado que no tenia un matiz limpio fue pronto reemplazado por el

\footnotetext{
44 El peligroso arsénico fue reconocido como elemento químico - dice Bordini (1999: 13) - en 1773 .

45 Según Harley (1982: 83), Scheele mencionó en 1775 el arseniato de cobre sin aportar explicaciones sobre su elaboración en un informe sobre sus experimentos con el arsénico. El químico no publicó detalladamente el proceso de elaboración del pigmento hasta 1778. Por esta razón algunos investigadores consideran que el verde Scheele fue descubierto en 1778. Pero Harley asegura que en esa publicación, Scheele expuso que el color lo había descubierto tres años antes, es decir, en 1775 .
} 
acetoarseniato de cobre o verde esmeralda ${ }^{46}$ que se elaboró por primera vez en Alemania en $1814^{47}$. No obstante, según Bomford et al. ${ }^{48} 9$ (1990: 58) el verde Scheele estuvo disponible para artistas hasta que, a finales de la década de 1870, empezó a ser difícil de encontrar en los comercios.

Únicamente, dos de nuestras fuentes decimonónicas mencionan estos pigmentos pero con otras denominaciones. L. Péant é Hijos (1895: I, 6): en su carta de Colores Extrafinos de Lefranc ofertaba "Arseniato de cobre" bajo la denominación verde mineral. Con el nombre verde Veronés ${ }^{49}$, marcado como sólido “*”, estaba a disposición de los pintores el "Acetoarseniato de cobre". Estos colores aparecen también - pero sin indicar la composición química - en la carta de "Colores Finos Preparados al Oleo" de Lefranc \& Cie (L. Péant é Hijos, 1895: I, 9); mientras que en las cartas de colores para el decorado de Lefranc \& Cie (L. Péant é Hijos, 1895: I, 11) y en la carta de colores Extrafinos de Félix Mommen (L. Péant é Hijos, 1895: I, 13) desaparece el verde mineral.

Vibert (1908: 251) aporta un poco más de confusión y entre los pigmentos verdes que no recomienda están presentes el "Verde Scheele ó mineral (arsenito de cobre)", el Verde Schweinfurt (arsenito de cobre y acetato de cobre)" y el "Verde Viena (arseniato de cobre)". Como vemos, todos estos verdes son combinaciones diferentes de arsénico y cobre. Vibert (1908: 252) expone algunas

\footnotetext{
${ }^{46}$ Mérimée (1830: 197) comenta que el acetoarseniato de cobre se comercializaba con diferentes nombres: "vert de Vienne, vert de Brunswick, ou vert de Schweinfurt”. El acetoarseniato de cobre recibía el nombre de verde esmeralda en Inglaterra y esta denominación es la que actualmente impera para este compuesto químico. Sin embargo, en Francia durante el siglo XIX el nombre verde esmeralda se concedía a un pigmento compuesto por óxido de cromo hidratado; mientras que al acetoarseniato de cobre se le llamaba verde Viridian. 47 Según Ball (2003: 202) Winsor \& Newton comenzaron a vender el acetoarseniato de cobre al color al óleo en 1832.

${ }^{48}$ Entre las obras impresionistas comprendidas entre los años 1862 y 1892 estudiadas en la National Gallery de Londres, el verde Scheele únicamanete se identificó en Música en los Jardines de la Tullería de Edouard Manet (1862). (Bomford et al., 1990: 58).

49 Bomford et al. (1990: 61) señalan que el acetoarseiato de cobre o verde esmeralda también se conocía en Francia bajo la denominación de vert Véronèse.
} 
precauciones que hay que tomar para emplear el verde Veronés al que otorga la misma composición química que al verde de Viena: "El verde Veronés es un arseniato de cobre que puede emplearse á condición de usarlo solo y recubrirlo con barniz para impedir que se mezcle con los otros colores."

Como muchos de los pigmentos artísticos, estos verdes se fabricaban a gran escala para la decoración de interiores. Pero el contenido en arsénico de estos pigmentos suponía un serio peligro para los fabricantes, para los pintores decoradores y para los moradores de las estancias pintadas con ellos. Cuando estos pigmentos se exponen a la humedad - cuenta Ball (2003: 202) desprenden un gas letal, el trióxido de arsénico. Según este autor, una leyenda cuenta que Napoleón Bonaparte murió envenenado por los vapores de arsénico que desprendían las paredes de su casa en el exilio de Santa Elena. Según Finlay (2004: 289 - 290), esta leyenda tiene visos de verdad. Siguiendo una curiosa tradición, alguien cortó un mechón de pelo del Napoleón cuando murió en 1821. Los cabellos salieron a la luz en una subasta en 1960 y pudieron ser analizados. Los resultados desvelaron que el mechón de pelo de Napoleón contenía una elevada cantidad de arsénico. Veinte años más tarde, a través de un programa de radio de la $\mathrm{BBC}$, un profesor de química británico comentó que para descifrar el misterio de la muerte de Napoleón seria necesario tener una muestra del papel de la pared de su habitación. Y algo increíble sucedió. El profesor de química recibió la carta de una mujer que conservaba un pedazo del papel de la habitación de Napoleón en la casa Longwood - Santa Elena - donde murió. Un antepasado de esta mujer visitó la estancia de Napoleón en Longwood; sigilosamente arrancó un trozo del papel que cubría la pared y lo pegó en un libro de recortes. El profesor de química, David Jones, recibió con gran alegría la muestra de papel estampado con flores de lis verdes y doradas sobre fondo blanco. Los análisis demostraron que el verde Scheele formaba parte de la decoración del papel. No obstante, este dato no es una prueba concluyente de la causa de muerte de quien fuera Emperador de los franceses pero demuestra que el verde Scheele alcanzó una gran difusión probablemente debido a la belleza de su timbre. 
Pero no sólo el arsénico y el cobre producían hermosos verdes, también el cromo se manifestó como una fecunda fuente de pigmentos verdes. Cómo ya se ha explicado en el apartado de los pigmentos rojos (Ver 5.1.3), el cromo fue descubierto en 1797 por Vauquelin quien utilizó el metal para investigar las posibilidades de extraer colores. Los resultados de esta investigación se publicaron en 1809 y entre los colores que logró elaborar se encontraba el óxido de cromo verde. Éste pigmento se utilizaba con éxito - aseguran Bomford et al. (1990: 61) - en la cerámica de Limoges; pero su aplicación como pigmento artístico acaeció en la década de 1840 y se difundió ampliamente dos décadas después. Comenta Harley (1982: 86) que el pigmento tardó en aplicarse a la pintura artística debido a su opacidad y su falta de brillo. Pero algunos conocían el pigmento y llegaron a elaborarlo. Este es el caso de George Field quien - según Harley (1982: 86) - en la primera edición de su Chromatography (1835) afirmaba que una de las muestras verdes correspondía al óxido de cromo. Por esto Harley afirma que los pintores a quienes suministraba Field tuvieron a su disposición éste verde de cromo en fecha anterior a su propagación mayoritaria. Bomford et al. (1990: 61) opinan que los pintores no debieron sentirse atraídos por este color dada su opacidad y débil matiz.

Encontramos referencia a este verde en el catálogo de L. Péant é Hijos (1895). En el elenco de "Colores Extrafinos en Tubos para Pintar al Óleo" de A. Lefranc aparece el "Óxido de cromo" llamado verde cromo y marcado con "***" que hacen referencia a la completa estabilidad del pigmento (L. Péant é Hijos, 1895: I, 6). También aparece el verde cromo en la carta de "Colores Finos Preparados para la Pintura al Óleo" de Lefranc \& Cie (L. Péant é Hijos, 1895: I, 8). Aunque en esta ocasión no consta la composición química y bajo esta denominación se podía suministrar otro compuesto. Como explican Gettens y Stout (1966: 105 - 106), una mezcla de amarillo de cromo y azul de Prusia se introdujo en el mercado con el nombre de verde de cromo $^{50}$ durante el primer cuarto

${ }^{50}$ La mezcla de estos dos pigmentos también recibía el nombre de verde cinabrio o verde inglés. 
del siglo XIX.

El fabricante de colores Pannetier desarrolló el óxido de cromo hidratado ${ }^{51}$ conocido en Francia como verde esmeralda y empezó a producirlo - según Gettens y Stout (1966: 173) - en 1838. Éste era un pigmento transparente y brillante. Pannetier y su socio Binet mantuvieron el secreto del método de elaboración. Gettens y Stout (1966: 174) explican que Guignet patentó en 1859 un proceso de elaboración de este pigmento que el propio químico describió como nuevo y único. De esta forma, según Ball (2003: 204 - 205) el pigmento alcanzó un amplio y receptivo mercado y reemplazó al venenoso acetoarseniato de cobre en sus aplicaciones decorativas e industriales.

El verde esmeralda - óxido de cromo hidratado - es el verde moderno que más refieren nuestras fuentes. Este compuesto, con el nombre referido, aparece entre los "Colores Extrafinos en Tubos para Pintar al Óleo” de A. Lefranc marcado con “**” de estabilidad completa (L. Péant é Hijos, 1995: I, 6). También comparece entre los "Colores Superfinos Preparados para el Óleo por los Procedimientos de J. G. Vibert” (L. Péant é Hijos, 1995: I, 7). Esto es coherente con las enseñanzas que Vibert (1908: 252) expone en La Ciencia de la Pintura. Pues para este artista sólo hay dos pigmentos verdes buenos: uno es el verde de cobalto y otro el "Verde esmeralda (óxido de cromo)"52. El resto de series de colores que presenta el catálogo de L. Péant é Hijos (1895) también ofertaban el verde esmeralda aunque no consta la composición química de los pigmentos. Así, este color se encuentra entre los "Colores Finos Preparados para la Pintura al

\footnotetext{
${ }^{51}$ Durante el siglo XIX el óxido de cromo hidratado recibía el nombre de verde viridian en Inglaterra. Este es el nombre que en la actualidad mantiene el pigmento.

52 Aunque Vibert parece referirse a la versión anhidra del pigmento (óxido de cromo), las aclaraciones de Lefranc \& $C^{\text {ie }}$ (1892: 22) sobre los colores que se fabricaban bajo las indicaciones del pintor desvelan que el verde esmeralda estaba compuesto por óxido de cromo hidratado. Entre las propiedades que la empresa francesa cita de este pigmento se encuentran la transparencia - adecuada para elaborar veladuras - y la vivacidad que proporciona tonos luminosos cuando se mezcla con blanco.
} 
Óleo" y entre los colores al óleo para el decorado artístico de Lefranc \& $\mathrm{C}^{\mathrm{ie}}$. (L. Péant é Hijos, 1895: I, 9 y 11). El verde esmeralda comparece además entre los colores al óleo de Félix Mommen, fabricante de Bruselas (L. Péant é Hijos, 1895: I, 13). Entre los colores que sugiere López Tomás también figura el verde esmeralda. López Tomás (1898: 49) cita este pigmento como "óxido de cromo" pero casi con toda probabilidad se refiere a la versión hidratada del pigmento.

Pero también encontramos algún testimonio que transmite cierta aversión hacia los verdes modernos y en concreto hacia el verde esmeralda, este es el caso de Bellanger.

El verde siempre es el escollo del paisajista principiante: debe abstenerse de utilizar el verde esmeralda y, en general, de todos los verdes ya hechos que fabrican y expenden los vendedores de colores. (Bellanger (1899: 289)

Esto podría deberse a que el artista sentía predilección por los verdes de mezcla. Sin embargo, el rechazo al verde esmeralda es una contradicción del artista pues Bellanger (1899: 217 - 218) enumera los colores que considera más útiles y entre ellos incluye el "Verde esmeralda (color transparente)". Este pintor, expone la composición de los principales colores empleados y considera que el verde esmeralda es "Óxido de cromo hidratado". (Bellanger,1899: 186).

Como todos los pigmentos, el verde esmeralda era susceptible de ser adulterado. Para averiguar las posibles falsificaciones del pigmento, Vibert (1908) explica los ensayos pertinentes que - pensamos - debían ser útiles tanto para el verde esmeralda como para su variante anhidra conocida bajo la denominación de verde de cromo.

Verde esmeralda

(Óxido de cromo) 
Se hace hervir con ácido nítrico puro, y no debe cambiar, Se agrega agua y se filtra: el líquido debe ser incoloro. Si se pone amarillo es señal de que hay cromato de estroncio, de plomo ó de cinc. Hervido con agua de cobre, el verde esmeralda, después de un corto reposo da un licor azul si contiene azul de Prusia; calentado en la cuchara no debe emitir vapores, Si se deja caer en la cuchara enrojecida, y despide un humo blanco de olor a ajos, es señal de que contiene arseniato de cobre. (Vibert, 1908: 259)

Otro de los elementos importantes en la producción de colores es el cobalto, éste proporcionó hermosos azules durante el siglo XIX y también un color verde de gran utilidad en pintura artística. El verde de cobalto está compuesto por los óxidos de cobalto y de zinc. El químico sueco Rinmann descubrió el pigmento en 1780. Sin embargo, como el óxido de zinc no se fabricó a gran escala hasta mediados del siglo XIX, la comercialización del verde de cobalto se retrasó hasta entonces. El verde de cobalto es un pigmento semitransparente con escaso poder cubriente, es estable e inerte. Gettens y Stout (1966: 109) explican que no fue un pigmento especialmente apreciado por los pintores porque amasado al óleo cubre poco, además era caro y fácilmente imitable mediante mezclas53.

L. Péant é Hijos (1895), López Tomás (1898), Bellanger (1899) y Vibert (1908) mencionan el verde cobalto. Este pigmento aparece en el catálogo de L. Péant é Hijos (1895: I, 6) entre los "Colores Extrafinos en Tubos para Pintar al Óleo" de A. Lefranc. La lista de colores reza que el verde cobalto está compuesto por "Combinación del cobalto y del zinc". El color está marcado con el signo de estabilidad completa. El verde cobalto también comparece entre los "Colores Superfinos Preparados para el Óleo por los Procedimientos de J. G. Vibert” con la misma expresión en la composición química: "Combinación del zinc y del cobalto" (Péant é Hijos, 1895: I, 6). De nuevo el color se muestra entre los "Colores

\footnotetext{
53 Harley (1982: 85) comenta que según Field, como verde de cobalto se conocía comúnmente una mezcla de azul cobalto y amarillo de cromo.
} 
Finos Preparados para la Pintura al Óleo" de Lefranc \& Cie (Péant é Hijos, 1895: I, 8). Como hemos reiterado constantemente, esta gama de colores no aporta la composición química de los pigmentos por este motivo, el color podría estar compuesto por mezcla de pigmentos o incluso podría haber sido substituido. Los colores Félix Mommen ofertaban dos matices de verde cobalto - claro y obscuro lo que nos hace pensar que podría tratarse de mezclas de pigmentos. (Péant é Hijos, 1895: I, 13).

López Tomás (1895: 49) y Bellanger (1899: 186) elaboran escuetas citas sobre el pigmento y se limitan a explicar que el verde cobalto está compuesto por óxidos de cobalto y zinc. Para Vibert (2908: 252) el "Verde de cobalto (óxido de cobalto y de cinc)" es - junto al "Verde esmeralda (óxido de cromo)" - el único pigmento verde útil en pintura al óleo. Para identificar las adulteraciones, Vibert (1908) explica los siguientes ensayos:

\section{Cobalto \\ (Óxido de cobalto)}

El cobalto puesto en un vaso con diez veces su volumen de agua de cobre, debe conservar su color. Se hace hervir ó se deja reposar un instante, debiendo ser incoloro el líquido. Si es azul, es señal de la presencia del azul Prusia.

El olor á huevos podridos indica la presencia del ultramar. El cobalto debe arder en la cuchara sin vapores. (Vibert, 1908: 258)

A lo largo del siglo XIX varias fuentes sugerían obtener los verdes por combinación ${ }^{54}$; ésta fue una práctica pictórica muy extendida y arraigada en el pasado. Soler y Ferrer (1837), O'Neille (1862), Algarra (1875) - y de manera contradictoria Bellanger

\footnotetext{
54 Según Mackim-Smith (1988: 84), durante el siglo XVII, la mezcla de pigmentos para conseguir el color verde se convirtió en una praxis popular entre los pintores. Aunque, por supuesto, los pigmentos verdes de la época - verdigrís, malaquita y tierra verde - siguieron utilizándose. Por este motivo, no resulta extraño que algunos pintores del siglo XIX continuara con esta práctica a pesar de los nuevos pigmentos verdes disponibles.
} 
(1899) - explican que los verdes se deben componer con mezclas porque se obtiene mejor resultado. En algunas de las mezclas que proponen estos autores los verdes se elaboran con azules y amarillos modernos que proporcionan verdes intensos. Soler y Ferrer enseñan las mezclas adecuadas para lograr diferentes matices de verde.

Los verdes todos se componen en la paleta en la conveniente mezcla y cantidad de amarillos y azules, tantos mas vivos los dos cuanto mas brillantes se quieran los verdes: con el ultramar ó cobalto, y el cromo se compone el mas vivo y claro: con el dicho cromo y el merlino es mas intenso: con el ocre claro y el mismo merlino otro mas bajo: con el mismo y el ocre obscuro, quemado, ó el de Siena otros mas bajos y variados, y los últimos mas obscuros con los negros y ocres, de modo que se puede con ambos azules y amarillos variar sus tintas al infinito, sin necesitar en nada los que venden de fábrica que tanto sirven en el temple y se hacen recomendables por su hermosura y sólidéz. (Soler y Ferrer, 1837: II, 56).

O'Neille (1862: 41), asegura que incluso algunos sabios pintores eliminaron casi por completo los verdes de sus paletas. Este paisajista afirma "que aun suprimiéndolo casi totalmente puede producirse un bello efecto de arboleda y representar un paisaje de carácter frondoso y rica vegetación." O'Neille previene a los principiantes de esta práctica que por su dificultad sólo ejecutan con éxito los grandes pintores. Algarra (1875: 251, 252), muy escueto en su descripción de los colores, expone que el verde es un "Color secundario, producido por la mezcla de amarillo y el azul. Los hay de muchas clases."

Bellanger (1899) resulta un poco contradictorio en su valoración de los verdes. En ocasiones desprecia todos los verdes del comercio, sin embargo incorpora dos verdes modernos entre los colores adecuados para componer la paleta. Ante el rechazo de los verdes sugiere: "Componed vuestros verdes con negro, cadmio claro y blanco, para las coloraciones apagadas; y con azul, cadmio claro y amarillo de Nápoles, para las coloraciones intensas." 
Ya hemos señalado que con el nombre de verde cobalto los comerciantes podían suministrar una mezcla de azul cobalto y amarillo de cromo; y bajo la denominación verde de cromo no era extraño encontrar una combinación de amarillo de cromo y azul de Prusia. Según Bomford et al. (1990: 63) esta mezcla también podía recibir el nombre de verde cinabrio. Éste aparece en el elenco de colores de Félix Mommen (L. Péant é Hijos, 1895: I, 13) ofertado en varios tonos: "claro", "núm. 2" y "obscuro". El catálogo L. Péant é Hijos (1895: I, 5 y 6) anuncia dos nombres diferentes para el compuesto "Cromato de plomo y cianuro de hierro". Esta mezcla, se encontraba entre los cinabrios: "verde claro y obscuro" y " amarillo núm, 1, 2 y 3". Exactamente la misma composición se le otorgaba al verde ingles que el mencionado catálogo ofrecía en cinco diferentes tonos. Todas las series de colores de Lefranc que se ofertaban en el catálogo de L. Péant é Hijos - a excepción de los colores preparados por los procedimientos de Vibert - contenían varios tonos de verde ingles. Vibert emplea la denominación verde inglés como sinónimo de cinabrio verde y a ambas denominaciones concede la composición "amarillo de cromo y azul de Prusia". El artista francés desaconsejaba este verde de mezcla, pues como ya hemos indicado, este autor considera que "Los colores verdes verdaderamente buenos son: Verde cobalto (óxido de cobalto y de cinc). Verde esmeralda (óxido de cromo) (Vibert, 1908: 252).

\subsubsection{Colores de Marte}

Los ocres y todo tipo de tierras naturales están compuestas fundamentalmente por óxido de hierro y han servido como pigmento en la pintura desde antiguo. La elaboración tradicional de algunos de estos pigmentos contemplaba la calcinación; así se obtenían, por ejemplo, sienas o sombras tostadas. Otra forma tradicional de obtener pigmentos de esta clase consistía en la calcinación del sulfato de hierro (caparrosa o vitriolo verde). El metal de hierro oxidado de forma natural o 
artificial también se empleaba como pigmento (Helwig, 2007: 69-71).

A finales del siglo XVIII comenzó a desarrollarse un nuevo proceso de elaboración de colores de óxido de hierro mediante precipitación acuosa. Los pigmentos preparados de este modo reciben el nombre de "colores de Marte". Harley (1982: 91) indica que esta denominación es una variación de "croccus martis" que es la designación que los alquimistas otorgaban al amarillo de hierro. Estos óxidos artificiales de hierro producían colores amarillos, naranjas, rojos, pardos y violetas55. Harley (1982: 92) asegura que el amarillo de Marte comenzó a utilizarse de forma general en Inglaterra debido a la expansión de la industria química y no a la demanda de los pintores.

Son muy escasas las fuentes de finales del siglo XVIII que explican el proceso de elaboración de los colores de Marte. De Massoul (1797) comenta que es un proceso conocido por pocas personas y oculta los pormenores de elaboración cubriéndolos con un velo de misterio y oscuridad.

The experiments we have made upon the nature, composition and use of Mars Yellow, have given us a perfect knowledge of its different qualities. We will not however enter into all the details of its composition, which, till this present day, has been known to few persons. It will be sufficient to assure our Readers, that this valuable colour, extracted from a disolution of iron, and afterwards precipitated, is of essential service in all the different styles of Painting. It is light, solid, transparent, easy to use, and, unites perfectly with all other colours. (De Masoul, 1797: 147)

Según Gettens y Stout (1966: 129), a mediados del siglo XIX las fuentes describen la elaboración de los óxidos de hierro artificiales a partir del vitriolo verde. Gettens y Stout (1966: 129) y Harley (1982: 92) coinciden en sus explicaciones sobre la fabricación de los colores de Marte. El sulfato de hierro - o caparrosa verde - en disolución con

55 Hemos visto en el apartado 5.1.5. que el violeta de Marte aparece citado por Bellanger (1899) y anunciado en el catálogo de L. Péant é Hijos (1895). 
alumbre se precipitaba mediante un álcali. Esto producía el amarillo de Marte. Este pigmento se calcinaba dando lugar a los diferentes colores amarillos, naranjas, pardos, etc.

El catálogo de L. Péant é Hijos (1895) oferta varios colores elaborados mediante la precipitación del óxido de hierro. Así, entre los colores extrafinos y los preparados según indicaciones de Vibert - todos de Lefranc - se encuentran diferentes amarillos, naranjas, pardos, rojos y tierras cuya composición química responde a "Oxido de hierro precipitado" (L. Péant é Hijos, 1895: I, 4, 5, 7). Tenemos que aclarar que en este catálogo, estos colores se presentan bajo la denominación "Marzo". Pensamos que esto es una confusión debida a que el término francés Mars ${ }^{56}$ puede traducirse como Marte o como Marzo. Los colores finos al óleo de Lefranc también incluyen amarillos, naranjas, pardos y violetas de Marzo (L. Péant é Hijos, 1895: I, 8, 9). Los mismos colores aparecen ofertados en la carta de colores de Félix Mommen (L. Péant é Hijos, 1895: 12, 13). Aunque recordamos que ni los colores finos de Lefranc \& $\mathrm{C}^{\mathrm{ie}}$ ni los colores de Félix Mommen incluyen la composición química.

Helwig (2007: 63) ha estudiado en profundidad un gran numero de fuentes y ha analizado diferentes recetas decimonónicas de los colores de Marte. Según esta investigadora, varios tratadistas sugieren que para producir colores específicos de Marte se añaden otros compuestos: alumbre para el amarillo ${ }^{57}$, cobalto o manganeso para el violeta y sales de zinc, manganeso, cobalto o níquel para lograr el marrón. En el catálogo de L. Péant é Hijos (1895: I, 6, 7) encontramos un violeta de Marzo que cumple esas características. Entre los colores Extrafinos y los Superfinos preparados bajo las indicaciones de Vibert comparece un violeta de Marzo compuesto

\footnotetext{
${ }^{56}$ Harley (1982: 92) comenta que Field en su "Practical Journal 1809", describía el amarillo de Marte como un pigmento francés. En el primer catálogo de Winsor \& Newton (h. 1835) - asegura Harley - se incluían "French Mars colors". Estos datos llevan a la magnifica investigadora inglesa a concluir que, hasta 1835, el amarillo descrito por De Massoul era una especialidad francesa.

57 Podemos ver esta apreciación en Mérimée (1830: 116): "Si l'on voulait avoir des ocres claires, il faudrait mettre de l'alum en certaine proportion avec du sulfate de fer, on pourrait alors precipiter la dissolution par de l'eau de chaux;".
} 
por "Oxido de hierro, cobalto y alúmina". No obstante, Helwig (2007: 64) presenta los resultados de los análisis de varios colores de Marte de los siglos XIX y XX: violetas, rojos, pardos, naranjas y amarillos. Sólo en un pardo del siglo XIX se ha hallado que la composición incluía óxido de cromo. Este dato podría indicar que la forma más extendida de elaboración de los pigmentos implicaba la calcinación del óxido de hierro y no la inclusión de otros elementos.

Las tierras naturales y los colores de Marte convivieron durante todo el siglo XIX. Según Lefranc \& Cie (1892: 21) ambas clases de óxidos de hierro tienen una ligera diferencia en la transparencia; los óxidos artificiales son un poco más transparentes que los naturales. Carlyle (2002) y Helwig (2007) indican que varios suministradores ingleses - Winsor \& Newton, Roberson o Rowney ofertaban colores de Marte desde mediados del siglo XIX. No es de extrañar que se vendieran colores de Marte bajo denominaciones de pigmentos de óxido de hierro tradicionales y viceversa. Es decir, que bajo la denominación de colores de Marte se suministraran pigmentos de óxido de hierro elaborados de manera tradicional.

\subsection{Colorantes Sintéticos}

Desde finales del siglo XVIII se sucedieron incuestionables avances químicos en materia de pigmentos. Pero fue durante el siglo XIX cuando se produjo un autentico y progresivo desarrollo de los tintes y los colorantes que contribuyeron, en gran medida, al cambio de la paleta de los pintores. La cantidad de colorantes - amarillos, rojos, azules, violetas, verdes, etc. - que se descubrieron a lo largo del siglo XIX resulta absolutamente desbordante y los datos que ofrece la literatura son a veces equívocos y confusos. Vamos a introducirnos ahora en el complejo, apasionante y oscuro mundo de los colorantes sintéticos.

Uno de los descubrimientos más importantes en el campo de 
la química demostraba la posibilidad de extraer sustancias orgánicas del alquitrán. Este hallazgo fue el resultado de las investigaciones del químico alemán W. Von Hofmann ${ }^{58}$ en 1828. Como consecuencia de esta conquista se consiguió aislar la anilina de dos formas diferentes. El investigador inglés F. F. Runge extraía esta sustancia del alquitrán de leña; mientras que Zinin, en 1842, probó que la anilina podía obtenerse mediante la reducción del nitrobenceno (Quartullo: 1995: 131). La anilina es una sustancia venenosa que, sometida a diferentes tratamientos, produce colorantes sintéticos. La aplicación de estas materias colorantes a la pintura llegó a tener consecuencias desastrosas; por eso, este importante hallazgo químico fue despreciado por Vibert (1908: 81) quien llegó a expresar: "El descubrimiento de la anilina especialmente ha sido una verdadera catástrofe para las artes".

Los químicos experimentaron de manera incesante, a veces incluso de forma obsesiva, y el empeño de muchos de ellos produjo interesantes descubrimientos en el campo de los tintes y colorantes. Hoffman encomendó a su joven discípulo William Perkin que elaborara la quinina sintética con compuestos derivados del alquitrán de hulla. Pero Perkin, en cambio, descubrió casualmente el primer colorante sintético: el malva. Este azaroso hallazgo acaecido en 1856 dio comienzo, según el acertado criterio de Gettens y Stout (1966: 142), a una nueva época en la historia de los pigmentos. Muchos fueron los experimentos para extraer colores de anilinas y muchos los que llegaron a comercializarse. Los tintes sintéticos se desarrollaron fundamentalmente para la tintura de telas pero pronto tuvieron aplicación en pintura artística y fueron recibidos con entusiasmo por los artistas.

El catálogo de L. Péant é Hijos (1895: 4) demuestra que incluso las gamas de colores de mayor calidad podían contener anilinas en su composición. El mencionado catálogo avisa que

\footnotetext{
${ }^{58}$ Bensaude-Vincent y Stengers (1997: 152) exponen que los metódicos análisis practicados sobre los alquitranes de hulla permitieron el descubrimiento de la naftalina (1820), el antraceno (1832), el fenol (1834) y el benceno, la anilina y el tolueno.
} 
algunos colores 'extrafinos' para pintura al óleo de Lefranc podían contener anilinas: "Los colores á base de anilina llevan la palabra ANILINA en cada etiqueta. Los colores sólidos van marcados*. Los de una fijeza completa van marcados ${ }^{* *}$." Pero los colores elaborados a partir de anilinas demostraron carecer de estabilidad suficiente. Para Vibert (1908: 227) todos los colores de anilina son "detestables, puesto que se destruyen con la luz" y deben desterrarse de la paleta. Este pintor francés advierte sobre el empleo de las anilinas para intensificar el color de algunos pigmentos:

...todos esos colores nuevos que no son otra cosa que los colores ordinarios de mala calidad, teñidos y realzados con los productos derivados de la anilina, los cuales, como es sabido, desaparecen bajo la influencia de la luz. (Vibert, 1908: 93)

El interés por la elaboración de los colores derivados de la anilina en el territorio español se manifiesta en la variada cantidad de privilegios y patentes que constan en el Archivo Histórico de la Oficina Española de Patentes y Marcas. En una fecha relativamente temprana, tan sólo seis años después de la invención del malva por Perkin, es decir en 1862, podemos encontrar un privilegio a nombre de Cleobul Paul Daguzan que protege "Un procedimiento para extraer del 'anilina' materias colorantes por medio de toda clase de reactivos"59. Pero otras patentes demuestran también el floreciente interés por los colorantes derivados de la anilina. En 1895 Getzner Mutter \& Co. / Schiefner, Théodor Euger solicitó la patente por "Un procedimiento para la vaporación de los colores de anilina"60. A finales de siglo, en 1899, Francisco de Diego patentó un "Procedimiento para la fabricación de colores químicos derivados de los aceite (sic) que producen la destilación del alquitrán y la fabricación del cok”. La fascinación por las anilinas no cesó y en 1900, Farbwerke vorm. Meister Lucius \& Brüning registró un "Procedimiento químico para la fabricación de productos de

\footnotetext{
59 Archivo Histórico de la OEPM. No de Privilegio 2567.

6o Archivo Histórico de la OEPM. No de Patente 17958.
} 
transformación de las materias colorantes derivados del alquitrán de hulla"61

Otro de los avances más interesantes y relevantes de la química con repercusión en la pintura fue la creación de la alizarina sintética. El malva de Perkin era un tinte sintético que no existía en la naturaleza, en cambio, la alizarina sintética era la imitación de una materia natural. Según Philip Ball (2003: 283), la premeditada y organizada creación de la alizarina sintética supuso un adelanto más significativo que el descubrimiento de las anilinas: "Lo natural y lo artificial habían convergido.”

En 1850, en un intento por establecer la fórmula química de la alizarina, se le asigno - erróneamente - una relación con el naftaleno, un derivado del alquitrán de hulla. En esos momentos empezó una carrera intensa por sintetizar, a bajo coste, esta materia que tanta importancia tenía en el comercio. Muchos experimentos se llevaron a cabo sin obtener los resultados deseados puesto que la alizarina deriva del antraceno. Un interesante documento conservado en el Archivo Histórico de la OEPM evidencia estos esfuerzos y estas ansias por sintetizar la alizarina artificial. En 1861 se concedió a Francisco Zacarías Roussin ${ }^{62}$ un privilegio de invención por un método de preparar la alizarina artificial ${ }^{63}$ (Ver Apéndice B). La caducidad del privilegio se comunicó en el Boletín Oficial del Ministerio de Fomento ${ }^{64}$ de 1865 “...por no justificarse en tiempo hábil la práctica de su objeto,...”.

Gettens y Stout (1966), Quartullo (1995) o Philip Ball (2003) aceptan que 1868 fue el año del descubrimiento de la alizarina artificial. El descubrimiento se debe a los químicos alemanes $\mathrm{C}$. Graebe y C. Liebermann. Pero el procedimiento de elaboración de la alizarina que proponían estos químicos era demasiado costoso debido a que se requería bromo. Por este motivo la elaboración

\footnotetext{
${ }^{61}$ Archivo Histórico de la OEPM No de Patente 25519.

${ }^{62} \mathrm{Z}$. Roussin fue un farmacéutico francés que tuvo gran importancia en el desarrollo de los tintes azo.

${ }_{63}$ Archivo Histórico de la OEPM No de Privilegio 2296.

${ }^{64}$ Boletín Oficial del Ministerio de Fomento. Tomo VIII. No ${ }^{\circ}$ 132. Año IV. Madrid, 1865. p. 352.
} 
a gran escala no era viable. Graebe y Liebermann vendieron los derechos de la substancia a la pujante Badische Anilin - \& Soda -Fabrik. ${ }^{65}$

Pronto se descubrió una manera asequible de producir la alizarina sustituyendo el bromo por ácido sulfúrico. Varios químicos llegaron a la misma conclusión en 1869: el primero fue Ferdinand Riese de la Hoechst; después Graebe junto al químico principal de la BASF, Heinrich Caro; estos resultados se obtuvieron en Alemania. Finalmente, William Perkin, en Inglaterra, que tenía su propia compañía. Perkin patentó el procedimiento un día después que la BASF. Para evitar disputas y competencias innecesarias e indeseables, dado que el mercado de la alizarina era francamente importante, los químicos decidieron repartirse el mercado. No obstante, diversas circunstancias modificaron con el tiempo esta situación y cuando la industria de los tintes se consolidó definitivamente, Alemania dominó el mercado. Entre los industriales españoles el interés por esta substancia queda acreditado por una patente de 1880. Hijos de Ignacio Carreras registraron "Un procedimiento para la fabricación de la alizarina artificial derivada del antraceno"66.

La alizarina sintética gozaba de enormes ventajas frente a la alizarina natural: era más brillante, más estable y de menor coste por lo que no tardó en sustituir a la alizarina natural. De hecho, el cultivo de la rubia resultó innecesario y como consecuencia se derrumbaron las industrias tradicionales basadas en este tinte vegetal.

Según Ball (2003: 285), las incesantes investigaciones químicas permitieron a Hofmann desvelar la estructura de la eosina, un colorante rojizo que se obtiene de la fluoresceína, un derivado del carbón de hulla. Aunque Gettens y Stout (1966: 114) sugieren que el primero en elaborar esta substancia fue Caro en 1871. Este colorante

\footnotetext{
${ }^{65}$ La Badische Anilin - \& Soda - Fabrik (BASF) fue fundada en 1865 y en el Archivo Histórico de la OEPM constan patentes de esta compañía desde finales de la década de 1880 .

${ }^{66}$ Archivo Histórico de la OEPM. No de Patente 984.
} 
- afirma Ball - comenzó a ser comercializado por la BASF en 1874. En el comercio se podía encontrar una "laca geranio" que denominaba un color rojo brillante elaborado - según Gettens y Stout (1966: 114) - mediante la precipitación de la eosina sobre una base de aluminio hidratado. Pero algunos pintores como Bellanger (1899) opinaban que la laca geranio era muy inestable y advertía sobre los problemas derivados de su uso.

La laca geranio no me inspira mucha más confianza que su hermana [laca rosa],... La creo capaz de las mismas veleidades y de idénticos inconvenientes. Indudablemente, su brillo es magnífico y seductor; pero no os fiéis de estas apariencias halagüeñas, porque son muy efímeras y desaparecen con desoladora rapidez. (Bellanger, 1899: 220)

Aunque el autor no aclara la composición de la laca geranio, la descripción encaja perfectamente con las características y comportamiento de las anilinas y los colorantes de eosina.

Otra de las destacadas familias de tintes que acabaron repercutiendo en los colores artísticos fueron los tintes azo. El químico alemán Peter Griess - que llegó a colaborar con Hofmann descubrió a finales de la década de 1850 los tintes azo. A pesar de que Griess encontró muchos compuestos coloreados azo, la mayoría de ellos no eran útiles como tintes. Pero los resultados de sus investigaciones, que publicó en 1876, permitieron el descubrimiento de muchos tintes azo valiosos. El primer tinte de esta clase fue un amarillo brillante conocido bajo la denominación amarillo de anilina o crisodina. Este colorante fue hallado de manera simultánea por Caro ${ }^{67}$, Witt y Roussin.

El Archivo Histórico de la OEPM alberga varias patentes de finales del siglo que reflejan diferentes procedimientos para extraer

\footnotetext{
${ }^{67}$ Bensaude - Vincent y Stengers (1997: 154) cuentan que Caro - un estampador de tejidos alemán instalado en Manchester - y Martius fabricaron en 1864 dos colorantes amarillos azoicos que llamaron amarillo y marrón Manchester.
} 
colorantes del tipo azo. La mayoría de los solicitantes de estos procedimientos eran empresas extranjeras. Así, en el Archivo Histórico de la OEPM consta que en 1889 la "Société Anonyme des Matières Colorantes et Produits Chimiques Saint Denis” registró "Un procedimiento químico para la producción de sustancias colorantes azoicas, amarillas, anaranjadas, rojas, derivadas de las azoxiaminas."68 Aparece inscrito en el mencionado Archivo sendas patentes a nombre de Vidal Vero: "La fabricación de materias colorantes diazoicas"69 en febrero de 1893 y "Un procedimiento de fabricacion de los colores artificiales tetrazoicos"70 en marzo del mismo año. La "Badische Anilin - \& Soda - Fabrik" (BASF) patentó diversos procedimientos para la elaboración de diferentes tintes azo. "Producción de materias colorantes azoicas, naranja a violeta - rojo, derivando de los ácidos alcoilmetamidobenzol-sulfóricos"71 en enero de 1895. En julio del mismo año, la citada empresa registró "Un procedimiento para la preparación de materias colorantes azoicas de la serie de la bencidina"72; al final de este mes ${ }^{73}$, en agosto ${ }^{74}$ y en septiembre ${ }^{75}$ la empresa inscribió mejoras del procedimiento anterior.

1895 fue un año en el que se inscribieron bastantes patentes sobre procedimientos para la elaboración de tintes azo. En febrero, Leopold Casella \& Co. Solicitó la patente de "Un procedimiento para la composición de materias colorantes poliazoicas derivadas del ácido y amidonaftolsulfónico.”76 En septiembre, la “Société pour

\footnotetext{
68 Archivo Histórico de la OEPM No de Patente 9488.

${ }^{69}$ Archivo Histórico de la OEPM No de Patente 14218.

$7^{70}$ Archivo Histórico de la OEPM No de Patente 14310.

${ }^{71}$ Archivo Histórico de la OEPM No de Patente 16896.

${ }^{72}$ Archivo Histórico de la OEPM No de Patente 17685.

73 "Mejoras introducidas en un procedimiento para la preparación de materias colorantes azoicas de la serie de la bencidina". Archivo Histórico de la OEPM No de Patente 17779.

74 Archivo Histórico de la OEPM No de Patente 17822 (Con el mismo enunciado que la patente anterior).

75 Archivo Histórico de la OEPM No de Patente 17969 (Mismo enunciado que las dos patentes anteriores).

${ }^{76}$ Archivo Histórico de la OEPM No de Patente 17038.
} 
l'Industrie Chimique à Bâle (C. I. B. A.)" solicitó la patente por "Un procedimiento para la producción de nuevos cuerpos tetrazoicos acoplados y de nuevos colorantes poliazoicos complejos derivados."77 Esta última compañía, en 1896, registró "Un procedimiento para la producción de nuevas materias colorantes disazoicas, trisazoicas y polizoicas". Y, el mismo año, “J. R. Geigy A. G." apuntó "Un procedimiento para la fabricación de materias colorantes azóicas negras"78.

Uno de los mayores avances químicos se alcanzó gracias a las investigaciones en torno al índigo. El trabajo de Baeyer sobre esta substancia - tras treinta años de asidua investigación - supuso un adelanto tan grande para la química orgánica que en 1905 obtuvo el premio Nobel. Los trabajos sobre el índigo del químico alemán comienzan en 1865 con el descubrimiento de la estructura del benceno. En 1880 logra elaborar el índigo artificial que era químicamente igual que su homólogo natural. Baeyer consigue esta síntesis a partir del ácido cinámico. Según Bensaude - Vincent y Stangers (1997: 156) se registraron ciento cincuenta y dos patentes de la síntesis del índigo a partir del ácido cinámico. Pero el procedimiento no era viable a nivel industrial porque producía una escasa cantidad de índigo. En 1882, Baeyer propone otro procedimiento a base de orto - nitro - tolueno que tampoco resultó viable. Finalmente, las incansables investigaciones del químico alemán dieron con un sistema de fabricación del índigo susceptible de ser trasladado a la industria. El índigo sintético ${ }^{79}$ elaborado mediante este procedimiento fue comercializado por la BASF en 1897. El empeño de esta compañía y sus químicos por encontrar un procedimiento provechoso para la elaboración a gran escala del índigo artificial fue enorme. $\mathrm{Y}$ en parte, queda reflejado por la cantidad de registros que figuran en el Archivo Histórico de la

\footnotetext{
77 Archivo Histórico de la OEPM No de Patente 17048.

${ }^{78}$ Archivo Histórico de la OEPM No de Patente 19713.

79 El químico Heumann también investigaba los procedimientos para elaborar el índigo artificial a gran escala y a precio reducido. Heumann encuentró un método más rentable que el de Baeyer en 1904. En 1910 ya no quedaba índigo natural en el mercado europeo (Bensaude-Vincent y Stengers, 1997: 156).
} 
Oficina Española de Patentes y Marcas. Entre 1890 y 1898 la $\mathrm{BASF}^{80}$ registró diez procedimientos diferentes para elaborar índigo artificial.

Aunque la alizarina y el índigo artificiales resultaron ser tintes bastante estables, la mayoría de colores de anilina, eosina o azo demostraron que eran perjudiciales para la pintura ${ }^{81}$. Los tintes y colorantes sintéticos fueron un gran problema para los pintores que podían ver en poco tiempo cómo sus obras mutaban cruelmente de aspecto. Bellanger (1899) cuenta un interesante relato en primera persona que explica perfectamente los desengaños que se llevaban los pintores en materia de color.

80 "Nuevo procedimiento para la preparación del añil artificial y otras sustancias colorantes indigóticas". (05/07/1890) Archivo Histórico de la OEPM. $\mathrm{N}^{\mathrm{O}}$ de Patente 11005.

"Un procedimiento para la producción de ácido fenilflicino - orto - carboxílico y convertirlo en índigo artificial.” (28/07/1890) Archivo Histórico de la OEPM No de Patente 11087.

"Un nuevo procedimiento industrial para la preparación del añil artificial y otras sustancias colorantes indigóticas." (22/01/1891) Archivo Histórico de la OEPM No de Patente 11686.

"Un procedimiento para la preparación del añil artificial y otras sustancias colorantes indigóticas" (21/02/1891) Archivo Histórico de la OEPM No de Patente 11774 .

"Un nuevo procedimiento para la preparación de añil artificial y otras sustancias colorantes indigóticas" (03/04/1891) Archivo Histórico de la OEPM No de Patente 11929.

"Nuevo procedimiento para la preparación del añil artificial y otras sustancias colorantes indigóticas" (07/04/1891) Archivo Histórico de la OEPM No de Patente 11937.

"Un procedimiento para obtener el ácido fenilglicino ortocarboxílico y convertirlo en índigo artificial." (25/09/1893) Archivo Histórico de la OEPM No de Patente 14993.

"Modificaciones y adiciones introducidas en el procedimiento para la producción de ácido fenilglicino - orto - carboxílico y convertirlo en índigo artificial.” (13/o6/ 1894) Archivo Histórico de la OEPM No de Patente 15937.

"Un procedimiento para la producción del ácido fenilglicino-ortocartoxilico [sic] y convertible en índigo artificial” (20/11/1894) Archivo Histórico de la OEPM No de Patente 16589.

"Un procedimiento para la producción de índigo". (29/12/1898) Archivo Histórico de la OEPM No de Patente 23591.

${ }^{81} \mathrm{El}$ desarrollo de estos colorantes permitió en el siglo XX la elaboración de colorantes estables para la pintura al óleo. 
Lo mismo puede afirmarse de la laca rosa, que palidece y se esconde pasados algunos años. Mi odio contra ella está bien justificado, y á propósito de esto referiré el siguiente episodio.

Cuando yo empezaba á estudiar la pintura, tuve ocasión de retratar á una muchacha adorable, exuberante y sanota, repleta de lirios y de rosas, como decían en el Almanaque de las Musas por el año de 1788. Para reproducir con exactitud aquel hermoso color bermejo, creí que lo mejor que podía hacer era echar mano de aquella laca rosa tan bonita y con tan seductoras apariencias. $\mathrm{Y}$, en efecto, el resultado que obtuve fué admirable. Los amigos se extasiaron ante tanta frescura y lozanía, y me pagaron espléndidamente llamándome Rubens en flor ó en agraz.

Algunos años después volví á ver mi cuadro. iAy!... icómo se habían modificado las opiniones de mi familia acerca del cuadro y del autor! iy con cuánta razón los aplausos de la víspera se habían trocado en reproches!

La muchacha del retrato había perdido sus hermosos colores, y sus mejillas y sus labios aparecían recubiertos por una palidez enfermiza.

La clorosis había invadido aquel rostro antes tan lozano, imprimiéndole una melancolía fúnebre.

Entonces procuré remediar el error de la mejor manera posible, pero desde entonces juré no volver á emplear nunca la inconstante y traidora laca rosa. (Bellanger, 1899: 219-220) 


\section{Soportes}

La información que aportan los tratadistas españoles decimonónicos sobre los soportes de la pintura resulta escasa pero es suficiente para entender las preferencias o consideraciones de la época. El lienzo y la tabla son los soportes que nuestros tratadistas consideran más adecuados para la pintura al óleo aunque también se mencionan otra clase de soportes como el cartón o el papel.

El desarrollo de los telares mecánicos en la década de 1840 permitió elaborar telas de grandes dimensiones, diferentes ligamentos y de menor precio. Además, el algodón se consolidó durante el siglo XIX como una alternativa a los tejidos de lino y cáñamo; de manera que, a finales de siglo un pintor tenía a su disposición una variada gama de telas para pintar. Las telas se vendían preparadas en largos rollos de diferentes anchos aunque también se podían adquirir montadas en bastidores de medidas estándar.

Las tablas permitieron la pintura de género, a veces, de tamaños francamente pequeños pero muy apreciada y codiciada por la burguesía. El soporte lígneo era utilizado para pintar bocetos o apuntes del natural aunque también las podemos encontrar excepcionalmente en obras de gran tamaño. Los cartones y papeles gozaron de cierta aceptación entre los pintores y eran especialmente empleados como soporte de bocetos y apuntes.

Las fuentes también citan otros soportes. O'Neille (1862) considera el hule como material adecuado para pintar al óleo. Las planchas metálicas aparecen en O'Neille (1862), De la Roca y Delgado (1880) y Poleró (1886). Algunos tratados aluden también al cristal, el pergamino, el cuero o las paredes como soportes para la pintura al óleo. 


\subsection{Lienzos y Bastidores}

Las ventajas que presenta el lienzo frente a otros soportes fueron expuestas por Soler y Ferrer (1837) y residían en la facilidad para aparejarse y trasladarse enrollado. Si bien esta última virtud ha sido alabada desde que el lienzo comenzara a emplearse como soporte pictórico en el siglo XV. Soler y Ferrer exponen las características propias de un buen lienzo.

...debe ser crudo y fino medianamente atendido el grandor del cuadro; no muy tupido, pero si muy igual y fino de hilo, sin prensa ó cilindro, de cuyas todas cualidades lo hay si se sabe escoger, tejido en el país. Hágase en cuanto se pueda el cuadro de una sola pieza, buscando para ello el de mayor ancho, y no bastando, se unirán sus tiras cosiéndose siempre por el canto vivo á lo largo de la pieza, y al punto que llaman por sobre, con hilo sencillo, crudo, fuerte y delgado para que relieve menos, no cogiendo nunca de las orillas del lienzo mas que el último hilo, dejando el punto poco é igualmente apretado, despues de lo que se estira y plancha la costura, con lo que queda asi toda la pieza unida, sin conocerse enteramente por donde. (Soler y Ferrer, 1837: II, 45)

Soler y Ferrer son los únicos tratadistas de nuestra investigación que advierten contra las telas 'prensadas' aunque no esclarecen el motivo de esta prevención. Una aclaración sobre este asunto podemos encontrarla en Palomino (1988: II, 126) quien explica que un lienzo "aprensado" cuando se encola o extiende la gacha de la preparación puede formar "vejigas"; por eso es necesario lavarlo y secarlo bien antes de montarlo en el bastidor. El "aprensado" de Palomino tal vez haga referencia al apresto de la tela. El apresto consiste en aplicar al lienzo una sustancia - como el almidón - que confiere a la tela mayor consistencia o rigidez. Para aplicar esta sustancia puede ser necesario el calor y la presión que podrían aplicarse mediante una prensa o cilindros. El apresto puede causar problemas en la pintura si no se elimina previamente. Tal vez, Soler y Ferrer se refieran al apresto cuando hablan de "prensa ó 
cilindro" y consideran que son mejores las telas que no han sido sometidas a ellos. A finales de siglo, Emilio Sala (1896: XLIII, 294) indica la necesidad de lavar y secar bien las telas antes de pintar sobre ellas posiblemente para eliminar el apresto.

Una similitud entre Soler y Ferrer y Palomino que no se repite en el resto de tratados españoles decimonónicos es el cosido de los lienzos. Tal vez, la forma de unir los lienzos no comparece en tratados posteriores porque en torno a 1840, según Bordini (1999: 16), se comenzó la producción mecánica de telas favoreciendo la variedad de dimensiones, peso y tejidos de diferentes fibras. La fabricación de lienzos de mayor tamaño, sin duda, pudo resultar tanto una ayuda como un incentivo para que los artistas pintaran los cuadros de historia en monumentales formatos.

Las fuentes de la presente investigación nos permiten navegar entre diferentes tipos de lienzos según la clase de fibra, suerte de tejido, género de grano, etc. Soler y Ferrer (1837) omiten el tipo de fibra adecuada para los lienzos; O’Neille (1862), en cambio, aconseja la tela de hilo, si bien, esta expresión puede aludir tanto al lino como al cáñamo. De la Roca y Delgado (1880: 260), en su transcripción de Palomino, expone lienzos propios del barroco tardío que resultan difíciles de identificar.

...para cuadros grandes, es el que en Andalucía llaman bramante crudo y en Castilla angulema; pero también es bueno el guingao, como sea igual y sin nudos ni canillas; y si fuere para lienzos pequeños, como de vara hácia abajo, es muy bueno el Santiago crudo ó el lienzo que llaman de Coruña; [...] (De la Roca y Delgado, 1880: 260)

Para Poleró (1886: 85) el tejido más apropiado es el cáñamo. Según Bomford et al. (1990: 46), la tratadística francesa, a partir de la década de 1840, recomendaba los lienzos de cáñamoํㅜ para los

\footnotetext{
${ }^{1}$ Encontramos esta recomendación en Bouvier (1827: 544). Para este tratadista los mejores lienzos son los de cáñamo “...parce qu'elles sont plus fortes, et qu'elles peuvent supporter d'être très - fortement tendues sans se rompe.” Un poco más adelante el autor recomienda elegir las telas más fuertes para los cuadros de gran formato (1827: 545)
} 
cuadros de gran formato porque eran más fuertes, permitían un mejor tensado en el bastidor y eran más baratos. Sin embargo, añade el investigador inglés, su disponibilidad durante la segunda mitad del siglo debió ser reducida dado que no fue empleado extensamente.

Para Camille Bellanger (1899) el lienzo es la superficie más perfecta sobre la que se puede pintar. Este pintor (1899: 231) únicamente contempla las telas de lino y aconseja "los lienzos llamados imputrescibles, de José Frappa, fabricados actualmente por la casa Lefranc”. Vibert (1908: 147) recalca la repercusión que la invención del ferrocarril tuvo en la pintura pues permitía el traslado de cuadros enrollando los lienzos. Vibert (1908: 148) también comenta que la tela utilizada como soporte se fabricaba primordialmente en Holanda dónde la mano de obra era más barata que en Francia; si bien - se extraña el pintor - el lienzo crudo pagaba más aranceles al pasar la aduana que la tela preparada.

En el siglo XIX los lienzos de algodón se convirtieron en una alternativa a los lienzos de lino y cáñamo aunque existían desavenencias sobre su idoneidad entre los pintores. Para O’Neille (1862: 30) los lienzos de algodón no eran útiles como soporte pictórico ${ }^{2}$. Sin embargo, en fuentes posteriores existe evidencia del empleo de lienzos de algodón. Poleró (1886: 85) explica que algunos pintores habían empleado el algodón. Una evidencia clara de la adaptación de este tipo de tejido como soporte artístico lo hallamos en el catálogo de L. Péant e Hijos (1895: I, 15) dónde se ofertaba tela de algodón preparada en rollos de 10 metros. Otro documento que atestigua el empleo de los lienzos de algodón como soporte pictórico lo encontramos en una patente de invención datada en 1895. La mencionada patente recoge "Un procedimiento para la preparación a mano de telas destinadas al arte de pintar al óleo"3. La patente propone aplicar la preparación a mano sin ningún tipo de utensilio sobre diferentes tejidos empleados en la pintura entre los que se incluye el algodón: “...toda clase de hilo, algodón ó de cualquiera otra

\footnotetext{
2 Bouvier (1827: 544) se expresaba de manera similar: "Les toiles de coton ne valent rien pour cet usage.”.

3 Archivo Histórico de la OEPM. No. de Patente 18360.
} 
material destinadas á pintar al óleo,..."

Con independencia del tipo de fibra con que estuvieran tejidos los lienzos, estos poseían otras características cuya variedad permitía que los pintores dispusieran de una gran oferta de telas. Algunas de las fuentes como el Tratado de Paisaje de O'Neille (1862: 26) diferencian los lienzos por su grano y define el término como “...la uniforme desigualdad del tejido,..."4. El paisajista expresa que cada artista tenía sus preferencias a la hora de elegir el tipo de lienzo.

...el lienzo varia en diferentes clases: los unos lo prefieren basto, muy grueso, y que su tejido forme cierta igual desigualdad que se llama grano gordo: otros lo prefieren fino, y que su grano sea mas pequeño: otros lo prefieren finisimo, y que su superficie sea lo mas igual y lisa posible.....en fin cada artista tiene sus ideas, sus manías, y sus preocupaciones. (O'Neille, 1862: 30)

Para O’Neille (1862: 30), los lienzos de grano gordo sólo eran adecuados para bocetos, pintura rápida de efecto y para pintar alla prima. Los pinceles fuertes resultaban imprescindibles para pintar sobre esta clase de tela. Este tejido - comenta O’Neille (1862: 31) - permite los golpes fuertes de pincel llamados entre los pintores escenógrafos de restregón “...pues las partes mas salientes de la superficie toman mayor parte de los colores, y las pequeñas profundidades quedan con el oscuro de la tinta preparatoria, aparentándose así un medio tono de gran dulzura.” Este paisajista considera que el lienzo de grano fino es el más apropiado para pintar con delicadeza mientras que la tela de grano finísimo presenta una superficie demasiado lisa y es necesaria mucha práctica y habilidad para obtener resultados satisfactorios. Este último lienzo únicamente es útil para pintar obras muy pequeñas y delicadas.

\footnotetext{
4 En cambio, Bomford et al. (1990: 47) aseguran que la denominación à grain se otorgaba a los lienzos con una preparación sencilla porque la trama permanecía vibrante. Las telas à grain eran apreciadas por los pintores impresionistas porque les permitían lograr adecuados efectos pictóricos en sus paisajes. En cambio, las telas con una preparación doble recibían el nombre de lisse porque la textura del lienzo se perdía por completo.
} 


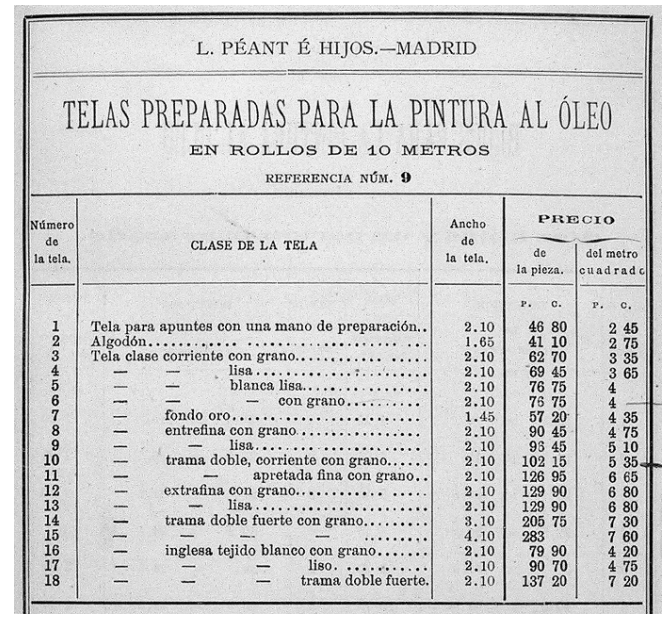

Fig. 30. L. Péant é Hijos: Catálogo General de Colores Extrafinos, Barnices, Aceites, Secantes (1893-1895). Lienzos Preparados.
A finales de siglo, L. Péant é Hijos diferencian entre tela de clase corriente, entrefina, extrafina ${ }^{5}$ o inglesa con grano o lisa. Además, estos comerciantes ofrecían telas preparadas con diferentes tipos de ligamento: de trama sencilla, doble o doble fuerte. El catálogo de este proveedor ofertaba telas preparadas en rollos de 10 metros cuyos anchos oscilaban entre 1'45 metros ó 1'65 metros de la tela "fondo oro" y la de algodón respectivamente a los anchos de 3'10 y 4'10 metros de las telas de trama doble fuerte con grano. El resto de telas alcanzaba un ancho de 2'10 metros. Como hemos señalado antes, es fácil imaginar que los pintores encontraran en los grandes lienzos que suministraba el comercio un aliado para elaborar sus gigantescos cuadros de historia. Los rollos de tela preparada se vendían enteros o por metro cuadrado aunque los lienzos también se proporcionaban montados en bastidores. L. Péant é Hijos suministraban a sus clientes tela para apuntes, corriente y entrefina montada en bastidores de medidas estándar.

Pero ¿qué suministrador estableció las medidas estándar de los bastidores?. Hasta ahora no se ha encontrado respuesta a esta pregunta. Ayres (1985: 82) explica que desde finales del siglo XVIII se vendían lienzos preparados y montados en bastidores que estaban marcados con el nombre del fabricante. Según este investigador, el

\footnotetext{
5 Para Bomford et al. (1990: 45 - 46) las denominaciones de lienzo ordinaire, fine o demi-fine obedecían a la obertura de la trama; es decir, el primero era de trama abierta, el segundo de trama cerrada mientras que el tercero correspondería a una clase intermedia. Los lienzo demi-fine - explican Bomford et al. (1990: 46) estuvieron disponibles desde finales de la década de 1880.
} 
primero de los ejemplos que se conoce data de 1799 y el sello es de un fabricante llamado James Poole; la obra que se encuentra marcada en su reverso en el retrato de Mrs. Elliot de John Opie.

Pero Bomford et al. (1990: 44) señalan que esta clasificación numérica de los tamaños de bastidores y telas data de mediados del siglo XVIII o probablemente del siglo XVII. En el Dictionnaire Portatif de Peinture, Sculpture et Gravure de Antoine Pernety (París, 1757) constan los tamaños numerados de los bastidores exactamente igual que en el siglo XIX. El número que indicaba el tamaño del bastidor hacía referencia a su precio en sous (un lienzo del número 10 costaba 10 sous antes de la Revolución Francesa). Esta numeración se sigue empleando hoy en día aunque no tiene relación con el precio del bastidor; actualmente la numeración únicamente hace referencia al tamaño.

A mediados del siglo XIX, ya estaba establecida una clasificación de los tamaños de los lienzos y bastidores que preveía los diferentes géneros pictóricos: figura, paisaje y marina. Cada formato seguía llevando el número establecido según el tamaño (1 Figura, 1 Paisaje, 1 Marina, etc). Los distintos formatos compartían una dimensión mientras que la otra era característica de cada uno. Bomford et al. (1990: 44) explican que por cada número de bastidor, los pintores tenían disponibles cinco formatos:uno de figura, dos de paisaje y dos de marina. Esto se constata en el catálogo de L. Péant é Hijos (1895: I, 14) donde se ofertan bastidores sin tela y con tela para retrato, paisaje (alto y bajo) y marina (alto y bajo). Sin duda, el lector atento habrá notado que el catálogo español se refiere al formato de figura bajo la denominación de retrato.

Hasta finales de la década de 1880 - cuentan Bomford et al. (1990: 44 -45) - los formatos de paisaje y marina estaban disponibles únicamente en los tamaños intermedios, desde el número 5 al 30. Pero en esas fechas se ampliaron los tamaños de ambos formatos pasando a ser el más pequeño del mercado el $n^{0} 1$ de marina (22 x $12 \mathrm{~cm}$. 


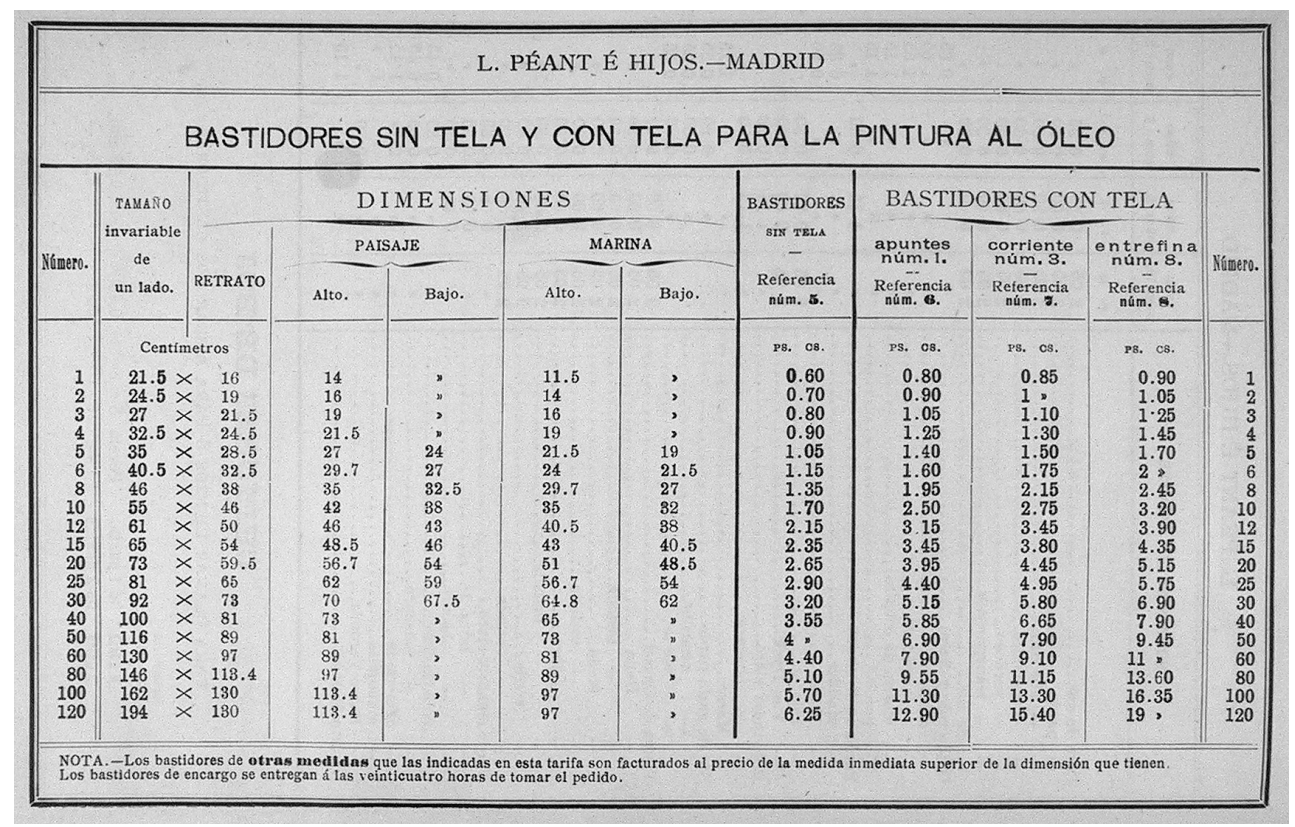

Fig. 31. L. Péant é Hijos: Catálogo General de Colores Extrafinos, Barnices, Aceites, Secantes (1893-1895). Medidas de los Bastidores.

En el catálogo de L. Péant é Hijos (1895: I, 14) los formatos paisaje bajo y marina bajo solo se comercializaban del $\mathrm{n}^{0} 5$ al 30 mientras que los formatos de paisaje y mariana altos se vendían en todos los tamaños, del $\mathrm{n}^{0} 1$ al 120. No obstante, tenemos que observar que varios tamaños de bastidores de L. Péant é Hijos difieren ligeramente, en algunas medidas, de los tamaños estándar actuales (Ver Tabla). En cambio, las medidas que Bomford et al. (1990: 46) muestra de las telas con bastidor del fabricante Bourgeois aîné (1888) son prácticamente exactas a las actuales. Únicamente se advierte diferencia en todos los formatos del número $12 \mathrm{y}$ en el número 120 de paisaje y marina. 


\begin{tabular}{|c|c|c|c|c|c|c|c|c|c|c|c|}
\hline \multicolumn{7}{|c|}{ MEDIDAS L. PÉANT É HIJOS } & \multicolumn{5}{|c|}{ MEDIDAS ACTUALES } \\
\hline \multirow{3}{*}{ № } & \multirow{3}{*}{$\begin{array}{c}\text { TAMAÑO } \\
\text { FIJO } \\
\text { (Cms) }\end{array}$} & \multicolumn{5}{|c|}{ DIMENSIONES } & \multirow{3}{*}{ FIGURA } & \multirow{3}{*}{ PAISAJE } & \multirow{3}{*}{ MARINA } & \multirow{3}{*}{$\begin{array}{c}\text { TAMAÑo } \\
\text { FIJO } \\
\text { (Cms) }\end{array}$} & \multirow{3}{*}{ № } \\
\hline & & \multirow[t]{2}{*}{ RETRATO } & \multicolumn{2}{|c|}{ PAISAJE } & \multicolumn{2}{|c|}{ MARINA } & & & & & \\
\hline & & & ALTO & BAJO & ALTO & BAJO & & & & & \\
\hline 1 & $21 ' 5 x$ & 16 & 14 & & $11 ' 5$ & & 16 & 14 & 12 & $\times 22$ & 1 \\
\hline 2 & $24 ' 5 x$ & 19 & 16 & & 14 & & 19 & 16 & 14 & $\times 24$ & 2 \\
\hline 3 & $27 x$ & 21.5 & 19 & & 16 & & 22 & 19 & 16 & $\times 27$ & 3 \\
\hline 4 & $32 \prime 5 x$ & $24{ }^{\prime} 5$ & $21^{\prime} 5$ & & 19 & & 24 & 22 & 19 & $\times 33$ & 4 \\
\hline 5 & $35 x$ & $28{ }^{\prime} 5$ & 27 & 24 & $21^{\prime} 5$ & 19 & 27 & 24 & 22 & $\times 35$ & 5 \\
\hline 6 & $40^{\prime} 5 x$ & 32 '5 & $29^{\prime} 7$ & 27 & 24 & $21^{\prime} 5$ & 33 & 27 & 24 & $\times 41$ & 6 \\
\hline 8 & $46 x$ & 38 & 35 & $32^{\prime} 5$ & $29^{\prime} 7$ & 27 & 38 & 33 & 27 & $\times 46$ & 8 \\
\hline 10 & $55 \times$ & 46 & 42 & 38 & 35 & 32 & 46 & 38 & 33 & $\times 55$ & 10 \\
\hline 12 & $61 \times$ & 50 & 46 & 43 & $40^{\prime} 5$ & 38 & 50 & 46 & 38 & $\times 61$ & 12 \\
\hline 15 & $65 \times$ & 54 & $48^{\prime} 5$ & 46 & 43 & $40^{\prime} 5$ & 54 & 50 & 46 & $\times 65$ & 15 \\
\hline 20 & $73 x$ & $59^{\prime} 5$ & $56^{\prime} 7$ & 54 & 51 & $48^{\prime} 5$ & 60 & 54 & 50 & $\times 73$ & 20 \\
\hline 25 & $81 \times$ & 65 & 62 & 59 & $56^{\prime} 7$ & 54 & 65 & 60 & 54 & $\times 81$ & 25 \\
\hline 30 & $92 \times$ & 73 & 70 & $67 ' 5$ & $64^{\prime} 8$ & 62 & 73 & 65 & 60 & $\begin{array}{r}\times 92 \\
\end{array}$ & 30 \\
\hline 40 & $100 \times$ & 81 & 73 & & 65 & & 81 & 73 & 65 & $\times 100$ & 40 \\
\hline 50 & $116 x$ & 89 & 81 & & 73 & & 89 & 81 & 73 & X 116 & 50 \\
\hline 60 & $130 x$ & 97 & 89 & & 81 & & 97 & 89 & 81 & x 130 & 60 \\
\hline 80 & $146 x$ & $113^{\prime} 4$ & 97 & & 89 & & 114 & 97 & 89 & x 146 & 80 \\
\hline 100 & $162 \times$ & 130 & $113^{\prime} 4$ & & 97 & & 130 & 114 & 97 & x 162 & 100 \\
\hline 120 & $194 \times$ & 130 & $113^{\prime} 4$ & & 97 & & 130 & 114 & 97 & $\times 195$ & 120 \\
\hline
\end{tabular}

Tabla comparativa de las medidas de los bastidores suministrados por L. Péant é Hijos a finales del siglo XIX y las medidas estándar actuales.

En cambio, las medidas estándar inglesas durante el siglo XIX mantenían una clasificación distinta estipulada en relación a la pintura de retratos. Las transcripciones de Carlyle (2002: 447) demuestran esta forma de estandarizar los bastidores tan alejada de la francesa o española. Un texto anónimo de 1808, A Compendium of Colours $^{6}$ presentaba las medidas estándar denominadas Kit - Cats, Three - Quarters, Half-Lenghts, Bishop Half lenghts y Whole - Lenghts. Unos años más tarde, en 1815, Charles Hayer en An Introduction to Perspective, Adapted to the Capacities of Youth7exponía estos formatos y ampliaba la oferta de los mismos con

\footnotetext{
${ }^{6}$ Anon. A Compendium of Colours, 1808. (Carlyle, 2002: 447)

7 Hayter, Charles: An Introduction to Perspective, Adapted to the Capacities of Youth, In a Series of Pleasing and Familiar Dialogues, Between the Author's Children; Accompanied with illustrative Plates, appropriate Diagrams, and a Sufficiency of Practical Geometry To Which is Added, A Compendium of Genuine Instruction in the Art of Drawing and Painting. The Whole Comprising a Body of Information, adapted equally to the Simplicity of Youth and to Mental Maturity. 1815, Second Edition. (Carlyle, 2002: 306, 447)
} 
nuevos tamaños estándar. Los paisajes se pintaban en estos lienzos de medida estándar pero colocados en horizontal. A finales de siglo, en 1892, Frederick Oughton en Students' and Amateurs' Notebook on Oil Colour Technique Etc ${ }^{8}$ demuestra que los mismos formatos de principios de siglo estaban en uso pero ya aparece mencionado el formato de paisaje en varios tamaños. Aún a principios del siglo XX esta clasificación seguía vigente. Winsor \& Newton (1902: 118 - 119) exhibía las misma estandarización: "Three - quarter”, "Kit - Cat", "Small half length”, "Half length”, "Bishop's half length", "Small whole length", "Whole length”, "Bishop's whole length” and "Landscape".

Las fuentes decimonónicas españolas dedican poco espacio a los bastidores. Ya hemos comentado la información que se deduce de lo expuesto en el catálogo de L. Péant é Hijos a finales de siglo. Pero, aparte de este testimonio, únicamente Soler y Ferrer, De la Roca y Delgado, Poleró y Bellanger hacen alusiones al armazón de los soportes de lienzo. Soler y Ferrer (1837: II, 46) explican que el bastidor debe ser “...de cualquier madera común, y muy ajustado en sus mechas sin pegarse ni clavarse estas;...” Los listones y travesaños deben estar rebajados para evitar que el lienzo los roce cuando se frota con la piedra pómez o se pasa la imprimadera. Los travesaños, apuntan estos autores, tienen la utilidad de evitar que el lienzo se vicie con el tiempo cuando no tiene marco que lo abrace. Las apreciaciones de De la Roca y Delgado (1880: 260) son similares e igualmente escuetas. Poleró (1886) en el apartado de Forración de su Tratado General de Pintura demuestra la importancia que se otorgaba a que los bastidores tuvieran la capacidad de abrirse para tensar la tela.

...se clava el lienzo en su correspondiente bastidor, que deberá construirse con cuñas en sus cuatro ángulos, y un montante si su tamaño lo exigiese, á fin de que, una vez asegurado con las

\footnotetext{
${ }^{8}$ Oughton, Frederick: Students' and Amateurs' Notebook on Oil Colour Technique Etc. London, 1892. (Carlyle, 2002: 318, 447)
} 
tachuelas, se pueda estirar con facilidad; operación sencilla, y para cuyo acertado desempeño basta sólo no fiar á las cuñas la misión que desempeñan, procurándose, por el contrario, estirar el lienzo con el auxilio de las tenazas. (Poleró, 1886: 169-170)

Los bastidores con cuñas ${ }^{9}$ también son mencionados por Camille Bellanger (1899: 230 - 231) que las define como “...pequeños trozos de madera puntiagudos colocados interiormente en cada uno de los ángulos, y que pueden apretarse a voluntad, según queramos darle al lienzo una tensión más ó menos considerable.”

Durante el siglo XIX se pintaron muchas obras de gran formato especialmente aquellas destinadas a las Exposiciones Nacionales. La monumentalidad de los lienzos debía suponer una dificultad tanto para exponer las obras como para trasladarlas o almacenarlas. Por eso no es de extrañar que se intentaran aportar soluciones a estos problemas. Un interesante intento para facilitar el traslado de obras de gran formato se plasmó en una patente de invención por un "Bastidor plegable para cuadros al óleo, o artísticos"10. Esta patente se registró en 1891 a nombre de Richard Eduard Butler.

La presente invención tiene por objeto facilitar el doblado por mitad de los bastidores destinados para pinturas al óleo, sin que el lienzo estirado sobre las dos mitades pueda arrugarse ni deteriorarse, y de modo que al abrir de nuevo dicho bastidor, queda bien estirado el lienzo.

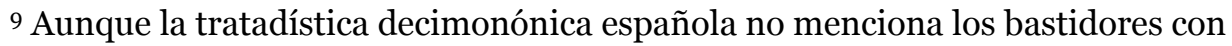
cuñas hasta finales de la centuria, estos bastidores aparecen en la Enciclopedia de Diderot et d'Alembert [1751 - 1772] y más tarde Bouvier (1827: 547 - 551) los describió detalladamente. Para este artista, los bastidores con cuñas son los mejores.

${ }^{10}$ Archivo Histórico de la OEPM. No de patente: 12648.
} 

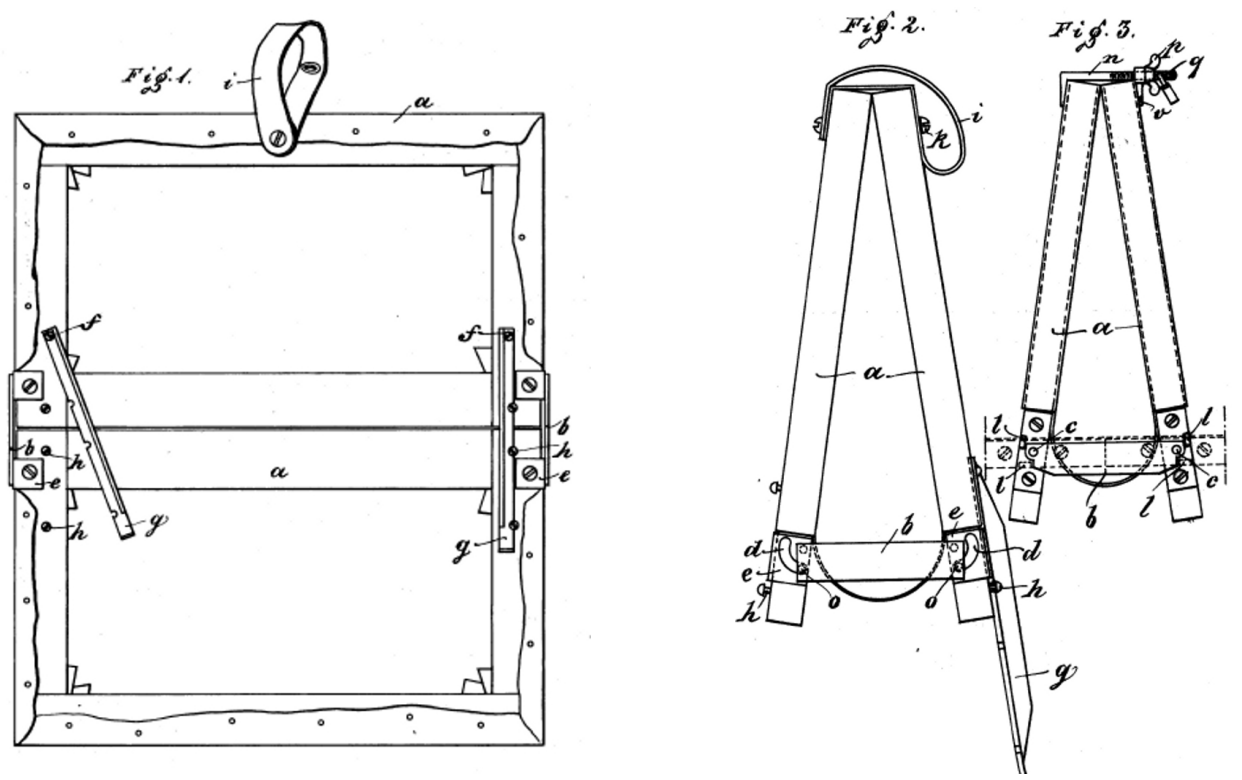

Figs. 32-33. Bastidor Plegable Para Cuadros al Óleo o Artísticos (1891).

Patente $\mathrm{n}^{\circ}$ 12648. Archivo Histórico de la OEPM.

Es evidente, que para obtener este resultado no es posible servirse de la conocida y sencilla bisagra, puesto que con ella no se impediría que el lienzo se moviera, ni se conseguiría un completo estirado del referido lienzo. (Archivo Histórico de la OEPM. No Patente 12648)

Sobre el montaje del lienzo en el bastidor encontramos un dato curioso. Estamos ante otra coincidencia entre Soler y Ferrer y Palomino. La concurrencia en esta ocasión se halla en la manera en que los lienzos se montan sobre el bastidor. Los citados tratadistas decimonónicos explican que el lienzo comienza a clavarse en el bastidor por las esquinas procediendo después a asentar los lados.

En este bastidor así dispuesto, se sentará el lienzo con las costuras que tenga hácia dentro, apuntandolo luego en las cuatro esquinas con dos tachuelas ó puntas, una á cada lado de ella, cuidando de que no haga bolsa, y tirando siempre hácia la esquina contraria; luego ir clavando las otras puntas de un lado el mas 
tasado primeramente, sentandolo sin violencia; seguidamente pasar á su opuesto tirando todo lo posible con los dedos, ejecutando lo mismo en los otros lados, y dirigiendo siempre las puntas ó tachuelas hácia la cara del cuadro, pero sin que salgan á ella, con lo que harán mas fuerza. (Soler y Ferrer, 1837: II, 46)

Esta forma de clavar los lienzos en el bastidor fue descrita de manera prácticamente similar en el siglo XVIII por Palomino (1988: 126-127) y fue recogido por De la Roca y Delgado (1880: 260 - 261) en su Compilación y es probable que se tratara de una práctica habitual. Esta manera de clavar los lienzos en el bastidor es notablemente diferente de la forma de ejecutar en la actualidad esta operación. Hoy en día, lo habitual es clavar primero los lados y terminar por las esquinas, de esta forma es más fácil evitar la formación de bolsas.

\subsection{Tablas}

El desarrollo del lienzo como soporte para la pintura supuso un paulatino abandono de las tablas como demuestran las palabras de Palomino (1988: II, 132) a principios del siglo XVIII: "Y así hoy sólo en cosas de mediano tamaño se usa de las tablas, de suerte, que puedan ser de una pieza,...” Durante el siglo XIX, los soportes lígneos tuvieron un especial uso en apuntes y pequeños formatos; Camille Bellanger (1899: 229) comenta que “...la madera se emplea mucho para pintar cabezas de estudio ó pequeños cuadros de género, pero con la condición que el tablero conste de una sola pieza. Son muy útiles para tomar algunos croquis en el campo.” La burguesía apreciaba enormemente los pequeños cuadros de género que los pintores acostumbraban a desarrollar en tablitas. Este soporte permitía elaborar pinturas de tamaños muy pequeños que los pintores llegaban a tratar de forma preciosista. Entre nuestros pintores despuntó en la pintura de tableautin o casacón el genial Mariano Fortuny de quien se conservan numerosas obras sobre tabla de tamaños muy dispares. Los pintores también utilizaron las tablas 
para ejecutar sus bocetos. Por ejemplo, Carlos de Haes pintó sobre tabla el boceto de La Canal de Mancorbo en los Picos de Europa ${ }^{11}$ (1874). También Gisbert elaboró sobre tabla el boceto de su monumental Fusilamiento de Torrijos y sus Compañeros en las Playas de Málaga ${ }^{12}$, (h. 1887).

“...la primera condición para que el tablero no se mueva es que sea pequeño y grueso;...” dice Camille Bellanger (1899: 228). Esto supone una limitación en las dimensiones de la obra. Si se desean tablas de grandes formatos, añade el mismo artista, es necesaria la unión de varias tablas reforzadas por el reverso con travesaños transversales de madera de encina. Bellanger (1889: 229) asegura que la amplitud máxima que pueden alcanzar estos tableros es de “..1 metro 50, en cuadro.” pero todos acaban por agrietarse y estropeando la pintura.

Según Vibert (1908: 267), las tablas tenían que someterse a ciertos tratamientos antes de utilizarse como soporte pictórico: "Debe frotarse la tabla con papel de vidrio oo, mojando dicho papel con petróleo al dar la última mano. Luego se conserva en un sitio seco hasta que haya estrechado próximamente un centímetro por metro." Para proteger la tabla de la humedad, el reverso debía pintarse con una mezcla de aceite de linaza y barniz de retoques sin secativo. Una vez seco este estrato era procedente aplicar un barniz de cuadros. Los cantos de la tabla se preservaban convenientemente pintándolos con una mixtura de blanco de plomo, barniz y un poco de secativo. Para que los bordes quedaran aislados eficazmente, el autor recomendaba pasar el papel de vidrio entre capas.

O’Neille (1862: 31$)$ esgrime la importancia de que los tableros sean viejos y estén bien secos para prevenir posibles fendas y roturas argumentando que, en el pasado, esta contrariedad se evitaba adhiriendo por el reverso de la tabla tiras de lienzo o

\footnotetext{
${ }^{11}$ Carlos de Haes: La Canal de Mancorbo en los Picos de Europa, 1874. Óleo sobre tabla, 33 x 23 cm. Colección Particular. (Díez, 2007: 282).

${ }_{12}$ Antonio Gisbert: Fusilamientos de Torrijos y sus Compañeros en las playas de Málaga (boceto), h. 1887. Óleo sobre tabla, 47 x $71 \mathrm{~cm}$. Madrid, Museo Nacional del Prado. (Díez, 2007: 269).
} 
hebras de cáñamo. De la Roca y Delgado (1880: 267) enarbolaba el mismo argumento: “...ya esto se ha dejado, por haberse visto los inconvenientes de saltar los aparejos y de torcerse y abrirse las tablas; no obstante que las enervaban ó encañamaban por detrás con cáñamo y cola fuerte;..." Vicente Poleró (1886: 85) comenta que para prevenir las alteraciones a que están sujetas las tablas conviene "embarrotarlas" antes de su preparación. El propio Vibert (1908: 143) retomando prácticas atávicas recuerda que los pintores del Medioevo utilizaban madera de encina o álamo para sus composiciones pictóricas. Por entonces - expone Vibert (1908: 143) -, las tablas se unían "con cola animal (taurocola) ó con engrudo mezclado con yeso ó tiza, y á veces con una cola de queso y cal cuya receta describe Teófilo en un manuscrito célebre.”

Las fuentes decimonónicas españolas sugieren varias clases de maderas convenientes como soporte pictórico. Poleró $(1886,85)$ es el autor que recomienda mayor diversidad de maderas; el roble, el haya, el nogal, el cedro y el castaño son sus alternativas lígneas como soporte pictórico. Ningún otro texto de esta investigación menciona estas suertes de madera para uso pictórico. Bellanger (1899: 229) prefiere las maderas de álamo y ojaranza para elaborar croquis de campo; y las maderas de encina y caoba para los cuadros. En cambio, Vibert (1908: 266) aconseja el álamo de Holanda porque "tiene el grano muy regular y los poros abiertos.” Según este pintor, el álamo y la encina eran las maderas empleadas por los maestros del pasado. A diferencia de Bellanger, este autor tan interesado en la estabilidad de los materiales pictóricos argumenta que las maderas de encina y caoba poseen vetas de dureza desigual que produce una absorción irregular del aceite de los colores. En cambio, las fuentes inglesas - dice Carlyle (2002: 187) - se refieren, con mayor asiduidad, a las maderas de roble y caoba como soportes adecuados para la pintura.

Un interesantísimo retrato de Raimundo de Madrazo demuestra que la caoba era una magnífica opción para pintar obras de gran formato. En 1875, este artista pintó, sobre una enorme tabla de caoba (227 x $127 \mathrm{~cm}$ ), el retrato de Josefa Manzanedo e Intentas, II Marquesa de Manzanedo. Según Díez (2007: 328), la tabla está 


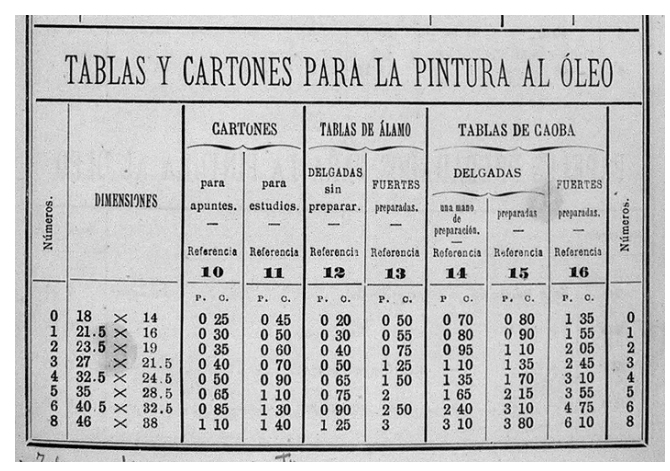

Fig. 34. L. Péant é Hijos: Catálogo General de Colores Extrafinos, Barnices, Aceites, Secantes (1893-1895). Tablas y Cartones. formada por una sola pieza. Pero un soporte de estas característica no era usual y el pintor, seguramente, tuvo que encargarlo ex profeso.

El catálogo de L. Péant e Hijos (1895: I, 15) muestra que la oferta de tablas para pintar comprendía las maderas de álamo, caoba y chopo y los tamaños no eran

excesivamente grandes. Las tablas de álamo y caoba compartían las medidas con los cartones para pintura al óleo. Estas eran las medidas estándar de retrato desde el número 1 (21'5 x $16 \mathrm{~cm}$.) hasta el número 8 ( $46 \times 38 \mathrm{~cm}$.). Aunque en este caso, los comerciantes han incluido un nuevo tamaño que no obedece a las medidas estándar: el número o (18 x $14 \mathrm{~cm}$.). Es decir, sólo las tablas y los cartones se ofertaban, en el catálogo de L. Péant é Hijos, con el número o; los lienzos y bastidores comenzaban la numeración estándar en el número 1 como en Francia. Las tablas de álamo y caoba se suministraban en dos grosores diferentes: delgadas y fuertes; todas ellas se vendían preparadas excepto las tablas de álamo de menor grosor. Las tablas de chopo se muestran siempre vinculadas a las cajas de pintura al óleo que utilizaban los pintores, especialmente, para salir a pintar al campo.

Pero tablas para pintar se proveían en tamaños muy diferentes debido a que formaban parte de las cajas para pintura al óleo que permitían a los pintores trasladarse cómodamente con sus utensilios de trabajo. Y estas cajas eran de tamaños muy diversos, desde las pequeñas cajas de bolsillo para apuntes de 10'5 x $15 \mathrm{~cm}$. hasta las cajas de paisaje de 39'5 x 28'5 cm. 


\subsection{Papeles y Cartones}

Los cartones aparecen mencionados como soporte para la pintura al óleo en O'Neille (1862), De la Roca y Delgado (1880), Vicente Poleró (1886) y, por supuesto, se ofertaban en el catálogo de colores de L. Péant é Hijos (1895). Una interesante muestra de pintura sobre cartón la encontramos en $\mathrm{El} \mathrm{Borracho}^{13}$ de Leonardo Alenza pintado a principios de la década de 1840 y en Plaza en Segovia ${ }^{14}$ de Darío Regoyos datado en 1882 . También los papeles preparados para pintar al óleo son citados por O'Neille (1862), De la Roca y Delgado (1880) y Poleró (1886) y también eran suministrados - sueltos o en blocs - por L. Péant é Hijos (1895).

O’Neille (1862: 26) explica que “... como cosa de puro estudio, muchos principios ó bocetos se hacen sobre cartón ó papel.” Para este paisajista (1862: 32), los cartones carecen de los inconvenientes de las tablas y de sus palabras se desprende que los artistas disponían de dos cartones diferentes. Unos cartones preparados que únicamente servían para realizar los primeros estudios y otros gruesos y consistentes cuya preparación ofrece una superficie homogénea que facilita la buena adherencia del color. Sin embargo, comenta el paisajista, estos cartones presentan el inconveniente de desgastar de manera extraordinaria los pinceles. De la Roca y Delgado (1880: 268) y Poleró (1886: 86) únicamente mencionan esta suerte de soporte entre otros muchos para pintar al óleo.

L. Péant é Hijos (1895: I, 15) ofertaban cartones para apuntes y estudios con las mismas medidas estándar que las tablas. Como se ha comentado con anterioridad, los pintores podían optar por varios tamaños de retrato comprendiendo desde el $\mathrm{n}^{0} 1 \mathrm{al} \mathrm{n}^{0} 8$; además se había añadido el $\mathrm{n}^{0} \mathrm{o}$ que no corresponde con ninguna medida estándar. Los cartones para apuntes y estudio compartían las mencionadas medidas, sin embargo los segundos eran más caros.

${ }^{13}$ Leonardo Alenza: El Borracho. Óleo sobre cartón, 22 x 16'8 cm. Museo del Prado. (Barón, 2007:. 138).

${ }^{14}$ Darío Regoyos: Plaza en Segovia. Óleo sobre cartón, 30 x 42'2 cm. Museo de Bellas Artes de Bilbao. (San Nicolás, 2006: 200) 
Algunas cajas de paisaje que suministraban estos empresarios incluían cartones para apuntes.

Una oferta interesante de este comercio de Madrid son los cartones cubiertos de tela de Reeves \& Sons. "Estos cartones tienen, sobre las tablas, la gran ventaja de no torcerse nunca, y el artista pinta en ellos sobre un lienzo superior, como si fuese tela tendida sobre un bastidor." (L. Péant é Hijos, 1895: I, 59). Según Carlyle (2002: 189), los cartones entelados aparecen por primera vez en los catálogo de Reeves \& Sons hacia 1886 y en esa misma fecha también comienzan a figurar en los catálogos de Winsor \& Newton aunque este tipo de cartones estuvo disponible con anterioridad. Comenta Carlyle (2002: 190) que en un libro de compras de Roberson puede leerse que adquirió "Canvas boards" a George Rowney en junio, julio y agosto de 1883 . En noviembre de ese año, el mismo comerciante compró una docena de "Canvas prepd Millboard” a Thomas Fisher de quien continuó proveyéndose.

Los papeles preparados para pintar al óleo eran otra alternativa como soporte que podían emplear los pintores. De la Roca y Delgado (1880: s68) y Poleró (1886: 86) los mencionan entre los soportes adecuados para pintura al óleo. L. Péant é Hijos (1895: I, 16) los ofertaban en un único tamaño $(65 \times 50 \mathrm{cms}$.) y en dos colores: amarillo o gris. Además la preparación confería a la superficie una cualidad lisa o con grano. Algunas cajas de pintor (L. Péant é Hijos 1895: I, 30 - 32) incluían "hojas de papel para pintar". Pero estos papeles, comenta Carlyle (2002, 190), estuvieron disponibles en el primer catálogo de Winsor \& Newton h. 1835 ("Prepared paper for sketching in Oil") y en el primer catálogo de Reeves and Sons que incluía soportes pictóricos (1856).

Los papeles preparados para pintura al óleo también se comercializaban en blocs. En el catálogo de L. Péant é Hijos se suministraban varios de estos cuadernos. Podemos decir, que dadas las medidas estándar, dos tipos de blocs eran de fabricación española. Una de estas libretas estaba compuestas por diez hojas de tela y un cartón preparado y la otra por diez hojas de papel y un cartón preparado. Las medidas de estos cuadernos corresponden a las dimensiones estándar para retrato desde el $\mathrm{n}^{0} 1 \mathrm{al} \mathrm{n}^{\circ} 8$ (L. Péant 
é Hijos, 1895: 16). Esto quiere decir que tenían las mismas medidas que las tablitas y cartones exceptuando el improvisado $\mathrm{n}^{0} \mathrm{O}$ que incluyen estos dos últimos soportes mencionados. Pensamos que son españoles porque - como ya hemos explicado - las medidas estándar españolas difieren en algunos medidas de las estándar francesas (Ver Tabla) y están muy alejadas de las medidas estándar decimonónicas inglesas. Otro bloc que se muestra en el catálogo español es de la marca Reeves \& Sons y constaba de 24 hojas con aislador de pinturas. Carlyle (2002: 191) asegura que cuadernos de estas características ya fueron anunciados por Winsor \& Newton $h$. 1840 y se suministraron a lo largo de toda la centuria.

Los pintores del siglo XIX utilizaron soportes muy variados. Encontramos, por ejemplo, que el papel pegado a cartón fue una alternativa que utilizaron algunos pintores en determinados momentos. Según Díez (2007: 207), Eduardo Rosales elaboró en 1863 un boceto al óleo para Doña Isabel la Católica Dictando su Testamento en un soporte de las características mencionadas. La obrita mide 22 x $32 \mathrm{~cm}$. y pertenece al Museo Nacional del Prado. Otro ejemplo del uso de este soporte es el espléndido óleo de $L a$ Batalla de Wad-Ras (1860-1861) de Mariano Fortuny. Díez (2007: 291) indica que esta obra (54 x $185 \mathrm{~cm}$.) muestra el planteamiento preliminar de La Batalla de Tetúan que Mariano Fortuny abordó un poco más tarde. También Carlos de Haes (h. 1874 - 75) pintó al óleo sobre papel adherido a cartón Una Arroyada. Picos de Europa. Asturias (Gutiérrez Márquez, 2006: 108). La obra perteneciente al Museo de Bellas Artes de Bilbao mide 25 x $35 \mathrm{~cm}$. 


\section{Preparaciones e Imprimaciones}

El tema de las preparaciones o imprimaciones de los soportes resulta siempre conflictivo por la confusión terminológica. Según Stefano Marconi (1993: 11), el término imprimación nació en una descripción que Leonardo da Vinci ${ }^{1}$ hizo sobre la preparación de las tablas en su tratado. Queremos resaltar que el término nació vinculado a la preparación de soportes lígneos. Según Garrido (2006: 16-17), las preparaciones sobre tabla ${ }^{2}$ durante el siglo XV y el tránsito al XVI solían impregnarse con una materia oleaginosa. En este periodo de tiempo era habitual elaborar o trasladar el dibujo sobre la preparación y encima extender una imprimación, translúcida y más o menos blanquecina. Aunque se podían añadir otros pigmentos para lograr otros matices. Los objetivos fundamentales de esta imprimación eran: fijar las líneas y trazos del dibujo, atenuar la presencia de este diseño, prevenir efectos tonales posteriores $\mathrm{y}$ reducir la elevada absorción de la preparación ${ }^{3}$. Con el tiempo esta

COMO PREPARAR UNA TABLA PARA PINTAR

La madera ha de ser de ciprés, peral, acafresna o nogal. Esta debes

embadurnar de almaciga y trementina blanca destilada dos veces, o cal, si así prefieres, y disponer después en un bastidor, de forma que pueda dilatarse y contraerse en conformidad con la humedad o la sequedad. Dale entonces [un baño de] aguardiente en el que hayas disuelto dos o tres veces arsénico o soliman y a continuaci6n, aceite de linaza hirviente, de suerte que penetre por doquier; antes de que se enfríe, fr6tala bien con un paño, hasta dejarla seca, y dale barniz liquido y blanco con el estique; después, cuando ya este seca, lávala con orina. Debes entonces estarcir y delinear tu dibujo con cuidado y dar sobre el una imprimaci6n de treinta partes de cardenillo y una de cardenillo mas dos de amarillo.

(Leonardo da Vinci [s. XVI], 1980: 430)

2 Recordemos que estas preparaciones solían estar compuestas por varios estratos y podían llegar a alcanzar grosores significativos.

3 Carel van Mander en El libro de los pintores (1604) cuenta que el pintor Roger van der Weyden extendió una imprimación anaranjada muy suave sobre el dibujo de su pintura El descendimientos de la cruz (h. 1435) (Garrido, 2006: 17, 52n), Las notables investigaciones sobre los dibujos subyacentes de la pintura, llevadas a cabo en el Museo del Prado, han desvelado detalles interesantes sobre los estratos preparatorios. Destacamos usos concretos de las imprimaciones que hicieron algunos pintores. El Bosco en La mesa de los pecados mortales (h. 1480) aplicó sobre el dibujo diferentes tonalidades de imprimación. Un tono anaranjado en las escenas de las Postrimerías y blanca con excepciones puntuales bajo la 
práctica se modificó y el dibujo comenzó a realizarse sobre la imprimación. Este procedimiento lo encontramos explicado en Vasari (1550). Cuando en el siglo XVI se adoptó el lienzo como soporte pictórico las preparaciones tuvieron que adaptarse a este nuevo material; especialmente tenía que atenderse su flexibilidad. La evolución que sufren las preparaciones de los lienzos para pintura al óleo dan lugar a la confusión de los términos preparación imprimación y a la lógica fusión de ambos. La asimilación del significado de las referidas voces puede apreciarse en Palomino.

IMPRIMAR, V.a. Aquellas primeras manos, que se dan al lienzo, o a qualquiera otra superficie, para disponerla apta, para pintar en ella: llámase también aparejar. Lat.

Præparare, Disponere. Y llámase imprimar, por ser la primera disposicion para pintar. (Palomino, 1988: I, 667)

Vemos que además se incorpora el vocablo aparejar que aparece reiteradamente en los tratados de Pacheco (1649) y Palomino (17151724). No obstante, la lectura atenta de los tratados de Pacheco y Palomino deja entrever que ambos pintores preferían el término aparejo para designar los estratos magros y el vocablo imprimación para referirse a las capas grasas.

En la tratadística española decimonónica los términos preparación e imprimación se emplean indistintamente para referirse a los diferentes estratos que adecúan el soporte para la pintura ${ }^{4}$. Además el vocablo aparejo es recurrentemente utilizado por

representación de los siete Pecados Mortales (Garrido, 2006: 97). Otro caso claro del empleo de la imprimación sobre el dibujo se puede hallar en una interesante obra inconclusa de un pintor anónimo castellano: Cristo mostrado al pueblo datada hacia 1500. En esta pintura se aprecia perfectamente el elaborado dibujo y una imprimación blanca semitransparente superpuesta (Finaldi y Jover, 2006: 224). También hacia 1500 - 1505 El jardín de las delicias de El Bosco presenta una imprimación selectiva - puntual - de blanco de plomo sobre el dibujo (Garrido y van Schoute, 2000: 90).

4 Carlyle (2002: 165) asegura que en la tratadística inglesa del siglo XIX los términos preparación e imprimación se usaban indistintamente: “...preparation of the ground or 'priming' (the terms were used interchangeably).” 
nuestros tratadistas. Las siguientes definiciones de algunos de los autores de este estudio pueden aclarar el uso de ambos términos durante el siglo XIX.

APAREJAR: preparar ó dar á la tela ú otra superficie, unas manos de color, disponiéndola asi para que reciba mejor lo que sobre ella se quiera pintar. Dicese tambien imprimar, por ser la primera operación que se hace en todo el cuadro.

APAREJO, PREPARACION Ó IMPRIMACION: aquellos materiales ó pasta que sirven para lo dicho. (Soler y Ferrer, 1837, II, 134-135)

IMPRIMAR: lo mismo que aparejar ó preparar. (Soler y Ferrer, 1837: II, 150)

O'Neille (1862: 26) explica que "Preparar, ó imprimar es dar una, dos, ó las necesarias manos de color, sobre el objeto en que ha de pintarse:...”. Borbón (1860) también asimila los vocablos preparación e imprimación; y Poleró (1886) equipara los términos aparejo e imprimación. Por su parte, en Vibert (1908) se aprecia el empleo de aparejo, preparación e imprimación como sinónimos. De la Roca y Delgado (1880) y López Tomás (1898) que, en esta materia, - recordemos - transcriben a Palomino y Pacheco respectivamente, muestran las diferentes acepciones de los términos de los autores barrocos. Como ya hemos explicado, Pacheco se refiere al aparejo como los estratos magros de la preparación y a la imprimación como los estratos grasos. El caso de Palomino es similar: las preparaciones y aparejos hacen referencia a las capas magras y las imprimaciones a los estratos oleosos; a pesar de la propia definición del autor que hemos transcrito anteriormente. Por otra parte, Algarra (1875) y Bellanger (1899) prefieren la voz preparación para aludir a estos estratos.

Los pintores podían adquirir en el comercio sus lienzos y tablas ya preparados o bien podían comprar estos soportes crudos y prepararlos ellos mismos. O'Neille (1862), Algarra (1875), Bellanger (1899) y Vibert (1908) aluden a los lienzos de preparación comercial. 
Por supuesto, L. Péant é Hijos (1895) suministraban telas de diferentes clases (Ver 6.1.) preparadas y también ofertaba tablas, papeles y cartones preparados para la pintura al óleo. Soler y Ferrer (1837), O'Neille (1862), De la roca y Delgado (1880), Poleró (1886), López Tomás (1898), Bellanger (1899) y Vibert (1908) explican la manera de preparar, fundamentalmente, lienzos y tablas. Aunque también podemos encontrar referencias a la preparación de cartones, papeles y otras superficies cómo paredes, metales o cristales.

\subsection{Preparaciones comerciales}

Palomino [1715 - 1724] (1988: II, 134) informa que en su tiempo, los pintores ya podían adquirir los lienzos preparados " $\mathrm{Y}$ también advierto que es menester saberlo hacer para saberlo mandar: bien que en Madrid hay imprimadores de oficio, que nos alivian de este cuidado." Mérimée (1830: 243) también expresa que los pintores compraban sus lienzos preparados: "Ajourd'hui les peintres sont beaucoup plus soigneux, et les marchands de couleurs sont, par leur intérêt, excités à bien préparer leurs toiles; la moindre négligence à cet égard leur ferait perdre leur crédit.

Realmente, no es extraño que los pintores abandonaran la tarea de preparar los soportes en manos de los fabricantes y comerciantes de colores puesto que es una labor mecánica y agotadora. Por eso, desde que los fabricantes y comerciantes de colores se asentaron a mediados del siglo XIX, los pintores debieron sentirse atraídos por los soportes preparados industrialmente.

Varios autores españoles decimonónicos aluden a los lienzos y otros soportes de preparación comercial, incluso los recomiendan. O'Neille (1862) y Algarra (1875) son los únicos tratadistas españoles del siglo XIX que hacen referencia a las ventajas de los soportes preparados comercialmente. Hay que esperar a las traducciones de los textos franceses de Bellanger (1899) y Vibert (1908) para encontrar de nuevo referencias a esta clase de soportes. O'Neille plantea el tema considerando el ahorro de tiempo que suponen al 
pintor los soportes de preparación comercial. No obstante, este paisajista aborda también - aunque de manera somera - la preparación de los lienzos (Ver 7.2.).

Véndense lienzos preparados perfectamente de varias clases y tonos de color, desde lo mas fino hasta lo mas grueso y de mayor grano: [...] yo aconsejo que si bien sale algo mas caro comprar lienzo preparado, es mas conveniente, no solo por ser de escelente calidad, sinó porque así no se pierde tiempo en esta parte tan material: escepto cuando se haya de pintar cosas de grandes dimensiones, pues en este caso la diferencia ya es notable. Igualmente véndese muy bien preparado, tablas, cartones, papel etc. ( O'Neille,1862: 26-27)

Algarra (1875) afronta el tema desde un punto de vista ligera pero substancialmente diferente. Este artista es el único que omite por completo cualquier indicación o explicación sobre la elaboración de la preparación de los soportes. Algarra resulta claro y conciso:

[Los lienzos...] La preparacion que sufren antes de emplearse se hace por los expendedores de objetos de pintura, y seria una cosa enojosa hacer aquí una detallada descripcion de dicha preparacion y su mecanismo; descripcion que sobre ser inútil á todas luces, solo serviria para poner de manifiesto la reconocida economía que resulta comprándolos ya preparados.

Por otra parte, la misma práctica que en ello tienen los que se dedican á esta industria, hace, como es lógico, que resulten los lienzos preparados con mas igualdad. (Algarra, 1875: 157-158)

A finales de siglo, Bellanger (1899) explica cómo preparar lienzos y tablas; de hecho sugiere que los pintores se preparen sus propias tablas. A pesar de aportar estas aclaraciones, el pintor francés aconseja los lienzos “...imputrescibles, de José Frappa,..." que fabricaba Lefranc (Bellanger, 1899: 231). Vibert (1908) cuenta que en Francia adquirían los lienzos preparados de Holanda con la ventaja de obtenerlos más baratos y no llenar los almacenes. Los lienzos se 
enrollaban demasiado pronto y el aceite de las imprimaciones se enranciaba aunque la flexibilidad era una cualidad que se conservaba.

Dichas telas son por consiguiente perfectas para los comerciantes, pero son amarillas, apestan y dejarán á la posteridad cuadros negros y agrietados. Verdad es que los fabricantes no trabajan para la posteridad. (Vibert, 1908: 148)

Vibert (1908: 147) asegura que la invención del ferrocarril influenció de manera decisiva en las preparaciones de los lienzos porque de esta manera los cuadros y las telas viajan constantemente y se enrollan y desenrollan a menudo. Por este motivo necesitan dotarse de mayor flexibilidad. Este autor, para conferir flexibilidad a las imprimaciones, sugiere caucho 5 disuelto en petróleo, cera, resina y goma laca (Vibert (1908: 157-158).

El catálogo de L. Péant é Hijos (1895: I, 15) muestra una gran variedad de lienzos, tablas, cartones y papeles preparados pero no aporta ninguna información sobre la composición de las preparaciones. Los datos más relevantes indican que las telas para apuntes llevaban solo una mano de preparación o que se suministraban lienzos de algodón preparados. El resto de datos indica aspectos relativos a la trama, el grano o la cualidad lisa de la superficie (Ver 6.1). No obstante, es de suponer que si los fabricantes suministraban las telas preparadas en rollos de 10 metros, los aparejos debían estar dotados de flexibilidad. El catálogo de L. Péant é Hijos tampoco aporta información concerniente a la preparación de tablas, cartones o papeles (Ver 6.2. y 6.3.).

\footnotetext{
5 Según Carlyle (2002: 170-171), George Field en su Chromatography (1835) ya se cuestiona la utilidad del caucho en las imprimaciones de los soportes. Fielding en 1839 también menciona esta sustancia y las nuevas preparaciones con caucho. También en la década de 1840, Winsor \& Newton ofrecía en sus catálogos "India Rubber Canvass" pero en el catálogo de 1849 estas preparaciones dejaron de ofrecerse.
} 
Una noticia muy interesante sobre la procedencia de los lienzos preparados que se utilizaban en España la aporta una patente de invención de 1895: "Un procedimiento para la preparación a mano de telas destinadas al arte de pintar al óleo" registrada por Eugenio Lloret ${ }^{6}$.

Hasta hoy ha sido preciso importar del extrangero las telas para tal objeto preparadas, sin que por los medios empleados para ello, hayan llegado al perfeccionamiento, pues ocurre con demasiada frecuencia, que el artista al aplicar el pincel á la tela, esta absorve el color debilitandolo; observandose así mísmo, y esto acontece en todos los casos, que las telas extrangeras en que se pintan cuadros, pasado algun tiempo, se rechupan, alterando los tonos de los colores empleados por el artista. (Archivo Histórico de la OEPM. No de patente 18360)

Resulta curioso este dato de que en España no se preparaban los lienzos para pintar sino que venían del extranjero. En cualquier caso, la patente referida propone preparar a mano los lienzos - “...prescindiendo de toda clase de artefactos...” -, es decir, sin imprimaderas ni espátulas que ayuden a extender la preparación. El autor considera esta forma de proceder como algo desconocido y novedoso en España y el extranjero. El documento no incorpora los ingredientes ni el procedimiento de imprimación, simplemente dice que la superficie del lienzo queda lisa y con los poros tapados. El inventor de esta patente indica que los lienzos preparados así mantienen los colores frescos y sin rechupados aún después de mucho tiempo. Lloret insiste en que si las pinturas realizadas sobre sus preparaciones sufren alguna alteración es debido a la mala calidad de los colores.

${ }^{6}$ Archivo Histórico de la OEPM. Patente No 18360. 


\subsection{Preparaciones Tradicionales}

Las fuentes españolas decimonónicas se refieren especialmente a la preparación de lienzos y tablas. Existen algunas coincidencias entre las fórmulas que explican los tratadistas de esta investigación aunque cada autor demuestra sus preferencias. Las preparaciones que exponen la fuentes que estudiamos son fundamentalmente de carácter tradicional y podemos encontrarlas referenciadas en textos de épocas anteriores.

Por lo general, los autores proponen preparar los lienzos con estratos magros a los que se superponen uno o varios estratos grasos. Aunque podemos encontrar indicaciones para elaborar preparaciones únicamente con estratos magros. La excepción la presentan Soler y Ferrer (1837) que aconsejan adecuar los lienzos para la pintura al óleo con estratos de imprimación oleosa sin encolado o aparejo previo.

Aunque algunos dan al lienzo una mano de cola de retazo, antes de la primera mano de imprimación al ólio, con lo que dicen se une el hilo del lienzo, y se cierran sus poros; es también cierto que impide esto el que penetre el aceite en el hilo y sus intersticios, quedando de este modo pegado únicamente á la cola; y como esta por otra parte se restriñe con la sequedad abriéndose en grietas, cae del cuadro; de esto indudablemente procede el quebrajarse á muy pocos años, y destruirse finalmente los lienzos asi preparados... (Soler y Ferrer, 1837: II, 46)

Pero aunque esta preparación pueda parecer poco adecuada, podemos encontrarla en un texto tan relevante como el de Mérimée: De la Peinture a l'Huile (1830: 243). Este autor francés matiza que estas imprimaciones son buenas siempre que el lienzo sea de trama apretada y unida. Ésta imprimación también fue propuesta en épocas anteriores. Un claro ejemplo lo hallamos en Pacheco [1649] (2001: 481): "También digo que sin cola se puede muy bien aparejar un lienzo con las tres manos de imprimadura, que habemos dicho, aunque la cola flaca lo hace más suave.” Marconi (1993: 30) indica 
una preparación de lienzos explicada por De Mayerne en que tampoco era necesario el encolado previo. La curiosa receta de este médico incluía aceite de nueces cocido con litargirio; la mezcla se espesaba con agua caliente y se aplicaba directamente sobre el tejido.

Resulta curioso que Soler y Ferrer - e incluso Mérimée propongan esta preparación pues ya en el siglo XVII comenzaron a expresarse sus inconvenientes. Por ejemplo, Volpato [ca. 1680] (Merrifield, 1849: II, 728 - 729) explicaba que el aceite de las imprimaciones que carecían de estrato de cola previo se secaba y caía como la corteza de un árbol. Según Vibert (1908: 145), los pintores se dieron cuenta que los aparejos oleosos aplicados directamente sobre la tela causaba problemas y volvieron a aplicar el primer estrato de cola.

...el lienzo, en contacto directo con el aceite, se quemaba y no tenía más consistencia que la yesca. Una vez observado aquel triste resultado, se volvió á dar á los lienzos una capa de cola, para aislar la tela del aparejo del aceite.... (Vibert, 1908: 145)

Realmente, las preparaciones sobre lienzo que únicamente contemplan estratos magros también resultan excepcionales en nuestra tratadística decimonónica. El primero de los casos lo encontramos en De la Roca y Delgado (1880). Este autor, que - recordemos una vez más - transcribe a Palomino, recomienda estas preparaciones en casos de prisa y alude a la menor calidad de las pinturas realizadas sobre ella.

Yo he visto, en casos de prisa, dar una mano de cola templada á un lienzo y pintarle al óleo, sin más preparacion. Lo mismo se puede hacer en una tabla, y en una lámina, ó un vidrio, estregándole primero un ajo mondado; pero esto es bueno para casos de prisa y de necesidad, que verdaderamente no se puede hacer tan bien ni tan definido y grato á la vista, como con las debidas preparaciones. (De la Roca y Delgado, 1880: 259) 
Poleró (1886) ofrece ciertas dudas en lo referente a las preparaciones de los lienzos. El autor comenta que hay dos modos de preparar las telas para pintar: bien con gacha o bien con cola7. Poleró indica que sobre el estrato de cola se pueden extender una o dos manos de color pero no indica la composición de estas capas coloreadas; no obstante nos inclinamos a pensar que era un estrato oleoso coloreado. En cuanto a la preparación de gacha explica Poleró (1886: 85) que “...se extenderá el engrudo mezclado con greda diluída en agua, por medio de una brocha, y después de seca se apomazará, dejando la superficie más ó menos lisa, según se quiera." Como veremos más adelante (Ver 7.3.), tanto Pacheco como Palomino recomendaban el empleo de la greda o barro de Sevilla para conferir color a las preparaciones. No obstante, los tratadistas barrocos sugerían mezclar la greda con óleo y superponerla a los estratos magros de la preparación. Es probable que las preparaciones de gacha y greda que comenta Poleró fueran excesivamente susceptibles de ser atacadas por la humedad.

Finalmente, entre las preparaciones magras sobre lienzo contamos con una interesante propuesta de Vibert (1908) quien trata de conciliar procedimientos ancestrales de la pintura con los materiales modernos propios de su tiempo. Para este autor, los aparejos de aceite tienen el problema de oxidar y amarillear; pueden provocar reacciones químicas con algunos pigmentos y se quiebran con el tiempo. Y dado que, según su experiencia, los cuadros mejor conservados están pintados sobre preparaciones de cola, concluye que se deben rechazar los aparejos de aceite y emplear las preparaciones elaboradas con cola (Vibert, 1908: 149). Este artista francés asegura que la cola de caseína es la sustancia más adecuada para la preparación de lienzos, tablas y cartones siempre que se prepare de manera correcta. Vibert (1908: 143) alude al empleo de la caseína que Teófilo [s. XI - XII] describe en su tratado. El monje medieval utilizaba la cola de caseína (cheese glue) para unir las tablas destinadas a la pintura y para adherir sobre ella trozos de

\footnotetext{
7 Palomino [1715-1724] se expresa de igual manera. Pero el pintor tardo barroco es claro en sus explicaciones e indica que el lienzo aparejado con cola o gacha se imprima con estratos de color al óleo.
} 
cuero. Teófilo [s. XI-XII] (1979: 26) explica la confección de la cola de caseína a partir de queso ${ }^{8}$, en cambio, Vibert (1908: 267) prefiere preparar la cola de caseína con métodos modernos.

Se toma caseína del comercio, 20 gramos, y se pone á remojar en 100 gramos de agua fría durante un cuarto de hora, agitando bien con una espátula, ó una cuchara de madera, no de metal.

Se agregan después 4 gramos de amoníaco, poco á poco, sin dejar de menear. La mezcla se espesa lentamente y queda hecha la cola cuando forma un jarabe espeso sin grumos. Se le añaden entonces 10 gramos de glicerina, que se mezcla bien con una cuchara, y se pasa por una muselina ó un tamiz fino. En este estado puede emplearse la cola en seguida. Al cabo de un día puede aún servir, pero pierde después todo su valor y se descompone.

Si no se tiene caseína, y se quiere emplear el queso, se tomarán 100 gramos de requesón á los que se añaden 4 gramos de amoníaco ${ }^{9}$, continuando como en la operación anterior. Es sin embargo preferible emplear caseína, porque el queso la contiene en cantidad variable. (Vibert, 1908: 267-268)

La preparación que propone Vibert está compuesta por cola de caseína y blanco de zinc y es apropiada para lienzos, tablas y cartones. El autor sugiere aplicar varias capas - cuatro en total - de la mezcla mencionada. En cada capa la proporción de los ingredientes varía; se va reduciendo la cantidad de cola de caseína mientras que se aumenta la de blanco de zinc. Para esbozos rápidos al óleo en lienzo o tabla, el autor recomienda reducir la capacidad de absorción de este aparejo incorporando una capa de barniz para pintar “...pues de otro modo sería demasiado absorbente el aparejo. Si se quiere sin embargo utilizar esta cualidad, será preciso mezclar con los colores

\footnotetext{
${ }^{8}$ Mérimé (1830: 239-240) explica como extraer la caseína del queso y elaborar la cola. Este artista reconoce también que ha extraído el procedimiento de Teófilo. 9 Teófilo utiliza cal e lugar de amoníaco para producir la cola (Teófilo [s. XI-XII] 1979: 26).
} 
una cantidad bastante grande de barniz de pintar, para hacer más fácil el trabajo." (Vibert, 1908: 164). Lefranc (1892) también explica la manera de proceder con esta preparación de caseína:

Préparer la colle de caséïne comme il est dit dans " $L a$ Science de la Peinture" et la mélanger par parties égales en poids avec du Blanc de zinc opaque donner légèrement au papier de verre fin, donner un frottis très léger de Vernis à tableaux Vibert, attendre son parfait séchage et donner ensuit une seconde couche de blanc préparé et au besoin une troisième si on désire une toile très couverte.

Pour les panneaux en pas donner de couche de vernis. (Lefranc, 1892: 45)

Las preparaciones sobre lienzo que parecen haber tenido más aceptación entre nuestros pintores decimonónicos estaban formadas por estratos de cola, gacha o cola y carga cálcica sobre los que se aplicaban capas de aceite y pigmento. Esta suerte de preparaciones son tradicionales en la pintura y aparecen también mencionadas en tratados de épocas anteriores. Como ya hemos señalado previamente, uno de los aspectos más importantes de las preparaciones sobre lienzo es la flexibilidad para que las telas puedan enrollarse sin sufrir daños. Esta ha sido una preocupación desde que los lienzos comenzaron a sustituir a las tablas como soporte pictórico. Por este motivo, De la Roca y Delgado (1880: 270) aporta una "regla infalible" que se debe considerar sobre las preparaciones.

...que cuanto más delgada estuviere la imprimacion, y que se vea la superficie del lienzo y este se halle más penetrado y abrazado de la imprimacion del óleo, tanto más segura, firme y durable será la pintura. (De la Roca y Delgado, 1880: 270)

O'Neille (1862) y De la Roca y Delgado (1880) recomiendan preparaciones de harina con estratos de óleo coloreado superpuesto. También De la Roca y Delgado (1880) y López Tomás (1898) sugieren preparaciones compuestas por estratos iniciales de cola y 
capas de acabado oleosas. Mientras que Bellanger (1899) propone otro tipo de preparaciones formadas por unas primeras capas de cola y carga cálcica seguidas por manos de aceite y pigmento.

Las preparaciones de harina podemos encontrarlas recomendadas por Le Brun [1635] (Merrifield, 1849: II, 772-773) o Palomino [1715-1724] (1988: II, 127-128). La primordial función de la gacha consistía en cubrir los intersticios de la tela antes de aplicar los estratos oleosos ${ }^{10}$. Sin embargo, estas preparaciones tuvieron grandes detractores como Pacheco [1649] y Volpato [ca.1680]. Este pintor barroco italiano comenta de las preparaciones a la gacha:

S. Ho veduto in certe botteghe ove si imprimisce tele usar colla di farina, che forse non è buona?

F. La cola di farina è pessima, perchè come è un poco gagliarda crepa il colore e si scorza, e se pur è poca, al umido marcisce le tele, e li topi le mangiano, e queli l'adoperano perchè imprimono tele tristissime, che in otto o dieci anni restano consumate, e perchè la cola di farina ottura li buchi della tela, si servono di questa.

(Merrifield, 1849: II, 729-731)

De la misma opinión es Pacheco [1649] (2001: 481) quien además descarta las preparaciones de cola y carga cálcica y de cernada bajo la imprimación oleosa coloreada. López Tomás (1898: 47) transcribe las preparaciones de este autor barroco, por consiguiente demuestra igualmente la aversión a estas preparaciones magras.

Entre los tratados españoles del siglo XIX, hacen referencia a las preparaciones de harina O'Neille ${ }^{11}$ (1862: 26) y De la Roca y Delgado (1880: 261-262). El primer tratadista citado es muy parco

\footnotetext{
10 La harina, por lo general, se mezclaba con agua y otras sustancias para la elaboración de las preparaciones de gacha. Sin embargo, Vasari [1550] (1997: 83) y Armenini [1587] (1999: 172) proponen mezclar la harina con aceite para los estratos preparatorios previos a la imprimación coloreada. Armenini aconseja las preparaciones de harina y cola para las pinturas al temple sobre lienzo. ${ }_{11}$ O'Neille indica que puede emplearse tanto la harina como el almidón para elaborar estas preparaciones.
} 
en indicaciones puesto que, como hemos visto, recomienda las preparaciones comerciales. En cambio, De la Roca y Delgado - en su transcripción de Palomino - describe de manera detallada la elaboración de la gacha y su aplicación sobre el lienzo.

...de gacha; esta se hace cociendo el agua á proporcion de lo que es menester, y echándole despues su harina de trigo [...] y algunos le echan despues un poco de miel y un poco de aceite de linaza, á discrecion, (pero no aceite de comer ${ }^{12}$, porque es muy perjudicial á la pintura, y la hace tomarse,)... (De la Roca y Delgado, 1880: 261)

De la Roca y Delgado (1880: 263) advierte que si la gacha no lleva miel y aceite el aparejo no es bueno. Estos ingredientes eran necesarios para conferir elasticidad a la masa y esta cualidad era deseable especialmente si el lienzo iba a ser enrollado para trasladarlo. O'Neille y De la Roca y Delgado coinciden en que el estrato de gacha debe ser muy delgado.

Las preparaciones de yeso y cola - explica Marconi (1993: 28) - no soportan bien el enrollado de los lienzos y, además, son vulnerables a la acción de la humedad por eso se impuso gradualmente la preparación de los lienzos con pigmento y aceite. A pesar de esta contrariedad evidenciada por Marconi, Bellanger (1899) aconseja preparar los lienzos con estratos - presumiblemente delgados - de cola y yeso bajo la preparación oleosa.

La tela se prepara con una mezcla caliente de cola de pescado, yeso pulverizado y blanco de creta, todo ello bien molido y desmenuzado. Cuando esta preparación está bien seca, se la cubre, mediante el cuchillo de paleta, con una capa de blanco de plomo disuelto en aceite. (Bellanger, 1899: 231)

\footnotetext{
12 Pacheco [1649] (1990: 481) desvela que este condimento era habitual en las mencionadas preparaciones: "Unos aparejan con gacha de harina, o de harijas, aceite de comer y una poca de miel (que casi se puede comer sin apetito); desto dan una mano al lienzo bien estirado, con que quedan tapados los poros..."
} 
El artista francés recomienda dos estratos de imprimación blanca aunque indica que puede darse una tercera capa de imprimación gris.

Las preparaciones del lienzo con cola y una posterior imprimación oleosa aparecen también reflejadas entre nuestros tratadistas decimonónicos. Esta clase de acondicionamiento de los lienzos fue expuesto por De la Roca y Delgado (1880) y López Tomás (1898). Pero también la podemos encontrar en tratados anteriores como en el MS. de Bruselas de Le Brun [1635] (Merrifield, 1849: II, 772-773), en El Arte de la Pintura de Francisco Pacheco [1649] (2001: 481), en Modo da Tener nel Dipingere de Volpato [ca. 1680] (Merrifield, 1849: II, 730-731), en Museo Pictórico y Escala Óptica de Palomino (1715-1724) (1988: 129-130) o en Élémens de Peinture Pratique de Roger de Piles [1684] (1766: 126-128).

Los tratadistas españoles decimonónicos que proponen esta clase de preparación recogen una práctica interesante. Una vez más recordamos que De la Roca y Delgado transcribe a Palomino y López Tomás - en materia de preparaciones y otros asuntos técnicos - a Pacheco. De modo que las características que exponen ambos tratadistas decimonónicos provienen de prácticas barrocas. Según De la Roca y Delgado (1880: 264), el aparejo de cola de retazo “...no se puede dar caliente, y así se ha de aguardar á que se hiele, y en estando helada la cola, se irá dando al lienzo...”. El término helada no debe interpretarse literalmente sino que se refiere a la cola fría y coagulada como un gel. En este estado, la cola se acomodaba a espátula y no a pincel. Sobre este aparejo, explica el autor, se aplica la imprimación oleosa rojiza. López Tomás (1898) - que recoge una parte del texto de Pacheco - describe igualmente el uso de la cola helada ${ }^{13}$.

${ }_{13}$ Soler y Ferrer (1837: II, 108) aluden a la cola helada de las preparaciones de los lienzos para pintar al temple siempre que estos no se tengan que enrollar. Igualmente, podemos encontrar referencias el empleo de la cola helada en De Piles [1684] (1766: 126-127) “...on l'encolle d'abord avec de la colle faire de rognure de gants ou de cuir, qui doit être figée \& refroidie. Cette colle se couche avec le tranchant d'un grand couteau qui est assez mince,...” 
...tengo por más seguro la cola de guantes flaca, dando un par de manos con ella al lienzo estando helada y con un cuchillo, que sirva para tapar los poros ó lo ralo de la tela, dejarlo bien descargado y dándole de piedra pomez, después de seco, empremiar [sic] encima. (López Tomás, 1898: 47)

La imprimación que describe López Tomás está formada por aceite y barro de Sevilla, este último ingrediente le confería el color rojo tan característico de las preparaciones barrocas (Ver 7.3.)

De la Roca y Delgado (1880) y López Tomás (1898) también mencionan el aparejo de cernada como estrato magro sobre el que se aplica la imprimación oleosa; pero ambos autores desaconsejan este tipo de preparaciones. Una clara explicación de los aparejos de cernada $^{14}$ la brinda De la Roca y Delgado:

...el de cernada, que es sobre la primera mano de cola, darle al lienzo otra de una cernada, á manera de gacha de ceniza cernida y cola de retazo, con lo cual queda el lienzo bastantemente cubierto, y con solo un enjuague de imprimacion muy rala al óleo, se le hallan

14 Giovanni Alcherio [1398-1411] sugiere un aparejo que se elabora con ceniza de huesos de animales y cola. Este aparejo está destinado al dibujo y no porta encima imprimación oleosa.

To prepare parchment, or paper, primed panels, and linen, so that you may be able to draw upon them...Take bones of any animal or bird, or stag'shorn, which is better, and burnt it, and make it white and friable and soft by long and violent boiling, and afterwards grind it upon a hard stone with pure water. Then put it on a brick of backed clay or of white chalk, that the moisture may enter into it, and that the bone may remain thickened and almost dry. Remove it from the stone, and burn it a second time in a crucible in which silver or gold is usually melted, and afterwards, that it may be made still more fine and white, grind it a second time upon a stone with water, en the same way as you did before; and if you wish to use it immediately, wet up as much of it as you require in a shell or a glazed earthen jar, with size made from glue or from clippings of white leather or parchment, and which must be of a moderate consistence and warmth. Having done this as directed, paint or draw with it, with a broad paint-brush, upon paper which has been polished with a boar's tooth. Also lay it over parchment, cloth, sindone, and wooden panels.... (Merrifield, 1849: I, 274-279) 
imprimado; y áunn sobre la mano de cernada, apomazándola le dan otra de cola, que todos son medios para facilitar que á poco tiempo salte la pintura. (De la Roca y Delgado, 1880: 270)

Las explicaciones de los tratadistas españoles del siglo XIX evidencian diferentes preferencias en las preparaciones para pintura al óleo sobre tabla. Vibert (1908) sugiere los mismos aparejos de cola de caseína y blanco de zinc que propone para los lienzos. Por su parte, De la Roca y Delgado (1880: 266) rechaza rotundamente aparejar las tablas con cola antes de extender la imprimación oleosa. Según este autor, la cola hincha la madera y además tapa los poros impidiendo que el aceite penetre en la madera.

El modo de aparejar las tablas para pintar en ellas al óleo es más fácil, pues estando bien raspadas y lijadas, se le puede dar desde luego con brocha, su mano de imprimacion al óleo, sin más preparacion; pero de suerte que esté suelta y bien tirada igualmente, sia que quede cargada en una parte más que en otra y unida con brocha suave; y en estando esta bien seca, rasparla suavemente con un cuchillo y darle otra en la misma conformidad; y en casos de prisa puede bastar la primera mano. (De la Roca y Delgado, 1880: 266)

Según De la Roca y Delgado, esta clase de preparación da también buenos resultados en papeles y cartones ${ }^{15}$.

Las preparaciones tradicionales sobre tabla consistían en una gran cantidad de estratos de cola y carga cálcica y aunque varias de las fuentes lo recuerdan este procedimiento estaba ya obsoleto. De la Roca y Delgado (1880: 267) señala sobre las costosas y elaboradas preparaciones de las tablas de los antiguos: “...quien lo quisiere hacer

15 Poleró y Vibert también indican como preparar papeles y cartones. Poleró (1886: 86) propone preparar los papeles con aceite de linaza y los cartones con un estrato de cola y otro de aceite y pigmento. En cambio, Vibert (1908: 164, 157) prefiere preparar los papeles con fijativo de acuarela y los cartones con la cola de caseína como los lienzos y las tablas. 
así podrá, pero ya esto se ha dejado, por haberse visto los inconvenientes de saltar los aparejos y de torcerse y abrirse las tablas;...” No obstante, algunas fuentes españolas decimonónicas comentan preparaciones en las que se incluyen estratos - eso si, finos - de cola y carga cálcica. Poleró (1886) explica estas preparaciones:

Elegido el tablero más ó menos grueso entre las maderas de roble, haya, nogal, cedro ó castaño, y nivelada la superficie cual corresponde, se le dará una mano de agua cola, á la que se aumentarán otras dos de yeso mate, batido con la templa. Después de seco y apomazado, se repetirá otra mano ligera de color al óleo, ó bien sencillamente aceite de linaza clarificado. (Poleró: 1886: 85)

Aunque para prevenir posibles alabeos de las tablas, Poleró (1886: 86) sugiere adherir sobre la superficie un lienzo fino antes de aplicar la preparación. Bellanger (1899: 230) enfatiza que debe ser el propio pintor quien prepare sus tablas. La propuesta de este artista contempla aplicar al soporte lígneo una masa compuesta por cola de pescado y blanco de España sobre la que se extienden dos capas de aceite y pigmento. Por razones de conservación, el artista francés recomienda impregnar de aceite todas aquellas partes de la madera que no estén cubiertas por la preparación, es decir, los cantos y el reverso. Para preservar el soporte de madera de la humedad, Vibert (1908) propone actuaciones similares (Ver 6.2.).

O'Neille (1862: 159) aporta un dato interesante que no aparece en el resto de fuentes españolas decimonónicas. Nos referimos al empleo de "polvos finos de piedra pomez" mezclados con el color de la imprimación para conferir una cualidad arenosa a la superficie de la tabla. Estos polvos reducen el exceso de tersura de las tablas y facilitan el agarre del color.

También encontramos formas innovadoras de emplear las tablas. Para la elaboración de esbozos al óleo, Vibert (1908: 164) indica que pueden emplearse las tablas en bruto. Aunque, para regular la absorbencia de la madera, comenta este artista, puede aplicarse una mano de fijativo de acuarela o de barniz de retocar. 
También Bellanger (1899: 230) señala que algunos pintores han pintado - por capricho - directamente sobre la madera; en este caso, la tabla debe impregnarse previamente de aceite de lino.

Vibert (1908) aporta una imprimaci6n diferente a todo lo que hemos visto hasta ahora que, asegura, "...se debe a un viejo practicón que ha dedicado su vida al estudio de la pintura...”.

Se muele blanco de cinc con esencia de petróleo, se agregan barniz de retocar y fijativo de acuarela en partes iguales, se pasa una sola mano y, cuando está bien seca, al cabo de algunos minutos, se pasa el papel de vidrio. (Vibert, 1908: 159)

Estamos ante un aparejo instantáneo, se aplica a cuchillo y seca en muy poco tiempo. Llama la atención que, un artista tan preocupado por los materiales y que quiere que los comerciantes de colores etiqueten los colores con la composición de los pigmentos, no esclarezca que sustancias componen el barniz de retocar o el fijativo de acuarela. Aunque todo apunta a que esta substancia contenía alguna resina natural. Vibert (1908: 159, 276) asegura que sobre esta imprimación se puede pintar al óleo y a la acuarela.

\subsection{El color de las imprimaciones}

Una de las funciones de la imprimación es dotar a la preparación de una base tonal. Según Marconi (1993: 34), durante el Neoclasicismo las preparaciones oscuras fueron sustituidas por las blancas de albayalde y aceite que se convirtieron en los sustratos más empleados por los pintores. Marconi asegura que durante los primeros decenios del siglo XIX estas imprimaciones eran más gruesas pero después comenzaron a emplearse preparaciones más sutiles que evidenciaban la trama de los lienzos como las que preferían los pintores de la Escuela de Barbizon y los impresionistas. 
Subraya Marconi que el blanco de plomo, a veces, se mezclaba con los nuevos blancos que aparecieron en el mercado durante el siglo XIX: el blanco fijo (sulfato de bario) y el blanco de zinc (óxido de zinc). Bomford et al. (1990: 48) confirman que en las preparaciones de las pinturas impresionistas se ha detectado blanco de plomo mezclado con otros ingredientes como sulfato de bario o creta. Es probable que estas mezclas de blancos fueran baratas y por eso se emplearan en las preparaciones. Aunque entre algunas pinturas impresionistas se han detectado imprimaciones ligeramente coloreadas.

La investigación de Carlyle (2002: 177-178) demuestra que los tratados ingleses del siglo XIX preferían preparaciones coloreadas claras. Esto pone de manifiesto una clara diferencia con la mayoría de las fuentes españolas del mismo periodo que preferían las preparaciones rojas. Aunque algunas de nuestras fuentes del Diecinueve también sugieren los fondos grisáceos y, como veremos, de forma excepcional las imprimaciones blancas.

Soler y Ferrer (1837), De la Roca (1880), Poleró (1886) y López Tomás (1898) recomiendan las imprimaciones rojas con barro o tierras rojas que - recordemos - fueron muy estimadas durante el periodo Barroco. Soler y Ferrer sugerían a los pintores:

...el légamo ó barro fino que deja el rio en sus crecientes, y el que se encontrará cuando seco en unas como tejuelas en sus orillas, y escójase de cada una la parte ó capa superior y mas fina; ó también á falta de esto greda fina, ó barro de alfareros; de cualquiera de estos tómese digo dos partes con una de albayalde fino,... (Soler y Ferrer, 1837: II, 46-47)

La vinculación de este texto con los tratados barrocos queda demostrada si comparamos la imprimación de Soler y Ferrer con la de Pacheco [1649] o Palomino [1715-1724]. Pacheco dice en El Arte de la Pintura: 
La mejor emprimación y más suave es este barro que se usa en Sevilla, molido en polvo y templado en la losa con aceite de linaza,...para recibir la tercera; a la cual, si quieren, pueden añadir al barro un poco de albayalde para darle más cuerpo, o usar sólo el barro;... (Pacheco, [1649] 2001: 481)

Este párrafo fue recogido por López Tomás en su Educación Artística (1898: 47-48) lo que demuestra, una vez más, el interés de este tratadista por Pacheco. También se evidencian la similitud entre el texto de Soler y Ferrer y el de Palomino.

...la imprimaci6n a el óleo, la cual en Andalucía, y otras partes, se hace con el légamo, que deja el río en las crecientes, que después de seco, en los hondos se levanta como tejuelas, y con aquello, y la falta de esto con greda (que en Madrid llaman tierra de Esquivias, y es la que gastan los boteros)... (Palomino, [1715-1724] 1988: II, 130)

Las imprimaciones rojizas de greda o Tierra de Esquivias eran típicas de la escuela madrileña del siglo XVII ${ }^{16}$, explica Carmen Garrido (1992: 15). Según esta notable investigadora, el barro que conforme a Pacheco se empleaba en Sevilla es el que Palomino refiere como légamo. Estas sustancias arcillosas que conferían una intensa coloración rojiza precisaban pigmentos secantes. Soler y Ferrer (1837: II, 47) sugieren el minio o el cardenillo en polvo, o bien, los colores viejos o rancios. Mientras que De la Roca y Delgado (1880: 265) - transcribiendo a Palomino - recomienda los colores

16 Otras escuelas y otros pintores barrocos mostraron predilección por las imprimaciones rojizas. Volpato, activo en Bassano durante el Diecisiete, indicaba en su manuscrito que todas las tierras son buenas para “...la primitura macinata ad olio di lino...”. Sin embargo, reconoce que el preparaba las imprimaciones para su maestro con ..."terra di bocali, terra rossa, et un poca di terra d'ombra..." (Merrifield, 1849: II, 731). Roger De Piles [1684] (1766: 127-128) señala que una imprimación adecuada puede componerse “...du brun rouge broyé à l'huile, médiocrement épais, dans lequel on met quelque sicatif qui est pour l'ordinaire un peu de mine rouge ou de blanc de plomb bien broyé, pour le faire plutôt sécher.” 
viejos o la sombra del viejo ${ }^{17}$. Debemos matizar que mientras todos los autores citados explican que estas imprimaciones rojizas se aglutinan con óleo, Vicente Poleró (1886: 85) expone en una de sus fórmulas que la greda puede añadirse directamente a la gacha (Ver 7.2.)

Las preparaciones rojas presentan inconvenientes relevantes porque con el tiempo se descompensa la relación cromática de la obra. La influencia del color rojo de la imprimación produce mayor profundidad en los matices oscuros de la pintura; también las medias tintas se ven alterados por el tono de base. Por este motivo, Soler y Ferrer (1837: II, 47) aconsejan que la preparación de los lienzos sea “...todo lo posible ligera de color, de modo que se entrevea la luz, ó quede transaprente, y de una tinta baja para que subiendo con los años de otra manera no obscurezca los colores que sobre él asientan." Borbón (1860) y Poleró (1886) aportan argumentos en contra de las preparaciones rojas. Borbón (1860: 5) asegura que las preparaciones o imprimaciones de las telas pueden constituir una causa importante de alteración de las pinturas. Según este autor, “...el almazarrón ${ }^{18}$ compuesto, como todos saben, de óxido de hierro y de alúmina.” es el gran culpable de las alteraciones que sufren las preparaciones rojas propias del siglo XVII. Para Borbón, los pintores hacían uso de esta imprimación porque obtenían resultados pictóricos con facilidad y rapidez. Este autor tenía clara las repercusiones que las imprimaciones rojas tenían sobre los matices oscuros y medias tintas de una pintura y añade que “...han sido devorados finalmente, por la acción del óxido ferruginoso, los mas delicados matices, destruyendo á la vez el modelado, la armonía y el efecto.” Poleró (1886: 85) también esgrime los inconvenientes de las preparaciones rojas ${ }^{19}$; sin

\footnotetext{
17 Antonio Palomino [1715-1724] (1988: II, 580) define las sombra del viejo como "Tierra parda, obscura, tosca: llamada así, por haberla descubierto en estas provincias un viejo, o anciano. Es muy apta para las sombras en temple, y fresco..." 18 Almagra.

19 Vicente Poleró (1886: 85) explica que las preparaciones negras sufren tantas alteraciones como las rojas. Según este artista, las primeras fueron empleadas por Ribera, Murillo, Ribalta y por otros pintores de las escuelas sevillana y valenciana; y las segundas por los artistas italianos y franceses de los siglos XVI y XVII.
} 
embargo, este tratadista menciona que estos aparejos tienen la ventaja de absorber el aceite de la pintura y de esta forma, la pinturas quedan libres de sufrir el amarilleamiento de los aceites.

Las imprimaciones rojas parecen ser las apreciadas por los tratadistas que demuestran mayor vínculo con los presupuestos pictóricos barrocos; sin embargo, algunas fuentes aconsejan preparaciones blancas o medias tintas grises. O'Neille (1862) sugiere tanto las preparaciones rojas como las grises; éstas últimas también están recomendadas por Borbón (1860), Poleró (1886), López Tomás (1898) y Bellanger (1899). O'Neille, Borbón y Poleró no aportan la forma de conseguir los tonos grises de sus preparaciones; en cambio, López Tomás (1898: 48) explica que para conseguir medias tintas en el último estrato de la imprimación, se puede añadir “...al barro un poco de albayalde (y ocre ó sombra ó negro, etc.,...)”. Bellanger (1899: 231) indica que en la última capa de preparación se puede añadir al blanco de plomo una pequeña cantidad de rojo de Puzol y de negro marfil resultando un tono gris muy adecuado como base.

Los únicos autores que mencionan las preparaciones blancas son Borbón (1860) y Vibert (1908). Para Borbón (1860, 6), el empleo de preparaciones blancas o grises es fundamental para la óptima conservación de las obras; en cambio, Vibert expone otros argumentos para explicar las ventajas de las imprimaciones blancas.

No vacilaremos en afirmar que debe ser blanco, y esto por varias razones. En primer lugar, para poder obtener efectos de transparencia sin verse obligados á pintar los blancos al óleo para glasearlos después, lo cual obliga á esperar bastante tiempo á que estén secas las capas inferiores y además nos hace caer en los inconvenientes de los aparejos al aceite. Por lo demás, el color acaba siempre por aparecer algo, y un cuadro, pintado sobre un aparejo de un tono determinado, acabará siempre por parecer del color de dicho aparejo, sobre todo en las partes poco cubiertas. (Vibert, 1908: 159-160)

Vibert (1908: 160) añade además que las imprimaciones blancas conducen al artista a desarrollar su pintura más luminosa y esto es 
deseable dado que las pinturas "ennegrecen" con demasiada rapidez. A pesar de que el blanco de zinc es un pigmento que estuvo disponible para pintura al óleo desde 1849, Vibert es el único autor que basa sus imprimaciones en el uso del éste blanco. 



\section{Conclusiones}

Dos grandes artistas delimitan el siglo XIX español: Goya, cuyo último tercio de vida transcurrió en el siglo XIX, y Picasso formado en esta centuria de la que datan sus primeras obras. Entre Goya y Picasso se sucedieron diferentes movimientos y tendencias pictóricas: Neoclasicismo, Romanticismo, Realismo, Impresionismo, etc. Pero los artistas decimonónicos españoles revisaron continuamente el legado del Siglo de Oro, especialmente de Velázquez. La fascinación de los artistas decimonónicos por el Siglo de Oro español se refleja en diversas fuentes de este periodo. Soler y Ferrer (1837), De la Roca y Delgado (1880), Poleró (1886) y López Tomás (1898) recogen prácticas y enseñanzas de Pacheco y Palomino demostrando así la atracción por la praxis pictórica del Barroco.

La recuperación de estas prácticas en los últimos veinte años del siglo XIX resulta algo confusa puesto que la industria de los materiales artísticos estaba en pleno desarrollo. Podemos establecer dos conclusiones con respecto a esta circunstancia: 1) los materiales comerciales presentaban deficiencias considerables que los pintores trataban de evitar elaborando sus materias y tomando como punto de partida las enseñanzas barrocas; y 2) los artistas decimonónicos se sentían tan atraídos por la pintura barroca que trataron de conseguir ingredientes similares a los de esta época para emular sus efectos pictóricos.

Sin embargo, algunos tratadistas como O'Neille, Algarra, Bellanger o Vibert plantean la ventaja que obtienen los pintores al dejar de prepararse sus materiales. Sin duda, esta liberación contribuyó a que los pintores pudieran dedicar más tiempo a la creación o al estudio. Los pintores ganaron libertad dejando la elaboración de sus materiales en manos de fabricantes y comerciantes especializados. Pero esta emancipación tuvo sus consecuencias. Los pintores tuvieron que enfrentarse a nuevos materiales o a ingredientes tradicionales elaborados con métodos novedosos por lo que adquirían propiedades ligeramente distintas. Sin olvidar que las adulteraciones causaron el desvelo de muchos artistas. 
Pigmentos azules, verdes, amarillos y anaranjados intensos y brillantes renovaron la paleta de los pintores durante las primeras décadas del siglo XIX. Entre 1840 y 1860 las innovaciones revolucionaron aún más el ámbito de los materiales pictóricos. Se inventan los tubos plegables, aparece una alternativa para el venenoso blanco de plomo, los secativos se popularizan y empiezan a elaborarse los primeros tintes sintéticos. De modo que, los pintores de finales del siglo XIX contaban con materiales muy diferentes a los que tenían los pintores de principios de la centuria. La actitud antiacadémica de los pintores fue decisiva para la elaboración de las nuevas y llamativas estéticas vanguardistas pero estas no hubieran sido posibles sin los nuevos materiales pictóricos. Aunque no sólo los nuevos colores fueron fundamentales, algunos instrumentos como los pinceles planos o las espátulas en forma de llana facilitaron novedosos recursos pictóricos. También los equipos de campo y los soportes pequeños y manejables fueron cruciales para pintar al aire libre y la práctica del paisajismo.

Las fuentes decimonónicas españolas demuestran de manera diferente los adelantos en materia de ingredientes e instrumentos pictóricos. Soler y Ferrer (1837) están muy anclados a las prácticas tardo barrocas. En cambio, O'Neille (1862) y Algarra (1875) demuestran mayor vinculación con la industria de materiales artísticos llegando incluso a despreciar algunas de las elaboraciones de sus ingrediente. Por eso resulta sorprendente que a finales de siglo algunos autores como De la Roca y Delgado, Poleró o López Tomás vuelvan a exponer prácticas pictóricas del Siglo de Oro. Especialmente, porque el catálogo de L. Péante é Hijos demuestra que a finales de siglo una gran variedad de materiales y utensilios pictóricos modernos estaban disponibles en España. Las traducciones de Bellanger y Vibert manifiestan los adelantos de la industria del color. Vibert es muy claro explicando los problemas derivados de los ingredientes industriales y de la falta de conocimientos técnicos de los pintores. El texto original de Vibert se publicó en 1891 y aporta mucha información sobre los ingredientes aparecidos en su época. Sin duda este texto constituye un contraste 
con los tratados españoles del mismo momento que transcriben recetas y descripciones de materiales propias del Siglo de Oro Español.

Uno de los datos más interesantes que hemos podido demostrar a lo largo de esta investigación promueve la idea de que los pintores adaptaban materiales 'locales'. Hemos visto que el aceite de piñones aparece por primera vez en Palomino y fue mencionado en el siglo XIX por Soler y Ferrer, Borbón, De la Roca y Delgado y Poleró. Estos autores explican los usos y características propias de este óleo. También, de manera excepcional, Algarra y Poleró sugieren el aceite de claveles; e incluso una patente registrada en La Habana proponía emplear el aceite de algodón. Creemos que estos datos ayudan a configurar una visión más amplia de los materiales pictóricos. La industrialización y el desarrollo de los modernos medios de transporte estandarizaron los materiales pictóricos; pero hasta mediados del siglo XIX no es difícil encontrar en las fuentes preferencias o adaptaciones de materiales según la zona geográfica. 



\section{BIBLIOGRAFÍA}

\section{Fuentes}

ALGARRA, 1875

Algarra, Agustín: Manual del Pintor Teórico-Práctico o sea Principios Fundamentales sobre la Pintura al óleo y a la Acuarela. París: Librería de Rosa y Bouret, 1864. París:

Librería de A. Bouret é Hijo, 1875.

ARMENINI, [1587] 1999

Armenini, Giovanni Battista: De los Verdaderos

Preceptos de la Pintura. Madrid: Visor Libros, 1999.

BELLANGER, 1899

Bellanger, Camille: El Pintor: Manual de Pintura

al Alcance de Todo el Mundo. París: 1899.

BORBÓN, 1860

Borbón, Sebastián María Gabriel de. Infante de España:

De los Aceites y Barnices de que se Hace Uso en la Pintura:

Memoria Dirigida á la Real Academia de S. Fernando en

Madrid. Madrid: [s.n.], 1860 (Por Aguado Impresores)

BOUANT, h. 1888

Bouant, Emilio: Nuevo Diccionario de Química Aplicada a las Ciencias, a las Artes, a la Agricultura, a la Industria y a la Farmacia. Barcelona: Espasa y Cia. [ca. 1888]. Vols. 2.

BOUCHARDAT, 1845

Bouchardat, Apollinaire: Elementos de Química, con sus Principales Aplicaciones a la Medicina, a las Artes y a la Industria. Traducidos de la $2^{\mathrm{a}}$ edición y adicionados por Gregorio Lezana y Juan Chavarri. Madrid: Librería de los Señores Viuda e Hijos de Antonio Calleja, 1845. 
BOUVIER, 1827

Bouvier, P. L.: Manuel des Jeunes Artistes

et Amateurs en Peinture. París, 1827.

CARDUCHO, [1633]

Carducho, Vicente: Dialogos de la Pintura, su Defensa, Origen, Esencia, Definicion, Modos y Diferencias. Madrid, 1633 .

CHAPTAL, 1816

Chaptal, M. J. A.: Química Aplicada á las Artes. Traducida del frances al castellano por el Doctor D. Francisco Carbonell y Bravo, Catedrático de Química. Barcelona, 1816. Vols. 4.

CHAPTAL, 1821

Chaptal, M. J. A.: Química Aplicada á las Artes. Traducida del frances al castellano por el Doctor D. Francisco Carbonell y Bravo, Catedrático de Química. Barcelona, 1821. Vol. no 4.

\section{CHURCH, 1915}

Church, Sir Arthur H.: The Chemistry of Paints and Painting. $4^{\text {a }}$ Edition. London, 1915.

\section{DA VINCI, [s. XVI] 1980}

Da Vinci, Leonardo: Tratado de Pintura.

Madrid, Editorial Nacional, 1980.

DE LA ROCA Y DELGADO, 1880

De la Roca y Delgado, Mariano: Compilación de Todas las Prácticas de la Pintura, desde los Antiguos hasta Nuestros Días. Madrid: León P. Villaverde. 1880.

\section{DE MASSOUL, 1797}

De Massoul, Constant: A Treatise on the Art of Painting, and the Composition of the Colours, Containing Instructions for All the Various Processes of Painting. Londres: 1797. 
DE PILES, [1684] 1766

De Piles, Roger: Élémens de Peinture Pratique.

Nouvelle Édition. Entierement refondue, \& augmentée considérablement par Charles-Antoine Jombert, 1766.

\section{DESMAREST, 1828}

Desmarest, Eugene. Química. Compendio de esta

Ciencia y de sus Aplicaciones a las Artes. Traducido del

francés al castellano por D. Jose Luis Casaseca. Madrid, 1828.

Vols. 2.

DIDEROT ET D' ALEMBERT [1751 - 1772], 1980

Diderot, Denis et D'Alembert, Jean Le Round: “Dessin et

Peinture." en L'Encyclopédie Diderot et Alembert:Recueil de

Planches, sur les Sciences, les Arts Libéraux, et les Arts

Méchaniques, Avec Leur Explication. Grimbergen:

Continental Printing, (s. a. 1980)

EASTLAKE, 1847

Eastlake, Sir Charles Lock: Materials for a History of Oil Painting. Londres: Longman, Brown, Green and Longmans, 1847. Methods and Materials of Painting of the Great Schools and Masters. New York: Dover, 2001. (Reprint)

GUEVARA, [h. 156o]

GUEVARA, DON FELIPE DE: Comentarios de la Pintura. h. 1560 .

L. PÉANT, 1895

L. Péant é Hijos: Catálogo General. Colores Extrafinos. Barnices, Aceites, Secantes. Material para la Pintura al Óleo, la Acuarela, la Gouache, el Pastel, el Dibujo, la Fotominiatura. Madrid, 1895. 
LEFRANC \& Cie, 1892

Les Couleurs et les Vernis de J.-G. Vibert. Notes et Reseignements sur les Produits Préparés pour la Peinture Artistique d'après les Procédés de J.-G. Vibert, ArtistePeintre. Paris: Lefranc \& $\mathrm{C}^{\mathrm{ie}}, 1892$.

\section{LÓPEZ TOMAS, 1898}

López Tomás, Jose: Educacion Artistica: Teoria y Practica del Dibujo, Pintura, Grabado y Escultura y Resumen Historico de Estas Artes en Europa. Alicante : V. Soler, 1898.

MÉRIMÉE, 1830

Mérimée, Jean-François-Léonor: De la Peinture à l'Huile ou des Procedes Matériels Employés dans ce Genre de Peinture, despuis Hurbert et Jean Van Eyck jusqu'à nos jours. [Paris: EREC, 1981] Reprod. Fac-simil de l'éd. de Paris: Mme. Huzard (née Vallat La Chapelle), 1830.

\section{MERRIFIELD, 1849}

Merrifield, Mary P.: Medieval and Renaissance Treatisses on the Arts of Painting. Londres, 1849. Nueva York: Dover, 1999 [Reprint]

O’NEILLE, 1862

O'Neille y Rosignol, Juan: Tratado de Paisaje.

Palma de Mallorca: Imprenta de Pedro José Gelabert, 1862.

\section{PACHECO, [1649]}

Pacheco, Francisco: Arte de la Pintura, su Antigüedad y Grandezas, Descrivense los Hombres Eminentes que ha Avido en ella, asi Antiguos como Modernos, del Dibujo y Coloridos...y Enseña el Modo de Pintar Todas las Pinturas Sagradas. Sevilla, 1649. 
PACHECO, [1649] 2001

Pacheco, Francisco: El Arte de la Pintura.

$2^{a}$ Edición. Madrid: Cátedra, 2001.

PAILLOT DE MONTABERT, 1829 - 1851

Paillot De Montabert, Jacques-Nicolas: Traité Complet de la Peinture. J. F. Delion: Paris (typ. Panckoucke), 1829-1851. Vols. 10.

PALOMINO, [1715-1724]

Palomino, Antonio: El Museo Pictorico y Escala Optica. Madrid, 1715-1724.

PALOMINO, [1715-1724] 1988

Palomino De Castro y Velasco: Museo Pictórico

y Escala Óptica. Madrid: Aguilar, 1988. 3 vols.

POLERÓ, 1886

Poleró, Vicente: Tratado de la Pintura en General.

Madrid: 1886.

RIFFAULT, 1850

Riffault-Deshêtres, Jean-Rene-Denis: Manual Teórico y

Práctico del Pintor, Dorador y Charolista. Tr. Por D. Lucio

Franco de la Selva. Última edición aumentada. Madrid:

Alejandro Gómez Fuentenebro, 1850.

SALA, 1896

Sala, Emilio: "La Desecación de la Pintura" en $L a$

Ilustración Española y Americana. Año XL. Num. 42 y 43.

Madrid, 1896.

SOLER y FERRER, 1837

Soler J., y Ferrer A.: Curso Completo Teórico y Práctico de Diseño y Pintura en sus Tres Principales Ramos de Olio, Temple y Fresco. Barcelona: Imp. De José Torner, 1837. 
TEÓFILO, [s. XI-XII) 1979

Theophilus: On Divers Arts. New York: Dover Publications, 1979.

TINGRY, 1804

Tingry, Pierre François: The Painter and Varnisher's

Guide: or, a Treatise, both in Theory and Practice, on the Art of Making and Applying Varnishes, on the Different Kinds of Painting and on the Method of Preparing Colours both Simple and Compound. London: Printed for G. Kearsley, Fleet - Street, 1804.

TINGRY, 1816

Tingry, Pierre François: The Painter and Varnisher's Guide: or, a Treatise, both in Theory and Practice, on the Art of Making and Applying Varnishes, on the Different Kinds of Painting and on the Method of Preparing Colours both Simple and Compound. $2^{\text {nd }}$, corr. and aug. London: Sherwood, Neely and Jones, 1816.

VASARI [1550] 1997

Vasari, Giorgio: Le Vite dei più Eccellenti Pittori, Scultori e Architetti. Terza Edizione. Roma: Grandi Tascabili Economici Newton. I Mammut, 1997.

VIBERT, 1908

Vibert, Jehan-Georges: La Ciencia de la Pintura.

Versión castellana por Miguel de Toro y Gómez, París; [Ligné:

Eugenio Aubin], 1908.

WATIN, [1782]

Watin, Jean Felix: L'Art de Faire et d'Employer le Vernis, ou l'Art du Vernisseur, Auquel on a Joint ceux du Peintre et du Doreur. París, 1782. 
WINSOR \& NEWTON, 1902

WINSOR \& NEWTON. Manufacturing Artists Colourmen; Trade Catalogue. London, 1902. (Casa Museo Sorolla. REG: 624)

\section{Bibliografía Específica}

ADMELLA et al., 2008

Admella, C., De Tapol, B. y Pedragosa, N.: "La Mesa de Trabajo de Mariano Fortuny" en Art Technology. Sources and Methods. Proceedings of the Second Symposium of the Art Technology Source Research Study Group. London: Archetype Publications, 2008.

AYRES, 1985

Ayres, James: The Artist's Craft. A History of Tools, Techniques and Materials. Oxford: Phaidon, 1985.

BALL, 2003

Ball, Philip: La Invención del Color. Madrid: Turner Publications, 2003.

BARÓN, 2007

Barón, Javier: "Pintura y Escultura Españolas del Siglo XIX en las Colecciones del Prado” en Díez, Jose Luis y Barón, Javier (a cargo de): El Siglo XIX en el Prado, cat. exp. Madrid: Museo Nacional del Prado, 2007.

BEER, 1958

Beer John, J.: "Coal Tar Dye. Manufacture and the Origins of the Modern Industrial Research Laboratory" en Isis, Vol. 49, No. 2 (Jun., 1958), pp. 123-131. 
BENSAUDE-VINCENT Y STENGERS, 1997

Bensaude-Vincent, Bernadette y Stengers, Isabelle:

Historia de la Química. Madrid: Addison - Wesley

Iberoamericana, S.A., 1997.

BERRIE, 2007

Berrie, Barbara H. (ed): Artists' Pigments. A Handbook of their History and Characteristics. Vol. 4. Washington: National Gallery of Art, 2007.

BOMFORD ET AL., 1990

Bomford, D., Kirby, J., Leighton, J., and Roy, A.: Art in the Making. Impressionism, cat. exp. Londres-New Haven, The National Gallery-Yale University Press, 1990.

BORDINI, 1995

Bordini, Silvia: Materia e Imagen. Fuentes sobre las Técnicas de la Pintura. Barcelona: Ediciones del Serbal, 1995.

BORDINI, 1999

Bordini, Silvia: "Colore e Tubetti” en Bordini, Silvia, (a cargo de): L'Occhio, la Mano e la Macchina. Pratiche Artistiche dell'Ottocento. Roma: Lithos Editrice, 1999. (p. 13-19)

CALLEN, 1983

Callen, Anthea: Técnica de los Impresionistas. Madrid:

Herman Blume Ediciones, 1983.

CALVO SERRALLER, 1991

Calvo Serraller, Francisco: La Teoría de la Pintura del Siglo de Oro. Madrid: Cátedra, 1991.

CARLYLE, 1993

Carlyle, Leslie: "Authenticity and Adulteration: What Materials Were 19Th Century Artist Really Using?” en The Conservator, 1993. No 17, p. 56-60. 
CARLYLE, 2002

Carlyle, Leslie: The Artist's Assitant: Oil Painting

Instruction Manuals and Handbooks in Britain 180o-19oo: with Reference to Selected Eighteen-Century Sources. London: Archetype, 2002.

CHANNING DOWNS, 1976

Channing Downs JR., Arthur: "Zinc for Paint and Architectural Use in the 19th Century" en Bulletin of the Association for Preservation Technology. Vol. 8, No. 4 (1976) p. 80-99.

DÍEZ, 1992

Díez, Jose Luís: "Evolución de la Pintura Española de Historia en el Siglo XIX" en AAVV: La Pintura de Historia del Siglo XIX en España, cat. exp. Madrid: Museo del Prado, 1992.

DÍEZ, 2007

Díez, Jose Luis y Barón, Javier (a cargo de): El Siglo XIX en el Prado, cat. exp. Madrid: Museo Nacional del Prado, 2007.

FELLER, 1986

Feller, Robert, L..: "Barium Sulfate - Natural and Synthetic" en Feller, Robert L. (ed): Artists' Pigments. A Handbook of their History and Characteristics. Vol. 1. Editado por Robert L. Feller. Washington: National Gallery of Art, 1986. (p. 4764).

FINALDI Y JOVER, 2006

Finaldi, Gabriele y Jover, Maite: "Cristo Mostrado al Pueblo (ca. 1500)" en Finaldi, Gabriele y Garrido, Carmen (a cargo de): El Trazo Oculto: Dibujos Subyacentes en Pinturas de los Siglos $X V$ y XVI, cat. exp. Madrid: Museo Nacional del Prado, 2006. (p. 224-229) 
FINLAY, 2004

Finlay, Victoria: Colores. Barcelona: Ocáno, 2004.

GARCÍA MELERO, 1978

García Melero, José Enrique: Bibliografía de la Pintura

Española. Madrid: Fundación Universitaria Española, 1978.

GARRIDO, 1992

Garrido, Carmen: Velázquez: Técnica y Evolución.

Madrid: Museo del Prado, 1992.

GARRIDO Y VAN SCHOUTE, 2000

Garrido, Carmen y Van Schoute, Roger: "El Estudio Técnico de El Jardín de Las Delicias" en AAVV: El Jardín de Las Delicias de El Bosco: Copias, Estudio Técnico y

Restauración. Madrid: Museo Nacional de El Prado, 2000. (p. 71-97).

\section{GARRIDO, 2006}

Garrido, Carmen: "El Trazo Oculto: Dibujos Subyacentes en las Tablas del Museo del Prado." en Finaldi, Gabriele y Garrido, Carmen (a cargo de): El Trazo Oculto: Dibujos Subyacentes en Pinturas de los Siglos XV y XVI, cat. exp. Madrid: Museo Nacional del Prado, 2006. (p. 16-53).

GETTENS Y STOUT, 1966

Gettens, Rutherford, y Stout, George L.: Painting Materials. A Short Encyclopedia. Nueva York, Dover Publications Inc., 1966.

HARLEY, 1971

Harley, Rosamund Drusilla: "Oil Containers: Development Work by Artists and Colourmen in the Nineteenth Century" en Annals of Science, Marzo de 1971. Vol. 27, $N^{0}$ 1. (p. 1-12). 
HARLEY, 1972

Harley, Rosamunda Drusilla: “Artists' Brushes-Historical Evidence from the Sixteenth to the Nineteenth Century" en Conservation of Paintings and the Graphic Arts. Preprints of Contributions to The Lisbon Congress. London The International Institute for Conservation of Historic and Artistic Works, 1972.

HARLEY, 1982

Harley, Rosamund Drusilla.: Artists' Pigments c. 16oo-1835. A Study in English Documentary Sources, $2^{\mathrm{a}}$ ed., Londres, Butterworths Scientific, 1982.

HELWIG, 2007

Helwig, Kate: "Iron Oxide Pigments: Natural and Synthetic" en Berrie, Barbara H. (ed): Artists' Pigments. A Handbook of their History and Characteristics. Vol. 4. Washington: National Gallery of Art, 2007. (p. 39-109).

KEUNE, 2005

Keune, Katrien: Binding Medium, Pigments and Metal Soaps Characterised and Localised in Paint Cross-Sections. [s. 1.]: [s. n.], MOLART Reports, 2005.

KÜHN, 1986

KÜHN, HERMANN: "Zinc White” en Feller, Robert L. (ed): Artists' Pigments. A Handbook of their History and Characteristics. Vol. I. Washington: National Gallery of Art, 1986. (p. 169-186).

KÜHN Y CURRAN, 1986

KÜHN, HERMANN and CURRAN, MERY: "Chrome Yellow and Other Chromate Pigments" en Feller, Robert L. (ed): Artists' Pigments. A Handbook of their History and Characteristics. Vol. I. Washington: National Gallery of Art, 1986. (p. 187-200). 
MACKIM-SMITH, 1988

Mackim - Smith, Gridley: Examining Velázquez. New

Haven \& London: Yale University, 1988.

MALTESE, 1993

Maltese, Corrado (a cargo de): Preparatorio e Finitura delle Opere Pittoriche. Milano: Mursia, 1993.

MARCONI, 1993

Marconi, Stefano: "Preparazioni e Imprimiture dei Dipinti su Tavola e Tela: Materiali, Metodi e Storia” en Maltese, Corrado (a cargo de): Preparazione e Finitura delle Opere Pittoriche. Milano: Mursia, 1993. (p. 9-38)

MAYER, 1993

Mayer, Ralph.: Materiales y Técnicas del Arte. Madrid:

Herman Blume, 1993.

\section{MILANESCHI, 1995}

Milaneschi, Annamaria: "Gialli” en Rinaldi, S., Quartullo, G., Milaneschi, A. et al: La Fabbrica dei Colori. Pigmenti e Coloranti nella Pittura e nella Tintoria. Roma: Il Bagatto, 1995. (p. 196-252)

PLESTER, 1993

Plesters, Joyce: "Ultramarine Blue, Natural and Artificial" en Roym, Ashok (ed): Artists' Pigments. A Handbook of Their History and Characteristics. Vol. 2. Washington: National Gallery of Art, 1993. (p. 37-65)

PORRETTA, 1999

Porretta, Sebastiano: "L'Occhio e l'Obiettivo. Chi Influenza Chi?” en Bordini, Silvia, (a cargo de): L'Occhio, la Mano e la Macchina. Pratiche Artistiche dell'Ottocento. Roma: Lithos Editrice, 1999. (p. 113-145) 
PORTELA, 1998

Portela, Eugenio: "La Química en el Siglo XIX" en Historia de la Ciencia y de la Técnica. No 39. Madrid: Akal, 1998.

PORTELA, 1999

Portela, Eugenio: "La Química Ilustrada" en Historia de

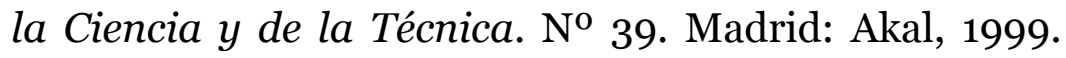

\section{QUARTULLO, 1995}

Quartullo, Giuliana: "Rossi” en Rinaldi, S., Quartullo, G., Milaneschi, A. et al: La Fabbrica de Colori. Pigmenti e Coloranti nella Pittura e nella Tintoria Roma: Il Bagatto, 1995. (p. 78-136)

REYERO, 2006

Reyero, Carlos et al.: De Goya a Gauguin. El Siglo XIX en la Colección del Museo de Bellas Artes de Bilbao, cat. exp. Valencia: Consorcio de Museos de la Comunidad Valenciana. D. L., 2006.

RINALDI, 1995

Rinaldi, Simona: "Bianchi e Neri" en Rinaldi, S., Quartullo, G., Milaneschi, A. et al: La Fabbrica dei Colori. Pigmenti e Coloranti nella Pittura e nella Tintoria. Roma: Il Bagatto, 1995. ( p. 2-77)

ROY, 1993

Roy, Ashok (ed): Artists' Pigments. A Handbook of Their History and Characteristics. Vol. 2. Washington: National Gallery of Art, 1993.

SAN ANDRÉS Y GARCÍA, 2008

San Andrés Moya, M. y García Fernández-Villa, S.: "Patents as Source of Documentation for Studying Art Technology" en Art Technology. Sources and Methods. Proceedings of the Second Symposium of the Art Technology Source Research Study 
Group. London: Archetype Publications, 2008.

TOWNSEND ET $A L ., 1998$

Townsend, Joyce H,. Carlyle, Leslie, Burnstock, Aviva et al.:

"Nineteenth - Century Paint Media: The Formulation and

Properties of Megilp" en Painting Techniques History,

Materials and Studio Practice. Contributions to the Dublin

Congress. London: The International Institute for

Conservation of Historic ans Artistic Works, 7-11 September 1998. p. 205-210.

UEBELE, 1913

Uebele, Charles L.: Paint Making and Color Grinding. The Trade Papers Publishing Co., 1913.

VAN DEN BERG, 2002

Van Der Berg, J. D. J.: Analytical Chemical Studies on

Traditional Linseed Oil Paints. Amsterdam: MOLART

Project, 2002.

VIRNO, 1995

Virno, Cinzia: "Porpora” en Rinaldi, S., Quartullo, G., Milaneschi, A. et al: La Fabbrica dei Colori. Pigmenti e Coloranti nella Pittura e nella Tintoria. Roma: Il Bagatto, 1995. (p. 384-427)

WEST FITZHUGH, 1986

West Fitzhugh, Elisabeth: "Red Lead and Minium" en Feller, Robert L. (ed) : Artists' Pigments. A Handbook of their History and Characteristics. Vol. 1. Washington: National Gallery of Art, 1986. (p. 109-139) 
APÉNDICES 



\section{Apéndice A: Descripción de las Fuentes}

1. Curso Completo Teórico y Práctico de Diseño y Pintura en sus Tres Principales Ramos de Olio, Temple, y Fresco por D. J. S. O y A. F. Barcelona: Imp. De José Torner, 1837.

Este pequeño manual está escrito por un profesor y un académico de mérito de la Academia de San Carlos de Valencia. Según Antonio Palau ${ }^{1}$ (1951: IV, 241), las iniciales D. J. S. O. y A. F. que rezan en la cubierta del tratado corresponden a D. José Soler Oliveres y a D. Antonio Ferrer, “...naturales de Manresa”. Sin embargo, el Manual de Palau, en un volumen posterior (Palau, 1969: XXI, 452-453), alude a las siglas D. J. S. y A. F. cómo criptónimos de José Soler Oliveres y Antonio Farran (318363).

El tratado consta de dos volúmenes divididos en tres partes; las dos primeras partes están dedicadas al dibujo mientras que la tercera aborda diferentes técnicas pictóricas. El primero tomo - que contiene la primera parte del Curso - trata íntegramente el dibujo de la figura humana, animales, flores, frutas, paisajes, arquitecturas y expone nociones de perspectiva. El segundo tomo consta de dos partes claramente diferenciadas. La primera se adentra en el dibujo ideal que trata de la belleza de las formas del dibujo, de las expresiones, de la composición y del claroscuro. Mientras que la segunda parte de este volumen se adentra en explicaciones de las diferentes técnicas pictóricas: temple, óleo y fresco. El manual concluye con un escueto Diccionario del Diseño y Pintura cuyo objetivo es aclarar términos que se han empleado en el texto. Soler y Ferrer (1837: I, 3) reconocen haberse basado en autores de diferentes épocas: 'Arfé, Arce, Azára, Alberti, Bruquel, Boubier, Dante, Lavater, Mengs, Merimie, Palomino, Pacheco, Pozo, Preciado, Scefero, Vignola, Vinci, Zucaro'.

\footnotetext{
${ }^{1}$ PALAU y DULCET, ANTONIO: Manual del Librero Hispano Americano. Bibliografía General Española e Hispanoamericana desde la Invención de la Imprenta hasta Nuestros Tiempos con el Valor Comercial de los Impresos Descritos. Barcelona: Librería Palau, 1951. $2^{\mathrm{a}}$ ed. Tomo IV. p. 241 (66518).
} 
El Curso contiene varias láminas cuyo objetivo es auxiliar en la comprensión de las explicaciones. Pero los autores no mencionan ni el origen ni el artífice de sus imágenes. Algunas de estas láminas están inspiradas en las ilustraciones del Museo Pictórico o Escala Óptica de Antonio Palomino ${ }^{2}$; sin embargo, otras parecen ser originales aunque expresamos nuestra reserva por falta de información. En cualquier caso y sin ninguna clase de dudas, la lámina más interesante muestra un curioso, original y novedoso mortero para la molienda de los colores (Ver II. 2).

El Curso está especialmente orientado a la enseñanza de la pintura de historias o de narración y conserva interesantes instrucciones vinculadas a una tradición pictórica que desaparecerá a lo largo de la centuria. Soler y Ferrer exponen dos tipos de pintores: el copista y el inventor ${ }^{3}$. Los autores presentan al pintor de invención cómo un artista erudito que precisaba conocimientos de mitología, geografía, historia natural, historia profana y sagrada, óptica aplicada a la perspectiva, fisonomía, anatomía y conocimientos químicos sobre los colores (Soler y Ferrer, 1837: II, 80-81). Desde finales del siglo XVIII y gran parte del XIX, estos artistas eruditos dirigidos por la Academia estuvieron al servicio del poder y aproximaban en sus obras estética y ética.

\footnotetext{
${ }^{2}$ La mayoría de los grabados que aparecen en el tratado de Palomino son copias totales o parciales de reconocidos modelos documentales (Vesalio, Pozzo, Arfe...) que el autor encargó grabar a Hipólito Rovira y Brocandel (vol. I) y a su sobrino Juan Bernabé Palomino (vol. II). Sobre las ilustraciones del tratado de Palomino: Bonet Correa, Antonio: "Láminas de "El Museo Pictórico y Escala Óptica" de Palomino" en Archivo Español de Arte. Madrid: Instituto Diego Velázquez, CSIC: 1973, No. 182, p. 131-144.

3 Para Palomino, el pintor inventor está en el cuarto grado de los pintores, “...animándose ya con la cercanía de la eminencia, a que aspira, a continuar con mayor estímulo sus bien logrados afanes, para llegar a el delicioso término de su apetecida gloria." (Palomino, 1988: II, 238).
} 
2. BORBÓN, SEBASTIÁN MARIA GABRIEL DE: De los

Aceites y Barnices de que se hace uso en la Pintura. Memoria dirigida a la Real Academia de S. Fernando en Madrid. Madrid, 1860.

Este es un texto corto, de veintisiete páginas, que aborda únicamente aspectos técnicos de la pintura. Borbón, motivado por la alteración de la pintura al óleo y la insuficiente permanencia de las pinturas de su época, investigó la forma de desarrollar aglutinantes oleosos estables. Para el autor de esta memoria, la falta de conocimientos de los aspectos materiales de la pintura era una de las principales causas de deterioro de los óleos.

El autor expone las conclusiones de sus experimentos que centró en los aceites de linaza y piñones. Las experiencias que relata esta memoria se basan en la disolución de sustancias que confieren elasticidad al aglutinante oleoso: la guta percha y la goma elástica. Borbón también propone un barniz que incluye caucho - entre otros ingredientes - y que resultaba útil para amasar los colores destinados a la reintegración de pinturas durante las operaciones de restauración. El esfuerzo de Borbón por introducir el caucho como materia artística no fue el único. En el siglo XIX se realizaron varios intentos en este sentido pero carecieron del éxito necesario. La memoria finaliza con una receta para acabar con la carcoma de las tablas pintadas. En definitiva, es un texto muy interesante y rico en notas y apreciaciones materiales.

3. O’NEILLE Y ROSIGNOL, JUAN: Tratado de Paisaje.

Palma de Mallorca: Imprenta de Pedro José Gelabert, 1862.

Éste es el primer tratado español dedicado exclusivamente a la pintura de paisaje, de esto se infiere una creciente consideración hacia éste género pictórico. Recordemos que esta disciplina pictórica fue admitida en las Academias en 1844 y fue la Academia de San 
Fernando la primera que creó una cátedra de pintura de paisaje aquel año. La intención de O’Neille (1862:I-II) era mostrar el camino a quienes aspiraran a pintar paisajes. Para alcanzar su objetivo, O'Neille consultó los escritos de "Palomino, Mengs, Lairesse, Desphertes, Lecarpentier, Parrasio Tebano, Lauréense, Dolz y otros”. O'Neille lamenta que, a diferencia de las escuelas holandesa, flamenca, italiana y francesa, los artistas españoles no desarrollaran la pintura de paisaje.

El autor de este tratado expone las enormes dificultades que encuentra el pintor de países. Tantos matices de colores y luces, tantos géneros, términos y sutilezas parecen querer demostrar la grandeza de un género pictórico considerado durante mucho tiempo un género secundario. Aunque O'Neille reconoce la importancia que tiene para un paisajista los conocimientos de perspectiva, no incluye lecciones de esta materia porque el aspirante a paisajista debe haber adquirido previamente estos conocimientos. El autor también expone la relevancia del dibujo para el paisaje y comenta los materiales más apropiados de esta disciplina. Pero el cuerpo del tratado está especialmente dedicado a explicar los diferentes géneros del paisaje, las partes, los diferentes elementos que lo forman - árboles, figuras, animales - y los matices de luces y colores que se aprecian en las diferentes estaciones del año, diversas horas del día, en los celajes, etc.

El Tratado de Paisaje de O'Neille pertenece a un momento en que algunos paisajistas incorporan pequeñas escenas históricas en sus obras como justificación argumental de sus paisajes y marinas. De esta forma los pintores conseguían que su clientela burguesa ${ }^{4}$ valorara estos paisajes como obras de mayor rango. En estos paisajes

\footnotetext{
4 Según Díez, el género de historia no cuajó entre la nueva clientela burguesa nacida en época isabelina; la burguesía prefería pinturas más decorativas y fútiles. Algunos pintores especializados en marina y paisaje introducen figuras en sus pinturas en respuesta a la demanda de sus clientela. Este fenómeno pictórico ocurrió ya en el siglo XVII. Díez expone como artistas destacados en este género a Perez Villamil (1807-1854), Antonio Brugada (1804-1863) y José María Avrial y Flores (1807-1891). DÍEZ, JOSE LUÍS: "Evolución de la Pintura Española de Historia en el Siglo XIX” en La Pintura de Historia del Siglo XIX en España. Madrid: Museo del Prado, 1992. p. 76.
} 
históricos - expresaba O'Neille - todo debía ser sublime y poseer grandiosidad. El pintor representaba historias sagradas, profanas o mitológicas y se le exigían muchísimos conocimientos. Las historias, los personajes, los trajes, la arquitectura, etc. son materias que debía dominar el pintor que se dedica a este género.

O'Neille expone varios tipos de paisaje además del histórico o sublime: las vistas, el paisaje campestre, mixto, compuesto, ideal, marinas, etc. Podemos apreciar cierto rechazo hacia la postura romántica que se desprende del concepto de paisaje ideal que admite extravagancias y efectos fantásticos. Según O'Neille (1862: 61) el paisaje ideal “...traspasa los límites del buen gusto, y entra en los de la estravagancia, la exageración, y amaneramiento.” Sin embargo, el autor parece comulgar con la tendencia realista no idealizadora que Carlos de Haes legó a la escuela paisajística que creó hacia 1858 1860.

Uno de los aspectos más significativos de este texto es que demuestra una completa asunción de los fabricantes y comerciantes de colores. O'Neille expresa gran admiración por las innovaciones materiales - como los tubos de pintura o las preparaciones comerciales - y obvia por completo cualquier problema de adulteración o conservación de los colores. Estamos ante una concepción nueva del artista que considera que éste no debe emplear su tiempo en las pesadas preparaciones de sus materiales e instrumentos. Y, aunque O'Neille entiende que los pintores aún precisaban algunos conocimientos para preparar los colores que pudiera no encontrar en su expendedor, no aporta ninguna explicación sobre la elaboración de materiales.

En este tratado se describen escasos rasgos técnicos, lo que evidencia la decreciente importancia de estos aspectos del oficio de pintor. El texto demuestra perfectamente la desvinculación que los pintores tenían de la parte material de su oficio. Para O'Neille (1862: 97) el mejor concepto de paisaje es el de Lairesse ${ }^{5}$ según el cual hay que pintar el paisaje tres veces con osadía, atención y paciencia: "Osadía para bosquejarlo, atencion para repintarlo, y paciencia para

5 Gérard Lairesse ( Lieja, 1640 - La Haya, 1711). 
terminarlo." O'Neille critica abruptamente la pintura alla prima ("pintar de primera") y a los artistas que practica esta forma de pintar.

4. ALGARRA, AGUSTÍN: Manual del Pintor Teórico-Práctico o sea Principios Fundamentales sobre la Pintura al Óleo y a la Acuarela. París: Librería de Rosa y Bouret, 1864. $2^{\mathrm{a}}$ Edición: París: Librería de A. Bouret é Hijo, 1875.

Algarra escribe este manual para ayudar a los jóvenes que desean dedicarse a la pintura pero que ya han adquirido conocimientos de dibujo y perspectiva. Para aquellos que deseen profundizar en estas disciplinas, el autor recomienda la lectura de obras especializadas “... de las cuales si desgraciadamente en nuestro país no tenemos muchas de que echar mano, existen en idiomas extranjeros muchas y recomendables...” (Algarra, 1875: 93). Algarra se adentra en cuestiones pedagógicas y cuestiona los métodos de enseñanza artística. El autor revisa brevemente los sistemas de enseñanza artísticos de Mengs y Reynolds; y, demostrando tener una nueva sensibilidad docente, se confiesa partidario de renovar las Academias de Arte $^{6}$. No obstante, este autor no penetra en discusiones sobre el tema.

La mirada neoclásica de Algarra le lleva a exponer unas breves "Observaciones de Nicolas Poussin sobre la Pintura". Éstas son pequeñas disertaciones que tratan de la pintura y la imitación de la naturaleza, la magnificencia de una obra, la idea de belleza o la magia de los colores sin aportar cuestiones técnicas ni materiales de la pintura. Para el autor de este manual, los preceptos del artista francés aún estaban vigentes cuando el escribía su texto. Estas

\footnotetext{
${ }^{6}$ José Galofre y Coma publicó en España en 1851 sus ideas antiacadémicas que tituló "El Artista en Italia y demás Países de Europa". El pintor español redactó el texto en Roma en 1849. Durante los años 1852-1858 José Galofre y los Madrazo mantuvieron un enfrentamiento sobre la necesidad de reformar las Academias de Arte.
} 
'Observaciones' podrían proceder de las observaciones de Poussin acerca de la pintura que publicó Bellori7 en las páginas siguientes a la biografía del pintor francés.

Algarra parece volcado en el pasado cuando se basa en Leonardo da Vinci para explicar la importancia del dibujo y la perspectiva; o cuando expone las "Observaciones de Nicolas Poussin sobre la Pintura”. Sin embargo, demuestra un gran interés por los conocimientos científicos del color que se desarrollaron en las primeras décadas del siglo XIX. Las "Nociones Elementales sobre el Color" que explica Algarra están acordes con las teorías de Chevreul. Recordemos que éste químico francés experimentó con el efecto de los colores complementarios yuxtapuestos. Sus investigaciones comenzaron a divulgarse cuando en 1839 publicó De la Loi du Contraste Simultané des Couleurs ${ }^{8}$ que se convirtió - asegura Ball 9 (2003: 225) - en un manual esencial para los pintores.

Las técnicas pictóricas que aborda Algarra son la aguada y la pintura al óleo. El autor pasó seis años cultivando la acuarela en Inglaterra y enfoca sus lecciones de esta técnica para aquellos que ya saben dibujar. Nociones teóricas, materiales y prácticas se elaboran de manera sucinta en esta sección del Manual del Pintor que finaliza con una pequeña nota sobre la pintura a la sepia. El artista se adentra en la pintura al óleo aportando únicamente breves nociones materiales y técnicas. El discurso de este autor demuestra que los fabricantes y comerciantes de colores, materiales y utensilios artísticos estaban plenamente establecidos y no explica la preparación de ningún material. Resalta los escasos pigmentos de la época citados por Algarra. Esto resulta curiosa puesto que el autor advierte que la química "...ha causado en la pintura, ó mejor dicho en los colores, una completa transformación, laudable por mas de un concepto." (Algarra, 1875: 156).

\footnotetext{
7 Bellori, Giovanni Pietro: Vite de' pittori, scultori e architecti moderni. 1672.

${ }^{8}$ Éstas ideas de Chevreul fueron recogidas por Francisco Javier Lluch en el Arte de Armonizar los Colores o Ley del Contraste en la Yuxtaposición de los Mismos. Con Aplicación de Dicha Ley á las Bellas Artes, Tejidos Estampados, Bordados, Trajes, Ebanisteria, Decoracion y Floricultura. Barcelona, 1856.

9 Ball, Philip: La Invención del Color. Madrid: Turner Publications, 2001.
} 
El Manual concluye con una "Explicación de los Términos Técnicos Empleados en este Manual" y con "Un Catálogo de Algunas Obras que Pueden Consultarse sobre Pintura y Ciencias Auxiliares". En la Explicación de Términos aparecen vocablos referentes tanto a los materiales como a otros aspectos teóricos e incluso algunos términos más generales del arte. En el catálogo de obras aparecen textos de dibujo, perspectiva, anatomía, teoría del color, de técnicas pictóricas etc. de todos los tiempos. Fundamentalmente son autores franceses porque Algarra estima que son los más reputados; pero ha incluido algunos tratados españoles e incluso de otras nacionalidades por su mérito probado. En la edición de 1875 hay un error o defecto de encuadernación pues la primera página del diccionario de términos aparece encabezando el catálogo de obras y al revés. Es decir, la primera página del Catálogo figura como inicio del Diccionario de términos.

5. DE LA ROCA y DELGADO, MARIANO: Compilación de Todas las Prácticas de la Pintura, desde los Antiguos Griegos hasta Nuestros Días. Madrid, 1880.

'Contiene los tratados de pintar al temple, al aguazo, al fresco, al óleo, curiosidades y secretos accesorios á la pintura y dorar á mate, modo de pintar los escudos de armas, y la simetría del cuerpo humano; escritos en 1724, por D. Antonio Palomino de Castro y Velasco, pintor de cámara del rey D. Luis I de España: y los del encausto y cera, en 1755, por Mr. Le Comte de Caylus; esmalte, pastel, en 1767, por Mr. De Piles; miniatura, en 1822, por Mr. Mansión, discípulo de Mr. Isabey, traducidos libremente: $y$ originales, los de aguada, limpieza, forración y restauración de las pinturas al óleo'.

Los tratados expuestos en esta recopilación son fundamentalmente del siglo XVIII aunque el autor ha incluido cómo veremos - escritos de los siglos XVII y XIX. De la Roca incluyó en esta compilación textos de difícil obtención para que sirvieran de 
provecho a pintores y aprendices a pintor. De la Roca pensaba que algunas prácticas pictóricas olvidadas como el fresco, la miniatura sobre marfil o el pastel volverían a imponerse. No cabe duda que este conjunto de textos obedece a un marcado gusto romántico por procedimientos pictóricos de épocas pretéritas.

Los textos recogidos no se presentan de forma íntegra, es decir, están mutilados y organizados según el criterio e interés del compilador. De hecho, De la Roca (1880: 6) informa que ha aligerado “...las digresiones de todos los autores,...”. Además los escritos pertenecientes a la compilación mantienen un orden extremadamente particular. Comienza con el "Tratado de la Pintura al Temple; de Aguazo; y de la Simetría del Cuerpo Humano por D. Antonio Palomino de Castro y Velasco". Bajo este título De la Roca a refundido y adaptado partes del Museo Pictórico y Escala Óptica de Palomino ${ }^{10}$. A continuación, De la Roca ha incluido el "Tratado de la Pintura al Fresco" ${ }^{11}$ que reproduce de manera íntegra "De la Práctica y Observaciones de la Pintura al Fresco” del mencionado tratado del pintor tardobarroco.

La reunión de textos continúa con el "Tratado de la Pintura al

${ }^{10}$ Los pasajes del Museo Pictórico y Escala Óptica de Palomino que ha utilizado De la Roca para este tratado del compendio son:

- Tomo I

- Tomo II

- Libro I (El Aficionado), Capítulo VI: “De la Pintura Colorida ó Manchada, y sus Especies".

- Libro VI (El Aprovechado), Capítulo V: "Práctica de la Pintura al

Temple";

- Libro V (El Copiante), Capítulo III: "Modo de Imprimar o Aparejar los

Lienzos";

- Libro IV (El Principiante), Capítulo V: “De la Simetría del Cuerpo

Humano".

${ }^{11}$ En este tratado de la compilación, De la Roca ha utilizado las siguientes partes del Museo Pictórico:

- Tomo I

- Libro I (El Aficionado), Capítulo VI: “De la Pintura Colorida ó Manchada, - Tomo II y sus Especies”.

- Libro VII (El Inventor), Capítulo IV: “De la Práctica y la Observación de la Pintura al Fresco". 
Encausto y a la Cera por Mr. Le Comte De Caylus, en 1755." En realidad se trata de un extracto de la Memoire sur la Peinture a l'Encaustique et sur la Peinture a la Cire del artista francés. El descubrimiento de las pinturas de Herculano (1738) y Pompeya (1748) y la equivocada creencia de que estaban realizadas a la encáustica impulsó, en el siglo XVIII, una serie de investigaciones para determinar la técnica empleada durante la antigüedad. $L a$ Memoire de De Caylus ${ }^{12}$ fue uno de los textos más importantes del siglo XVIII dirigidos a la recuperación de la técnica de la encáustica.

La compilación prosigue con sendos textos que De la Roca atribuye a Mr. De Piles: "Tratado de la Pintura al Esmalte" y "Tratado de la Pintura al Pastel" editados, según el compilador, en 1767. Ambos textos proceden de Élémens de Peinture Pratique de Roger de Piles, publicados por primera vez en $1684^{13}$.

Tras los referidos tratados extractados de De Piles, el compilador ha insertado un texto autógrafo: "Tratado de la pintura a la aguada" fechado - según reza la portadilla - en 1867. No obstante, mostramos la mayor cautela sobre la originalidad del texto por falta de datos. Y tras la pintura a la aguada, De la Roca adjunta el "Tratado de la Pintura a la Miniatura según Mr. Mansión...” fechado en 1822. Este tratado traducido y arreglado por De la Roca en 1871 versa sobre la pintura con colores aglutinados con goma arábiga sobre marfil.

El compilador introduce después otra parte del tratado de Palomino; en esta ocasión trata el óleo y diferentes aspectos abordados por el pintor tardobarroco. Esta sección de la

\footnotetext{
${ }^{12} \mathrm{El}$ estudioso francés estableció una clara diferencia entre los métodos a la encáustica y los métodos de pintura a la cera en frío. La Memoire del Comte de Caylus trascendió las fronteras francesas y se tradujo al inglés en 1760 aunque con el contenido simplificado. Las investigaciones del Comte Caylus repercutieron en algunos pintores de su época. John Mills y Raymond White demuestraron que las pinturas de Georges Stubbs estuvieron claramente influenciadas por los escritos del Comte de Caylus. Mills, John y White, Raymond: "The Mediums Used by George Stubbs: Some Further Studies" en National Gallery Technical Bulletin. Londres: 1985. Vol. 9, p. 60-64.

${ }^{13}$ Según Bordini, algunos atribuyeron la primera edición de este libro a J. B. Corneille, sin embargo otros consideran que éste fue únicamente el autor de los grabados del texto.
} 
Compilación ha recibido el nombre de "Tratado de la Pintura al Óleo, su Práctica y Curiosidades para hacer los Barnices y Colores, y Dorar a Mate ${ }^{14}$ ". De la Roca añade a este capítulo un apéndice: 'De las Observaciones sobre el Resultado que Han Dado con el Tiempo los Aceites y Barnices' que asegura ser de su propio caudal. Sin embargo, se trata de la Memoria de Sebastián María Gabriel de Borbón que hemos visto anteriormente. Por supuesto, De la Roca ha adaptado el texto a su conveniencia. La parte final de este apéndice si parece deberse al autor de la Compilación. En ella expone cómo elaborar un retrato a personas - como reyes o grandes personajes - que no puede conceder poses largas al pintor. El autor narra un procedimiento realmente curioso para elaborar estos retratos con aceite de olivas porque al tratarse de un aceite no secante las tintas permanecen frescas hasta concluir el trabajo. Igualmente sorprendente resulta el modo de secar estos retratos espolvoreando greda por el reverso.

La Compilación finaliza con el "Tratado de la Limpieza, Forración y Restauración de las Pinturas al Óleo" escrito por

\footnotetext{
${ }^{14}$ Los capítulos del Museo Pictórico de Palomino que ha adaptado De la Roca para este 'Tratado' son:

- Tomo I

- Libro I (El Aficionado), Cap. VI: “De la Pintura Colorida ó Manchada, y sus Especies".

- Tomo II

- Libro V (El Copiante), Cap. II: "Instrumentos que ha de Preparar el Principiante para Ponerse a Pintar." Cap. III: "Modo de Imprimar o Aparejar los Lienzos y Otras Superficies para Pintar.” Cap. IV: “Cuáles y cuantos sean los colores del Óleo y cómo se han de Preparar, y de los Aceites y Secantes que Sirven para su Mano." Cap. V: "Cómo ha de comenzar a Pintar el Copiante, y los medios con que ha de facilitar el Colorido." Cap. VI: "Del Colorido de los Paños o Ropas, y de los Cambiantes, y los Medios con que ha de Facilitar el Colorido." Cap. VI: "Del Colorido de los Paños o Ropas, y de los Cambiantes de Diversos Colores."

- Libro VI (El Aprovechado), Cap. II: "Del Modo de Estudiar por el Natural, y lo que se Debe Observar en los Retratos"

- Libro IX (El Perfecto), Cap. XV: “”De Algunas Curiosidades y Secretos Accesorios a la Pintura y de Importancia para el que la Profesa."; Cap. XVI: "Manufacturas, y Secreto de Algunos Colores Artificiales que se Gastan en la Pintura."
} 
Mariano de la Roca y Delgado. El mencionado tratado forma parte de una publicación anterior de éste autor cuyo título completo es Francisco Pacheco: Arte de la Pintura, su Antigüedad y Grandezas. Extractado y Enriquecido con un Tratado Nuevo para Saber Limpiar y Restaurar las Pinturas sobre Lienzo, Madera, Cobre y Piedra $^{15}$. A pesar que el Arte de la Restauración de Vicente Poleró fué publicado en 1853, este tratado de De la Roca no parece en absoluto dependiente del mismo.

\section{POLERÓ Y TOLEDO, VICENTE: Tratado de la Pintura en General. 1886.}

Vicente Poleró escribió el Tratado de Pintura en General con el deseo de indicar a los principiantes y aficionados a la pintura los caminos que debían seguir para su formación. La forma en que Poleró estructura los temas del Tratado de la Pintura mantiene un marcado cariz académico. De modo que el libro comienza con un relato histórico sobre las diferentes escuelas pictóricas desde los griegos hasta el siglo XIX. Después, el autor explica brevemente aspectos de geometría y perspectiva que podían ser útiles a los pintores. En cambio, la anatomía humana es un asunto al que Poleró dedica más atención y detalle. El escritor expone el estudio del dibujo siguiendo parámetros tradicionales. El aprendiz debía comenzar copiando láminas, después continuaba con el estudio del antiguo y finalizaba por el 'estudio del modelo vivo'. Éste era el último paso en el aprendizaje de un pintor antes de empuñar los pinceles para copiar la naturaleza. El autor enumera los materiales y utensilios del dibujante. Poleró sugiere a los aprendices que se inicien en el manejo del color siguiendo la tradición de los artistas del siglo XVII; es decir, copiando un bodegón o alguna cabeza. El autor no dedica un capítulo

\footnotetext{
${ }^{15}$ La fecha de publicación que aparece en el compendio es 1872, sin embargo, en el catálogo de la Biblioteca Nacional de España consta que la fecha de publicación de este texto fue 1871 .
} 
o apartado a los utensilios y materiales de la pintura al óleo; sino que las enseñanzas de este tema están incluidas en el 'Estudio del Modelo Vivo'.

Aunque Poleró reconoce que el barroco era un estilo amanerado y decadente demuestra una gran admiración por pintores como Murillo o Zurbarán y una extraordinaria fascinación por el maestro Velázquez. Esta fascinación llevó a Poleró a exponer información sobre materiales pictóricos de un manuscrito de 1630 por ser de la misma época del gran pintor. En esta interesante transcripción sobre el precio de algunos pigmentos, aceites, gomas, etc. de 1630, Poleró hace una pequeña crítica a los colores de su época y comenta que preparó los colores al óleo como explica el citado manuscrito y obtuvo excelentes resultados. Estamos ante una postura completamente romántica que miraba el pasado - en este caso el barroco - con anhelo. A pesar de este anclaje en el pasado que demuestra el texto, Poleró reconoce la importancia que adquirió la fotografía para el estudio del natural, la reproducción de cuadros y otras ayudas al arte. El tratadista despliega toda su erudición para remitir al artista a los documentos pertinentes de los que puede extraer información precisa para pintar trajes y ropajes de los personajes de sus cuadros de historia.

El Tratado de la Pintura demuestra interés por diversos géneros pictóricos como el retrato, el paisaje y las marinas de los que expone breves nociones. También dedica el autor del tratado algunos pensamientos a la pintura decorativa puesto que cada vez con mayor asiduidad se precisaban artistas para la decoración de establecimientos, instituciones, palacios, casas señoriales, etc. Poleró también aborda otras técnicas pictóricas aunque de forma poco extensa: encáustica, temple, fresco, aguada, miniatura, pastel, imitación de tapices, encarnación de esculturas de madera, imitación de porcelanas y pintura embutida, mosaico y esmaltada. Además el autor explica la pintura de abanicos y de escudos de armas. Entre los temas abordados en este tratado podemos encontrar el grabado al agua fuerte y la litografía.

Por supuesto, Poleró incluye la restauración entre los asuntos que aborda en el Tratado de la Pintura. Recordemos que este autor 
publicó en 1853 el Arte de la Restauración que fue el primer tratado de restauración publicado en España. El Tratado de la Pintura en General recoge los temas de restauración que el pintor-restaurador abordó en su libro sobre restauración aunque con algunas modificaciones y añadidos. En el tratado de pintura aparecen unos asuntos que no existen en el libro de restauración: Forración y Limpieza y restauración de grabados y dibujos. El apartado de la Forración explica con gran detalle el tema e incluso describe la transposición de tablas. También aparecen pequeñas diferencias entre ambos textos de Poleró en los materiales empleados en la restauración.

Vicente Poleró fue restaurador del Museo del Prado y como tal conocía el estado de las obras pertenecientes a esta pinacoteca. En 1868 publicó la memoria Breves Observaciones sobre la Utilidad y Conveniencia de Reunión en uno solo, los Dos Museos de Pintura de Madrid, y sobre el Verdadero Estado de Conservación de los Cuadros que Constituye el Museo del Prado. En el Tratado de la Pintura en General se incluye parte de la citada publicación; en concreto la que trata el estado de conservación de las pinturas de la pinacoteca nacional.

La Importancia de las Tasaciones de Bellas Artes ${ }^{16}$ es el siguiente tema que Poleró incluye en su tratado de pintura. Aborda la formación y condiciones que debe tener el tasador de obras de arte y que aspectos debe valorar de una obra. También ofrece algún comentario sobre las diferentes y cuantiosas colecciones y coleccionistas de arte que a lo largo de la historia se crearon en España. Otorga Poleró gran mérito al Diccionario Histórico de los más Ilustres Profesores de las Bellas Artes en España de Ceán Bermúdez. Por eso publica un extracto muy reducido de esta obra. El tratado culmina con el Vocabulario de los Términos más Usuales en las Artes en el que se incluyen términos relativos a los materiales y las técnicas de la pintura, la arquitectura, el dibujo, el

${ }^{16}$ Poleró elaboró este texto con anterioridad y por el “... mereció ser nombrado por el Gobierno en $1^{\circ}$ de Junio de 1868 tasador de pinturas.” Ossorio y Bernard, Manuel: Galería Biográfica de Artistas Españoles del Siglo XIX. Madrid: Ediciones Giner, 1975 . 
grabado, etc.

7. L. PÉANT É HIJOS: Catálogo General de Colores Extrafinos, Barnices, Aceites, Secantes. Material para la Pintura al Óleo, la Acuarela, la Gouache, el Pastel, el Dibujo, la Fotominiatura. Papeles y Cartones de Dibujo para Lápiz, Pluma, Acuarela. Papeles, Telas y Pergaminos para Ingenieros y Arquitectos. 2 Vols. Madrid, 1895.

Este catálogo comercial es un documento de la época francamente interesante y atractivo. La prudencia ante la falta de datos nos impide calificar este documento cómo 'único superviviente en su género'. Sin embargo, hasta el momento en que se redacta esta tesis, es un documento exclusivo entre las fuentes españolas que pertenecen al ámbito de los materiales artísticos decimonónicos.

El catálogo está dividido en dos pequeños volúmenes independientes. En el primero se exponen los materiales, utensilios e instrumentos de la pintura al óleo, la decoración y la fotominiatura. El segundo volumen está dedicado a los productos y utensilios propios de la acuarela, el pastel, la pintura de imitación de tapices y el dibujo. En estos pequeños catálogos se ofrece de todo: desde los colores a los soportes; desde los caballetes a las cajas porta colores; desde los pinceles a los barnices... Ambos volúmenes contienen ilustraciones con grabados y fotografías de algunos productos que ofrecen.

La fecha que consignan las portadas de los dos volúmenes es 1895 y va acompañada de las direcciones en que L. Péant é Hijos tenía las tiendas abiertas al público y los talleres, todos en Madrid. Sin embargo, la primera página del tomo primero lleva inscrito el año 1893 y cuenta con una dirección menos. Esto podría ser indicio de que en 1893 la empresa también editó un catálogo comercial y que en los siguientes dos años experimentó cierto crecimiento. L. Péant é Hijos fabricaban materiales para las Bellas Artes y los vendía al por menor junto con productos de otros fabricantes del gremio. Es 
probable que vendiera sus productos al por mayor a pequeños comerciantes ${ }^{17}$.

Entre los productos de su propia elaboración encontramos aceites para la pintura al óleo, esencias, barnices para cuadros y secantes; así como pinceles de pelo de león, de marta roja y de meloncillo. Para el dibujo elaboraba carboncillos, lápices compuestos, goma americana y fijativo para el lápiz y el pastel. Además eran confecciones propias de estos industriales el barniz para acuarela, la sepia líquida o la tinta litográfica. La contracubierta de los dos volúmenes da noticias sobre otras fabricaciones y negocios de L. Péant é Hijos: "Fábrica de libros rayados. Proveedores especiales de oficinas, academias, ingenieros y comercio. Impresiones de lujo y administrativas". Además expendía materiales para escuelas. Sin duda, se trataba de un negocio muy diversificado que tal vez tuviera sus orígenes en la impresión de libros y otra clase de documentos ${ }^{18}$.

Entre los artículos de otros fabricantes, L. Péant é Hijos

${ }^{17}$ Según Bomford et al. (1990: 34) este tipo de fabricantes-vendedores formaba parte de la estructura del mercado de productos artísticos de mediados del siglo XIX.

${ }^{18}$ Hemos localizado varias publicaciones de finales de la década de 1880 en las que consta como impresor L. Péant e Hijos:

- Presupuesto de 1885-86. Balance general de créditos y gastos y monografías consideradas bajo su parte económica de todas las obras y servicios durante el expresado ejercicio en los ramos de Instrucción pública, Agricultura, Industria y Comercio y Obras públicas. Madrid: Tipografía de L. Peant é hijos, 1887. En folio.

- Dirección general de Obras públicas. Memoria sobre el estado de las carreteras en el año 1885,presentada al Excmo. Sr. Ministro de Fomento por el Excmo. Sr. D. José Gallego Díaz, Director general de Obras públicas. Madrid: Tipo-litografía de L. Peant é hijos, 1887. En folio.

- Memorias sobre las obras públicas desde $1 .^{\circ}$ de Enero á 31 de Diciembre de 1884. Comprende la parte primera: asuntos generales, personal y varios asuntos; y la parte segunda: puertos, faros, boyas, valizas, ríos, canales y aprovechamientos de aguas, presentada al Excmo. Sr. Ministro de Fomento por el Director general de Obras públicas. Madrid: Tipo-litografía de L. Peant é hijos, 1887. En folio.

- ANÓNIMO (1891), Avance Estadístico sobre Cultivo y Producción de la Vid en España formado por la Junta Consultiva Agronómica 1889, Ed. Tipolitografía de L. Peant e Hijos, Madrid. 
suministraba principalmente productos ingleses de Reeves \& Sons, belgas de Felix Mommen y franceses de Lefranc \& Cie. L. Péant é Hijos se presentan como los únicos depositarios de los "Colores Extrafinos en Tubos para Pintar al Óleo marcados A. Lefranc” y de los "Colores Superfinos Preparados para el Óleo por los Procedimientos de J. G. Vibert”. Podemos encontrar artículos para acuarela, tinta china o litográfica, lápices, papeles, etc. de otros fabricantes menos conocidos.

8. SALA, EMILIO: "La Desecación de la Pintura" en $L a$ Ilustración Española y Americana. Año XL. Num. XLII (p. 275-278) - Num. XLIII (292, 294). Madrid, 1896.

Éste es un texto corto que critica abierta y ferozmente los materiales comerciales. Según Sala, los pintores se encuentran con deficiencias en la 'cocina de la pintura' por dos motivos. El primero de ellos es el descuido de las Escuelas de Bellas Artes en el conocimiento, estudio y manipulación de los ingredientes preparados para la práctica de la pintura. El segundo son las falsificaciones de los productos comerciales. Con éste escrito el pintor quiere llamar la atención de sus compañeros sobre el modo de secarse la pintura.

Para estudiar el secado de los materiales Emilio Sala elaboró unos experimentos que consistían en amasar sus propios colores al óleo y pintar con ellos. Luego comparó el uso y comportamiento de estos materiales con los materiales comerciales. El pintor juzgó como excelentes los resultados obtenidos con los materiales que el preparó. Sala dedica sus esfuerzos a explicar el secado de la pintura al óleo porque considera que si los pintores comprendieran este tema podrían evitar algunas alteraciones que se producían en las obras. Por esto Sala considera que sería muy útil que en las Escuelas de Bellas Artes se impartieran clases cuyo objetivo fuera que el pintor conociera sus materiales. Este pintor también desvela su admiración por el maestro Velázquez. Sin embargo, en cuestión de fuentes escritas este pintor decimonónico no menciona a Pacheco - maestro 
de Velázquez - y critica a Palomino. Emilio Sala demuestra tener más interés en el tratado medieval de Cennini y en sus explicaciones materiales y técnicas.

9. LÓPEZ TOMAS, JOSÉ: Educacion Artística: Teoría

y Practica del Dibujo, Pintura, Grabado y Escultura y

Resumen Histórico de estas Artes en Europa. Alicante: V.

Soler, 1898.

Este libro mantiene un marcado carácter pedagógico renovador y una estructura didáctica a modo de libro de texto. La Educacion Artística está compuesta por dos Libros cada uno de los cuales se divide en dos capítulos fraccionados en varias Lecciones. López Tomás (1898: 77) menciona un “...libro $3^{\circ}, \ldots$, sin embargo, no parece que éste llegara a ver la luz. El texto contiene temas novedosos y enfoques diferentes de asuntos habituales en los tratados de pintura; pero también comparte aspectos con otros tratados de la época.

La obra tiene una dedicatoria muy significativa que explica el carácter tan distinto y especial de éste texto frente a los tratados y manuales de otros pintores: "Al Señor D. Hermenegildo Giner de los Rios, catedrático y escritor,...”. Sin duda esta dedicatoria es muy reveladora e indica una mentalidad e ideas renovadoras en el autor de la Enseñanza Artística. Hermengildo Giner de los Rios colaboró en la fundación de la Institución Libre de Enseñanza llevada a cabo en 1876 por su hermano Francisco y otros catedráticos ${ }^{19}$.

\footnotetext{
${ }^{19}$ Recordemos que el Ministro de Fomento Manuel de Orovio trató de imponer en 1868 y 1875 unas severas medidas para el control de la enseñanza superior. Los catedráticos de talante liberal protestaron y el Gobierno contestó con duras y arbitrarias medidas hasta que finalmente fueron despojados de sus cátedras. Éstos fueron unos de los motivos por los que éstos profesores privados de su reconocimiento académico - apoyados por algunos intelectuales progresistas crearon en 1876 la Institución Libre de Enseñanza basada en la neutralidad religiosa y política y la completa independencia del Estado y de cualquier comunidad religiosa o filosófica. Los principales fundadores de la Institución fueron Francisco Giner de los Rios, Gumersindo de Azcárate y Nicolás Salmerón.
} 
Hermenegildo Giner fue un gran estudioso y uno de los principales renovadores de la enseñanza en España. La Educacion Artística del pintor José López Tomás parece estar influenciada por el Manual de Estética y Teoría del Arte e Historia Abreviada de las Artes Principales hasta el Cristianismo escrito por Hermenegildo Giner de los Rios y publicado en $1895^{20}$. Éste fue el primer manual español de Historia del Arte destinado a servir de guía a los profesores de enseñanza secundaria.

La parte teórica de este texto presenta grandes innovaciones con respecto a los tratados anteriores. Para López Tomás, educar y dirigir la inteligencia y el sentimiento de un artista era una tarea verdaderamente difícil. El maestro debía lograr que el discípulo desarrollara su propia personalidad sin dejar rastro de su influencia. Este sencillo pero abrumador matiz marca una de las grandes diferencias de este escrito. El texto permite apreciar un método de enseñanza del artista menos rígido que el sistema tradicional. Por ejemplo, el autor sostiene que en el estudio del dibujo debe desterrarse por completo la copia de láminas o grabados porque sus resultados son perjudiciales ${ }^{21}$. Recordemos que la copia de estampas es el primer paso en el estudio del dibujo según el sistema de enseñanza académico tradicional que aparece referido en tratados anteriores. Otro aspecto discordante que presenta López Tomás es la no necesidad de rigor histórico ${ }^{22}$ en las obras.

Una de las grandes virtudes de este escrito radica en que el autor no plantea una visión estricta de los temas que aborda sino que analiza los asuntos desde diferentes ópticas y puntos de vista. Una muestra de esto es la concisa pero clara explicación de los diferentes tipos de bocetos y los artistas que los han practicado: bocetos de dibujo (Leonardo da Vinci, Miguel Ángel, Rafael, etc.), de claroscuro

\footnotetext{
${ }^{20}$ Un análisis y valoración del mencionado texto de Giner de los Rios se puede encontrar en Caballer, $\mathrm{M}^{\mathrm{a}}$ Rosario: "El Primer Manual de Historia del Arte con Destino al Bachillerato. Su Autor: Hermenegildo Giner de los Rios” en Imafronte, $\mathrm{n}^{\mathrm{O}}$ 15. Murcia: Universidad de Murcia, 2000. p. 17-27.

${ }^{21}$ Esta idea también aparece defendida en el Manual de Pintura de Bellanger.

${ }^{22}$ Hemos visto como algunos tratadistas - Soler y Ferrer, O'Neille y especialmente Poleró - consideran necesaria en el pintor una esmerada formación que redunda en el rigor histórico de sus obras.
} 
(Rembrandt) o de color (Rubens). También apunta diversas maneras de abordar la obra según la conveniencia del artista: pasando el boceto con cuadrícula, pintando directamente o haciendo estudios aislados y de los grupos y colocando de nuevo el modelo para el trabajo definitivo. Esta es una diferencia sustancial con el resto de tratadistas que, por lo general, explican un único procedimiento.

En el capítulo de Teoría, el autor además incorpora temas innovadores e incluso de carácter controvertido que argumenta de manera reflexiva y documentada. López Tomás expone las consideraciones sobre la belleza y la forma de percibirla o la conveniencia del desnudo en el arte según diferentes pensadores. El autor de la Educacion Artística se muestra atraído por el pensamiento filosófico y en especial por las ideas alemanas de su tiempo aunque el texto también se ve apoyado por las reflexiones de otros pensadores y especialmente del crítico de arte francés Charles Blanc $^{23}$.

Otra de las aportaciones novedosas de la Educacion Artística se encuentra en que el autor plantea cómo debe ser la Crítica del arte o explica los diferentes tipos de público que se mueven alrededor del arte. Uno de los asuntos más controvertidos que trata López Tomás es la idoneidad de las Exposiciones Oficiales o Libres. Ninguno de los tratados analizados hasta ahora comenta la existencia de estas exposiciones libres. De éstas, López Tomás dice que son las que realmente cimentan la reputación y el porvenir de los artistas.

El capítulo dedicado a la Práctica está integrado por diversas lecciones dedicadas al dibujo, la pintura, el grabado y la escultura. Las lecciones de pintura están dedicadas al fresco, al temple y al óleo y de manera escueta a la acuarela y al pastel. López Tomás presenta los procedimientos o materiales pictóricos del

\footnotetext{
23 Charles Blanc publicó en 1867 Grammaire des Arts du Dessin; un texto que - según expresa Ball (2003: 226) en la Invención del Color - se convirtió en un manual estándar en Francia que influyó notablemente en el pintor neoimpresionista Paul Signac. También Gage (1997: 205) explica que Van Gogh y Gauguin fueron atentos lectores de los libros de Blanc y dejaron un conjunto de obras relacionadas con el debate sobre las relaciones cromáticas.
} 
fresco, temple y óleo en extractos arreglados de El Arte de la Pintura de Francisco Pacheco. Al igual que otros tratados que ya hemos revisado, el autor de la Educacion Artística comenta que los colores preparados por el pintor son más baratos y de mejor calidad que los elaborados por la industria. Por este motivo, son útiles las explicaciones tecnológicas de Pacheco sobre la preparación de aceites, lienzos o barnices. Para explicar los problemas de estabilidad de los óleos comerciales, su deficiente secado y otras alteraciones, López Tomás reproduce pequeñas partes del artículo "La desecación de la Pintura" de Emilio Sala.

Las lecciones dedicadas al grabado describen diferentes procedimientos: xilografía, talla dulce, agua fuerte, a puntos, en negro, lavado, imitación a lápiz y litografía. En cuanto a la escultura, López Tomás explica aspectos relativos al modelado del barro y a la forma de extraer moldes tanto de figuras de barro como de personas vivas o muertas. También explica sumariamente la forma de sacar los puntos de la figura y pasarlos al material definitivo. López Tomás retoma de nuevo a Pacheco para explicar el modo de preparar las esculturas de madera para realizar carnaciones mate.

El Libro II: Historia se estructura en dos capítulos. El primero expone el arte antes del Renacimiento y el segundo desde el Renacimiento hasta el siglo XIX. López comenta cómo se ha desarrollado el arte en diferentes épocas y naciones y explica algunos rasgos característicos de las obras de los grandes maestros. Así, el capítulo I trata de Grecia, Bizancio y la escuela greco - italiana. Mientras que en el segundo capítulo aborda el arte y los artistas de diversas naciones desde el Renacimiento hasta el siglo XIX: Italia, Flandes, Holanda, Alemania, Francia, Inglaterra y España. El libro concluye con un apartado que comenta la educación artística en España y el funcionamiento de las Academias, Escuelas de Arte y otros establecimientos y entidades dedicadas al arte. 
10. BELLANGER, CAMILO: Manual de Pintura al Alcance

de Todo el Mundo. Traducido del francés por E. Zamacois. París, 1899.

El autor de este texto ha querido reunir todos los temas relacionados con la pintura para facilitar al lector los medios para estudiarlos simultáneamente. Las explicaciones son muy sencillas y llanas lo que indica que el libro estaba dirigido a principiantes o aficionados. En definitiva, este autor ofrece pautas a seguir para que el alumno pueda aprender sin muchas dificultades el arte de pintar. El dibujo, la anatomía y la perspectiva son abordados de manera didáctica y con ejemplos e ilustraciones explicativas. En el estudio del dibujo, Bellanger - igual que López Tomás - prescinde del estudio de láminas.

Otra similitud con López Tomás reside en la forma de considerar la anatomía humana: conocer el esqueleto es más imprescindible que saber los músculos. Los primeros determinan longitudes, proporciones y estructura del cuerpo y es necesario su estudio. La forma de los músculos se aprende con una atenta observación del modelo. Sin embargo, argumenta el autor, el artista debe conocer los principales músculos de la cabeza y de la cara que provocan las diferentes expresiones del rostro. Por eso alude a éstos músculos y comenta diferentes ángulos faciales. También trata las proporciones del cuerpo humano. No obstante, para aquellos que deseen profundizar en el conocimiento de los músculos remite a los tratados de anatomía; recomienda los de Sappey, Matías Duval y Paul Richer.

Antes de estudiar la pintura, el aprendiz debe conocer los colores, de manera que Bellanger se adentra en la teoría de los colores. No quiere extenderse en el punto de vista científico de la teoría de los colores porque el pintor no necesita conocimientos exhaustivos sobre el tema. Por otra parte, si el estudiante tiene interés puede dirigirse a las obras que tratan el color desde la óptica científica.

Bellanger mantiene durante toda la obra el tono didáctico. Las lecciones de pintura comienzan comentando los materiales e 
instrumentos del pintor y los diferentes géneros pictóricos. Aunque el autor considera un gran adelanto los materiales industriales subraya algunas de sus carencias e inconvenientes. En el "Modo de Pintar", Bellanger aporta interesantes consejos técnicos para abordar las pinturas. De la misma manera, en las lecciones sobre naturaleza muerta, flores, paisaje, animales, retrato o ropajes explica interesantes recursos técnicos y procedimientos prácticos. En el tema de ropajes, Bellanger demuestra un gusto extremadamente clásico como evidencian las ilustraciones. Es decir, sus enseñanzas plantean cómo colocar trapos - no trajes de su época - a los modelos, maniquíes o figuras de barro, señalando la dificultad de colocar los trapos que vuelan o se suspenden en el aire. Esto, sin duda, plantea presupuestos estéticos algo distantes con el momento en que se publica el manual y más acordes con la pintura de Bouguereau, uno de los maestros de Bellanger.

11. VIBERT, JEHAN-GEORGES: La Ciencia de la Pintura. Versión castellana por Miguel de Toro y Gómez. París, 1908.

A pesar de que la edición en español de este libro es de 1908 lo hemos incluido por tratarse de un texto del siglo XIX. Éste manual es el fruto de treinta años de estudio y experiencia de su autor, el pintor francés Jehan-Georges Vibert. La Ciencia de la Pintura reúne las conferencias impartidas por Vibert en un curso público en la Escuela de Bellas Artes de París. El autor se muestra muy crítico con la formación del pintor, con la industria de colores y con el propio artista; desea, realmente, que los pintores recuperen su oficio. Es un tratado francamente interesante y muy descriptivo en cuanto a los problemas materiales a los que se enfrentaba el pintor decimonónico.

La primera edición francesa es de 1891 y presenta dos notas inexistentes en la edición en español: $A u$ Lecteur, al principio del libro, y Garantie Commerciale al final. En Au Lecteur, Vibert explica que sus lecciones se ocupan de los 'secretos del oficio', es decir, de aspectos prácticos y publica sus conferencias a petición de varios de 
sus oyentes. En la nota final descubrimos que el autor del libro supervisaba los productos Lefranc que se fabricaban bajo sus indicaciones y con sus fórmulas. También garantizaba la marca de acuarela Mary et fils.

Este texto abarca, únicamente, cuestiones de conservación y solidez aportando digresiones científicas para comprender algunos comportamientos de las materias pictóricas. Esto quiere decir que no se detiene en explicar cuestiones estéticas, de dibujo, anatomía, perspectiva o composición pues no afectan a la conservación de la obra. Uno de los rasgos más característicos de esta obra es la dureza con la que el autor critica los materiales artísticos y sus fabricantes. Aunque hace extensiva la crítica a los pintores despreocupados por los aspectos materiales del arte y a la formación que reciben. El autor mantiene durante toda la obra una actitud implacable por concienciar a los pintores de que deben conocer los materiales que emplean y saber utilizarlos. Vibert opinaba que los artistas pronto volverían a preocuparse por sus materiales y por su oficio.

El pintor francés no pretende dar consejos a sus colegas pero desearía que éstos adoptaran métodos más racionales. Vibert propone recuperar las tradiciones perdidas y completarlas mediante los descubrimientos de la ciencia moderna. La Ciencia de la Pintura comienza con la historia de la pintura; sigue con la teoría del color y la pintura al óleo y su restauración. Luego se adentra en la pintura mural y en otras técnicas pictóricas como el pastel, los temples o la acuarela siempre desde la óptica material. Para concluir Vibert aporta un Apéndice en el que se tratan Recetas y Manipulaciones de algunos materiales. 
Apéndice B: Método para Preparar la Alizarina Artificial. Privilegio 2296 otorgado a Francisco Zacarías Roussin el 31 de mayo de 1861. Archivo Histórico de la Oficina Española de Patentes y Marcas.

(Original y transcripción) 
e) 290296

Gipediente de Cotfricald de in.

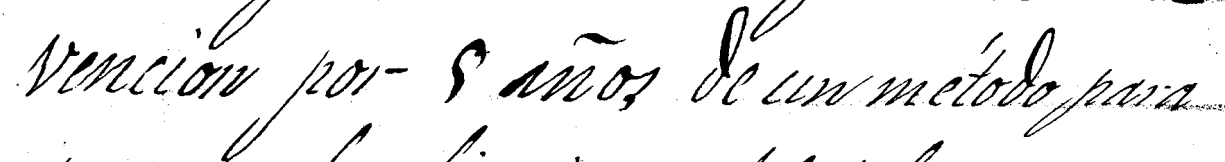

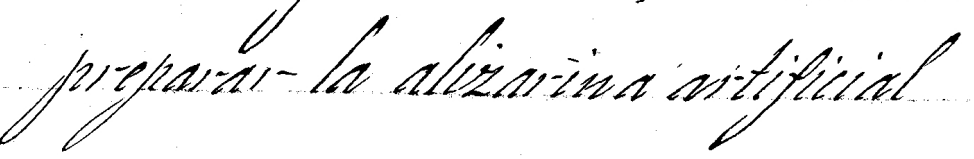

Don, Finncino Lacaín, Pousim, verino So Paris.

310 


\section{$\underline{\text { Número } 2296}$}

\section{Expediente de Certificado de}

invencion por 5 años de un método para

preparar la alizarina artificial

Don Francisco Zacarías, Roussin, vecino de París. 


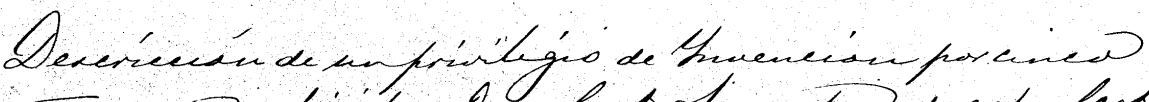

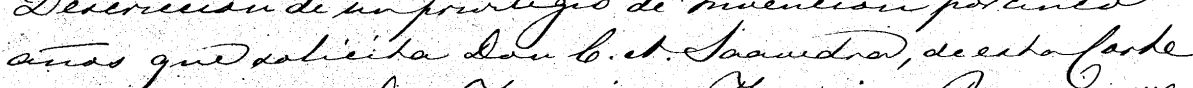

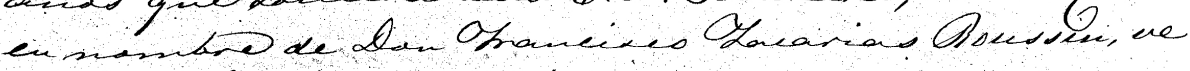
sinodedare

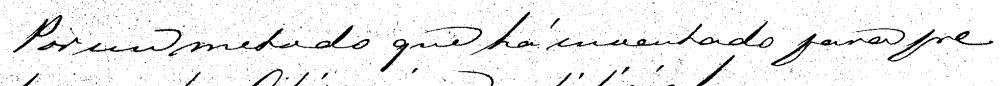
fanar la Dlisarma Dartifiécel.

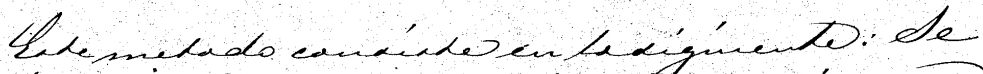

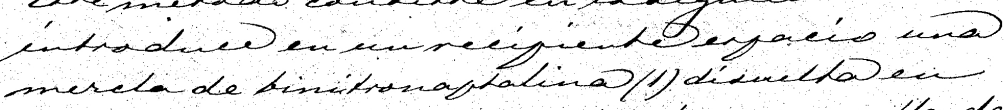

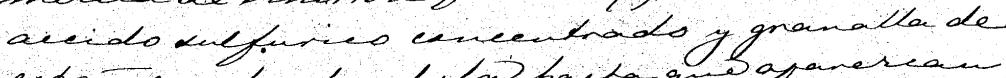

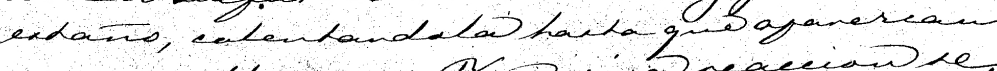

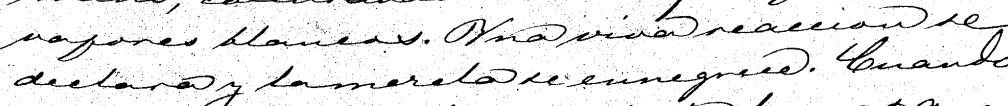

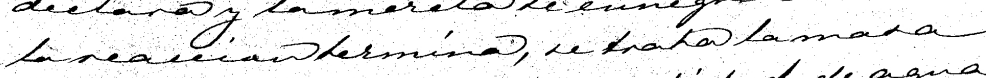
farld ta en una gnaw cartidad de agra

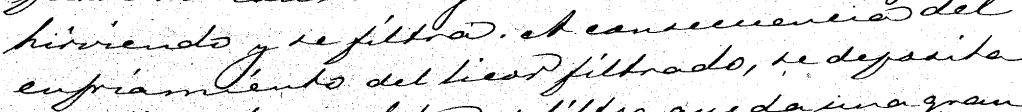
la alísarina, dabroufiltro guedacinagran

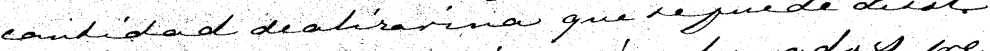

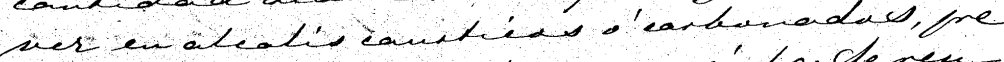

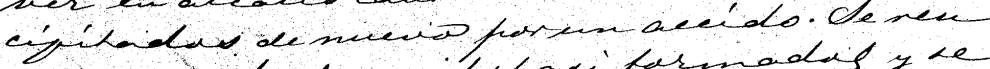

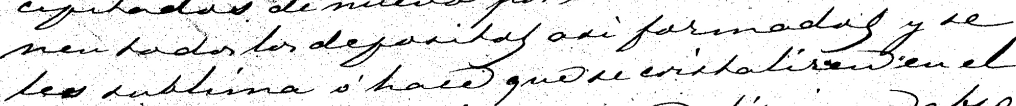

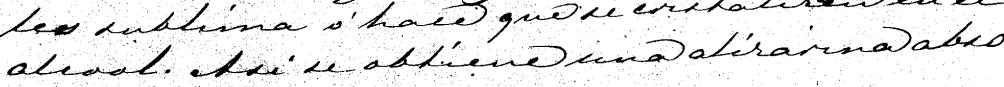
hitanentofina.

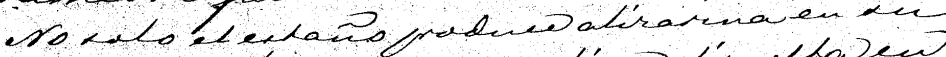

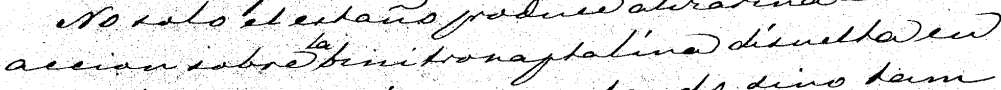
elacédodulfarés encentrads, dino tan

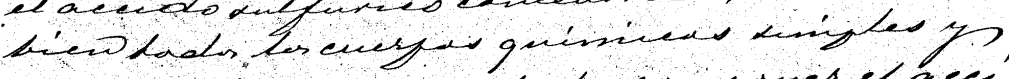

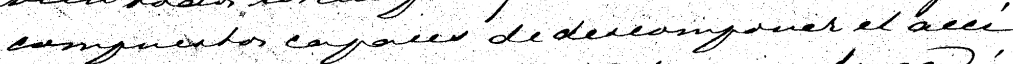

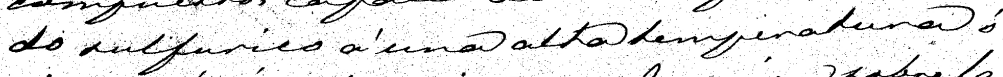

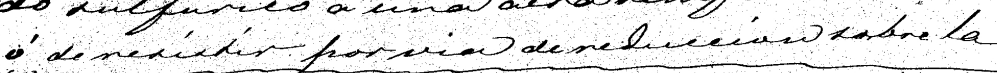

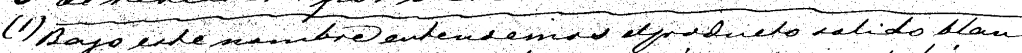

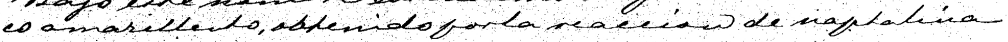


Descricción de un privilegio de Invención por cinco años que solicita Don C. A. Saavedra, de esta Corte en nombre de Don Francisco Zacarias Roussin, vecino de París.

Por un metodo que ha inventado para preparar la Alizarina artificial.

Este metodo consiste en lo siguiente: Se introduce en un recipiente [espacio?] una mezcla de binitronaftalina (1) disuelto en accido sulfurico concentrado y granalla de estaño, calentandola hasta que aparezcan vapores blancos. Una viva reaccion se declara y la mezcla se ennegrece. Cuando la reaccion termina, se trata la masa pastosa con una gran cantidad de agua hirviendo y se filtra. A consecuencia del enfriamiento del licor filtrado, se deposita la alizarína. Sobre el filtro queda una gran cantidad de alizarína que se puede disolver en alcalis causticos ó carbonados, precipitados de nuevo por un ácido. Se reunen todos los depositos asi formados y se les sublima ó hace que se cristalizen en el alcool. Asi se obtiene una alizarina absolutamente pura. No solo el estaño produce alizarina en su accion sobre la binitronaftalina disuelta en el accido sulfuríco cocentrado, sino tambien todos los cuerpos químicos simples y compuestos capaces de descomponer el accido sulfurico á una alta temperatura ó ó de resistir por via de reduccion sobre la

(1) Bajo este nombre entendemos el producto salido blanco amarillento, obtenido por la reaccion de naftalina sobre el accido azotico monohydratado. 


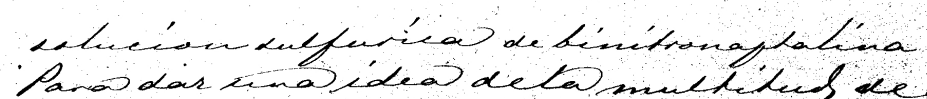

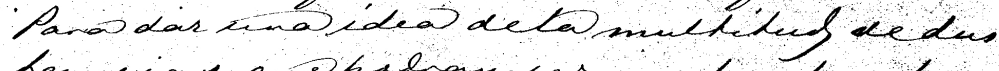

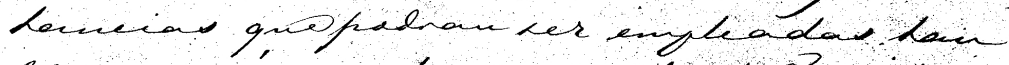

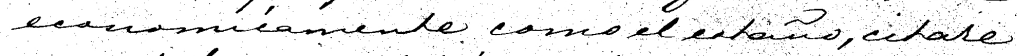

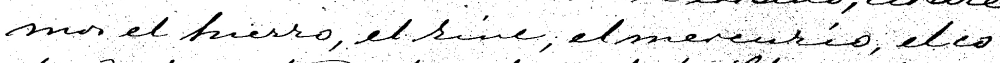

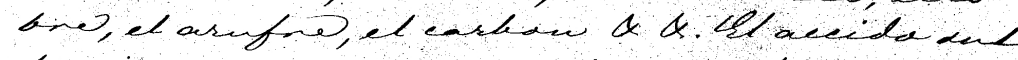

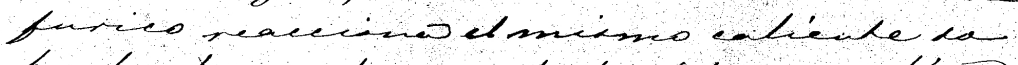

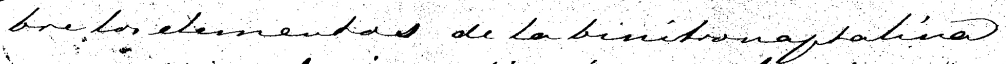

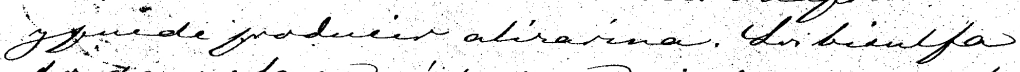

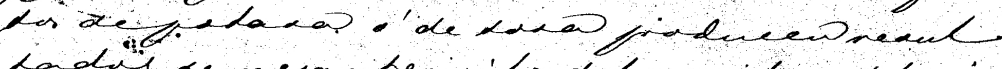

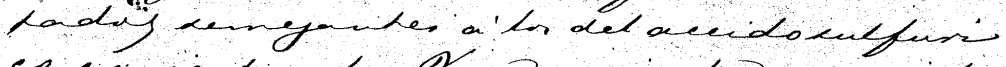

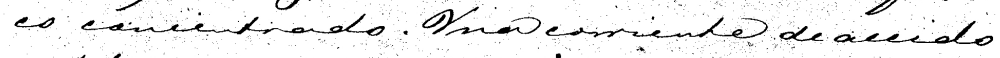

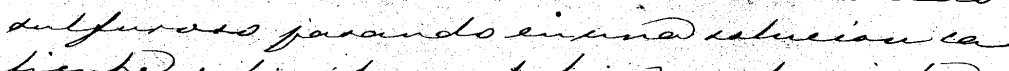

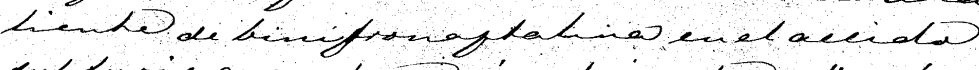

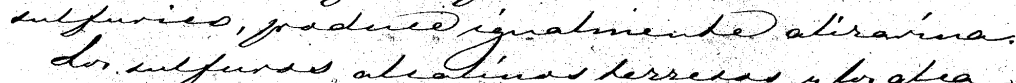

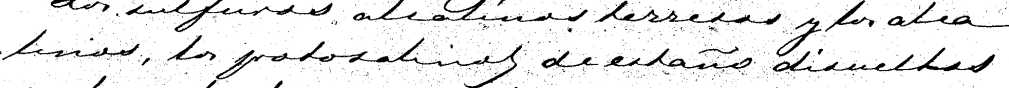

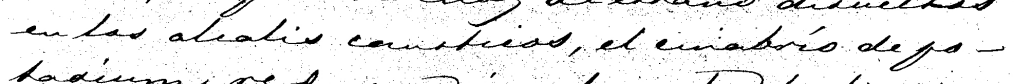

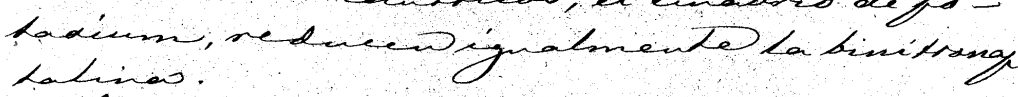
Encancencueso

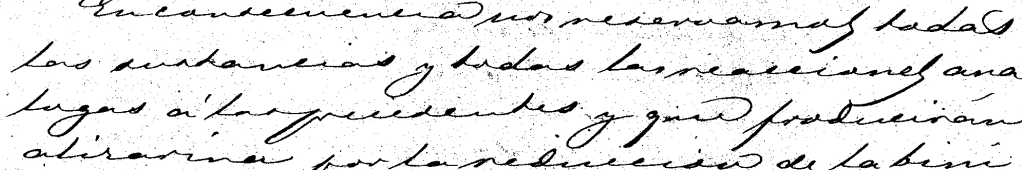
tryact linos.

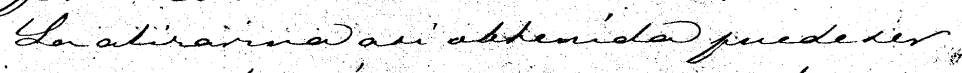

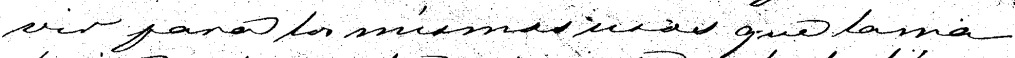

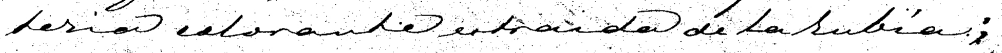

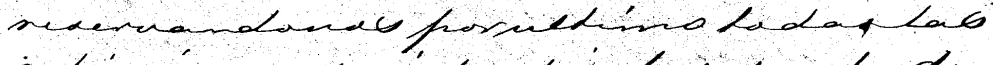

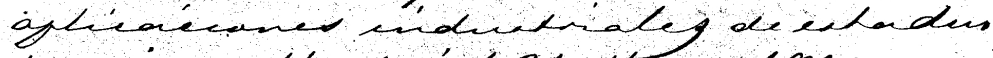

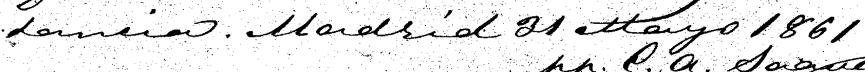

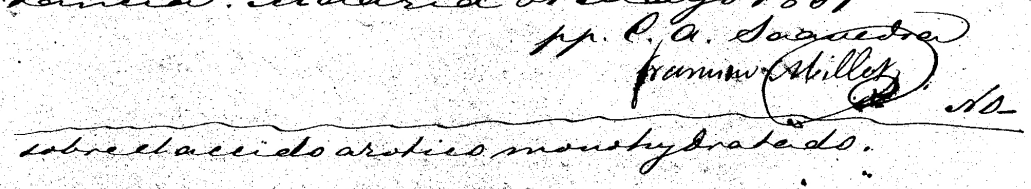


solucion sulfurica de binitronaftalina. Para dar una idea de la multitud de sustancias que podran ser empleadas tan economicamente como el estaño, citaremos el hierro, el zinc, el mercurio, el cobre, el azufre, el carbon \&\&. El accido sulfurico reacciona el mismo caliente sobre los elementos de la binitronaftalina y puede producir alizarina. Los bisulfatos de potasa ó de sosa producen resultados semejantes a los del accido sulfurico concentrado. Una corriente de accido sulfuroso pasando en una solucion caliente de binitronaftalina en el accido sulfurico, produce igualmente alizarina.

Los sulfuros alcalinos [terrosos?] y los alcalinos, los protosalinos de estaño disueltos en los alcalis causticos, el cinabrio de potasium, reducen igualmente la binitronaftalina.

En consecuencia nos reservamos todas las sustancias y todas las reacciones analogas á las precedentes y que produciran alizarina por la reduccion de la binitroftalina [sic].

La alizarina asi obtenida puede servir para los mismos usos que la materia colorante estraida de la Rubia; reservandonos por ultimo todas las aplicaciones industriales de esta sustancia. Madrid 31 Mayo 1861

pp. C. A. Saavedra

[firma] 


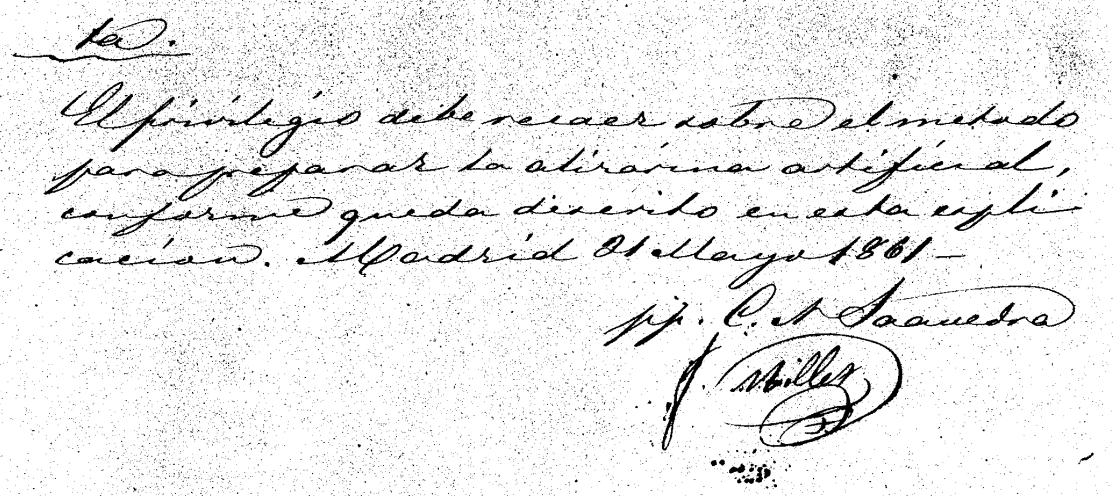

$+2$

Q 
Nota.

El privilegio debe recaer sobre el [metodo?] para preparar la alizarina artificial, conforme queda [descrito?] en esta expliacion. Madrid 31 Mayo 1861

pp. C. A. Saavedra.

[Firma] 